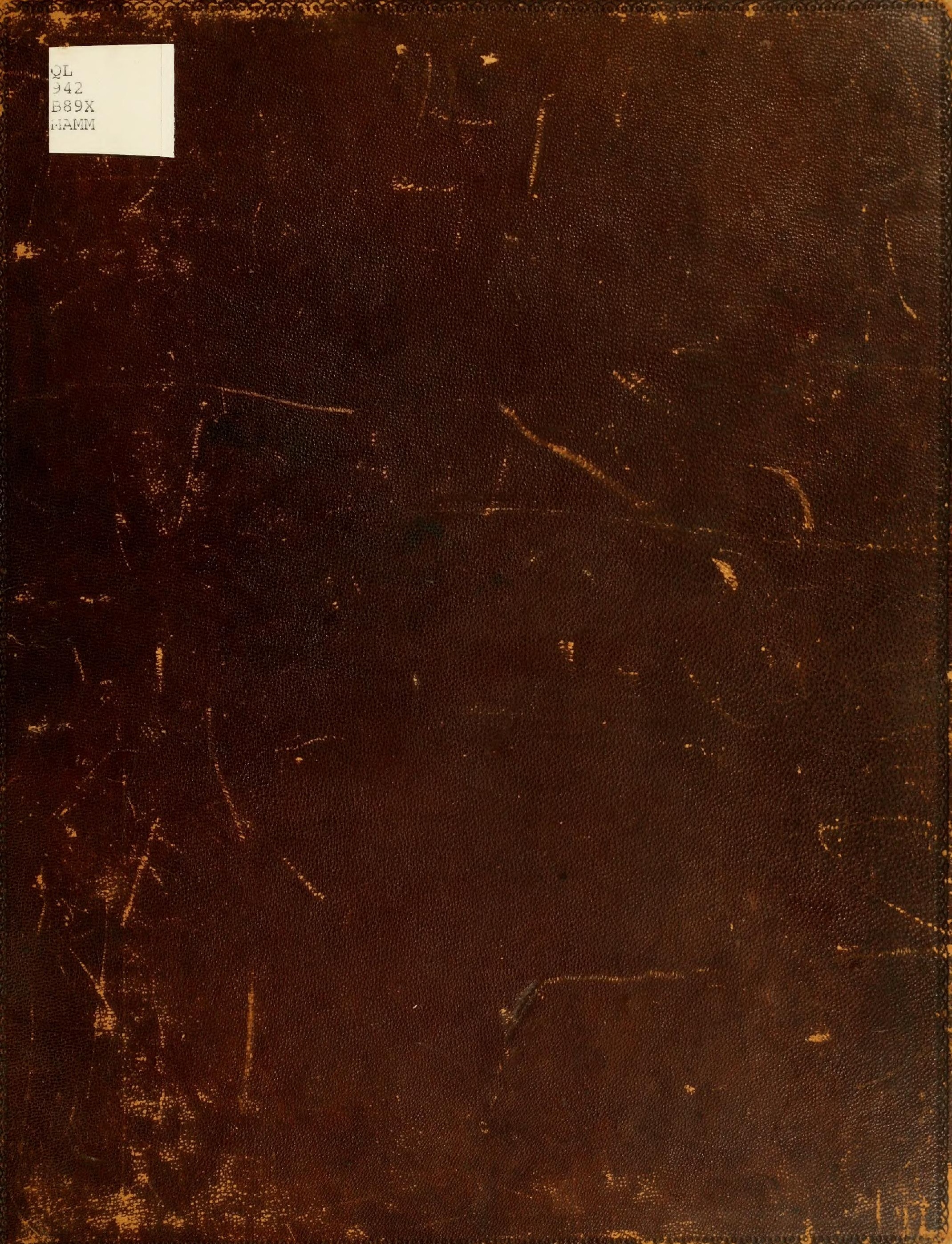




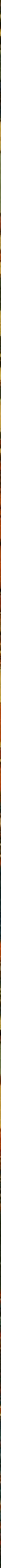











\section{PLATE A.}

REPRESENTING THE THREE SPECIES OF MANKIND.
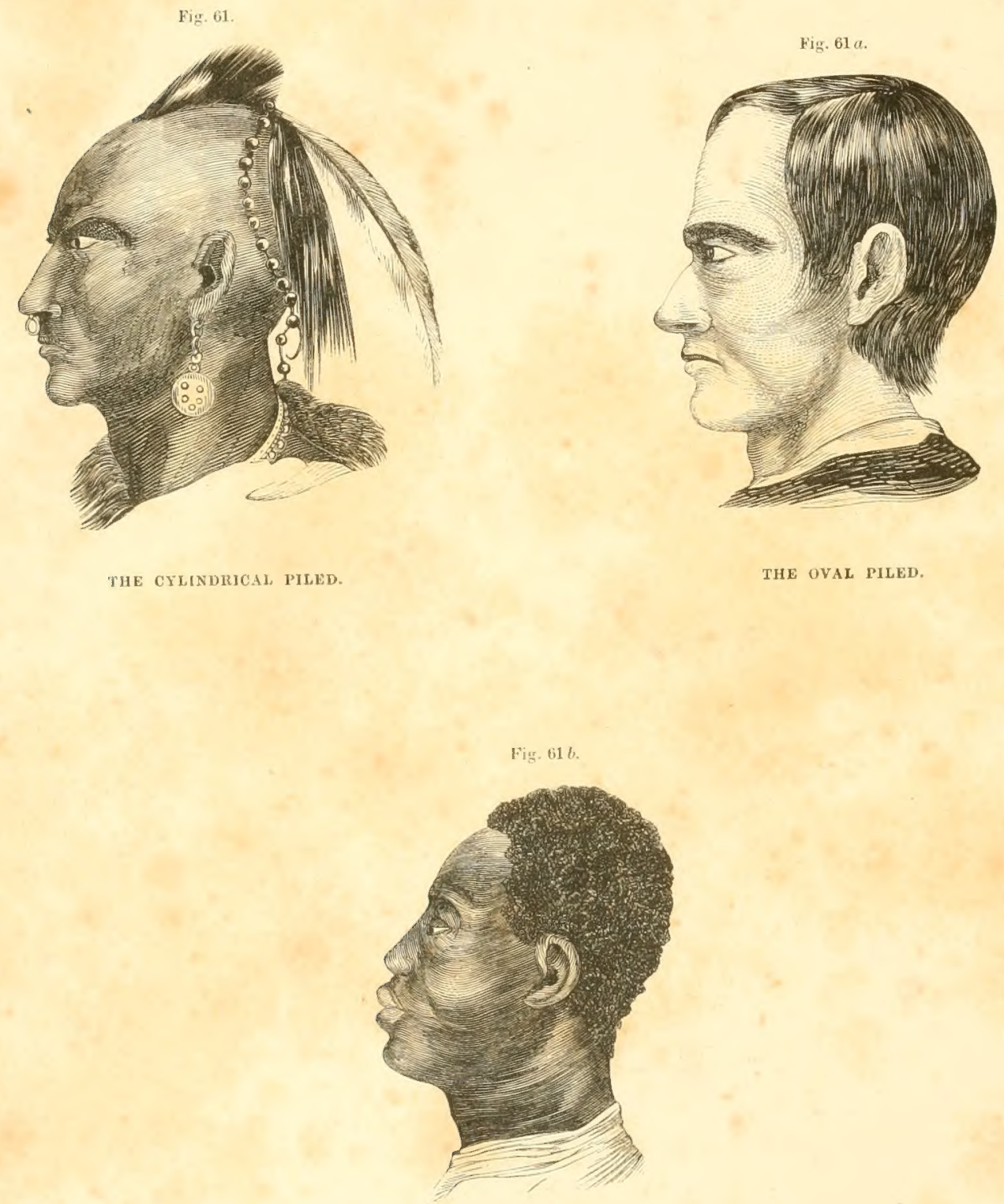

THE ECGENTRICALLY-ELLIPTICAL PILED. 


\author{
A 'TREATISE
}

ON THE ORGANIZATION, PROPERTIES AND USES OF

\title{
HAIR AND WOOL;
}

TwiETHLE WIT!

\section{AN ESSAY UPON THE RAISING AND BREEDING OF SIIEEP.}

BI

PETER A! BROWNE, L. L. D.,

OF I'HLLADLIHIS.

"DUCIT AMOTE PATRIA:"

PUBLISHED UNDER THE PATRONAGE OF TIE COMMONWEALTH OF PENNSYLVANIA.

PHILA DELPHIA :

J. II. JONES, PRINTER, NO. 34 CARTER'S ALLEY.

185:3. 
TO TILE IIONORABLE

THE SENATE AND HOUSE OF REPRESENTATIVES

OF THE

COMMONWEALTH OF PENNSYLVANIA,

THIS WORK IS RESPEUTEULY INSCRIBED BY ITS

AUTHOR.

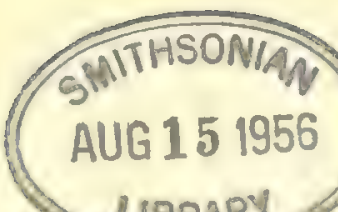

LIBRARY 
Entred acenrling to the Act of Congress, in the yenr 1853 , by PETER A. BROWNE, L. L. D., In the Clerk's Office of the District Court of the Eastern District of Pennsylrania. 



\section{PREFACE。}

Natural History includes all the works of the Mighty Creator; her votaries, will the aid of the telescope, measure the parallax of the most distant stars, and, with the microscope, scrutinize the minutest portion of the smallest infusoria, plant, or crystal. Nothing for them is too large, nothing too small for examinatiom, which God has placed within their reach. If the Deity has not deemed it beneath His dignity to create an object, surely it would be presumptive in man to consider it too insignificant for his study. Then let no one marvel that we have devoted so much lime to ascertain the organization, properties and uses of hair and wool. To the unreflecting, this department of knowledge may, at first view, appear to be trifling; but, with each successive advance, it will acquire more importance.

The Science which relates to Pile may be called Trichology, (from Trix, a hair;) its descriptive part is Trichography. It is a branch of Zoölogy, or rather of Mammology; and, so far, it is connected with Physiology, Anatomy and Comparative Anatomy. Some of its discoveries shed new light upon the ethnological problem of the unity of the human species, and others will be found to be intimately connected with those branches of agricultural industry, which relate to the raising of Sheep and producing of wool, and the raising of Swine for the bristles. It embraces a large field of inquiry, many parts of which are yet only partially explored.

In our progress we lave endured considerable mental labor and encountered some unexpected difficulties; but, cheered by the countenance and aided by a few scientific friends, we have pursued a steady course, and have, at length, brought our examinations to a tolerably successful termination. It will be recollected that we were obliged, in the first instance, to collect the materials; and, after years of untiring exertions, we have at length the largest and the most valuable known cabinet of pile. In the meantime we attended lectures on Physiology and Anatomy. We have made use of none but superior instruments, and some of these are entirely new-either in themselves or their application to this study. We have availed ourselves of the researches of those who have gone over the ground before us, at all times acknowledging their truthfulness and pointing out their errors. We have carefully preserved the specimens from which our drawings are made, for future re-examination, if desirable. Upon a theme so extensive, and comparatively so novel, we do not expect to have escaped error; but we trust that when pointed out, we shall ever be found ready to acknowledge and correct them.

P. A. IBROWNE,

Philialelpliai 



\section{TABTE O I CON'ENIS}

CIAPTER I.-Part I._-Of the word "Pile," page 7. The Definition of Pile, 7. The Description of Pile, 7. The most important Division of Pile, 8. Of Fleece, 9. Pile and Feathers have teen confounded, 9. Description of a Feather, 9. The difference between a Hair and a Feather, 10. The 'Tegumentary Appendages of the Ostrich, 11. The Down of young Birds, 11. The Fye-Lashes of the Ostrich, 11. The Beard of the Turkey, and Whalebone, 11. The Pile of the Ornithorynchus, 12.

Part II.-The Mantle and Hair-like Processes of the Armadillo, 14. Description of the Trair-Like Processes, 14. Of Scales, 15. The Scales of the Pangolin, \&c., 15. Particular Description of them, 15. Scales of Prehensile Tails, 16. The Scales of tlie Tail of the Possum, 16. Scales of the Tail of the Muskrat, 16. Scales of the Tail of the Field-MIouse, 16. Scales of the 'Tails of some Monkeys, 16. Remarks on the Scales of Prehensile Tails, 17. Of Fibrous Protuberances resembling Horn, 17. Their Comparison with true Horn, 17. The Horn of the Rhinoceros, 18. The Hair of the Ear of the same, 18. Of Spines, 18. The Spines of the Porcupine, 18. The Spines of the Pecary, 19. Of Whiskers, 19. The Whiskers of the Rabbit, 20. The Whiskers of the Irish Hare, 20, The Whiskers of the Possum, 21. Of Bristles, 21. The Bristles of the Russian Wrild Boar, 22. Cornparison of Dimensions of Bristles, 22. Comparison of Ductility, Elasticity and Tenacity of the same, 22. Of Mane Hair, 2:? The Mane of the Lion, 24. The Mane of the Horse, 24. Mane of the Cervus Canadensis, 24. Mane of the Cameleopard, 24. Of Tail IIairs, 24. The Tail Hairs of the Hippopotamus, 25. 'The Tail Hairs of the Zebra, 25. 'The Tail Hairs of the Cervus, 25. 'The Tail Hairs of the Arabian I3ull, 25. 'Ihe Tail Hairs of the Elephant, 25.

CHAPTER II.-How Pile grows, 26. Of the different parts of a Filament of Pile, 26. Of the I3utton, 27. The Cells of the Button, 27. 'The Normal Shape of the Button of the Head of one of the OralHaired Species, 27. The Shaft, drawn out of the Button, 27. Buttons of Hairs that fall out, D3. Hairs with no Button, 28. The Button of the Cylindrical-Haired Species, 28. The Button of the liccentrically Eiliptical-Piled Species, 28. Buttons on other Hairs of the Borly, Ec., 28. Of the Ear, 29. Of the Eye-Brow, 29. Of the Eye-Lashes. 29. Of the Nose, 30. Of the Common Whiskers of Man, 30. Of the Beard, 30. Three Shafts growing out of one Button, 30. The Fashions of wearing the Hair and Beard, 30. Button of the Hair of the Arm-pit, 31. Of the Pubes, 32. A Remarkable Case, 32. Of the Button of the Hair of the Limbs, 33. Of the Borly, 33. General Remarksupon Buttons, 33. Of the Buttons of the Hairs of the Lower Animals. 34. Of the Apex of Pile, 31. Of Dichophy, 35. Of 
its Cause, 36. Of 'Branched Pile, 36. Of the Cortex of Pile, 36. Or the Scales of the Cortex, 37. 'Their Use, 37. Of Ribbons of Cortex, 37. Of the Paved Cortex, 37. Examples of the same, 37. Of the Hair of the Stag, 38. Of that of the Elk, 39. That of the Dicranocerns Americanus, 39. That of the Sloth, 40. Of the Fibres of Pile, 41: A Crushed Hair, 41. The Use of Fibres, 42. Of the Centre of Pile, 42. Of the Pile of the Dog-Faced Monkey, 42. Of the Coloring Matter in the Hair of the Bat, 43. An Optical Deception, 43. The Coloring Matter of Pile in general, 44. Of the Follicle of Pile, 46. Where the Follicle is found, 46. How it is formed, 47. Of Pile without in Follicle, 48. Examples of Follicles of the three Species of Men, 49. The Follicle of the Hair of Hybrids, 49. Of the Vitality of Pile, 49. Of Vessels of Pile, 50. Of the Secretion of Pile, 50.

CHAPTER III.-Of a Perfect Hair, 51. Characteristics of Pile of the Heal of Man, 51. Examples of three General Forms, 51. Of Particular Forms, 51. To whom these forms belong, 52. Of the Ductility, Elasticity and Tenacity of Pile, 53. The Essential Properties of Pile, 53. The Endurance of these Properties, 54. Of Contractibility, 55. Table of the Ductility, Elasticily and Tenacity of Pile, 56. Of the Trichometer, 57. Modus Operandi, 57. Ot the Direction of Pile, 57. The Laws of Direction of Pile, 57. The Reasons of the Laws, 57. The Proofs, 58. The Consequences, 58. Of the General Inclination of Pile, 58. Of Particular Inclinations, 58. On the Body and Members, 59. Of the Inclination of the Pile of the Lower Animals, 59. The Classification of Pile of the Human Heat, 59. The Classification of Mankind by the Pile of their Hearls, 59. The Pile of the present American Indians' Head, 59. The Pile of the Nound and Munmy American Indian, 59. The Peculiarities and Affinities of these Piles, 63. Of the Pile of the Chinese, 63. Of the Pile of the Oval-Haired Species, 63. The Pile of Egyptian and Thebes Mummies, 64. Of the Pile of the Eccentrically Elliptical Species, 65. Of the Bushman Boy, 65. The Description of his Wool, 66. The Wool of Congo Billy, 66. Inferences from the foregoing, 66. Of Hybrids, 67. The Division and Nomenclature of Iybrids, 67. Examples of the same, 67. Tables of Simple Hybrits, 63. Tables of Compound Hybrids, 70. Of the Covering of the Heads of Hybrids, 73. Some Examples of the same of Simple Hybrids, 74; and of the Compound IIybrils, 74. Of the Classification of the Lower Animals by their Pile, 76.

CHAPTER IV.-Of the Color of Pile, 77. Of Black Hair, 77. Of the Oilyinal Color of Hair, 77. Blackness in Hair no sign of Strength, 78. The Variance between the Color of the IIair and that of the Eyes of Man, 78. Brown Hair, 78. Red Hair, 79. Yellow Hair, 79. White Hair, 79. The Pile of the Albino, 79. The Examination of the Pile of the White Albino, S0. The same of the Black Albino, 81. Of Albinos among the Eccentrically Elliptical Species, 83. Inferences from the foregoing Examinations, 83. Change of Color of Pile at the Perior of Puberty, 34. Of Monochromatic and Polychromatic Pile, 84. Of the Changes of the Color of Pile other than at the Perind of Puberty, 85. Of Athipilie, 86. Of Pile of Man losing its Color, 86. Several Interesting Cases, 86. An Experiment, 87. The Cause of the Sudden Loss of Color of Pile, 88. Of the Gratual Loss of Color in Pile, 88. Of the Cause of this Gradual Loss, 88. Of the American Indian turning Grey, 88. Of the Rete Mucosum, 89. How it is with the Lower Animals, 90. Whether the Color of Pile is Influenced by External Canses, 90. Of the Polarization of Light by Pile, 91. Of Dyeing Pile, 92. 
CIIAPTER V.-Pile belongs on the Dermis, 9:3. Where Pile not usually found in the Dermis, 93. Of Pile of the Scalp, 94. Of Climactric Pile, 94. When Pile first makes its appearance, 95. Its first appearance on the young Possum, 95. Of the three Varieties of Pile of the Hearl of the Oval-Haired Species, 95. Of Accidental Pile, 96. The Hair found in Ovaries, 96. Their Examination and Description, 97. Pile from the Uterus, 98. From the Stomach, 99. Of Pile which appears to grow on the Interior of the Skin of some of the Lower Animals, 99 .

CHAPTER VI.--Of the Dimensions of Pile, 101. The Cornparative Length of the Pile of some of the Lower Animals, 101. 'The best manner of ascertaining the Diameter of Pile, 102. Of Hypertrophy, 10:3. Of Depilation, 103. The Discotome, 103. Of Tapering Pile, 104. Of Pile Manipulations, 105. 'The Exuberance of Pile, 105. Of Pile growing in Tufts, 106. 'The Rapid Growth of Pile, 106. 'The Regeneration of Pile, 106. Gradual and Periodical Decilence of Pile, 107. 'Ihe Restoration of Pile, \&c., 108. The Endurance of Pile, 109. The Transplanting of Pile, 110. 'The Effect of Diseases of the Body upon Pile, 110. The Diseases of Pile, 110. Of Pile in Plica Polonica, 110. An Incipient Case, 111. Of Pile in 'Tinea Capitis, 112. Of Pile in Softening of the Brain, 113. In Coxalgia, 114. In Scrofula, 114. In Phthisis, 114. In Phthisis Cavernis, 115. In Chronic Pleurisy, 115. In African Fever, 115. In Intermittent, 116. In Acute Rheumatism, 116. In Albuminurea, 116. In Scrofula, 116. In 'Iyphoid Fever, 116. In Intermittent, 117. In Anomia, 117. In I'hthisis 'Tuberculosis, 117. In Syphilis, 117 and 118. In Chronic Bronchitis, 118. In Pregnancy, 118. In Acute Rheumatism, 118. In Neuragia, 118. In Amenorrher, 119. In Albuminuria, 119. In Typhoil Fever, 119. Of the Pile of Lunatics, 119. Pile from the Pennsylvania Hospital, 119. From the Frankford Hospital, 119. Recapitulation in Tabular form, 121. The Pennsylvania Hospital Cases examined, 122. 'The Decay and Death of Pile, 123. Of Balduess, 124. Of Pilc Growing after Death, 125. 'I'he Examination of the same, 125.

CHAP'TER VII.-Of Hair separated from the Borly acquiring a New Life, 127. 'The Electricity of I'ile, 127. Pile as a Conductor of Caloric, 128. The Effect of Climate and Seasons upon Pile, 128. The Effect of the Skin upon Pile, 128. The Specific Gravity of Pile, 129. Fossilized Pile, 131. The IIygroscopic Property of Pile, 131. The Analysis of Pile, 131. Pile Dyed, Melted and Distilled, 132. 'The Elements of Pile in Bloorl and Milk, 132. The Examination of Pile, 132. The Hair Revolver ard Stretcher, 133. Of Describing Pile, 133.

CHAPTER VIII. - The Beauty of Pile, 135. The Uses of Pile to the Animal, 135. Its Uses in Manufactures and the Arts, 139. The Wool of the Sheep, 139. Of the Mountain Sheep, 140. Of the Goat, 141. The Goat of Thibet, 141. The Angora Goat, 141. The Goat of Kirguis, 142. 'The Introduction of these Goats into the United States, 149. The Mazama, 14\%. The Pile of the Common Goat, 144. The Camel, 144. The Lama, 146. The Vicunia, 147. The Paca or Alpaca, 147. Of Staple, 148. Of Stapling, 148. The Strength of Pile, 149. Of the Fineness of Flece, 150. Softness of Stajle, 151. Of Breeding and Raising Swine for the Bristles, 151.

CHAPTER IX. - Of Raising and Breeling of Sheep, 153. Of Felts and Feltine; 154. The leelting Property, 154. The Scales upon the Cortex, 155. 'Iheir Shape and Position, 156. Of Fulling, 156, 
Spiral Curls, 156. Of the Fleece for Manufacturing Articles that will not Shrink, 15\%. Of Sheep, $15 \%$ The Two Species of Sheep, 158. The Golden Rule in Sheep Breeding, 158. Two Questions propounded, 158. 'The Definition of Species, 158. The Rer. Thomas Smith's Definition, 158. Those of Van Amringe and Mills, 159. The application of the former to our Subject, 159. That of the latter, 160. The Principles of Agassis, 161: The 'True Criterion of Species, 161. Some Examples, 161. Of the Ass, 162. Of Goat and Sheep Intermixing, 163. Mr. Yonatt's Account of an attempt to Amalgamate two Species of Sheep, 164. Dr. Robert Knox's Opinion, 164. Col. Randall's Opinion, 164. The Abhorrence of Animals to Amalgamate, 165. Van Amringe's Opinion in regard to Nulattoes, 166. The Admission of Dr. Prichard, 167. An Answer to a supposed Objection, 167. Col. Smith's Notion of a White Person, 169. Prof. Wagner's Definition of Species, 170. Our Position supported by Scripture, 170. Answer to an anticipaterl Objection, 171. Example of the Woolly Sheep Species, 171. Example of the Hairy Sheep Species, 172. Of Worsted Manufactories in the United States, Conclusion, 173. 


\section{CHAPTER I.}

\section{PLATE I.}
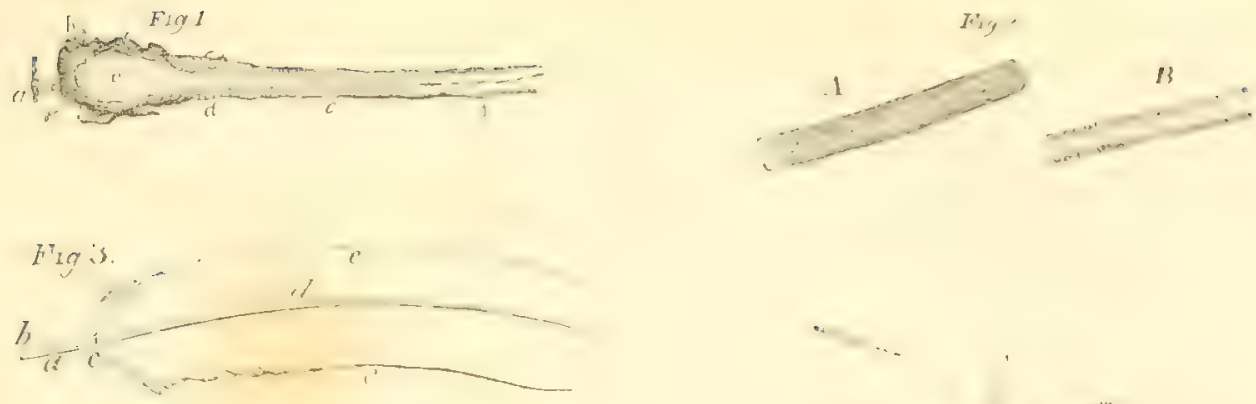

\section{Firfo at}
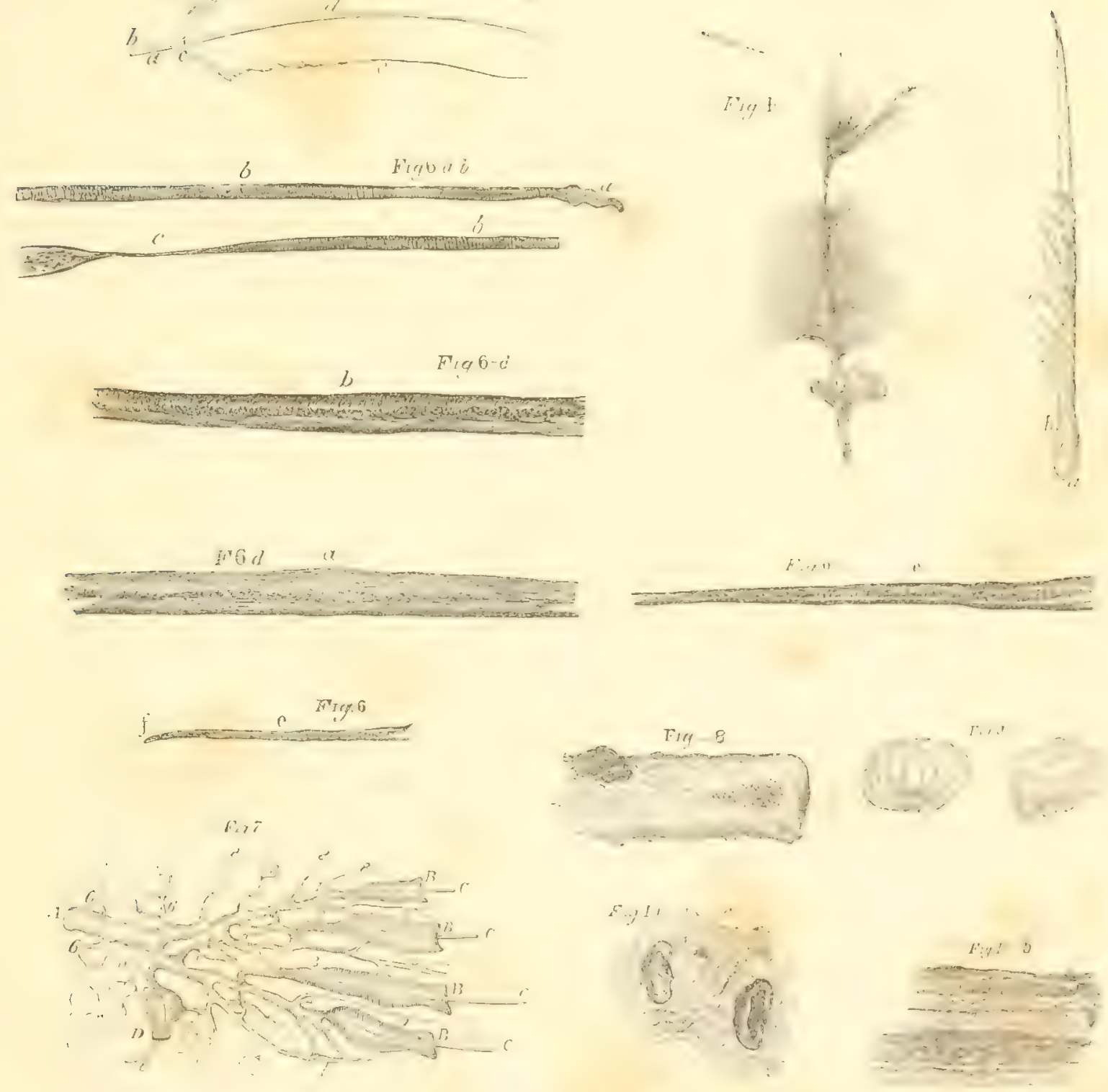

P LATE I I.
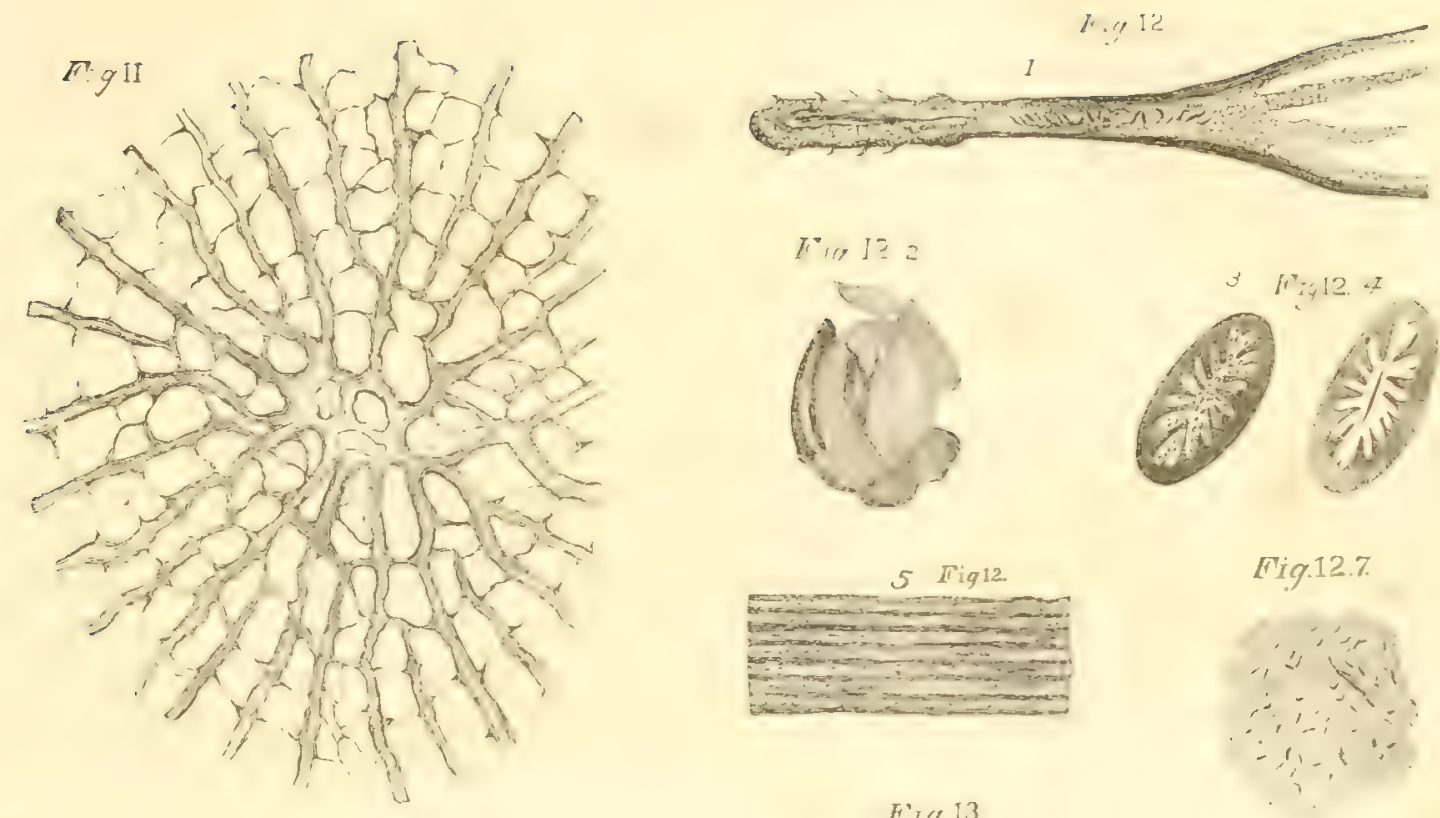

IPI) ID
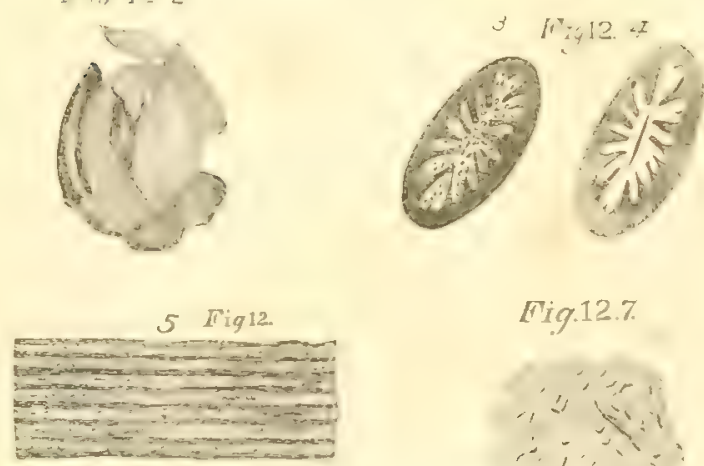

Fig.12.7.

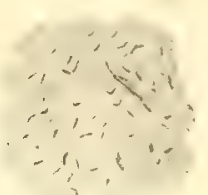

Fir 13

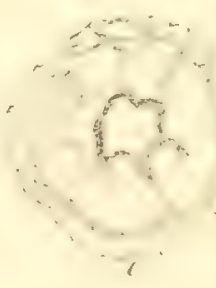

Fiquis $a$.
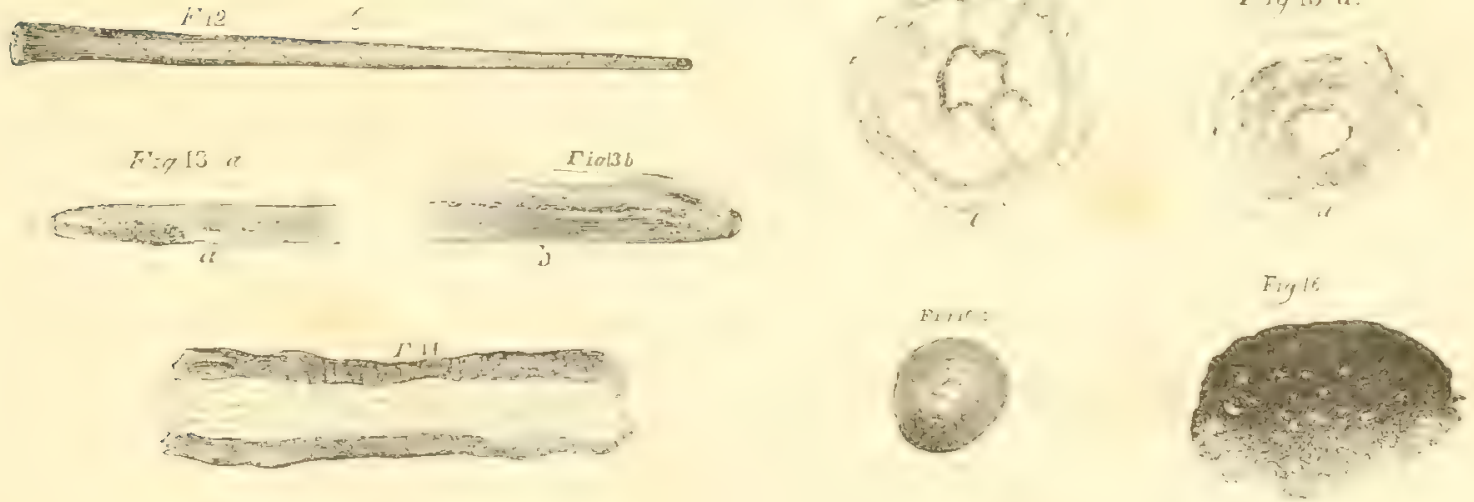



\title{
TRICHOLOGIA MAMMALIUM;
}

or,

\section{A TREATISE ON PILE.}

\section{CII $\perp$ P'T IF R}

\author{
P A R T I .
}

OF the IVord PILE.-There is no English term, in common use, which includes hair and wool; we have, therefore, adopted the word "Pile." It is true that there are some animals, (belonging partly to the Carnaria, and partly to the Rodentia, ) upon whose bodies are found both hair and wool, that are called "the fur-bearing animals," from which some might infer that "fur" is a generic term, including both these integuments; but there are other animals, upon whose bodies are found both hair and wool, that are not so denominated, wherefore it would have been improper to have placed the word "fur" at the head of this Chapter.

Of the Definition of Pile.-We have never seen an accurate definition, nor even an exact description, of pile, hair or wool.

A definition, to be logical, should furnish a general idea of the nature of the genus of the object defined, with all the essential specific differences. 'To do this we are not, at present, prepared. But a description may pass examination, if it contains the most remarkable properties of the object described. This we shall attempt to make with the word pile.

Of the Descripition of Pile.-(See fig. 1.) - We describe pile to be a filamentous appendage of the dermis of the mammalia,_formed of gelatine and proteine,-emanating from cells, - growing at its lower extremity only, - consisting of, first a follicle, which is, for the most part, imbedded in the dermis; though sometimes found partly in the adipose tissue, connected with vessels and nerves; and, secondly, an insensible protruding shaft, terminating at its inferior extremity in a button, and at its superior one in a point. 'This shaft is composed of, 1st, a squamose and imbricated or paved cortex; 2dly, a fibrous intermediate substance, and 3dly, a coloring matter. Pile possesses great ductility, flexibility, elasticity and tenacity,-being highly electric,-polarizing light in an eminent degree; is of great endurance,- having but little hygroscopic property; very little power to conduct

$$
\text { * From "pilus," a hair. }
$$


caloric; a very low specific gravity; no contractibility, and is of gradual and periodical decidence.**

\section{The most Important Division of Pile,-Pile is divided into hair and wool. (See fig.} 2.) Hair and wool differ, one from the other, as follows:-

1st. In shape,- hair being either cylindrical, cylindroidal, oval or ovoiclal,-while wool is eccentrically elliptical.

2d. In uniformity of shape of the same filament,-lnair being generally the same shape throughout the filament, - while wool is less uniform in this particular.

3 d. In the formation of the cortex, the seales of which upon hair are less numerous, less pointed, and more depressed,-while those upon wool are more numerous, more pointed, and less depressed.

4th. In direction,-hair being either straight, flowing, or curled,-while nool is crisped and frizzled, and sometimes spirally curled. (See Frontispiece.)

* Exrlasition of teras.-Every part of the abore description will, in its turn, in the succeding pages, become a subject of discussion; wherefore, all that is here required, is to explain, briefly, some of the terms.

"Filamentus," from (filamentum,) a fine slender thread; used synonymously with "fibre," (fibra;) but we prefer the use of the word filamentous, reserving the words fibre and fibril, (a small fibre, for the description of the intermedinte substince of the shaft.

"Appendage." Something that, being less than the principal, is annexed or added to it.

"Dermis." The cutancous system is divided into an external, including the dermis and epidermis, and an internal or mucous membrane. Pile belongs to the dermis, but sometimes penetrates to the adipose tissuc.

We have not made an cxtensive microscopic cxamination of the skin; and will therefore content oursclres with giving the description of it fuand in the books.

It is represented as consisting of four prineipal portions, viz:-

1st. The epidermis, or cuticle, which forms the outermost layer. This is of memlranous structure, and is deroid of vossels and nerves, and of course insensible. It is piereed with minute oblique holes, for the passage of hairs, and for the orifices of exhalent and alsurbent ressels. The cuticle exfuliates, in the form of scales, from the head, and also from the body after ccrtain cutaneous discases.

21. The rete mucosum, the appareil pigmental of Flourens, (sce Anat. Gen'l. de la Peau, \&e., p. 34,) of the colored race. Some are of opinion that in the white race this is entirely wanting; others suppose it exists, but is of a red color.

$3 d$. The corpus papillare. It consists of a collection of suall papill $x$, formed by the extremities of nerres and ressels passing the corium which is beneath. Flourens considers these papilla as prolongations of the true skin, and not as a separate layer.

Ath, and lastly, comes the derma, corium, cutis-vera, or true skin; in which, priacipally, pile is set.

Beneath all these is the adipose tissue.

"Mammalia." We confine pile to this, notwithstanding the teachings of some physiologists that it is extended to other classes of animals, and even to vegetables. "Quadrupedia corpus pilosum."-(Lin.) "The bodies of all quadruped animals are covercd with hair."-(Goldsmith.) "Les mamifores sont les scul animaux dont le corps est guurert de poil."-(Elem. de Zo0. 232., \& \&e.

"Follicle," the sac, in which the button of the hair is generally found, is most commonly, but improperly, called the "root," whiels tends to mislead by suggesting a too intimate relation to a plant. We call it the "Follicle."

The word "follicle" is generally applied, in anatomy, to excretory organs; but there is nothing in its derivation or terminology to prerent us from using it in the sense here notified. Follicle, from the Latin "folliculus" (which is a diminutive of "follis," a bag, purse or scrjpt,) is a small bag, purse or script, only, without limiting the use to which it is applied; and in lBotany, where it has been introduced, means, "a seed vessel, husk, or corer. It is so used by the French, also, by whom "follicle" is defined, in Botany, to be "l'envelope membrancuse, dans la quelle sont contenue les graines des plantes." We therefore use the word follicle to designate the little sae in which the posterior termination of the shaft, with ita button, is contained, when the pile is perfect and has come to maturity.

"Inscrsible." Fosscesing no fecling, yet not deprived of all the properties of life. 
5th. In inclination, - hair issuing out of the epidermis, at an acute angle thereto,-while wool issues out of the epidermis at a right angle thereto.

6th. In color,-hair often assuming a variety of colors, - while wool is generally white, brown, or black.

7th. In uniformity of color in a single filament; each separate filament of wool being mono-chromatic; while that of the hair of some of the lower animals is often poly-chromatic.

8th. In dimensions, - hair being, generally. longer, and of a greater diameter than wool.

9th. In exuberance,-wool being produced, generally, in greater profusion, upon a given area of skin, than hair.

10th. In the apex, - that of hair being less pointed, in proportion to the diameter.

$1 \mathrm{lth}$. In the disposition of the coloring matter of a perfect hair, being in a central canal, which is not found in nool. (Sce fig. 2, $a$ hair and $b$ wool, contrasted.)

OF FLEECE.-The covering of sheep is called "flece," from the Saxon "flys." It is either hair, or wool, or a mixture of both.**

Pile and Featuers irave been Confounded.-Dr. Ure (in his Philos. of Manufac.) says, "wool is a filamentous substance, which covers the skin of sheep and some other animals, as the beaver, the ostrich, the lama, the goat of Thibet and Cashmere," \&c., \&c.

Eble (in Die Lehre ron der Haaren,) writes of the hair of birds. He says, "only few birds possess stiff bristles and corneous hair, which we find more frequently with the mammalia; and it seems undetermined whether we are to comnt the fine down, which covers the body of a young bird before the formation of the real feathers, as hair or feathers."

In Goodrich's Geography, p. 444, it is said that "the Rhea, or American Ostrich, has black eye-lashes."

And in Agasie's and Gould's Principles of Zoology, p. 151, it is asserted, that the "chicken completely changes its covering from down to feathers."

Eble also states, that "the male turkey has a tuft of stiff hair on his neck."

To judge of the value of the above assertions, we must understand what is a feather.

Description of a Feather.-(See fig. 3.)-A feather consists of, 1st, a cylinder, at the inferior extremity of which is a sheath, which connects it with the slin, but it has no follicle. The cylinder is horny, is always of a circumference greater than that of its stalk; is transparent, or translucent, and terminates in a point more or less abrupt, which is pierced at the posterior extremity. This orifice is called the "inferior navel," to distinguish it from another situated on the internal face, at the point where the cylinder unites with the stalk, which latter is called the "superior navel." Inside of the cylinder is a series of capsules, fitting one in another,-and sometimes united by a central stalk, forming a spire or chain. "This series is called the "heart" of the feather.

\footnotetext{
* 'There is no gool reason for not extending it to that of the gnat.
} 
2d. A stalk, situated anteriorly to the cylinder, the shape of which inclines more or less to square, being slightly curved on one side. It gradually diminishes in circumference, from the superior navel to the anterior extremity. The face inside of the curve is called the internal face, and that on the opposite side, the external face. These two faces are united by a horny matter, somewhat resembling that of the cylinder; but generally less transparent. In the interior of it is a white opaque, soft, elastic substance, called the "pith," or "sponge" of the feather. The surface of the external face is smooth, and forms the segment of a circle, being sometimes longitudinally striated. The internal face is, generally, for its whole length, divided into two equal parts or sections, by a longitudinal canal. Occasionally, instead of the canal, there is a projection of the same dimensions.

3d. On each side of the stalk is a beard and a steno-beard. The fibrils of the stenobeard are generally crooked, giving them a tendency to entangle and adhere.

4th. A feather possesses flexibility and tenacity, but no ductitity nor elasticity.

By comparing this description of a feather with the previous one of a hair, we will readily perceive the differences between these two integuments.

Of rhe Difference between a Hair and a Feather.-(Compare figs. 1 and 3.)-A feather and a hair differ in these particulars:-

1st. A feather, at the inferior extremity of the cylinder, has a perforation, but no butlon; a hair, at the same extremity of the shaft, has a button, but no perforation.

2d. A hair is set in a follicle; but a feather has none.

3d. A feather has, at the point where the cylinder unites with the stalk, a superior navel; a hair has no such perforation.

4th. The stalk of a feather has two different faces, an external and an internal one; a hair is the same for its whole contour.

5th. A feather has, in its cylinder, a series or chain of capsules, which, in a hair, is entirely wanting,-except in one solitary instance, which will be presently noticed.

6th. The stalk of a feather is provided with a pith or sponge; which in a hair is entirely wanting.

7th. The stalk of a feather has, on its interior face, a canal; which, in a hair, is entirely wanting.

8th. A perfect hair has, in its centre, a canal, in which the coloring matter, when present, flows; a feather has none.

9th. The exterior of the shaft of a feather is smooth, and the steno-beard is generally hooked; the cortex of the shaft of a hair is squamose.

10th. 'The stalk of a feather is furnished with a beard and a steno-beard; a hair has neither.

$\mathbf{1} \mathbf{t h}$. The stalk of a feather gradually diminishes in diameter anteriorally; but a hair is, generally, of the same diameter throughout. (There are exceptions.)

12th. A feather has flexibility and tenacity, but no ductitity nor elasticity; a hair has ductility, flexibility, elasticity and tenacity. 
These discrepancies being once clearly pointed out, no one need be at a loss to decide upon all the cases above mentioned.

The Tegunentary Appendages of the Ostrich are Feathers. (See fig. 4, and compare it with 1 and 3.)

1. The inferior extremity is cylindrical, and has no button.

2. The stalk has a smooth surface, no scales, but a beard and a steno-beard on a part of it.*

Of tile Down of Young Birds.-We examined the down plucked from a chicken, immediately after it emerged from the egg, and some taken on four succeeding days; and discovered no change take place, except an enlargement of the parts. They all have a minute cylindrical termination, which is transparent, and an inferior navel, but no button; and, issuing from the shaft, is a beard and steno-beard.

We have also examined the eider-down, and find it to be feathers.

The Eye-Lasies of the Ostricii.- (See fig. 5.) - We have examined the eye-lashes of both the American and African Ostrich, and find them to be feathers. The length of one of these is $\frac{60}{90}$ of an inch, the length of the cylinder being $\frac{7}{50}$, and the width $\frac{2}{90}$. From the termination of the cylinder to that of the most distant beard, $\frac{2}{y} \frac{6}{0}$. On the lower half of this shaft are five long beards, then three short ones; which are succeeded by two long and two short ones.

Of the Turkey's Beard, and of Whalebone.-There is a tuft of dark-colored, angular fibres, pending from the neck of the turkey, (Meleagris gallopavo, which is generally denominated his "beard." We submitted one inch of a fibre of it, of the width of $\frac{1}{30}$ th of an inch, to the trichometer; with 470 grains, it stretched $\frac{2}{90}$ ths of an inch; but as it was originally undulated, this elongation may have been caused by the act of straightening. From that weight to 2100 grains, gradually and increasingly applied, it showed no ductility whatever; and it finally parted with the last mentioned weight. We therefore determined, inasmuch as ductitity is one of the inseparable properties of pile, that this is not hair.

There is also a fibrous, horny substance, with which the mouth of the whale, (Balæna

\footnotetext{
* But it differs from ordinary feathers in these particulars: 1st. It is smaller in proportion. 2u. The cylindrical form is less perfect. 3d. It terminates in a single flat projection. 4th. Both the faces of the stalk are convex-no canal in cither. 5th. The stalk is partly naked and partly invested with a beard and a steno-beard.

A transverse section of one, from the $S$. casuarius, exhibits, under the microscope, 1st, a black exterior; $2 d$, a white intermediate, and $3 \mathrm{~d}$, a central porous matter. One inch of the same, with 1,770 grains, stretched $\frac{1}{9} \overline{0}$ of an incls, elasticity entire.

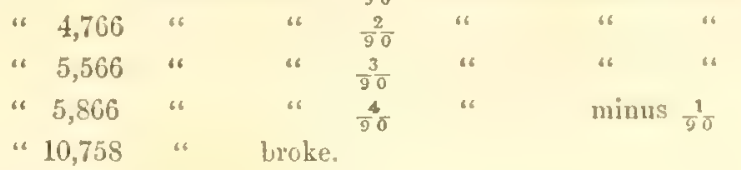


mystecetus,) is furnished, which is sometimes called his "beard," and, at others, his "whiskers;" it is the fanon of the French Naturalists, and the whalebone of commerce and manufactures. We selected one of the natural fibres of this substance, of the diameter of $\frac{1}{30}$ of an inch, and upon subjecting one inch of it to the trichometer, it stretched about $\frac{x}{10} \overline{0}$ of an inch; which we supposed would be required to straighten it. We added to this weight ten grains at a time, till it arrived at 373 grains, when, without obtaining any further elongation, it broke. We therefore pronounce this article not to be hair.

OF the Pile of tile Ornithorynchus.-The animal whose pile bears the strongest resemblance to a feather, is the Platypus Ornithorynchus. (See fig 6.)

This animal belongs to the Order Monotremata. The specimen we examined was presented by H. Wheatland, Esq., of Salem, Massachusetts.* General appearance, upon first view, coarse, dark brown, and very lustrous; but when the external filaments are raised or separated, that of an exuberant, plumbeous colored wool. The skin (in ours, which is a dried specimen, ) is coarse, thick and rough, on the inner side. The pile is set in the dermis in tufts. The integument is of two kinds, one of a finer quality, closely impacted, and covering the epidermis like the wool of the fur-bearing animals; the other, which is longer, having at its lower extremity a similar fine fibre which, near the centre, becomes broad and flat, and lies loosely over, hiding the fine woolly portion. It resembles the anterior termination of the ostrich feather. The length of the long hair is about $\frac{6}{10}$ of an inch, the inferior half of this integument has a diameter of $\frac{1}{6} \frac{1}{5}$ of an inch; is composed 1st, of a white cortex, marked with dark-colored, transverse, varying lines; $2 \mathrm{~d}$, a transparent white substance, enclosing a multitude of black rings, of the diameter of $\frac{1}{50} \overline{0}$ of an inch, with interstices of the same dimensions. These black rings being too minute to be discerned, separately, with the naked eye, blend color with the white interstices, and cause this portion of the pile to appear to be plumbeous.

Between this part and the one next to be described, is a neck of the length of $\frac{1}{12} 5$, and diameter of $\frac{1}{12} 00$ of an inch; it is white, and encloses a dark coloring matter in elongated spots.

From this neck the shaft gradually widens to the $\frac{1}{3} \frac{1}{3}$ of an inch, and then gradually tapers again to the apex, where it is only $\frac{1}{1} \frac{t}{0} \bar{v}$ of an inch. This portion is dark brown colored, and very lustrous; it is composed of a white cortex, with a disseminated coloring matter. In the centre is a darker colored spire, composed of a series of capsules, resembling those found in the interior of the cylinder of a feather. Their diameter is $\frac{1}{120}$ of an inch. They do not continue the whole length of this broad portion of the shaft; but commence at the distance of $\frac{1}{6} \frac{1}{0}$ of an inch from the neck, and terminate at about $\frac{1}{400}$ from the apex. This last portion is colorless.

Shape of the fine portion, cylindrical; that of the flat and coarse part, lenticular, $\frac{1}{2} \frac{1}{2}$ by ${ }^{\frac{1}{3}} \frac{1}{8}$ of an inch in diameter. There is no button, but there is a shaft to this pile.

The second kind of pile upon this animal resembles the posterior portion of the first one, 
above described; it is $\frac{3}{10}$ of an inch in length, and has a diameter of $\overline{2} \frac{3}{5}$ of an inch; it contains the same kind of black rings with white interstices, but this pile is destitute of the flat portion found in the kind first described.

Remarks.-1st. The plumbeous color, formed by blending the color of the black rings with that of the white interstices, is not pecutiar to this pile, but may be seen in the wool of many of the fur-bearing animals, and in the beard of some feathers.

2d. The same filament having its inferior extremity fine and resembling wool, and its superior one broader and somewhat resembling the feather found upon the head of the Toucan and on the Ostrich, although uncommon, is not peculiar to this pile; it may be witnessed in that of the Ferret, the Mink, and some others of the fur-bearing animals, and also in the pile of the Sloth.

3d. It is very unusual to find in the same filament, the coloring matter so variously distributed and disposed as it is in this pile.

4th. The peculiarities of this pile are the spires or capsules, resembling those found in the cylinder of a feather, and the absence of a button.

$a$ "The mouth of this quadruped, (says J. Rymer Jones,) resembles that of a Duck, whence the common name 'Duck-Bill." It has, moreorer, a distinct furcular bone in addition to what would seem to be the ordinary clavicle; but, in reality, these are the coracoid bones, still largely dereloped. Moreover, the anterior or sterual ribs are ossified, and a spur is attached to the hind foot of the male; not remotely resembling that of a cock. This last appendage is perforated by a duct, and has a gland connected with it, situnted on the inner side of the thigh, by which a poisoned secretion was formerly supposed to be claborated."

From Professor Owen we learn that the ovaria of the fenale ornithorynchus exhibit all the essential characters of tho mammiferous type of structure; that the eggs hare no connection with the walls of the uterus, and that each orum has an albumen and a yolk. For these, and other reasons, he infers that it is a riviperous animal. But, in some other respects, the ovum differs from an ordinary egro; and there is no analogy to the bird in the disposition of its pubic bones, which secms to confirm the riew that the animal is produced alive. Some, however, to get rid of this difficulty, conjecture that it is oro-viviparous. There is no reason to believe that a placenta exists; neither is there any marsupial pouch, in which to carry the young, if prematurely born. In a rery young specimen, examined by Professor Owen, the stomach was flled with milk, but there was no trace of an umbilical cicatrix. The animal is dull and inactive in confinement aud can lire a month without food, in which respect it resembles reptiles. 


\section{CHA P T E R I.}

\section{PAR'T II}

Of the Mantle and Hair-lire Processes of the Armadillo.-This animal, instead of heing covered with pile, has his body protected by a mantle, out of the divisions of which issue hair-like processes.

This mantle we have heretofore particularly described, *ै but it will be necessary to recur briefly to the buckler. This is composed of unequal sided hexagons and parallelograms, the internal structure of the latter of which is represented in figure 7, where it will be seen that the main arterial trunk, A., lies horizontally, communicating with the interior of the armor by a foramen situated near the end of the parallelogram towards the hexagons. This main trunk divides, successively, into five horizontal limbs; four of which, viz: 1, 2, 3 and 4, after anastomosing, terminate near the other end of the parallelogram in as many fusiform follicles, B., from each of which emerges, horizontally, a hair, or hair-like process, C. The fifth limb, No. 5, inclines abruptly to one side of the parallelogram, and after a much shorter course, comparatively, terminates in an orbicular capsule, D., from which, through a foramen communicating with the anterior surface, issues, vertically, another hair, or hair-like process, invested with a sheath, $e$. Besides these five limbs, there are six branches. Four of these, i. e. two on each side, issue out of the main trunk, below its first limb-fork. These subdivide into numerous twigs, which do not anastomose. From limb No. 4, about half way beyond its fork, is another and the largest branch of all, 7. This anastomoses with the limb, and divides into numerous twigs, but does not terminate in either a follicle or capsule. The limb on the opposite side, No. 1, above its fork, has four branches, 8, which do not anastomose or terminate in either follicle or capsule, but divides into numerous twigs. Between limbs Nos. 1, 2, 3 and 4, are three interfolical vessels, 9. These anastomose with the follicles, and open out at the end of the parallelogram.

Some of the anastomosing vessels empty into culs de sac, o, approaching, in dimensions, almost to that of the main trunk. These are generally situated at, or near, the root of a follicle, and may be reservoirs.

Each of the above mentioned vessels may be, and probably is, accompanied by an artery and vein; for the animal possesses the power of repairing and re-producing injured or lost plates; we have examined a specimen of an Apara that bears the marks of that operation having been performed.

Description of the hairs and hair-like processes.-Greatest length 2 inches and $\frac{2}{10}$. Shapes, cylindrical and oval. Diameters, some $\frac{1}{150}$, others $\frac{1}{17}$ by $\frac{1}{91}$, $\frac{1}{2} \overline{2}$ by $\frac{1}{9} \overline{2}$, and others again $\frac{1}{1 \frac{2}{2}}$ by $\frac{1}{92}$. Color, corneus. Lustre, feeble. Direction at an acute angle. Inclination, straight. 


\section{Ductility, Elasticity and Tenacity.-}

With 1,750 grains, one inch stretched $\frac{1}{90}$ of an inch, elasticity entire.

$$
\begin{array}{lll}
2,000 & \text { "6 } & \\
2,500 & \text { "broke. }
\end{array}
$$$$
\frac{3}{90}
$$

"6 6

Button, none; the posterior terminating in a navel resembling that of a feather, and of whiskers. Shaft, bright yellow and lustrous. Cortex so thin that its presence camnot always be detected. Interior a mass of white fibres with a central opening. Apices often ruptured. Very difficult to crush; when it does, separating the fibres.

OF Scales.-These tegumentary appendages belong (among reptiles) to the Samrians and Ophidians, and to fishes; but they are sometimes found upon the mammalia.

Of the Pangolin or Manis Scales, and Hair-like Processes that grow between AND. BENEATH THEII.-This animal belongs to the Order Edentata. For a general description of it see Eléméns de Zoölogie, p. 354. It is found in Asia and Africa, and a specimen may be seen in the Academy of Natural Sciences of Philadelphia.

The number of scales are as follows: Upon the head, 64; neck, 14; body, 122; tail, 160 ; legs, $136=496$.

There are a few hairs, or hair-like processes, issuing from between these scales, but none from the scales themselves.

Particular Description of the Scales.-Form, nearly flat; slightly convex on the superior and slightly concave on the inferior surface. Outline, sub-quadrilateral; the inferior extremity,- that connected with the skin,- - ovoidal at the angles; the superior extremity inclining to semi-circular. Color brown, opaque, dull. 'To the touch smooth, when the fingers are passed longitudinally; but, when passed in an opposite direction, slightly rugose. No ductility nor elasticity.

Structure-Composed of two plates, an inferior and a superior one.

The inferior one, (which is the smallest,) at its inferior extremity, is bounded by two straight lines, which respectively commence at the inferior angle of the sides of the scale, and meet at right angles. At its superior outline it is semi-circular. This superior extremity of this inferior plate is soldered to the superior one, with an opening in the form of a pouch.

The superior plate, (which is the largest,) is divided by a slightly curved midrib, into two nearly equal triangular portions. The posterior. portions of each of these triangles, from their inferior outlines to points opposite to the pouch, are again divided by ribs running nearly parallel with the midrib. The lateral edges of this plate, where they correspond with those of the inferior one, are turned over and felled. Nearly the whole interior between these plates, is filled with muscle; and with it the midrib and ribs, which also are muscular, communicate; thus enabling the animal to raise its scales, and, perhaps, allowing it to communicate to them a slight lateral motion. 
Composition.-No earthy matter can be detected in these scales, either by incineration or treatment with diluted hy dro-chloric acid.

The hair-like processes, issuing from between and under the scales. Fig. 8 represents one of them. The shaft is oval, diameter $\frac{1}{2} \frac{1}{50}$ by $\frac{1}{3} \frac{1}{3}$, color corneous, with irregularly shaped lines and dots. On one side a wart-like protuberance. No button. Disks exhibit a white corneous mass, with a small central crack.

Of the Scales of Preitensile Tails of some of tie lower animals, and tie Hairs acConpanYing TIE SAME.- Scales are found upon the tails of some of the lower animals. They may, possibly, be considered as hairs only partially developed; the matter which forms the ordinary scales of the cortex being in abundance, while that which forms the fibres is deficient. Their study may therefore prove interesting, both in themselves and on account of their comnection with hair-scales and woot-scales, which are the subject of a separate part of this work.

The Scales upon the Tail of the Possum.-(See fig. 9.) - These scales are, in general, oral and sub-oval, depressed upon the side of the attachment to the epidermis; diameter about $\frac{5}{1} \frac{5}{0} 0$ by $\frac{-\frac{r}{1} \sigma 0}{0}$ of an inch. They are the same color as the epidermis, which they cover. Hairs never issue out of these scales, but always from between them. They also partake of the color of the skin, whether that be black or white. They are in length about $\frac{3}{4}$ of an inch; diameter $\frac{1}{2} \frac{1}{5}$ by $\frac{1}{2} 8$ of an inch, gradually narrowing to $\frac{1}{6} \frac{1}{2}$ at the apex. Cortex conneous, diameter $\frac{1}{10 \overline{1}}$ of an inch; the remainder of the interior oval and white. When the scales are removed, the inferior termination of the hairs, which they overlay, may be seen in the dermis.

The Muskrat (Fiber Zibethicus of Lin.) has a tail $\frac{2}{3}$ the length of its body; compressed, convex on the sides, thickest in the middle, tapering to a point; covered with small scales and thinly scattered hairs.

The Field-Mouse (Agricola Pennsylvanica of Ord) has a tail which is cylindrical, scaly, and slightly covered with hair.

Of Scales upon trie tails of Monieys. - Of the Monkeys of the Old World there are said to be 54 species, and of these only one is found in Europe, 36 in Asia, 16 in Africa, and 2 whose country is unknown.

One of the distinguishing features of the Monkey of South America, is the having of a tail; but we observe that a species of Lemur is found in Madagascar, possessing a very long tail, peculiarly adapted to climbing.

Of the South American Monkeys, that have tails, all are not prehensile. Those with these strong, muscular, scaly tails, are called "Sapajous," and those with feeble, useless tails, are called "Sagoius." Of both these there are several varieties. Of the first, the Coati (Atelesater) has no thumb, and consequently but four fingers on the two fore-paws, but the defect is supplied by the tail, with which this animal slings himself from tree to tree.

Of the Sagoins, or Monkeys which do not hold by the tails, is the Samari, or Aurora. (Sanguinas sciureas.) 
The Saki, or Cagui, (Pittecia,) is remarkable for the length of the hair on its tail, and is often called, for that reason, the fox-tailed monkey.

The Wistiti, or striated Monkey, (Jacchus, has an annulated tail.

The Marikina (Midas rosalia) has a bunch of hair at the end of the tail, like the lion.

The Mico (Jacchus argeniatus) has a tail with deep brown hair, while that on the body is silver color.

Remartis of Tail Scales.-The scales upon the tails that are prehensile are intended, no doubt, to prevent them from slipping when an object is grasped. Some reptiles obtain a progressive movement by means of scales.

Of Fibrous Protuberances resenbiong Holx, but which are vot true HorxThese processes are found upon the nose of the Rhinoceros. This animal belongs to the orden "pachydermata," the family "ordinary pachydermas," and forms the genus "Rhinoceros," (so named from the Greek word "rin," the nose; in the genitive case "rinos," and "keras," a horn.) There are two species, viz: 1, R. cornu unico conico, and 2, R. cornibus duobus cuneiformibus. (Lin: O.5 Jumenta, No. 25, Rhinoceros.)

This animal is large, heavy, strong-limbed and thick-skimned, nearly hairless, (a few being found in the ear;) the bones of the nose, which are rery stout, are united, forming a vault, supporting upon its median line this solid, horn-like projection, which is unconnected with the bone, but is buried in and adheres to the skin. It is truly said to be composed of agglutinated fibres, which are thought to be hairs.

Specimen of the animal in the Zoological Institute, Philaclphia, and of the hom in the Academy of Natural Science, of this city.

Fig. $10 \mathrm{a}$ is a representation of a transterse section of this horn, where the ends of two hairs, and a part of the third, may be seen. Fig. 10 b is a longitudinal section, showing the lails.

Comparison with Real Homs.-This (so called) horn of the Rhinoceros, will be best understood by a comparison of its formation and growth with real homs, of which there are the following varieties: 1 . Those which are composed entirely of bony matter, and 2 , those which are composed of an inferior osscons portion, covered with an cxterior corneous matter. 'The first species is sub-divided into those that are perishable and renewable, and those that are persistant.

The antlers of the stag are solid and osseous, are rapidly produced by powerful bloodvessels, but, after a time, they perish and fall, and are renewed in like manner. 'The short, solid; bony processes of the cameleopard, are formed in the same mamner, but they are persistant. And the hollow horns of the ox, shcep, \&c, are composed of two distinct substances, viz: an interior one of phosphate of lime, and an exterior one of horn. 'These two substances appear to be simnltancously produced from the two sides, respectively, of a vascular membrane; and they are nourished in different modes; that of the bony interior from vessels belonging to the general system, but the exterior one is destitnte of vessels; and is, consequently, when once formed, removed from the influence of vital powers.

On the other hand, the (so called) homs of the Rhinoceros, (both of the onc and the two- 
liorned species,) grow from the tegument covering the nose, to which they adhere without having any connexion mith the subjacent bones. They have a sub-pyramidal shape, and are composed of parallel hairs, agglutinated together into a solid mass by a material which acts as a cement. This fibrous structure is most distinctly seen at the base of the horn, where the ends of the fibres project from the surface like those of a brush. When these horns are divided transversely, as in fig. $10 \mathrm{a}$, and examined with the microscope, a great number of orifices are seen, marking the empty spaces that intervene between the hairs; and if the section be made in a longitudinal direction, as in fig. $10 \mathrm{~b}$, the same spaces give rise to the appearance of parallel grooves. These (so called) horns are not deciduous, like those of the stag; but continue to adhere to the skin, and to grow from the root, in proportion as they are worn at the extremity. (See Roget An. and Veg. Phys. 356.)

The Horn of the Rhinoceros, in the Academy of Natural Sciences of PmiladelPIIA.-Examination and description of the horn of a two-horned Rhinoceros in the Academy of Natural Sciences of Philadelphia.-Isength, from the base to the point, 15 inches and $\frac{4}{10}$. Of this 1 inch and $\frac{8}{10}$ appears to have been buried in the skin. Cireumference at the base, 14 inches $\frac{5}{10}$. Diameters, $4 \frac{8}{10}$ by $4 \frac{4}{10}$. The inferior termination calyx shaped; depth of calyx, 2 inches. Circumference, at the former junction with the epidermis, 12 inches; apex oval; diameter, $\frac{1}{10}$ by $\frac{1}{2}$ of an inch. The surface in the interior of the calyx rugous and deeply fissured. The exterior striated longitudinally. The main body corneous and solid, except some slight longitudinal fissures.

Examination of the Hair of the Ear of the Rhinoceros.-Length, $\frac{6}{10}$ of an inch; shape, cylindrical; diameter, $\frac{1}{2} \frac{1}{7}$, gradually tupering to $\frac{1}{12} 50$ of an inch. Color, brown. Button resembles a mere swelling of the posterior portion of the shaft, slightly curved and pointed. When crushed, fibres are exhibited of the diameter of $\frac{1}{550}$ of an inch. Shaft undulating; apex rounded, sometimes furcated.

OF SPInes.-The word is from "Spina," a thorn or prickle.

A few animals only have spines; such as the porcupine, the hedgehog and the pecary.

Tile Spines of the Porcupine.-The Porcupine (Hystrix Dorsata, see Aud. and Back. Quadru., 1 vol., 277.)

Pile, at the roots yellowish-white, tipped with black. Head, cheeks and sides of the neck, grayish; legs, of dark brown. A whitish band two inches broad from the top of the shoulder on each side, towards the lower part of the neck. The long hairs on the dorsal line are so broadly tipped with black, that the animal, on these parts, appears of a blackish color; along the sides, however, the alternate annulations are so conspicuous that it has a deep gray or grizzled appearance. On the chest, outer surface of the shoulders and thighs, it is of a darker color than on the sides. Immediately behind the lightish collar on the shoulders, the hairs are dark, rendering the collar or band more conspicuous.

The young have a uniform shade of red. A spine now before us measures in length 
8 inches; diameter, $\frac{1}{4}$ of an inch. Thickest in the centre and tapering to both extremities; apex pointed.

Fig. 11, represents a transverse section of one of these spines.

OF the Spine of the Peciry.-Gen. Dycotyles of Cur., from "dis," double, and "Kotule," a cavity, or navel. There are two species, D. torquatus of F. Cuv., and D. labiatis, (white lipped, see Aud. and Back. Quad. 1 v., 233.) It somewhat resembles a hog, but has no tail, and the canine teeth do not extend beyond the margin of the lips. Found in South America.

The spine we are about to describe came from a full grown male, exhibited in Philadelphia, at the Zoölogical Institute in the winter of 1847-8.

Length of the button, $\frac{3}{10} \pi$ of an inch; of the neck, $\frac{5}{100}$, and of the shaft, 4 inches and $\frac{10}{100}=4$ inches and $\frac{18}{100}$. Diameter of the button $\frac{1}{10}$, of the neck $\frac{1}{90}$, of the shaft $\frac{2}{100}$ by $\frac{1}{10}$. Shape, oval; colors, horny white, brown and black, in clouds and patches. Weight, $\frac{1}{4}$ of a grain. Surface, smooth. Direction, at an acute angle. Inclination, straight, except slightly undulated. See fig. 12, where No. 1 represents the button, neck and a small portion of the shaft. No. 2, a transverse section of the button. Nos. 3 and 4, transverse sections of the shaft. No. 5, a longitudinal section of the cortex. No. 6, the termination of the shaft, and No. 7 , a longitudinal section of the stellated figure represented in No. 4.

\section{Ductility, Elasticity and Tenacity.-}

There was no extension under 6,298 grains.

With 6,298 grains the extension was $\frac{1}{1} 0$ of an inch, the shrinking upon removal of the

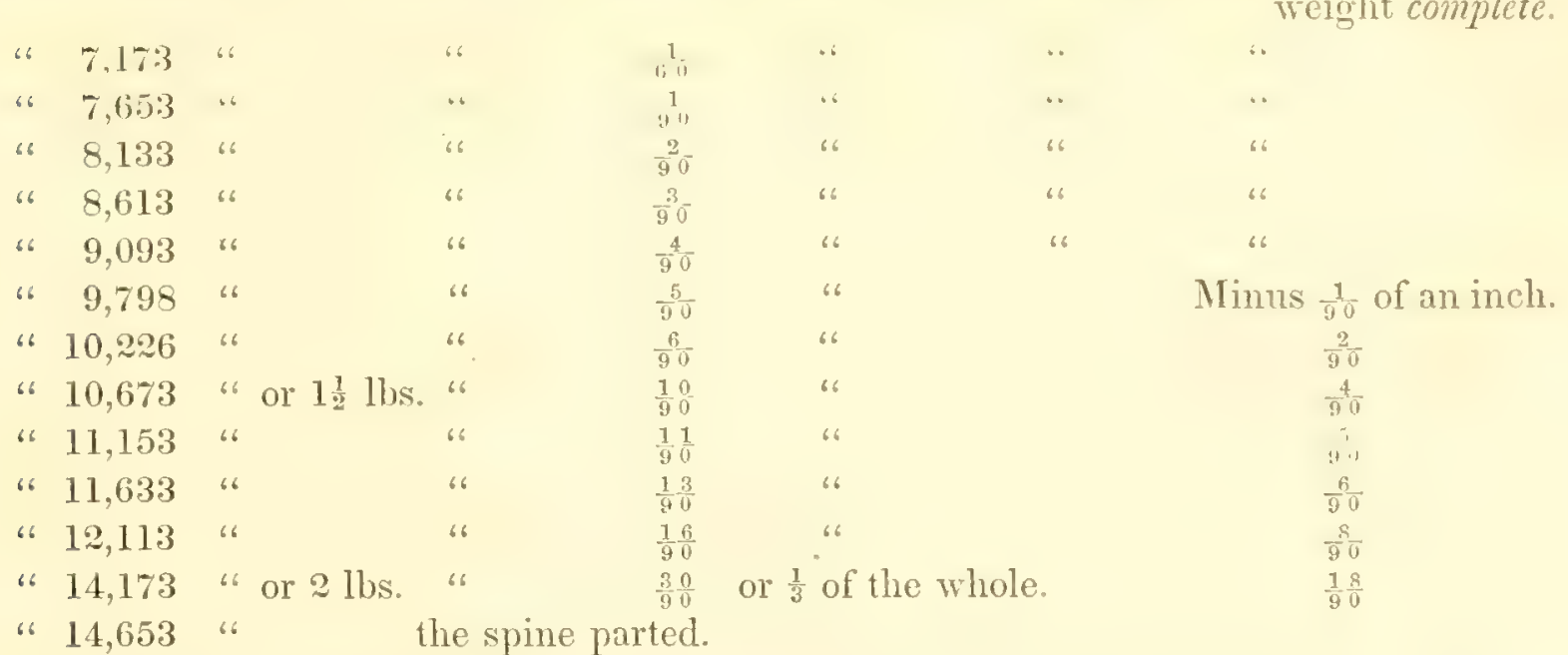

Of Whiskers.-Roget (Animal and Vegetable Physig. p. 25,) says that the whiskers of the feline, and of some other animals, are supplied with vessels and nerves, andar e thus converted into organs of touch*.

* In Illust. of Nat Hist. 355 , whiskers are said to increase the sense of smell. (!) 
Dr. Gross (in Elem. Path. and Anat., p. 327, ) assures us that on the African Lion he has traced filaments of the fifth pair of nerves to the bulbs (follicles) of whiskers. Rudolphi had previously announced the same discovery in regard to the whiskers of the Seal; and, at a still earlier period, Gaultier had asserted that these tegumentary appendages were supplied with vessels and nerves. Besides which, Malpighi found blood in the long hairs drawn from the lip of the horse, and Gurlt discovered the same fluid between the follicle and sheath of a moustache, (but of what animal, or under what circumstances, he has not informed us.)

And lastly, Eble considers the whiskers as the most perfect hair.

Mr. Broughton made some experiments with a kitten, who, while blind-folded, could thread her way out of a labyrinth by means of her whiskers, but, when deprived of those tegumentary appendages, was unable to do so.

OF tile IV insters of tie RabitT.-Examination and Description of the Whistiers of the Rabtit.-Specimen, common Rabbit, found wild near Philadelphia.

Length, from $1 \frac{1}{2}$ to 2 inches; diameter, $\frac{1}{90}$ of an inch. Shape, shaft cylindrical, gradually tapering to a very fine point; direction, undulated. 'The shaft, (with its sheath,) descending to the posterior extremity of the interior of the follicle, where it either ends abruptly, or swells slightly, and again contracts, with a fibrous appearance. Fibres intermediate; a central canal; no button. The fibres, upon being ruptured, evince great elasticity, contracting and spreading outward. Transverse sections or disks, taken from the portion. of the shaft covered with the sheath, show a central canal, in which are specks of a bloodred color; immediately anterior to the sheath is a canal, containing a substance which is either white or slightly colored red; anterior, still, to this point, is a roid canal, and near the apex are white rings. The white matter is cubic or cuneiform.

Sheath, length, $\frac{5}{9} 0$ of an inch; when dry, closely adhering to the shaft, but separating from it easily after a slight maceration. Color, white, or slightly stained red.

Follicle, length, $\frac{50}{9} 0$ of an inch; diameter, $\frac{4}{90}$ th; color, red; shape, turbinate.

Vessels are seen projecting from the exterior of the posterior extremity of the follicle, immediately beneath the perforation of the shaft.

Ductility, Elasticity and T'enacity.-One inch of a whisker, with 2270 grains, was deprived of its undulation only. With 7770 grains, it stretched $\frac{2}{9} 0$ ths of an inch, and broke. Fracture-the cortex was ruptured, and fibres projected from one portion. Three transverse dark marks, and one white, longitudinal furrow on the cortex. A portion of the follicle was bleached, when the vessels pending from its lower extremity were plainly seen.

OF the Whiskers of THE Irish HARE.-Examination and Description of the Whistiers of the Irish Hare._(Lepus Hibernicus.)-June 16, 1849.-Specimen in the Academy of Nat. Sei. of Phila.

Length, 3 inches and $\frac{4}{10}$ the; greatest diameter, $\frac{1}{100}$ of an inch; gradual tapering to a point. 
Shaft, color underneath the sheath, white; from the sheath for $\frac{8}{10}$ ths of an inch, black; for $\frac{6}{10}$ ths, white; slightly colored for $\frac{1}{10}$ hh; then white for $\frac{9}{10}$ ths; and dark brown 1 inch to the apex; the inferior termination quill shaped, surface squamose, perforated; no button.

Sheath-length, $\frac{4}{10} \overline{0}$; diameter, $\frac{1}{5} \overline{0}$ of an inch; color, dark brom; easily removed from the shaft with the fingers, after a slight maceration.

Disks-one cut from beneath the sheath has, 1st, a fibrous cortex; 2d, a large, black, solid substance; 3d, a small white circle, or ring; 4th, a perforation in the centre. Another disk, cut from the black portion above described, has, 1 st, a white fibrous cortex; $2 \mathrm{~d}$, a solid black substance; and $3 \mathrm{~d}$, a centre of solid white. In cutting this disk, a white fibre of the cortex is left pendant. A disk from the white shows, 1 st, a white substance; $2 \mathrm{~d}$, a centre whitish. A fourth cut from the portion which was slightly colored, shows, Ist, a white substance; 2d, a dark cloudy substance; $3 d$, a perforated white centre.

Apex-pointed, sometimes furcated.

Inferences. - The substance of the cortex is fibrous, but it may have a squamose exterior; the coloring matter is disseminated in the cortex and intermediate substance. The central canal is sometimes void, and sometimes filled with a white substance.

Note.-These whiskers were drawn out of a dried specimen, which accounts for our having no follicle to examine and seeing no vessels, they being left behind.

Of the Whiskers of tire Possur.-(Didelphis virginica.) Sepecimen, the common Possum, found wild near Philadelphia.

Length, from $2 \frac{3}{10}$ to 3 inches; diameter, $\frac{1}{5}$ of an inch. Stalk, cylindrical, gradually tapering to a point, unless, (which often happens,) it is furcated. Direction, undulated; posterior extremity perforated; no button. In ours, (which is a dried specimen,) bloodred central grains. Disks, - one exhibited a light cortex, a white substance, a compressed dark-colored ring, and a central canal. Another shows a white cortex, a dotted substance, a compressed dark ring, and a central canal. (See fig. 13, $a$ and $b$, for a representation of the stalk-13, $c$ and $d$, for the disks.)

Remarts on Whisters. - The differences between whiskers and common hairs are: 1st. An ordinary hair has a button, but a whisker has none. 2d. 'The posterior extremity of a whisker is perforated, that of a hair is not. 3d. The lower extremity of the shaft of a whisker is sometimes colored blood-red, which is not the case with that of an ordinary hair. 4th. There is a great ductility and tenacity in a whisker, compared with an ordinary hair. 5th. The vessels of a whisker are more apparent than in an ordinary hair. 61h. The cubic or cuneiform white matter, seen in the canal of a whisker, has not been detected in ordinary hairs.

Of Bristues.-The word is from the Saxon "bristl," and means the strong, stiff hairs that are found upon the back of the boar.

Cuvier says they are chamfered* their whole length, by 20 or more furrows, formed

* Chamfer is from the French "chambrer," a furrow or hollow in a column. 
by the union of as many filaments. We find them chamfered, but that they are formed by the union of 20 or more filaments, we are unable to confirm, and yet would not like positively to deny. We made many transverse sections, which were examined under the microscope, with the view of ascertaining if any such union exists. Sometimes, especially where the section is made in the neighborhood of the furcation, separate portions of the shaft may be seen; but they are not homogeneous in shape, as it seems to us they ought to be if they were an union of filaments; but, on the contrary, have the appearance of the fibres of other furcated pile. We separated one bristle throughout, into as many portions as there were furcations. Upon exposing these to view under the microscope, the sides that had been exterior could easily be detected by their smooth appearance, while those that were originally the interior were covered with ruptured fibrils. (See fig. 14.)

Cuvier says, also, that each bristle has two canals, one for the marrow and the other a humor. We could not find them.

Examination and Description of a Bristle of a Russian Wild Boar.-Length 9? $\frac{7}{2}$ inches; diameter $\frac{1}{80}$ of an inch. Color of the button, brown; of the shaft, white, and transparent for the distance of 3 inches, and opaque for the rest. Button in length, $\frac{1}{500}$ of an inch; diameter, $\frac{1}{90}$; posterior termination, quill shaped; shaft, chamfered. Apex very much furcated.

Comparison of Dimensions of Eleven Varieties of Bristles, Selected from Our Colmection.-

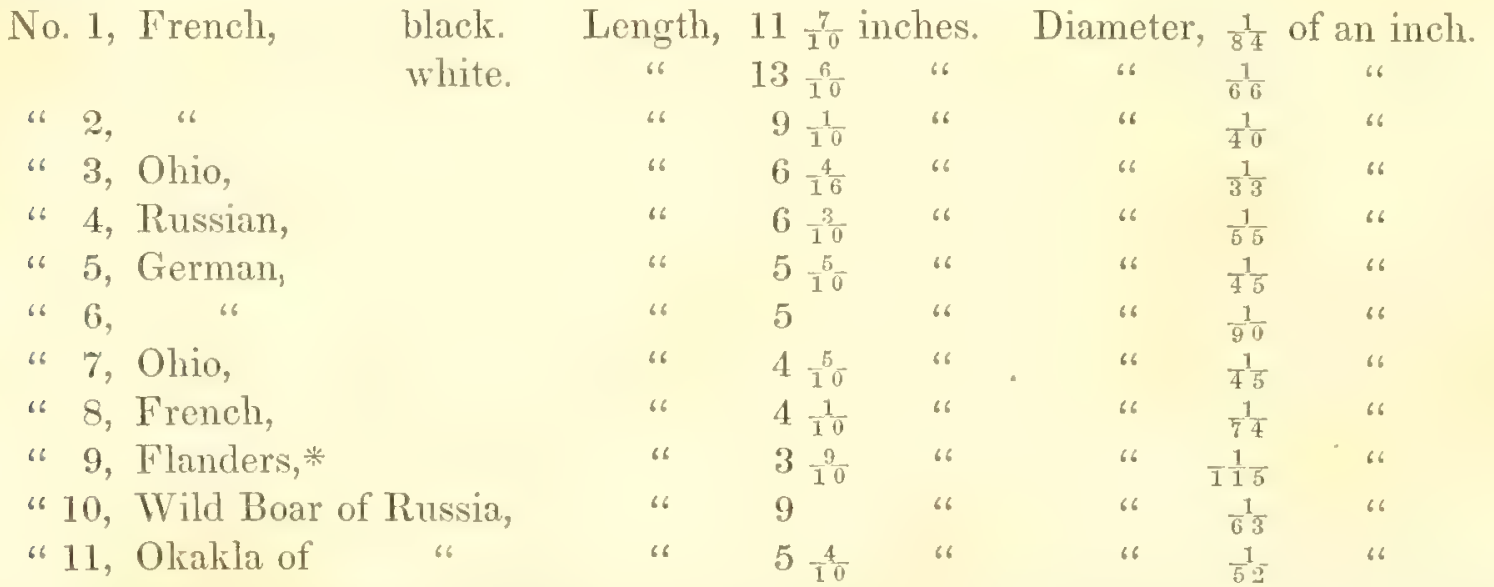

From the above it appears that the French bristle is the longest, but that of Ohio is the stontest.

Ductility, Elasticity and Tenacity of six Varieties.-

No. 1. One inch submitted to the trichometer May 28th, 1749.

With 1,070 grains it stretched $\frac{1}{90}$ of an inch, elasticity entire.

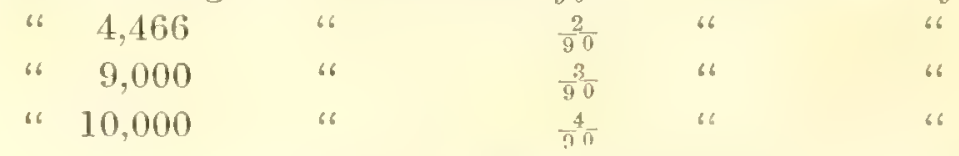

* Very much estecmed for paint brushes. 
With 11,362 grains it stretched $\frac{5}{90}$ of an inch, elasticity entire.

Fracture very rugged.

\begin{tabular}{|c|c|c|c|c|c|}
\hline * 13,000 & 6 & ". & $\frac{7}{90}$ & " & minus \\
\hline 15,038 & “ & "6 & $\frac{15}{90}$ & “ & "، \\
\hline 16,000 & “ & 6 & $\frac{25}{90}$ & “ & " \\
\hline 17,000 & 66 & it broke. & & & \\
\hline
\end{tabular}

No. 2. One inch examined, e. d.

With 11,362 grains it stretched $\frac{1}{90}$ of an inch, elasticity entire.

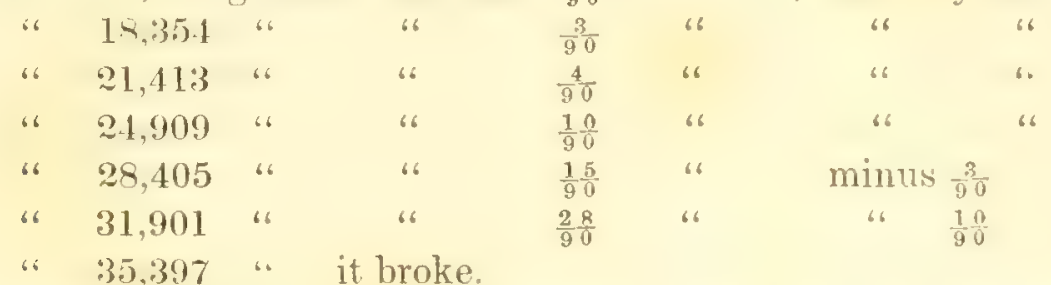

Fracture abrupt on one side, with the filament disrupted and displaced on the other. No. 3. Two experiments, e. d.

Experiment No. 1.-

With 21,874 grains it stretched $\frac{1}{90}$ of an inch, elasticity entire.

\section{Experiment No. 2.-}

$$
\begin{aligned}
& \text { " } 27,124 \text { " "6 "6 " " " }
\end{aligned}
$$

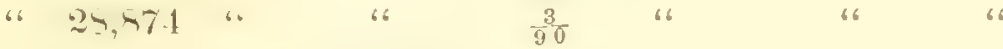

$$
\begin{aligned}
& \text { "31,061 " it broke. }
\end{aligned}
$$

With 23,624 grains it stretched $\frac{1}{90}$ of an inch, elasticity entire.

No. 4. e. d.

$$
\begin{array}{ccccc}
\text { " } & 27,124 & \text { " } & \text { " } & \frac{2}{90} \\
\text { " } & 29,774 & \text { " } & \text { " } & \frac{3}{90} \\
\text { " } & 34,124 & \text { " } & \text { " } & \frac{4}{90} \\
\text { " } & 35,574 & \text { " } & \text { it broke. }
\end{array}
$$

With 7,866 grains it stretched $\frac{1}{90}$. of an inch, elasticity entire.

$$
\begin{aligned}
& \text { " } 11,362 \text { " " " " " } \quad \frac{2}{90} \quad \text { " " } \\
& \text { " } 14,858 \text { " " " " " " } \quad \frac{7}{9} \overline{0} \text { " " } \\
& \text { " } 18,354 \text { " it broke. }
\end{aligned}
$$

No. 6. e. d.

With 1,070 grains it stretched $\frac{1}{90}$ of an inch, elasticity entire.

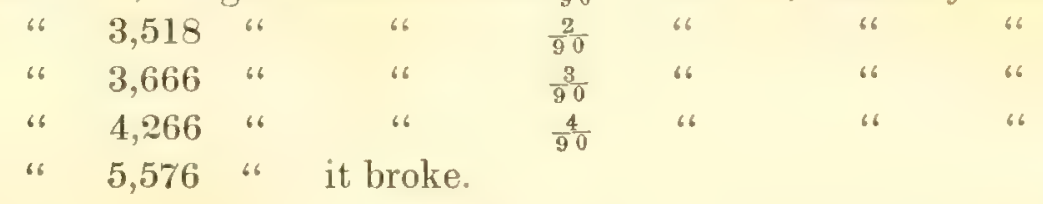

Of MANe HaIRs. - The word mane, (Maene Belg.,) designates the long hair which langs from the neck of certain animals. The French call it "crin;" but they call the hair of the tail by the same name. 
The Mane of the Lion.-The female of this species has no mane, and the male is born without it.

Examination and Description of the Mane of the Lion, exhibited in Philadelphia in 1849.-Length, about 12 inches; shape, cylindrical; diameter, $\frac{1}{2} \frac{1}{8}$ of an inch; color, black, white and corneous; lustre, feeble. Button, club-shaped and hooked; direction, flowing; inclination, at an acute angle.

Shrft, cortex; diameter, 396 of an inch; color, black; fibres, white; diameter, $\frac{1}{250}$ of an inch. One white shaft has a comeons cortex, and white fibres. Some of the shapes are polychromatic. A pices, furcated. Two hairs were found in one follicle.

(I) the Mune of the Horse.-Examination of the Nane of the celebrated running mare Fashion.-Length, about 12 inches; diameter, from $\frac{1}{45}$ to $\frac{1}{90}$ of an inch. Button, globose, ronterted. hookerl, black, or white and not hooked. Sheath seldom met with, and when it occurs, very thin, white, opaque. Follicle, had none to examine. Shaft, cylindrical and cylindroidal, black and brownish yellow. Transverse sections, (or disks,) show a brown compact ring, with a small white centre, in which the ends of the fibres can be seen. With 3,766 grains, one inch stretched $\frac{10}{90}$ of an inch, and upon removing the weight, recovered its original length. With 3,766 urains it broke. Fracture, angular transverse.

The Mane of the Cervus Canadensis.-Length, 6 inches; shape, oval and ovoidal; diameter, $\frac{1}{20} \overline{0}$ by $\frac{1}{16} \overline{2}$ of an inch. Black and rusty brown; no lustre; direction, nearly straight; inclination, at an acute angle.

Shaft, cortex; diameter, $\frac{1}{2} \overline{1} \overline{6}$ of an inch; color, corneous; fibres, dirty white color, loosely compacted, the end of them upon a vertical section shrivelled, and not well defined; diameter, $\frac{1}{200}$ of an inch, solid and heterogeneous in form.

The Cameleopard, or Giraffe, has a mane which commences between the horns; it consists of short and almost straight hair, and continues over the neck and on to the withers. (11lus. of Nat. Hist. 215.) We have none of this integumen in our cabinet.

OF TAIL HAIRs.-Examination of the Tail Hair of the celebrated running mare "Fastion."-Length, 9 to 12 inches; diameter, $\frac{1}{80}$ th of an inch; black, brownish yellow, or white; the black predominating. Button. irregularly shaped; mostly hooked and contorted. Sheath, thin, white, opaque, embracing the button closely; shaft, cylindrical or eylindroidal; transverse sections or disks of the black, solid, dark-colored, with a small point of a lighter color in the centre; of the brownish yellow, solid yellow, with a white spot in the eentre, and of the white, solid, dirty-white, opaque, with a lighter speck in the centre.

Trial with the trichometer:-Bar. 29; Ther. 80; Dew-point, 69.

With 3,766 grains, it stretched $\frac{1}{90}$ th of an inch; upon removing the weight, recovered its original length.

With 4,266 grains, it stretched $\frac{2}{9}$ ths, and elasticity entire

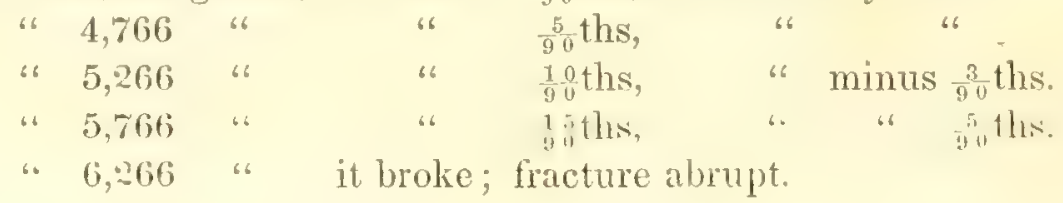


A shaving taken from the exterior of the black hair was dark-colored, and one from the brownish yellow, was brownish yellow; showing that the coloring matter was in the cortex.**

Remarks. - The delicate dimensions and lustre, smallness of the button, thimness of the sheath, and, above all, large number of the vessels of this liair of the body, show the thorough breeding of the mare; but the deficiency in ductility and tenacity of the hair of the mane, would not indicate much vital power.

T'ail of the Hippopotamus. - This tail is ovoidal; diameter, at the posterior extremity, $-\frac{6}{10} \overline{0}$ of an inch; at the anterior, $\frac{3}{100}$; color, black; disks exhibit the termination of small, irregularly shaped fibres. Fig. 16 represents a transverse section.

Tail of the Zebra.-This hair is cylindrical and oval; diameter, $\frac{1}{1} 5$ of an inch; color, black, except a minute white central spot.

Tail of the Cerous. - This hair is oval; diameter, $\frac{1}{2} \frac{1}{2} 5 y$ by $\frac{1}{8} \frac{1}{7}$, tapering to $\frac{1}{4} \frac{1}{6}$ by $\frac{1}{12}$.

Tail of the Arabian Bull.-This hair is cylindrical; diameter, $\frac{1}{12} 5$ of an inch; cortex, black, solid; diameter, $\frac{1}{3} \frac{1}{2}$; centre sometimes a void canal, and, at others, partly filled with a white scaly substance

Fig. 16-2 represents the disk of the tail of the Elephant.

* II AIR of THE BODY.-Length, from $\frac{4}{1}-$ ths to $\frac{5}{10}$ ths of an inch; greatest diameter, $\frac{1}{5} \overrightarrow{0}$ of an inch; button, quillshaped, white, opaque. Sheath, none; or, if any, adhering so elosely to the button as to be undistinguislialle. Follicle, had none to examinc. Vessels, - numerous, fibrous, - divergent from the lower extremity of the button. Shaft,--oral, brownish-yellow or white, lustrous. Cortex,- - transversely striated, indicating minute scales. Transverse sections, (or disks,) show a solid yellow ring, with a white centre. $\Lambda$ pes, pointed. 


\section{CHAPTER II.}

PILE is an animal apparatus, consisting of several organs, distinguishable by different membranes, but acting unitedly to accomplish destined ends. It possesses, per se, no sensation nor power of voluntary motion; but is connected with a tissue rich in vessels and nerves.

That Pile is not vegetable, as was anciently supposed, is proved by

The manner in which the Shaft elongates.-Hair does not grow by additions to its points, like the roots of vegetables; nor by a simultaneous elongation of the whole shaft, like their stems; but by additions at the LOWER EXTREMITY, so that the newly produced portions are continually forcing the old ones forward. This is the reason why no injuries, such as splitting at the apex; nor any losses, such as a deprivation of the point of pile, can ever be repaired. If the natural point of a hair (which is the first part of the stalk that is produced) be, accidentally or intentionally, removed, it is never repaired. This is also the reason why hair, which has been dyed, shows its undyed color first nearest to the skin; and why marks, made upon the fleece of sheep, become, in time, obliterated, beginning to blanche near the body of the animal.

This property of growing by additions at the lower extremity, only, distinguishes pile from vegetables, and is capable of being made use of as one of the tests of a true hair.

Of the different parts of Pile.-Pile, when in a normal and healthy condition, and fully developed, has the following parts:-

A shaft,-at the inferior extremity of which is a button, and at the superior one a point.

This shaft has a cortex, which is either squamose or pared,-intermediate fibres, which are divisible into fibrils, and a centre, which is either solid or has a canal. The canal (when present) either contains a granulated substance and pigment cells, or a granulated substance and no pigment cells-or, the canal is void.

The button, with the lower extremity of the shaft, is set in a follicle, which has a double lining membrane, called a sheath.

\section{Recapitulation:-}

1. SHaft.

1. Button.

2. Point.

3. Cortex.

1. Squamose.
2. Paved.

4. Intermediate fibres and fibrils. 
5. Centre.

1. Solid.

2. Canal.

1. Granulated substance and pigment cells.

2. 6\% 66 without "6 "

3. Void.

2. Foltirlele.

1. Sheath.

2. Vessels, \&c.

Of the Button.- When a hair is drawn out of the head, there is generally found, at its lower extremity, a swelling; this is the button. It is spheroidal, ovoidal, spindle, pestle, or club-shaped, or amorphous; is generally white and translucent, but sometimes darkcolored and opaque.

This part had (in common with the follicle) been called the "bulb;" but Henle (who has given an elaborate account of it) has conferred the name of button.

Of the Cells of the Button.-We drew a fully developed hair from the head of an ovalhaired lad of 14, who was in good health, and, placing it immediately under the microscope, saw in the button numerous globular cells, imbedded in a white translucent substance. Fig. 16 a represents this object. The length of this button is $\frac{34}{10}$ of a millimeter; the diameter, $\frac{19}{100}$, while that of the shaft is $\frac{7}{10} \overline{0}$. The cells do not exceed in diameter the $\frac{1}{4} \frac{1}{0}$ of a millimeter.

Upon recurring to this object again, after the lapse of a few days, those previously welldefined cells had disappeared, leaving irregularly shaped lines and shadows, as represented in Fig. 16 b.

Another button, drawn from the same head, and examined immediately, had no cells, but bore the appearance represented in Fig. 17.

Of the Normal Shape of a Button.-From numerous examinations, we are of opinion that the hair of the head of the oval-haired species, when the subject is in health, and the integument is in a normal condition, and fully developed, is well represented by figures $16 a, 16 b$, and 17. But we must not expect to find it always to conform to this outline,from which it varies in very many instances, sometimes to a considerable degree, -as will be shown in the progress of this work.

As to the color of the button, Henle represents it, when belonging to healthy hairs that are colored, to be, for the most part, colored also, and when found upon grey (colorless) hairs, to be white.

But, according to our experience, the button of a healthy hair is very apt to be white and translucent, even when the hair is colored. But this translucency diminished when the hair had been long drawn.

Note.-Care must be taken not to confound the button with the follicle, which will be hereinafter described. The follicle never draws out of the head of the oval-haired species. It must be dissected out or obtained by maceration. But the shaft often draws out, leaving the button in the follicle. Fig. 18 represents one of these, from the head of His Excel- 
lency Governor Johnson. The whole length is one millimeter; diameter, $\frac{r}{10} 0$ of a millimeter; that of the shaft being $\frac{8}{10} \overline{0}$.

It is easy to remove the button from the end of a shaft, immediately after it is drawn out,-when the same appearance, as in Fig. 18, is represented.

Buttons are often found upon the ends of hairs that fall ont. Fig. 19 represents one of these, from a hair of the head of His Excellency James Madison, combed out, in his lifetime, and presented to us by Mrs. Madison since his death.

Henle is of opinion, that the difference in appearance is owing to these fallen hairs having arrived at fuller maturity.

Of Hairs without a Button.-From what has been said in regard to the cells seen in the button, it is inferable that the shaft is generated by the button. Nevertheless, we occasionally find hairs without a bution.

This subject will be resumed and explained, under title "Follicle."

Of the Button of the Hair of the Head of the cylindrical-piled Man.-Generally, these buttons are not so regularly shaped as those of the oval-haired species.

Fig. 21, Nos. 1, 2 and 3, represent the buttons of three of these, all from the heads of pure American Indians, viz:-No. 1, is from the head of Bish-e-ki-se-quau, a female, aged 30, a pure Sac, a descendant of Black Hawk, sent to us by the Rev. Mr. Symington, of Independence, Missouri. No. 2, is from the head of Tuh-dulh-guh-mah-ke, a male, of about 25 , whose father was a pure Ottowa, and his mother a pure Chippewa. Sent by the Rev. Mr. P. Dougherty, of Grand Traverse, Michigan. No. 3, is from the head of South Wind, a male, aged 17, a pure Iowa. Sent by the Rev. Mr. William Hamilton, of St. Joseph's, Missouri.

It is not pretended that these three buttons furnish the types of all those of the cylindrical-piled man,--but only some examples, selected from those in our cabinet, where the greatest variety in shape may be seen, to show the general outline.

The button of the pile of the head of the pure eccentrical, elliptical species, comes next under examination.

Of this pile we have, in our. cabinet, one specimen, presented by Dr. Hering, of this city; one from Delaware, and several from the Southern States; but our principal supply is from Africa, obtained through the kindness of our missionaries.

Fig. 22 represents the button, or hair, of the head of a pure African.

The buttons, like the hairs of the heads of Hybrids, resemble, sometimes, those of one parent or ancestor, and sometimes those of the other parent or ancestor; therefore, it would be useless to describe those hairs or buttons.

Hitherto we have considered the button found upon the hair of the head; we must next speak of those found upon other parts of the human skin. They comprise the following, viz: 1 , the pavilion of the external ear; 2 , the eye-brows; 3 , the eye-lids; 4 , the nasal fossæ: 5 , the whisker hairs of man; 6 , the beard; 7 , the arm-pits; 8 , the pubes; 9 the limbs, and 10, the downy hairs of the body generally.

Each of these different varieties are possessed of definite characters, which we will endeavor to point out; but we warn the reader, in advance, that he must not expect to 
pluck out one of his own or his neighbor's hairs and to find it agree, in every particular, with our description or drawing; for pile, from the same region of different individuals, and eren from the sime individual, varies like leaves from the same species of tree or same tree.

1. Of the Hairs of the Pavition of the External Ear and its Button.-This pavilion is fibro-cartilaginous, thin and expanded. It has five eminences and three depressions, which are described in Dungl. Hum. Physi., 1 v., p. 147-8. The hairs upon these parts differ somewhat one from anothere they vary in lenerth, from three to five-quarters of an inch.

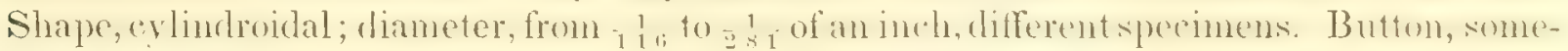
times club-shaped, at others amorphous; leneth of one of the latter ing of ant inch; diameter, $\frac{1}{2} \frac{1}{5}$; that of the shaft being $\frac{1}{2} \frac{1}{5}$; shaft, transversely striated; intermediate fibres, white, opaque, lustrous, easily separated; one of them measured $\frac{1}{120}$ of an inch; apex, pointed; diameter, $\frac{1}{5} \frac{1}{5} \pi$ of an inch; none furcated. These hairs are tough.

Fig 2. Nos. 1 and : represent two of these hairs fine a tuft that sumounded the meatus auditorius externus.

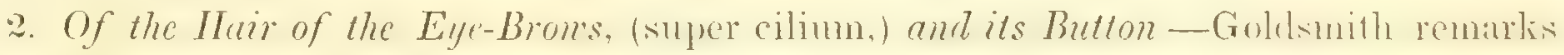
that next to the eyes, the features which give a character to the face, are the eye-brows. And Le Brun, in giving a painter directions in regard to delineating the passions, places the principle expression of the face on the eye-brows. The Chinese bestow great attention to these hairs.

They are in length from a half to a whole inch, and sometimes even longer. Inclination,

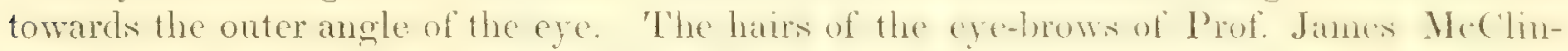
tock, M. D., measure one inch and $\frac{2}{10}$; have a diameter of $\frac{1}{1} \frac{2}{2}$ of an inch; are angular, curved; light brown colored at the posterior extremity, and light at the apex. "Whis pile' has generally a diameter of about $\frac{1}{\frac{1}{1} 6}$ of an inch. Fig. 25, No. 1, represents one of these hairs and buttons, drawn from the brow of a very fat person, where $a$ is a part of the shaft, $b$ the button, $c$ a part of the follicle, and $d$ a part of the tissue disrupted and drawn ont with the hair.

Vidal (Traitée de Path., v. 3, p. 579,) says that persons have been known who never had any eye-brows, but we have not witnessed this phenomenon.

3. Of the Eye-Lashes or Hairs of the Eye-Lids, (cilium,) and their Buttons.-Anciently the word cilium was applied to the utmost edge of the eye-lid, and the hair issuing therefrom. (See Plin. 2 Cels.) It is now confined to the hair.

It is said that persons have existed who had a double row of eye-lashes, which, in Burk's Greek derivative dictionary, is called "dystichia," from "duo," two, and "stikos" a row. But we have not seen any such persons. According to Goldsmith, man and apes are the only animals who have eye-lashes upon both the upper and lower lids of the eye. The eye-lashes of the Rhea, or American Ostrich, referred to in Goodrich's Geography, p. 444, are feathers. (See Ante., Chapter 1.) It is generally thought that eye-lashes contribute to the expression of the eye, particularly when they are lomg, close and black. 'They have the greatest diameter near the centre, tapering both ways, which forms, of each particular hair, a bov. This simple, but beautiful arrangement of these hairs is the 
best possible that can be imagined, for forming, when the lids are partly closed, a complete obstruction to the admission of insects, \&c., and yet when the lids are open, no way shutting out the light.

Fig 26 a represents an eye-lash of a lad of fourteen years, belonging to the oval-haired species, where may be seen a well-shaped button, a neck, a swelled part, and another portion gradually tapering to a point.

No. 26 represents another hair from the same place, where the shaft is drawn out of the button, with a small piece of the tissue adhering.

4. Hairs of the Nasal Fossa, (Vibrissee,) with their Buttons. - Whole length, from ' $\frac{1}{4}$ to $\frac{1}{2}$ an inch; shape, oval; diameter, $\frac{1}{50} \overline{0}$ by $\frac{1}{2} \frac{1}{8}$; button, club-shaped, with sometimes a neck between it and the shaft. Length of button, $\frac{1}{10} \overline{2}$; diameter, $\frac{1}{2} \frac{1}{7}$ of an inch; shaft, gradually tapering, greatest diameter, $\frac{1}{3} \frac{1}{7}$; apex, rounded; diameter, $\frac{1}{12} \overline{0}$ of an inch; disk exhibits a minnte central white speck of the diameter of $9 \frac{1}{3} \overline{7}$, that of the shaft being $\bar{\Sigma}^{1} \bar{y} \bar{y}$ of an inch.

Figure 27 represents one of these hairs, where may be seen the button sub-oval, a short neck which appears to have been twisted; $a$, shaft with its transverse strix, and a trace of coloring matter.

5. The common Whisker Hair of Man and its Button.-This word is sometimes confined to the hair of the face from the temple to the chin, and at others includes that which grows upon the upper lip, also called the moustaches. 'They belong to the category of the beard, and must be carefully distinguished from the nhiskers of sone of the lower animals; which, as we have shown in chapter 1 , are organs of tact.

6. Of the Beard and its Button.-This portion of the pile of man is important, as it is made, by some writers, one of the distinguishing characteristics of the oral-haired species. Mr. Smith, for instance, describes "the brarded intermediate or Caucasian type," and tells us it is so named because neither of the two other typical forms is distinguished by a wellgrown beard. (See Nat. Hist. of the Human Species, p. 368.) But the American Indian plucks out his beard.

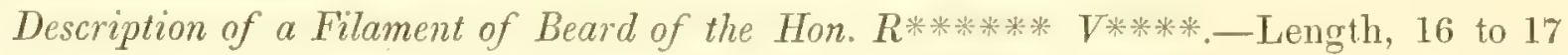
inches; shape, eccentrically elliptical; diameter, $\frac{1}{4 \frac{1}{6}}$ by $\frac{1}{2} \frac{1}{0}$ of an inch. Button, clubshaped, white, opaque; length, $\frac{1}{70}$; diameter, $\frac{1}{6} \overline{1}$, that of the shaft being $\frac{1}{5} 0$. Shaft, white, oparue; apex, pointed and sometimes furcated; shaft, cortex, easily renoved; intermediate fibres, white; diameter, $\frac{1}{200 \overline{0}}$ of an inch. Centre, white, $\frac{1}{6} \frac{1}{5}$ of an inch in diameter.

Figure 28 represents three shafts of beard of Dr. Burr, growing out of one button. It was drawn from a small papula that made its appearance upon his chin, and when it was drawn out, was succeeded by two more hairs similarly united.

Of the Fashions of Wearing the Hair and Beard-Upon the different habits and fashions of wearing the hair and beard, Goldsmith remarks: "That some, and among others the 'Turks, cut the hair off their heads and let their beards grow. Europeans, on the contrary, shave their beards and wear their hair. The negroes shave their heads in figures; at one time in stars, at another in the manner of friars; and still more cornmonly in alternate stripes; and their little boys are shaved in the same manner. 'The Talapoins 
of Siam shave the heads and the eye-brows of such children as are committed to their care. Every nation seems to have entertained different prejudices, at different times in favor of one part or another of the beard. Some have admired the hair upon the cheeks on each side, as we see with some young men among ourselves Some like the hair lower down; some choose it curled; and others like itstraight. Sone have it cul into a peak, and others shave all but the whisker. 'This particular part of the beard was highly prized among the Spaniards; 'till of late, a man, without whiskers was considered as unfit for company; and where nature had denied them, art took care to supply the deficiency. We are told of a spanish general, who, when he borrowed a large sum of money from the Venetians, panned his whiskers; which he afterwards took proper care to redeem. Kingson assures us that a considerable part of the religion of the Tartars, consists in the management of their whiskers: and that they waged a long and bloody war with the Persians, declaring them infidels, merely because they would not give their whishers the orthodox cut. The kings of Persia wore their whiskers matted with gold thread; and even the kings of France of the first races, had them knotted and buttoned with gold. But of all nations, the Americans [American Indians] take the greatest pains in cutting their hair and plucking their beards; so that some have supposed them to have no beard naturally; and even Linnaus has fallen into that mistake. The hair is cut into bands, and no small care is employed in adjusting the whisker."

To the above we wonld add that the ancient Hebrews wore a beard upon the chin, but not on the upper lip, and were divinely forbidden to cut their beards like the heathen Egyptians, who left only a tuft of hair on the chin. Neglecting to trim the hair and beard was expressive of great mourning. (See Isa., xv. 2. Jer., xli. 5, \&c.) 'Io forcibly shave the beard of any one was considered an insult. (2 Sam. x., 4,5.)

The first Indians seen by Columbus at San Salvador, are described as entirely naked, their black hair long and uncurled upon their shoulders, with no beards, and every part of the body perfectly smooth.

Mr. Jefferson remarks that "it has been said that the [North American] Indians have less hair than the whites, except on the head; but this is a fact of which fair proof can hardly be had. With them it is disgraceful to have hairs on the body, they say it likens them to hogs; they therefore pluck it out as fast as it appears. But the traders who marry their women, and prevail on them to discontinue this practice, say, that nature is the same with them as with the whites. Nor if the fact [assertion] be true, is the consequence necessary which has been drawn from it; negroes have notoriously less hair than the whites, yet they are more ardent."

In many African kingdoms, rank is estimated by the length and thickness of the beard. (Duncan's 'Travels in IVestern Africa, 2 v., p. 5.) The Miaou-tse, who are supposed to be the aborigines of China, cut off the forelocks and spread the hair behind. (Latham.) Some Tapuans, of the New Guinea Coast, dress their pile in long, narrow, pipe-like curls, smeared with red ochre and grease, with a band round the forehead. (Latham Hist. of Races, \&c., 214.) Others use wigs. (Ibid, 215.)

7. Of the Hairs of the Amm-pit, (axilla, and its Bullon.-This cavity, beneatl the 8 
junction of the arm with the shoulder, is covered with hair, contains much cellular membrane, lymphatic ganglions, important vessels and nerves, and numerous sebaceous follicles, furnishing an odorous secretion. 'The button of this hair often draws out with its follicle.

Figure $29 a$ is one of these, upon which may be seen the button, sub-oval shaped, the follicle, with parts of two disrupted vessels; also a portion of the shaft, with its transverse strix. Figure $29 b$ represents a section of the skin of a male of 25 , and the hair set therein.

These hairs are, in general, in length from one inch to an inch and a half; shape, oval; diarneter, $\frac{1}{4 \frac{1}{1}}$ by $\frac{1}{2} \frac{1}{8}$, gradually tapering to $\frac{1}{1 \frac{1}{7} 5}$ at the apex; color, rather lighter than that of the head; lustre, feeble; button, sometimes sub-oval, and at others double coneshaped; length, $\frac{1}{10} \frac{1}{2}$; diameter, $\frac{1}{2} \frac{1}{50}$, that of the shaft, at the junction, being $\frac{1}{500}$, others club-shaped; sheath small, white, opaque; intermediate fibres, white; centre, white, interrupted; apices, pointed; none furcated. Disks show a minute central spot.

8. The Hair of the Pubes, or Hyporgastric Hair, and its Button.-Called "pubes," because this part of the hypogastric region is, in both sexes, at the time of puberty, covered with pile. In some books this pile is called "Pubes lanúgo Pudendórum," and in others the word pubes is used to denote the parts, and the hair that grows thereabouts. These hairs belong to the same category as those of the beard.

Examination and Description of these Hairs, from the body of a Male, oval-haired person of sixty years of age.-Length, about three inches; shape, eccentrically elliptical; greatest diameter, $\frac{1}{2} \frac{1}{50}$; smallest, $\frac{1}{150}$ of an inch; crisped; color, brown, translucent; button, spindle-shaped, or tubular, and pointed at the inferior extremily, or rounded. It has sometimes vessels. Sheath, white, opaque, investing the button; occasionally two sheaths adhering, sometimes there is a neck between the button and the shaft; cortex, transversely striated; centre, white, interrupted; apex, striated and dotted, rounded; disk, with a central oval spot.

Hypogastric pile is generally of a lighter shade of color than the hair of the head of the individual.

Figure 30 represents one of these hairs with its button and follicle, and a large portion of the neighboring tissue; " $a$," the button; " $b$," a part of the follicle; " $c$," the shaft; " $d$, , the tissue disrupted and torn out of the soft sebaceous skin.

Remarkable Case.-Observing, in a recent number of a Medical Journal, a report of Robert King Stone, M. D., of Washington City, of a lad only eight years of age having hypogastric hair, I wrote for a specimen, and the Doctor kindly sent me a lock, accompanied by one of the boy's head. They are dark colored, while that of his head is light;

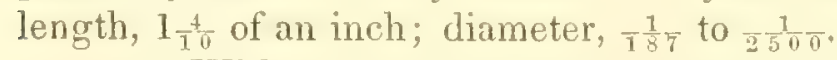

With 220 grains one inch stretched $\frac{2}{90}$ of an inch, elasticity minus $\frac{1}{90}$

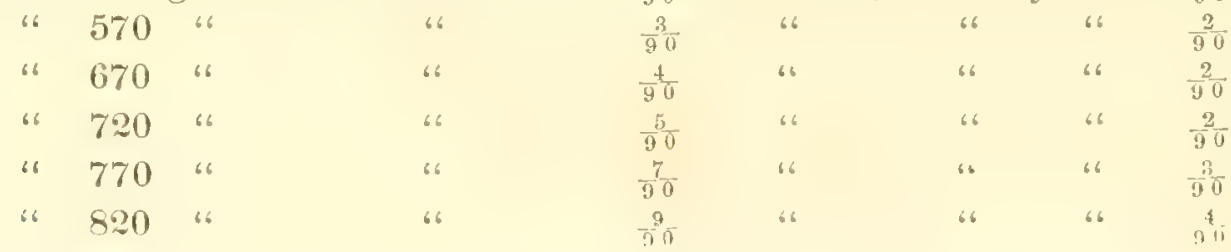




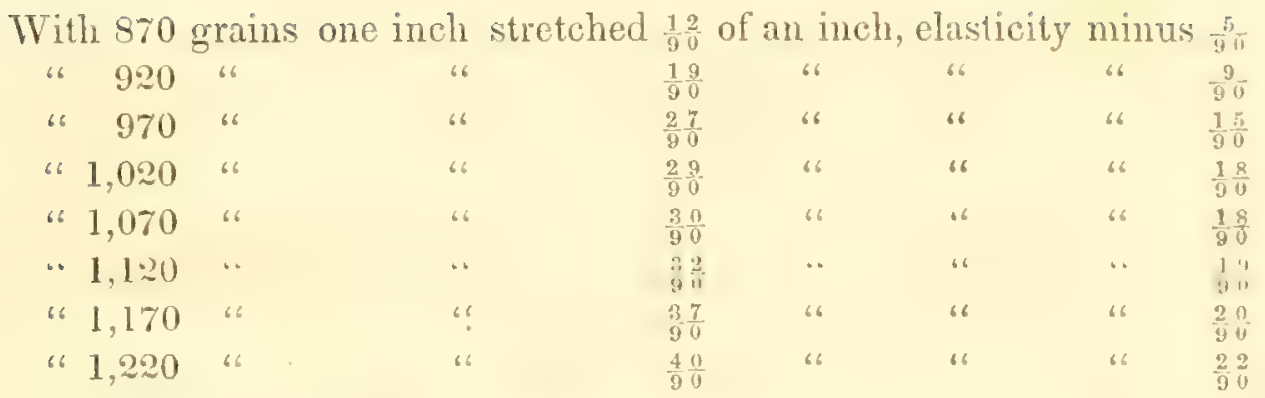

9. Hairs of the Limbs and their Button.-These buttons vary much in length on different individuals.

Figure 31 a represents one of the forearm; where " $a$," is the button; " $b$, portions of the follicle; "c," the shaft with its transverse strix; " $d$," a portion of a disrupted vessel; "e," a part of the tissue torn out.

A hair from the back of the hand has a length of $\frac{1}{2}$ an inch; is in shape eccentrically elliptical; greatest diameter, $\frac{1}{2} \frac{1}{1}$; smallest, $\frac{1}{4} \frac{1}{16}$; button, club-shaped; sometimes they are somewhat hamate; the shaft tapers gradually, and in the centre is an interrupted, dark, coloring matter; disk, exhibits an oval, white central spot.

Of the downy Hairs of the body, (lanúgo, and their. Buttons.-The word "down " is fiom the Danish "dunn," and means soft wool, or tender hair. Lanúgo has the same meaning. These downy hairs bear the same relation to larger hairs that down does to feathers. They are of various lengths on different individuals. The buttons are sometimes clubshaped, and at others pestle-shaped.

It is probable that the button of pile is more perishable than the shaft; for, upon a lock of Mexican mummy hair, which is otherwise in good preservation, not a vestige of a button is to be seen. Fig. 32 a represents one of these hairs, and attention is called to the singular shape of its posterior termination.

On a hair belonging to a lock of a Peruvian mummy, which is represented in Fig. $32 b$, there is no button.

In a lock of hair, expelled from the uterus, presented by Dr. Frost, of Charleston, South Carolina, we could find no hair with a button.

We have a lock of ovarian hair, presented by Professor Paul B. Goddard, M. D., of this city. We found only two buttons; and upon another lock of ovarian hair, presented by Professor William E. Horner, M. D., late of this city, no button could be found.

We have several hair-balls. found in the stomachs of Ruminants, the buttons upon the hairs of which are few in number, and are generally diminutive in size, and distorted.

Fig. 33 represents the ovarian hair first mentioned,-where " $a$," is the button; " $b$," the shaft, exhibiting the scales of the cortex; "c," a white substance, which is probably the remains of the sheath, with which it is invested.

We have dwelt upon the button of pile, but not more than the importance of its study demands, as will be made manifest in different parts of this work.

Some general remarks as regards Puttons.-1. To have a button, is characteristic of an ordinary hair of a healthy subject, and when it has arrived at maturity 
2. That the presence of a button, upon such a hair, distinguishes it from hair-like processes, which have no buttons.

3. That each variety of hair has its peculiarly shaped button, by which the hairs of that variety may be known.

4. But that this shape is liable to variation, owing to either a variation in that of the shaft. to which it belongs, - to disease of the hair, or disease in the tissue in which it is imbedded.

5. That the dimensions of the button differ; but, generally, it is of greater diameter than that of the shaft.

6. That hairs, not fully developed, are found with no button.

7. That it is probable that there is a connection, through the follicle, between the button and the vessels found in the tissue which surrounds the follicle.

8. That in combing and dressing the hair of the head, care should be taken not to disturb this connection.

9. That a separation of the button from these vessels converts the hair into effete matter, -causes it to fall out.

10. That the coloring matter of hair is not elaborated in the button; for hair of the head often loses its color, yet the button retains its integrity.

11. That the button is the most perishable part of pile.

It remains to notice the buttons of the hairs of some of the lower animals.

If we were not limited in regard to space, we would like to describe and depict the buttons of the pile of the principal part of the lower animals, as they are exhibited in our extensive collection of hair and wool. We feel confident that, at some day, not very remote, the lower animals will be classified by their pile, and that, in so doing, the buttons will be found to be valuable indices of species.

All that we can do, at present, will be to present the reader with a few of these interesting objects.

Fig. 34 represents these in outline:-A, the Quadrumana, Troglodyte gorilla; $B$, the Horse, (drawn from a hair of the famous running mare Fashion;) C, the Zebra; D, the Cow ; E, the Arabian bull-calf Holmes, belonging to _—_ _ F , the Gnou, or Horned-Horse, (this is believed to be a whisker;) G, the Rocky Mountain, American, or Long-Horned Antelope; H, the Elk; J, the Lama; K, the Dasyprocta Nigra; L, the Kangaroo Rat

Of tile Apex, on Point of tue Sinaft.-These terms have been used indiscriminately, to designate the superior termination of pile, but it would be better to confine ourselves to the first; for, although every hair has an apex, all hairs are not pointed; nor are any hairs pointed that have been cut or fractured. When viewed under the microscope, these latter are perceived to be more or less abrupt; some are even rounded, or inclined. When pile has been left in its natural state, it is generally pointed at the apex.

Some writers are of opinion, that the obtuseness of the apex of pile is the result of constant friction. (See Hassal's Micros. Anat., p. 9.) We have seen instances of even 
the shaft of hair being fractured from friction. Fig. 36 represents the hair of the eyebrow of an oval-haired person, fractured in the shaft so much, that some of the intermediate fibres are obtruding. The places to study the apex of hair is among the unshom locks of the foctus, or of young children, whose hair has never been cut; or the young hairs of adults; which are continually produced to supply the places of those that are continually falling out. In all these cases we find the apex more or less pointed.

Of the pile of the lower animals, the apex of some are pointed; as, for instance, the Mouse, the Ground-Squirrel, the Mole, the Jumping-Mouse, of Canada, the Muskrat, and many others; while the anterior extremity of the hair of the Goat, the Lama, \&c., \&c., are more abrupt.

M. Mandl is of opinion, that "with individuals who have had their hair recently cut, each hair preserves its diameter to its free end, [anterior extremity,] which presents a truncated extremity, where the eye may determine this distinction; but that if those same hairs are examined, after a long interval, each hair is found to be terminated by a pointed extremity, more or less long." M. Mandl considers this change to be the result of a vital process. (See Comptes rendus, 1845.) We believe that this learned gentleman has mistaken for renewed points on old hairs, the natural and original points of new hairs, which succeed those that fall out, during the "long intcrval," to which he has alluded.

Of Dichophy, * and growing double of Hairs and rurcated Pile.-Hairs furcated, or their fibres divided at the superior extremity, are not uncommon.

Fig. 37 a represents a hair of the head of a young lady of North Carolina, kindly presented to us by her physician, as a great curiosity. She is reported to be in health, yet nearly every filament of her hair is furcated. The hairs of the lock sent us, do not exceed five inches in length.

We have examined the hair of the head of a young married lady, of this city, who is supposed to be laboring under pulmonary consumption, and found nearly one-fourth of the filaments furcated. We have also examined the hair of her father, mother, and two of her children, none of which are furcated.

Fig. 376 represents the wool of Congo Billy, a pure negro, and will be seen to be furcated.

Figs. $38 a$ and $38 b$ represent two hairs of a full-blooded male Choctaw Indian; the specimen presented by Dr. J. O. Nott, of Mobile. The hairs are sixteen inches long, and they are, respectively, tri-furcated and quadra-furcated.

Sometimes the fibres of a hair are so much divided, at the superior termination, as to resemble a brush. (See fig. 39.)

Furcated hairs are found in the locks of the Chinese. In our collection of ancient hairs, - few are found that are furcated; only one in the hair of the head of a Mexican mummy, and none in those of a Peruvian mummy.

\footnotetext{
*Dichoply, from "dicha," double, and "phyyo," to grrow.
} 
They are also scarce in our collection of the hairs of lunatics, as will appear by the following Table:-

\begin{tabular}{|c|c|c|c|c|c|c|c|c|c|}
\hline \multicolumn{2}{|c|}{ Pennsylrania Hospital. } & \multicolumn{2}{|c|}{$\begin{array}{l}\text { Asylum for Lunatics, } \\
\text { at Frankford, Pa. }\end{array}$} & \multicolumn{2}{|c|}{$\begin{array}{c}\text { Western Virginia Asy- } \\
\text { lum. }\end{array}$} & \multicolumn{2}{|c|}{ Ohio Asylum, No. 1.} & \multicolumn{2}{|c|}{ Ohio Asylum, No. 2.} \\
\hline 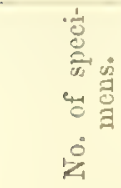 & 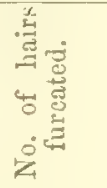 & 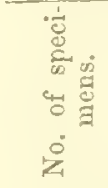 & 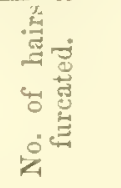 & 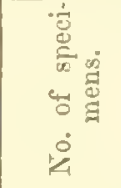 & 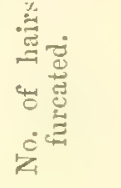 & 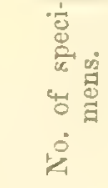 & 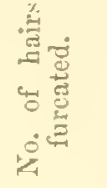 & 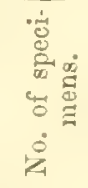 & 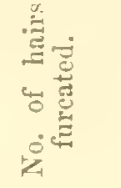 \\
\hline 22 & 0 & 21 & 1 & 6 & 4 & 16 & 2 & 21 & 1 \\
\hline
\end{tabular}

From the above exposition, we feel warranted in concluding that dichophy is not one of the effects of madness upon the hair.

'The hairs of the lower animals are'seldom found furcated. The bristles of the hog are, however, notable exceptions; they are always furcaled.

of the cause of Dichophy.- Some writers attribute the furcation of pile to disease, of either the animal or of the integument. 'The hairs of lepers are said always to be furcated. (Dict. de Sci. Med., v. 43, p. 499; and see Lib. of Useful Knowledge, of 1941, p. 55.)

Furcation may be owing, sometimes, to a deficiency of nutriment to support hair allowed to grow very long. According to the French plyssicians, pile is nourished and increased in length by a portion, only, of the fiuid that enters into the stalk, the residue being constantly thrown off. (See Nou. 'Treat. sur la laine par Iotemps and Fabry.) This would account for the hair of the Chinese and of some American Indians, being furcated; for I have Chinese hair four feet long, and several specimens of American Indians that measure two feet in length, all furcated. Bichat notices the occasional splitting of hairs, but is silent as to the cause. And Bakewell, whose experience in regard to fleece was great, speaks of wool sometimes bi-furcating, but does not say why it does so.

Far be it from us to discourage cleanliness; but we cannot help thinking that too frequent washing the hair of the head, especially if soap is used, will make it harsh, and cause its ends to furcate. Perhaps it would be as well, after bathing, to substitute a small quantity of castor oil for the natural fatty matter of the hair, which the soap decomposes.

OF Brancited Pilf.-A medical friend residing in the interior of this state, sent us some (so called) "Granched hair." As it is as fair a specimen of this variety of pile as we ever expect to possess, we procured the following drawing to be made. (See fig. 40.) "a:" represents the posterior extremity, where " $b$ " and "c $c$ " appear to be two separate shafts, emerging from one common button; " $d$," a branch from " $b$;" and " $e$," a branch from "c." We placed the specimen in tepid water, when it separated into four distinct shafts, and explained the phenomenon.

Of the Cortex of Pile.-There is a squamose or paved covering upon each filament of of pile, called the cortex. 'The scales of the squamose varying very much in number, shape, size and degree of adhesion to the fibrous portion of the shaft, and often exercising a very great influence upon the integument. 
Fourcoy first remarked that a hair, when rolled between the fingers, always passes from the button to the apex; this he attributed to the presence of scalcs, which had not then been seen.* Mr. Youatt first saw these scales upon wool, and Dr. Goring first saw them upon the hair of the head of man. So far as we know, Prof. Dungleson is the only one in the United States, (except ourselves, who has seen these hair scales.

Of the Scales.-The study of the scales is very interesting in a scientific point of view; and, since it has been demonstrated, that on wool they are the main causc of the felting and fulling property, they have become still more so in an economical one.

Figure 2 represents these scales as they are found upon hair and wool; and figure 42 shows a portion of the cortex that has no scales, but is paved; these ought to be examined and compared by those who wish to understand the nature of the cortex.

Of the Uses of the Scales on Pile to the Animal. - It is probable that the scales on the cortex of pile, by polarizing the rays of light, may contribute to the variation in the color or shade of the coats of some of the lower animals. By their form and number they are nicely adapted to admit to the interior of the filament just as much air and moisture as is necessary for the growth of pile, excluding the remainder which might prove injurious. In this latter respect they may be to the cortex what stomatre are to the cuticle of plants; and, like them, they may be endowed with the power of opening and closing, according to circumstances; but we acknowledge that we have not been able to detect such a motion. +

Ribbons of scaly cortex may be artificially separated from the body of the pile, to be viewed as transparent objects under the microscope. Figure 43 represents one of these from the spine of the pecary.

The scales may be detached from the cortex by concentrated sulphuric acid.

The cortex is sometimes the seat of the coloring matter, as will be explained under that head.

Of the Paved Cortex.-We use this word "paved," in the description of this variety of cortex upon the authority of Prof. Dungleson, who, in describing Epithelium, introduces the words, "paved and tesselated." (See p. 108 of Hum. Phys., fig. 23.) We prefer the word "paved," because "tesselated," from its derivation, might imply that the divisions are all squares, whereas some of them are pentagons, hexagons and polygons. They are not scales-do not lap one over the other; but are mere divisions of the cortex, into angular portions like a paved or tesselated floor. See fig. 44, for an illustration.

Examples of the Paved Cortex-(See. fig. 34.) - In the order "Ruminantia," in the Section "Horned," the Tribe "Solid and deciduous horns," is found one single genus, the "Stag," (Cervus, which is divided into five species, viz:-

* This experiment may be best repeated by rolling tiro hairs between the fingers in opposite directions.

† Roget, (in his Anat. Veg. Physi., 1 v., n. 68, ) says that it is erident from the functions the stomatre perform, that they must occusionally open and close; but the minuteness of their size precludes any accurate observation as to the nature of the apparatus, \&e. 
1. Stag or Deer, Cervus elephus. French:-Cerf common C. de Canada.

2. Fallow Deer, Cervus dama. " " " " Co daim.

3. Roe Buck, Ccrvus capreolus. " " " le chevreuil.

4. Elk or Moose Deer, Cervus alces. " " "'elan.

5. Reindeer, Cervus tarandus " " " le renne.

(Elem. de Zoology:)

Goodrich, in his Geography, enumerates the following species in the United States, viz:-

1. The American Elk, or Wapiti, C. Strongyloceros.

2. The Moose, C. alces Americanus.

3. The Caribou, or American Reindecr, C. tarandus.

4. Common Deer, C. Virginianus.

5. The long-tailed Deer, C. leucurus.

6. The black-tailed or Mule Deer, C. macrotis.

The tegumentary appendages of all these species, so far as we have had an opportunity to examine them, have a great sameness of structure; sufficiently so to connect them into one group. The cortex is paved, the divisions have the shape of compressed pentagons, octagons and polygons; the coloring matter lies immediately beneath the cortex, the centre being colorless, and the shaft laving no canal; the button is spindle-shaped, succeeded by a slender neck, the shaft is feebly flexible, bending at right angles; the ductility very considerable, but accompanied with little elasticity or tenacity.**

We will now give a particular description of a hair of one of the species.

1. The Stay or Deer, Coruse elephus.-Specimen from the Westem part of the Stute.Hair.-Length, about 2 inches; greatest diameter, $\frac{1}{0}$, and least diameter, $\frac{1}{1} \frac{1}{0}$ of an inch ; button, spindle-shaped ; length, ${ }_{2}$ of an inch, and diameter, is of an inch. Neck.Length, $\frac{3}{90}$ of an inch; diameter, $\frac{1}{3} \overline{0}$ of an inch, gradually widening to a stalk. $\dagger$ Apex, gradually tapering to a point; color, for one inch and $\frac{1}{20}$ white, opaque, gradually darkening for $\frac{7}{10}$ of an inch, succeeded by light brown or fawn color, and terminating in black at the apex. The whole stalk is undulated, the highest waves of which are in the centre. The interstices between the paved portions, darker colored than that of the pavement; flexibility feeble, bends at right angles, and remains bent. No central canal.

Ductility, Elasticity and Tenacity.-May 11th, 1849.-One inch with 170 grains was deprived of its undulations. Upon removing this weight the undulations returned.

With 180 grains it stretched $\frac{2}{90}$ of an inch, elasticity entire.

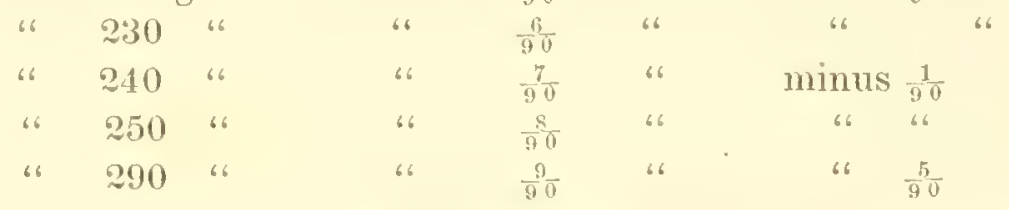

\footnotetext{
* Pcrhaps a largo portion of the animal ritality conreyed to the exterior is expended on the horns.

$f$ When the part that widens is obserred on its flat sides, the pared cortex is seen on it; while on the clipsoids tho cortex appears plain.
} 


\begin{tabular}{|c|c|c|c|c|c|c|}
\hline "6 & 330 & .6 & 6 & $-\frac{1}{8} \frac{2}{0}$ & "6 & " \\
\hline$" 6$ & 340 & "6 & 66 & $\frac{15}{90}$ & "6 & " \\
\hline " & 350 & . & .. & 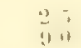 & . & .. \\
\hline ، & 360 & " & "6 & $\frac{35}{9} \frac{5}{0}$ & 6 & 6 \\
\hline . & 350 & ،. & . & $\because 7$ & ". & " \\
\hline " & 380 & " & " & $\frac{4}{8} \frac{0}{0}$ & " & "6 \\
\hline 66 & 460 & " & " & $\left.\frac{4}{8}\right)_{i}$ & " & 6 \\
\hline 16 & 480 & "6 & " & $\frac{5}{9} \frac{11}{0}$ & "6 & " \\
\hline "6 & 490 & " & & & & \\
\hline
\end{tabular}

OF trie Paved Cortex of the Elk.-(See fig. 44.) - Of the Hairs of the Elk, or Moose Deer.- (C. alces.) - Specimen from the Zoölogical Institute, of Philadelphia. 'The Elk has three varieties of pile:-1st. The Hairs of the Breast.-Length, 6 to 6 inches; diameter, from $\frac{1}{90}$ to $\frac{1}{1} \frac{1}{8}$ ths of an inch; undulated; highest waves in the centre of the stalk; number of waves, 25; flexibility, feeble; when bent forms a right angle, and remains in that position; button, spindle-shaped, succeeded by a tapering neck; both transparent; shaft, opaque, commencing at the inferior extremity with light stone color, which, after continuing for an inch, becomes light brown, gradually darker to the apex; cortex, paved; compressed pentagons, of a light shade, with darker interstices; apex, pointed.

2d. Hairs of the Body.-Length, 2 inches; diameter, $\frac{1}{30}$ of an inch to $\frac{1}{1} \overline{0}$ of an inch; undulated; color, white, opaque, passing into stone-color, and ending, at the apex, in light brown; flexibility, feeble; when bent forms a right angle, and remains in that position; button, spindle-shaped, succeeded by a narrow neck, both of which are trausparent; cortex, paved; compressed pentagons, with interstices of a darker shade.

Sometimes the coloring matter may be seen through the cortex, but it is not in a central canal, but in confused masses of various shades.

The wool of this pile seems to be formed of distinct sections; apex, pointed.

Duclitity, Elasticity and Tenacity.-It took 270 grains to deprive it of its undulation.

With 670 grains it stretched $\frac{y}{90}$ th of an inch, elasticity entire.

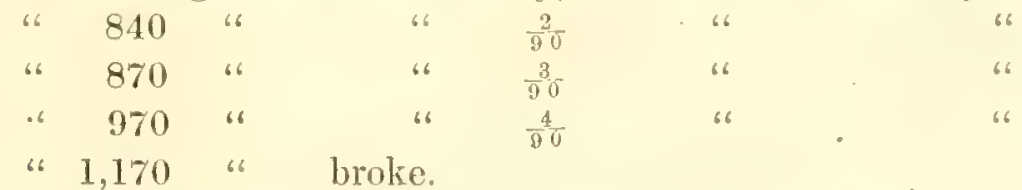

This hair is, by this experiment, much changed in shape.

The Pile of the Dicranocerus Americanus, Rocky Mountain, American, or LongHorned Antelope.-Specimen presented by Prof. Samuel S. Haldeman.

Hair of the Flank.-Length, about 3 inches; shape, imperfect, oval*; color, white;

* Care must be taken in fixing this hair so as to cut a perfect disk, as the filament is so flexible that it can be pressed into artificial shapes. 
Instre, considerable; direction, straight; undulated; button, spindle-shaped, succeeded hy a neck; shaft, cortex paved, divided into compressed pentagons, not well defined.

Exception.-The cortex of the hair of the Sloth, does not appear to be either scaly or pared.

Description of the Hair of ine Three-Toed Slotu, (Bradypus tridactylis.) Specimen in the Academy of Natural Sciences, of Philadelphia. Length, 2 inches and $\frac{6}{10}$ ths of an inch; color, dirty whitish-brown stone color, which, when viewed under the microscope, is found to be a mechanical mixture of irregular portions of the coriex, some of which are dirty white, and others brown color. Button, white, transparent, spindleshaped; length, $\frac{1}{1} \overline{0}$ of an inch; diameter, $\frac{1}{30} \overline{0}$ of an inch; sheath, white, opaque, encompassing and adhering to the button; shaft, neck, cylindrical. naked, white, opaque and translucent; length, $\frac{3}{10}$ ths of an inch; diameter, $\frac{1}{40}$ of an inch, gradually tapering from the centre both ways. Body, length, I inch $\frac{9}{10}$ ths ; flat; greatest diameter, (which is at the distance of 1 inch and $\frac{6}{10}$ ths from the neck, $\frac{1}{90}$ th of an inch, gradually tapering both ways to a diameter of $\frac{1}{8}$ th of an inch. The cortex, of the color above stated, of irregular, inelastic, brittle pieces, separated by dark lines, which sometimes open into cracks or fissures, extending to the central portion of the hair. When the cortex is removed, the cylindrical, elastic, central portion is seen of a diameter of $\frac{1}{2} \frac{1}{0}$ ths of an inch; sometimes a portion of the cortex may be removed, leaving the remainder adhering to the central portion, and presenting a rugged outline. At othess, the central portion obtrudes from beneath the cortex, exhibiting their fibrous texture. The cortex will not divide into fibrils, but may be broken into irregular pieces of white and brown colors. The central part is divisible into fibrils. A pex, length, $\frac{1}{2}$ th of an inch, naked, cylindrical, transparent and pointed.

Ductility, Elasticity and Tenacity.-One inch of the above hair, July 4th, 1£49, Bar. 30, 'Ther. 76, Dew-point, 66.

With 170 grains it stretched $\frac{5}{30}$ of an inch, elasticity entire.

\begin{tabular}{|c|c|c|c|c|c|c|c|c|}
\hline 66 & 150 & 66 & 16 & $\frac{T}{9} \pi$ & $" 6$ & 16 & 6 & \\
\hline 66 & 190 & 66 & 66 & $\frac{8}{9 \pi}$ & 66 & 66 & minus & $\frac{2}{90}$ \\
\hline 6. & 200 & 66 & 6 & $\frac{1}{9} \frac{11}{60}$ & 6 & 66 & 66 & $\frac{3}{911}$ \\
\hline$\because \because$ & 210 & "6 & 6 & $\frac{1}{9} \frac{3}{11}$ & 66 & 66 & 66 & $\frac{4}{90}$ \\
\hline 66 & 220 & $6 \alpha$ & 66 & $\frac{1}{9} \frac{3}{0}$ & 66 & 6 & $6:$ & $\frac{5}{9} 0$ \\
\hline 16 & 230 & 66 & 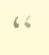 & $\frac{1}{9} \frac{\pi}{0}$ & 66 & 66 & 6 & $\frac{b_{3}}{90}$ \\
\hline 66 & 210 . & 66 & $6:$ & $\frac{1}{9} \frac{7}{0}$ & 66 & 66 & 66 & $\frac{8}{90}$ \\
\hline 66 & 250 & $" 6$ & lie & & & & & \\
\hline
\end{tabular}

While the hair was under the stretching operation, the sides of the cracks and fissures of the cortex separated; and they closed when the weight was removed, which shows ihat the central substance is ductile and elastic.

The Wool of the same animal.-The wool, when drawn out of the skin, is connected in tufts of 5, 7, or 9 filaments, held together by small portions of epidermis, below which a button is seen, and sometimes a button and sheath. Length, from 1 inch to $1_{2}^{\frac{1}{2}}$; 
diameter, $\frac{1}{139}$ of an inch; button, white, transparent, quill-shaped; sheath, white, opaque; apex, rounded; cortex, is divided by dark lines; central portion, yellow.

See fig. 45, where No. I represents the cortex and the interior, where the cortex has been removed; No. 2 , the fissure in the cortex; No. 3, grains of cortex removed from the stalk; No. 4, a disk; No. 5, tufts of the wool.

OF the infermedite fibrous part of Pile-Between the cortex and the central portion of a perfect hair, and in the interior of an imperfect one, is found a fibrous: substance, constituting the strength of the pile, which next demands our attention. Sometimes, when the cortex is sufficiently translucent, these fibres may be seen through it, in longitudinal strix, extending nearly the whole length of the shaft; they are then most apparent near the button, and vanish as you approach the apex; which may, possibly, be owing to their greater attenuation at the latter place. In an imperfect hair they extend to the centre of the shaft.

Fig. 46 represents a hair of the Hon. Henry Clay, artificially deprived of the cortex, except a small portion, left purposely, for comparison. For the most part, the fibres are seen in fasciculus; and the few narrow strips of the cortex are identified by their trans- verse strix. Their diameter is $\frac{1}{2} \frac{1}{500}$ to $\frac{1}{5000}$ of an inch.

Fig. 466 represents a hair of a male white, of 25 , the posterior termination of which has been split, and the fibrils are seen.

Fig $46 c$ is a hair of a person affected with scrofula, (which was disrupted in the act of drawing, showing the fibres and fibrils.

Fig. $46 d$ represents the fibres of a hair of the head of a Choctaw Indian, the cortex having been entirely artificially removed; $a$ and $b$ are bundles of fibres; $c$ and $d$ are fibrils.

Henle says that the fibrils of pile are flut; but we have never been able to determine the shape. Henlé also says that they are inelastic and brittle. 'This does not accord with our experience. We submitted an inch of the hair of the head of our esteemed fiend, Wm. F. Van Amringe, Esq., to the operation of the trichometer. It showed no disposition to stretch with a weight less than 290 grains, when it lengthened $\frac{1}{90}$ of an inch. With 670 grains, it stretched only $\frac{2}{90}$, and with 820 grains, only $\frac{4}{90}$ of an inch; but, upon 50 grains being added, it stretched $\frac{8}{90}$, and with 50 more, only, it stretched $\frac{15}{90}$ of an inch.

Upon examining the facture, under the microscope, after the manipulation had been completed, the cause of this extraordinary progression was revealed. The cortex had parted in two places, corresponding to the sudden movements above noticed. After the last fracture of it, the fibres (being left to bear the burthen of the weights used in the succeeding experiments) dic not yield suddenly and break, as they ought to have done, had the fibrils been inelastic and brittle, as Henlé teaches; but the one inch of hair gradually elongated to $\frac{4}{9} \frac{n}{0}$ of an inch, and finally parted with 1,570 grains.

Of a Crusind Harr.-Fig. 47 represents a hair of His Excellency General Andrew Jackivon, artificially crushed so as to expose the fibrous construction; a, the crushed portion, has a diameter of $\frac{1}{5}$ part of an inch, while $b$, the hair in its normal condition, is only $\frac{1}{2} \frac{1}{2}$ 
The diameters of hair fibres have been variously estimated; Ilenlé found them to be

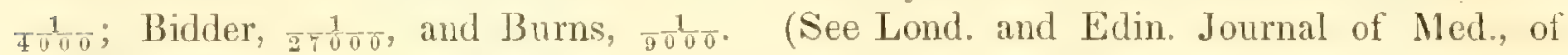
1842, p. 702 .

Of the further use of the fibres of Pile.-The fibrous arrangrement of pile is not only well calculated to impart strength to the filament, but to admit of capillary attraction, thereby furnishing a passage for such fluids as are not confined to the central canal of a perfect hair. It is also well adapted to encircle and protect the canal through which the coloring matter of a perfect hair is, when present, conveyed. With a high magnifying power, the ends of the fibres may often be seen, when examining transverse sections of hair cut so thinly as to be viewed as transparent objects; as in fig $48 a$, which represents the hair of the head of Annette Engle, aged 11 years, born in Poland, of Jewish parents, now in Philadelphia, supposed to be laboring under incipient plica polinica.

Fig. $48 \mathrm{~b}$ shows the fibres of an American Indian's hair. A disk of a hair of the Hybrid Elen Choate, is seen at fig. $48 \mathrm{c}$; and fig. $48 d$ represents a similar section of the hair of the head of the late Mr. Elias Hicks.

Of the central portion of a Perfect Hair.-This portion of the stalk of a perfect. hair, exhibits one of the three following appearances:-

1. A central canal, containing a granulated substance and pigment cells.

2. A granulated substance, and no pigment cells.

3. A void canal. (Henlé.)

An imperfect hair has no central canal.

The granulated substance consists of very small, brilliant globules, conglomerated iuto clots; they are oftentimes piled in series upon series; and at others, when less depressed, appear in distinct masses, with void spaces between. (Henlé.)

Fig. 49 a represents the hair of one of the oval-haired species, which has been made transparent, in order to show the coloring matter in a central canal.

Fig. $49 b$ is a hair of one of the cylindrical-piled species, which has undergone the same operation, but which is not made transparent, because, as it is believed, the coloring matter is in the cortex, or in the cortex and fibres.

Some examples of the disposition of the coloring matter of Pile.-One of the most interesting studies in regard to pile, consists in the way in which the coloring matter is disposed.

'The examination and description of the Hair of the Dog-Faced Monkey, O. 2.-Quadrumana Tribe, Monkeys of the Old World, (Mandril.)_-(Elem. de Zoöl., 274.)-Specimen alive in the Philadelphia Zoülogical Menagerie. Length, 2 inches and $\frac{4}{10}$ ths; greatest

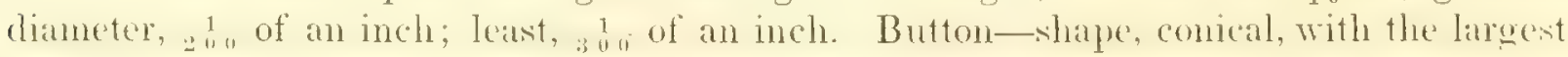
part of the cone towads the posterior extremity of the hair, and very abrupt, or spindleshaped; color, white; length, $\frac{4}{100}$ of an inch; diameter, $\frac{1}{80}$ of an inch. Sheath, investing loosely the button and lower extremity of the shaft; color, white, opaque; length, $\frac{7}{1} \frac{7}{0}$ of an inch, and diameter, $\frac{1}{50}$ of an inch. Follicle-had none to examine. Shaft-shape, oval; cortex, color, variegated, commencing at the button, dirfy-brown,-passing into 
dark-brown, nearly black, - then wax-yellow, and finally, black at the apex; the whole ornamented with minute ochreous-colored dots and lines; the shade of darkness of the filament depending upon the number of these dots and lines. 'Transverse strix, minute and irregular. Intermediate fibres, white and tramsparent, but marked with dots and lines like the cortex. The centre, solid and white; no canal. A disk or tranverse section shows an oval, dark-yellow figure, with a small, solid, white centre. Apex, abrupt, and often furcated.

The characteristics of this hair are:-1st, the variety of color upon the same filament; 2d, its peculiar formation, by the coloring matter being in the cortex and fibrons intermediate substance, and being disposed in dots and ines; $3 \mathrm{~d}$, the absence of a central canal, and central coloring matter. (See fig. $50 a$ and $50 \mathrm{~b}$.)

Example of the Colorixg Matter of the Pile of the Bat.-Examination and D $_{\boldsymbol{c}}$ scription of the Hair of the Bat: Vespertilio Noreborensis; order, Chiroptera; family, Vespertilionidæ; tribe, Bat. Specimen sent from Massachusetts, by Dr. H. Wheatland, of Salem. Length, $\frac{1}{15}$ to $\frac{1}{16}$ of an inch; diameter, 1 of an inch; button, a slight swelling of the lower extremity of the shaft only, with a pointed termination; sheath, none discovered; follicle, none perceptible, after a rigid search. For the purpose of detecting it the dermis was separated from the epidermis. The texture of the dermis is lined, that of the epidermis plain. Sheath, cortex, squamose; scales, of that peculiar shape, that the shaft appears like a succession or series of minute crucibles, nestled one in another; coloring matter, indistinct black; bands at the superior surface of each crucible-shaped figure. (See fig. 50 c.) Sometimes the coloring matter is internjited, and at others it is entirely wanting. This last variety occurs near the superior termination of the stalk, which is the cause that the fur there is, to the naked eye, of a lighter color than at the joot of the filament. Apex, generally very pointed, when in its natural state, but often appears to have been broken.

N. B. We have a specimen of hair from Paris, marked "Poil de Chaure-sourie," which does not materially differ from the above described.

There is also a specimen of a bat in the Academy of Natural Science, of Philadelphia, called the African Bat, in which the scales of the cortex are shaped more like those of a fish. The coloring matter is represented in figure $50 \mathrm{~d}$.

The characteristics of the hair of the Bat, (except the African,) so far as the above limited examinations and descriptions show, are, 1st, a variety of color in the same filament; 2d, the peculiar arrangement of the coloring matter in the cortex and fibrous matter being disposed of in borders to the crucible-shaped scales or rings; $3 \mathrm{~d}$, the absence of a central canal and central coloring matter.

The disposition of the coloring matter of some of the lower animals in dots, lines, rings, \&c, is often the cause of optical deception; the hair, to the natural eye, appears of onc uniform color, whereas, when placed under the microscope, it appears distinctly to be two. For instance, the hair of a grey rabbit, when so examined, is found to be composed of black rings with white interstices; but they are of so small a diameter that they blend 
together and appear to be grey to the unassisted vision. Figure $50 e$ shows some of these dispositions of the coloring matter: $a$, the Nouse; $b$, the Pouched Rat of Kentucky; $c$, the Otter; $d$, the Irish Ermine; $e$, the Ermine.

Of the Colorisg Mitter of Pluc.-Prof. Robert Hare remarks that "None of the operations of nature are more inscrutable, than those by which organic substances are endored with the immense variety of colors with which vegetables and animals are adorned. The chemist," he says, "may linow how to elaborate dyes, to fix them, by the interposition of mordants, to vary their hues; but. excepting the influence of transparent media, or crystalline structure, in dispersing refracted or polarized rays, he is still quite ignorant of the differences in the arrangement of particles which give rise to diversity of color, or the mode in which chemical combinations cause the various colors of the precipitates." (Compen. 419.) Moreover, liaspail informs ns, that "The coloring matter of vegetables, (which acts such a prominent part in their organization,) has been classed, sometimes, among fatty matters; but that it is, in fact, a variety of nax:" (New Syst. of Org. Chem., p. 462.) Henlé still considers the coloring matter of pile as a fat. This learned philosopher, after deploring that we do not possess a better analysis of hair, in which regard should be paid to the three substances which compose its stalk, adds that, "According to those we possess, hair is a combination of fat and a horny substance; the first belonging to the centre, and the last to the cortex and intermediate substance. "The fat," he says, "may be extracted by boiling the hair in alcohol; that it is, ordinarily, acids, riz: the margaric and the oléic." It has, (he avers,) a blood-red tinge in red hair, greenish grey in brown hair, and, (according to Jahns, Der. Haarcortz, t. 1., p. 49, white hair has a limpid oil. He concludes that after the extraction of the fat, brown hair becomes greenish yellow. L'Héritier analyzed the hair of an albino, and found that it contains a colorless liquid and a solid nhite fal. (Traité. de Chem. Path., 616.)

It would seem from the foregoing quotations, that this portion of our subject is fraught with intrinsic difficulties. Commencing under such unfavorable circumstances, shall we be able to trace this mknown to so small a particle of matter as the coloring of a hair.

"The names given to coloring matter are "Chromule and Chlorophyl." In regetables the prevailing color is green. and a combination of the black oxide of manganese and potash, (which is white) gives to water a green color. Now manganese and iron both enter into the composition of pile; so that if hair was green, we would experience little difficulty in attributing its color to the iron and manganese. But the green color imparted to watel by the manganese and potash, passes gradually through all the shades of the prism, and eventually becomes colorless after throwing down the black oxide; which shows that the manganese may enter into the basis of the coloring matter of pile, notwithstanding it is not green. How is it in regard to plants? Their chlorophyl, (or coloring matter,) although it imparts to the leaves, a green color, furnishes to the flowers, all those various tints, which, in those beautiful objects, so much delight the eye; and even in the leares, the green color, at certain seasons, or under peculiar circumstances, turn yell $w$, red and brown, the very colors found in hair. So Berzelius mentions two substances which color 
bile; one of which, found in the bile of the ox, is of a brownist-green color. W We linow that long continuance in the dark will bleach vegetables, which were previously colored; and we have the authority of Rayer, (in Diseases of the Skin, p. 337, ) for saying that it will have the same effect upon hair. Should we feel disposed, in accordance with this reasoning, to attribute the colors of hair to chromule, it will not be necessary to say with Berzelius, that there are three kinds of it; for we know that, in the inorganic world, different colors are displayed by the same matter, according to the different degrees of oxygen and light that are present. For instance, a piece of iron, by merely heating it, (i. e. by causing it to absorb oxygen and generate light, ) becomes first yellow, then red and finally white, colors which are all found in pile. A writer in the Baston Joumal of Science, (v. 1, p. 97, says that he mixed lime, alumine, silica, soda and boracic acid, and upon exposing the compound to a strong heat, had a whice product; this he ground and submitted to a red heat, when it turned of that color; upon increasing the heat it became white again. These changes were produced by heat and ligh. Chlorophyl has been found to be a coloring material of some of the lower animals of a green color. $\dagger$

From the whole of the above we may fairly infer that chlorophyl is not restricted to any form of matter, but belongs, in common, to inorganic and organic, to the animal as well as the regetable commonwealth. Tegetables borrow it from minerals and loan it to animals. We every day appropriate a quantity of it in our food, one portion colors the blood, another the bile, and a third dyes the hair.f A large quantity is not required, for, according to Berzelius, it is so potent that all the foliage of a large tree contains but ten grains! If it should be objected that the analogy between vegetable matter and pile is imperfect, inasmuch as vegetables have various secreting organs, corresponding with the different colors, while a perfect hair has but one, we would answer that all the coloring matter, howerer rarious the tints, of the shell of a mollusc, is deposited by the same mantle.

If we are correct in supposing that the rariegated colors of the golden mole, (Chrysochloris, ) are caused by the polarization of light, that which is called mithe hair is merely colorless, and black liair is opaque, the tints of hair are reduced to three; and, what is remarkable, these three belong to the modifications of the three colors the least dispersed of the solar spectrum, viz: red, orange and yellow.s It is, therefore, not umphilosophical to

* If to the fuid which contains the yellow coloring matter of bile, we gradually add nitric acid, it turns first bluc, then grecn, then violet, then red, and then Jellow or yellowish-brown.

it See the remarks on the green monkey.

$\$$ Bakewell says that in some parts of Gloucestershire the wnol acquires an orange color, in Hertfordshire and Warwickshire it is of a brownish red, and in the fens of Lincoln and Cambrilge, a dark blue tint; each corresponding rith the color of the soil. (Essay on Sheep, p. 31.)

\& The color of what is called the green monkey is a modification of yellow. Mr. Bennit says, the color is greenishyellow abore, arising from the ringing of the hairs with rarious shades of jellow and black, but assumes more of a dark irizzled appearance on the sides of the body, and outer sides of the limbs, which become gradually darker towards the hands. The face, ears, and naked part of the hand are jet black; the former is of a triangular shape, bounded abore the eyes by a straight line of stiff black hairs, and on the sides by spreading tufts of light hairs with a jellowish tinge, meeting, in a point, beneath the chin. The neck and chest are white; the under parts of the body hare a Jellorish tinge; and the inside of the limbs are grey. (Sce Nat. Lib. Mam., v. 1, Monkeys, p. 1t1.) We also read of the blue goat of the Cape of Good Hope. (See Gold. Hist. of Man, se., 260.) 
suppose that the basis of the coloring matter of all pile is the same substance differently modified.

OF тнe Smentr.-The cellular tissue, situated within the follicle and enveloping the button and a part of the shaft, at its posterior extremity, is called the "sheath." According to Henlé, it consists of two layers, between which is a fatty matter. This part is not said to be formed by the sinking donn of the dermis, as the follicle is said to be.

The sheath generally terminates at the epidermis, but may sometimes, in diseased hairs, be seen obtruding upon the shaft of the hair, above the epidermis, as in fig. 51 .

Of the Follicle of Pile.-The word "follicle," is derived from the Latin "folliculus," (which is a diminutive of "follis," a bag, purse or script,) and therefore means "a little sac."

In Anatomy it is defined to be "a secreting cavity." (See Dict. of Med. Terms, by Hoblyu.) Prof. Dunglison (in Hum. Phys., 41, says: "Follicles, or crypts, are secretory organs, shaped like membranous ampullie, or vesicles, always seated in the substance of one of the outer membranes of the body, the skin, or the mucous surfaces, and secreting a fluid intended to lubricate them." (See also Dung. Med. Dict., title "Crypta.")

In Botany, "follicle" means a seed-ressel, husk, or cover. "L'envelope membraneuse dans laquelle sont contenue les graines des plantes" (Dict. of the French Academy.)

There is nothing in its deriration or terminology to prevent us from using this word as we here do, to mean "a little sac, in which the posterior" portion of the shaft of pile, with its button, is found, when the pile has come to maturity;" without interfering with the questions whether it is secretory or excretory.

This part of pile has, sometimes, but very improperly, been called the "bulb;" for that term, (from bulbus, in Botany, is applied to the solid roots of plants that have many coats or peels; and in Anatomy, it is applied to parts that have the outward shape of bulbous roots.

"The word "root" has sometimes been, by analogy, but very improperly, applied to this part of pile. At other times the button is considered to be the root; as, for example, in Dunglison's Hum. Phys., 103, it is said, that "the roots of the hair are in the form of bulbs, taking their origin in small follicles or open sacs," \&c. It would be better to discontinue the use of the word "root" altogether, as regards pile; as it leads, insensibly, to error.

Where the follicle is found.-Professor Dunglison says, that the consideration of the hair belongs, naturally, to that of the shin; and this integument he describes as consisting of four parts, viz: the cuticle, rete mucosum, corpus papillare, and corium. He copies from Wilson's Hum. Anat, 493, a diagram in which all these, with the adipose. tissue (which underlays them all) are depicted; wherein there are seen two hairs, the follicle of one is represented as being in the adipose tissue, and the other below it. And that this did not arise from mere inattention in Wilson, we have a right to infer from the circumstance that in the explanatory notes it is observed, that in regard to these two hairs, enclosed in their follicles, their relative depth in the skin is preserved.

On the other hand, Cazenave (in Traité des Mal. de cuir chevelu, 1850, p. 41,) describes the follicle as a little wate lodyed in the dermis, having heneath it a conigue papilla, which is 
(he says) sometimes called the pulpe of the hair. But this papillo in Wilson's plate, albove referred to, is situated above the deeper layer of the cutis-the corium. Such is the state of uncertainty as to even the locality of the follicle.

Through the politeness of Dr. George Hewston, of this city, we obtained a suit of specimens of skins from different parts of the human head, body and limbs. We have made numerous horizontal and transverse sections, exhibiting the hair follicles in their natural positions, from which we infer that they are, for the most part, situated in the dermis, although occasionally the posterior termination of them reaches the adipose tissue.

How the Follicle is formed.-Prof. Dunglison* says, that the follicle is formed "by the inversion of the cutis, and is lined by a reftection of the epidermis." In lis Medical Dictionary he makes the word "cutis" synonymous with "skin;" which, as we have seen above, he describes as constituted of four distinct layers; but we presume that he here means by cutis, the cutis vera or corium; since he says that the follicle is lined by the epidermis.

That the follicle is formed by this inward turning of the cutis; is a very general opinion; even Henlé asserts, that "it is a true inward turning (renversement) of the dermis, forming a cul de sac, to receive the button." But we believe this to be a popular error, and shall endeavor to prove it so to be.

In the first place, we would inquire, if the follicle is formed in the dermis, how can it invert it? It seems to us that, in order to form this inversion, it should be formed above the dermis; but no one pretends that the follicle is formed in the epidermis. 'To invert (from inverto) means to change or reverse the natural order of things; and what reason can be given why a follicle, formed in the body of the dermis, should be made to change the natural order of this integument? Is it not much more reasonalle to suppose, that if the follicle belongs to the dermis, and is formed therein, that it should be formed like glands and ducts, without any inversion?

But the difficulty is increased by the assertion that the follicle is not conly formed by an inward turning of the dermis, but that it is lined by a reflection of the cpidermis.

How the epidermis, which is represented to be a dry, scaly structure, can be reflected or inwardly turned into each particular follicle of the hundreds and thousandst that are found in the dermis, is very difficult to conceive. What is it that causes this reflection? Is it the button? Then the button ought to be formed above, or at least in, the epidermis. If the follicle is formed after the button, how does it pass that portion of pile so as to invert it, as it is represented to do? And lastly, the epidermis is depicted (p. 100 of Dunglison's Hum. Phys.) with oblique pores, for the lassage of the hair; and that this diagram is so far correct, any one may satisfy himself by ocular demonstration. Let him cxamine his forearm, and among the hairs he will discover inmumerable small black specks;

\footnotetext{
* Prof. Dunglison's Ifuman Physiology, comprised in two octaro rolumes of nearly 1,350 pages, is full of valuable information, as we have a right to expect from a gentlcman of his talents and learning. All that he says upon pile is comprised in less than four pares, and the principal part of that is copied from others.

i $\mathrm{A}$ laborious German has taken the pains to count the hairs upon the human head, and finds the folloring, viz: blonde, 140,400 ; brown, 109,440 ; black, 102,962 ; red, 88,710 .
} 
let him pick one of these with a needle, and the end of a hair (the body of which lies under the epidermis) will obtrude. With a pair of tweezers, this new hair may be drawn out to a considerable length. In a section of the skin these young hairs may be detected, partly coiled, the apices seeking their way, as it were, through the epidermis, by one of these pores. But all this is entirely at variance with the notion that the follicle is formed by an inward turning of the cutis and is lined by a reflection of the epidermis.

Of Pile without a Follicle.-But it can be demonstrated that the idea of the follicle being formed by the turning inwardly of the dermis is chimerical: 1st. By the hair of the head of the foetus. We have, in our cabinet, a foetus of three months, upon whose head is no hair; we have another of five months, upon whose head there are hairs, but none of them have either button or follicle.* (See fig. 52 a.) We have a third specimen of hairs from a full-grown foetus, which was taken, dead, from the body of a female obtained for dissection. Upon these hairs, also, there are no traces of either button or follicle. (See fig. 52 b.)

These are specimens of imperfect hairs, and seem to prove that pile does not "take its origin in a follicle." We also call attention to fig. $53 c$, which represents a curious connection of three hairs of the horse "Diligence," viz: one mane hair that has come to maturity, and two smaller ones, one of which appears to be an imperfect hair, probably never having had a button or follicle.

But the suit of skin-specimens, above referred to, explains this subject completely, and puts this matter entirely at rest. In the various sections we have made of these, the young hairs that have not yet pierced the epidermis may be traced through every stage, from the cells to their development.

First is discovered, in the dermis, a collection of dark-colored dots, granules, or cytoblasts, the precursors and origin of the forthcoming hair. (See fig. 53 "a.")

secondly, (immediately alongside, is another collection of granules, partly enclosed in the faint outlines of a forming hair. Here we see some of the granules passing gradually into lines or fibres. (See fig. 53 "b.") No button or follicle is yet to be seen.

Thirdly, fig. $53 \mathrm{c}$ shows the button just forming; the inferior extremity of it a faint ontline, while the granules have ascended and condensed in the superior portion of the button and the inferior extremity of the shaft; but no follicle yet appears.

Fourthly, fig. $53 d$ represents a button formed, except that the lower extremity is not yet closed; but no follicle is yet seen.

* Exumination and Description of the hair of the head of a five months fietus, of one of the oral-haired species. - Specimen presented by Dr. Joseph Leidy, 11th of April, 1850. Length, about 2 millimeters; shape, oral; diameter, $\frac{2}{0}-$ of a millimeter; culor, very light, translucent; not much lustre; direction, flowing; inclination, at an acute angle to the epidermis; button, sheath and follicle, none. The shaft terminates in the dermis in a slight swelling, which exceeds, by $\frac{1}{3}$, the diameter of the slaft; truncated at the posterior cxtremity, and around which are asembled dark-colored dots or grains, in groups of various shapes and sizes, but generally extending laterally from the end of the shaft, and rarely measuring more than $6 T^{\frac{1}{6}}$ of a millimeter. Shaft-cortex, squamose, more than 200 scales upon the length of a millimeter. Intermediate fibres, minute; one measured the $\frac{1}{2} \frac{1}{0}$ of a millimeter. Centre-no central canal; the coloring matter disseminated throughout the shaft in lines too minute for measurement. Apex-generally pointed, but occasionally abrupt; none furcated; diameter of the point, the $\frac{1}{12} \overline{0} \sigma$ of a millimeter. 
Fifthly, fig. $53 e$ shows the button fully developed, and the follicle just commencing to form around it.

Sixthly, fig. $53 f$ is an instance where the follicle is beginning to form before the button is entirely developed.

Seventhly, fig. $53 \mathrm{~g}$ shows the button and follicle, both formed; this hair having come to maturity.

In this specimen the follicle was white, but opaque; and, in order to make it transparent, it was necessary to crush it, which has altered the original shape of the follicle; for which the reader will make allowance. The same of fig. $53 f$.

Some Examples of Follicles of the Pile of the three Species of Men.-Figure 54 a represents the follicle of pile of the oval-haired species, where " $a$," is the button; " $b$," the follicle, and " $c$," a portion of the slaft, with the cortex removed, to expose the fibres.

Figure $5+b$ is a hair of the cylindrical-piled man; " $a$," is the button; " $b$," the follicle; " $c$," a part of the shaft, and " $d, "$ a portion of the tissue disrupted and drawn out.

Figure $54 c$ shows the pile of an eccentrically elliptical piled man, where " $a$ " "is the button; " $b$," the follicle; "c," a piece of the shaft; " $d$," a portion of the tissue, and "e," a vessel. All these hairs have arrived at their full development.

The Follicles of the Hairs of Hybrids.-Figure 55 a represents the hair of a Hybrid, a tetra dimestisin.

Of tile Vitality of Pile.-The learned do not agree in regard to the vitatily of pile. Bichat divides a hair into two parts, viz: an exterior envelope, and an interior substance. The former he considers to be lifeless and insensible, and the latter to enjoy real vitality.

In the Lond. and Edin. Journ. of Med. Science, for 1841, p. 595, it is said that the vitality of hair itself, appears to be proverl by the fact, that in a majority of cases of a plica polinica, the matted hair tufts do not extend to the surface of the scalp, but consist of groups of hairs, which are healthy at the base, and are implanted in healthy bulbs [follicles.] But our examination of the hair of the head of Annette Engles, (who was laboring under "incipient plica polinica, ) shows that the button also is diseased.

It has also been asserted that if the shaft of the hair, in plica polinica, is cut, it will bleed. But both Mechel and Haller deny this assertion, and L'Heretier, (who analysed the substance which oozes out of this diseased hair,) found it to be only an ammoniacal soap. $\dagger$ (See Trait. de Chem. Path., p 616.)

Ellisten (in Hum. Phys., p. 277,) states, that in the disease Phrenitis, the hair is sensible to the slightest touch. But this might be, were the hair itself insensible, but were connected, (through its follicle,) with delicate nerves. A friend of ours sometimes suffers from severe attacks of Neuralgia in the scalp: and in the intervals of these attacks, the

* See Charleston Med. Rev, and Jour., v. ri., 367.

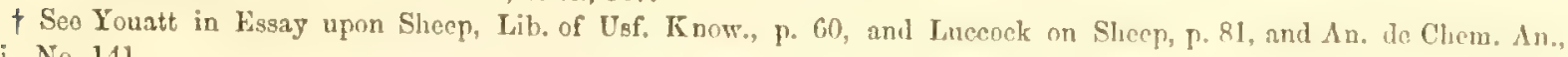
xi., No. 141. 
slightest touch of the hair is often sufficient to cause violent pain, which seems to be in the hair itself, but the sufferer, (who is very intelligent,) has no doubt of its being confined to the scalp.

OF VESSELS. - In the course of our pile manipulations we have often encountered small threads, which may be vessels or nerves, but which are too small to be identified under the microscope; some of these are attached to the posterior portion of the button, when drawn out, and others upon the same part of the follicles, obtained by dissection or maceration.

Figure 56 represents a hair of the oval-haired species, with a button somewhat deviating from the normal shape, but with small portions of four threads disrupted in the drawing.

Figure 24, which represents a hair of the pavilion of the external ear, shows threads. So does figure 29, which represents a hair of the axille. Figure 31 , which represents the hair of the forearm, exhibits a thread, (see "a.") The same may be said of figure 55 , " $e$."

Note.-In the drawings of hairs, in Wilson's Human Physiology, it is represented that each filament has two sebaceous glands opening by short ducts, one on each side thereof; but we have not found them in place.

From all which, we agree with Henle that common hairs, (by which term he excludes the whiskers of the lower animals, although unsensible themsetves, because they are destitute of nerves, are in connection, through their roots, with a tissue rich in nerves and sanguiferous vessels. (See Gen. Anat., y. 1., ch. iv., p. 300.*)

As the hair subsists from vessels, so they are influenced by the vital force and health of the individual; so that when we see a head thickly covered with strong, richly colored, lustrous hair, we may predict, that the person is in good health; but when the hair is weak, sparse, dull shades of color and devoid of lustre, we may as surely pronounce, that there exists some bodily infirmity, or that there is a diseased state of the system.

Of tue Secretion of Pile.-Admitting that there is no vitality in the shaft of a common hair, still it may be an organ of secretion. The pile of a healthy person is almost always amnointed, as it were, with an oleagenous substance; which is believed to be of that character. In that dreadful disease, milk sickness, the hair sometimes drops out, and in proof that the virus enters into the body of the filament, Bowyer assures us that it has been detected in hair and wool, after they have been cleansed, in the usual manner, and have been woven into cloth. Prof. John K. Mitchell, M. D., is of opinion that this class of diseases is caused by poisonous fungi, one variety of which resides inside of the follicle, between its walls and the button, and that it ascends to the epidermis. (See Mitchell on Fevers, p. 65 to 67.) And Mr. Yountt says that what is termed the yolk of sheep's wool, is a secretion. 


\section{CHA P'ER I I.}

PLA T E I.
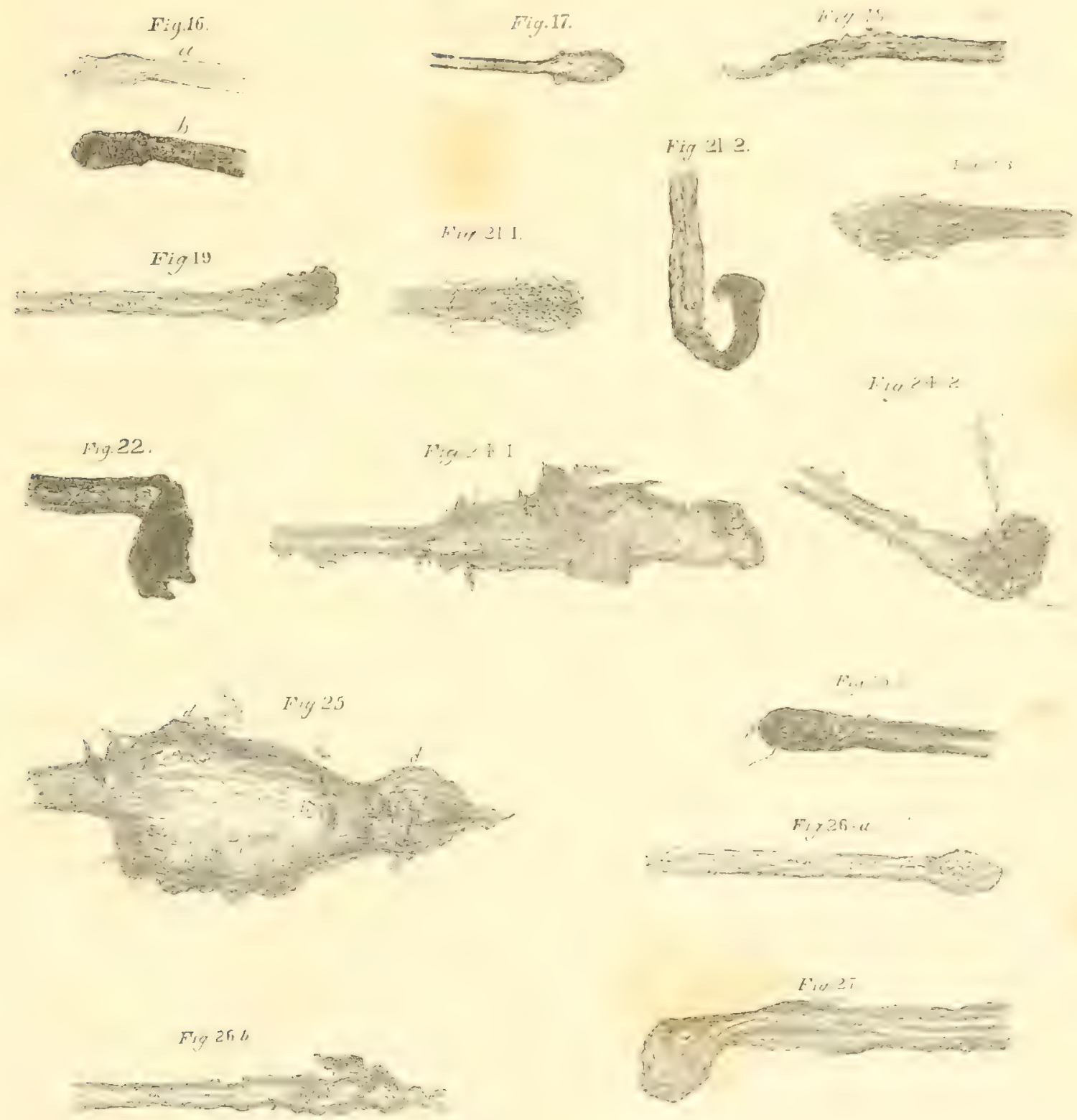

PLATEII.
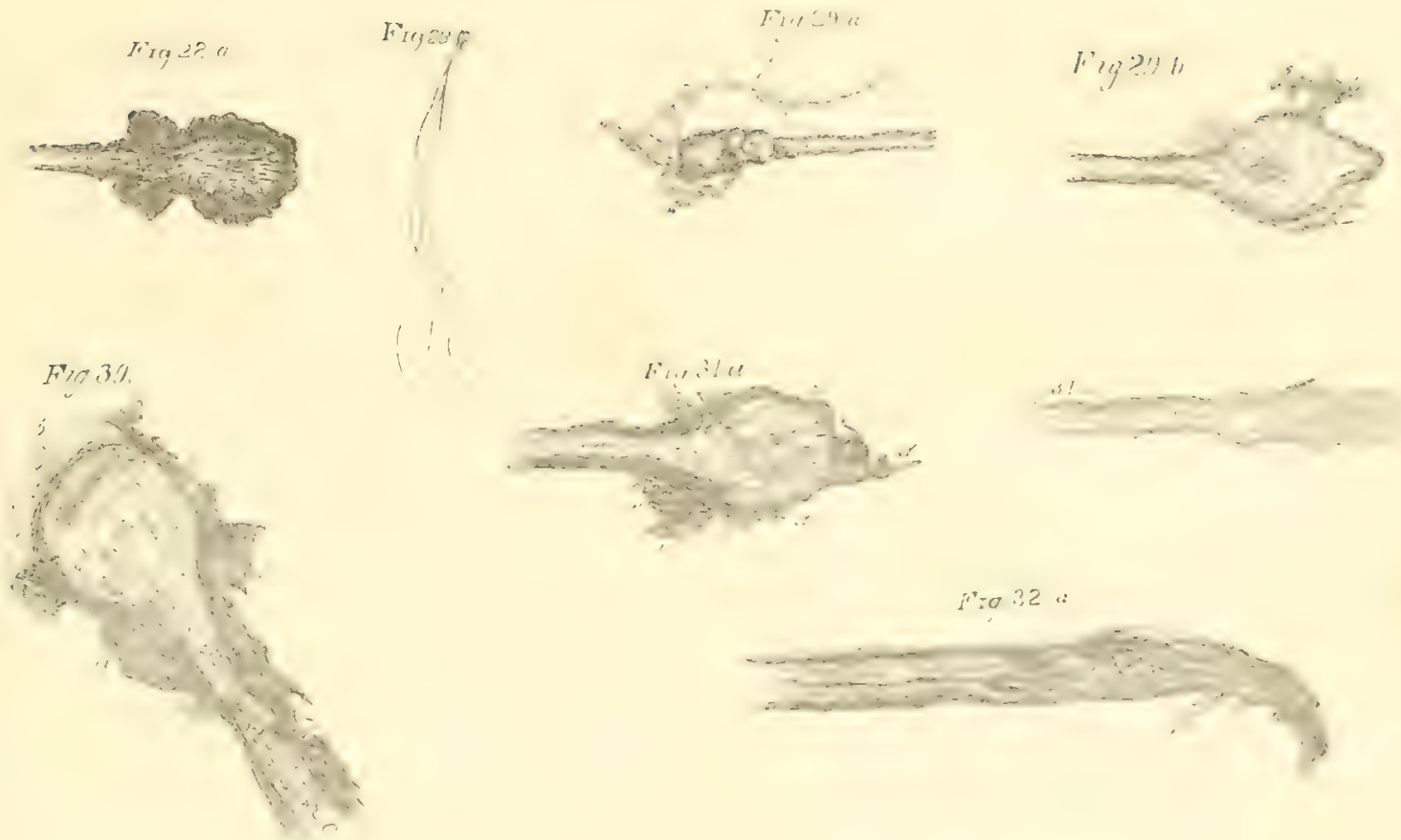

$F i, 3 ?$

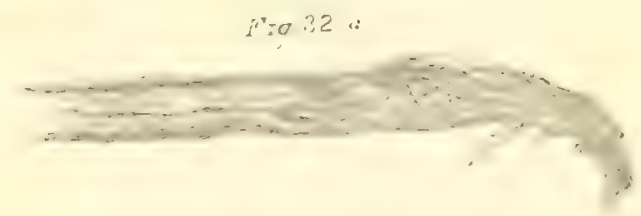

FI? ,
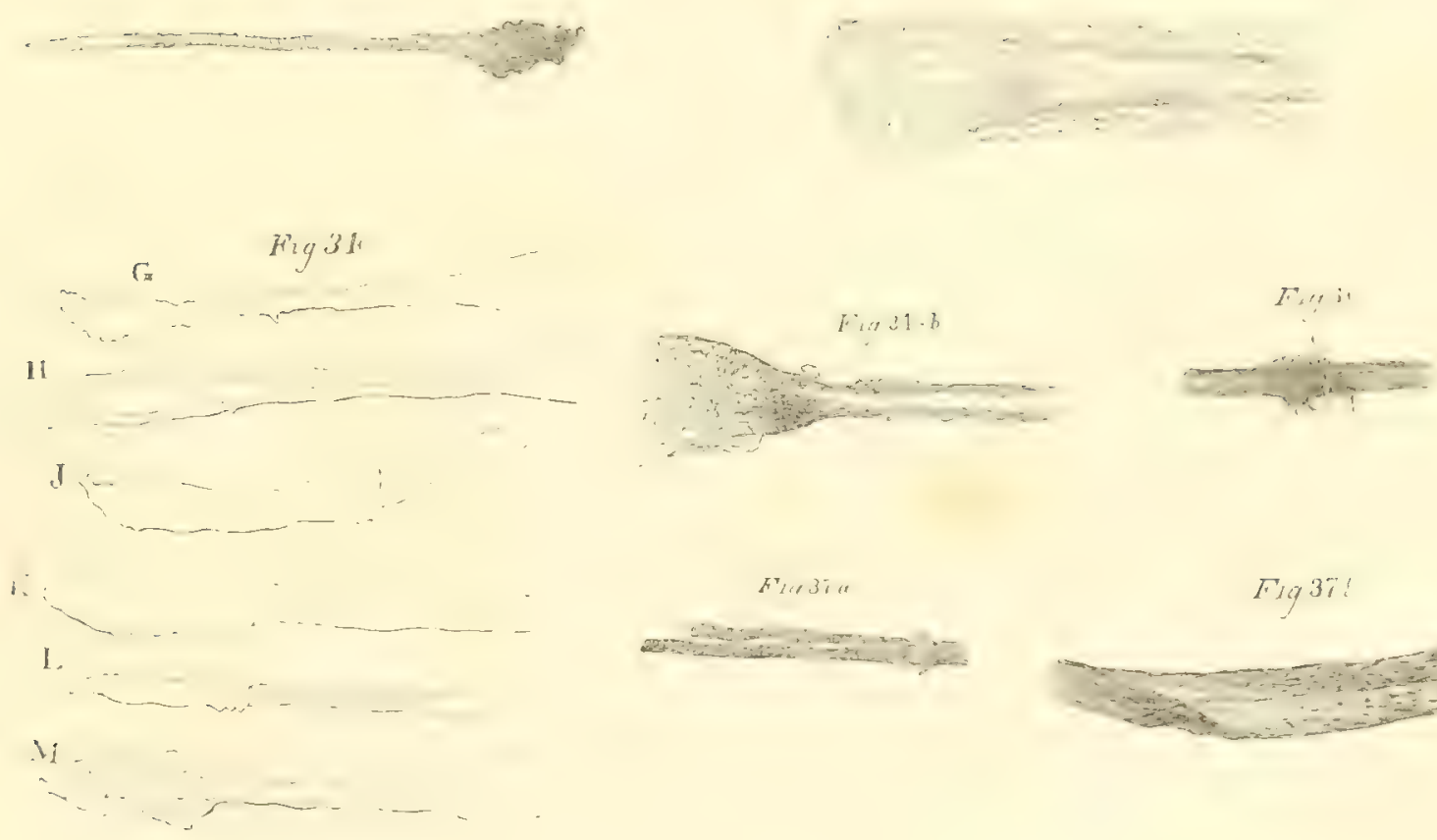



\section{PLATE III.}
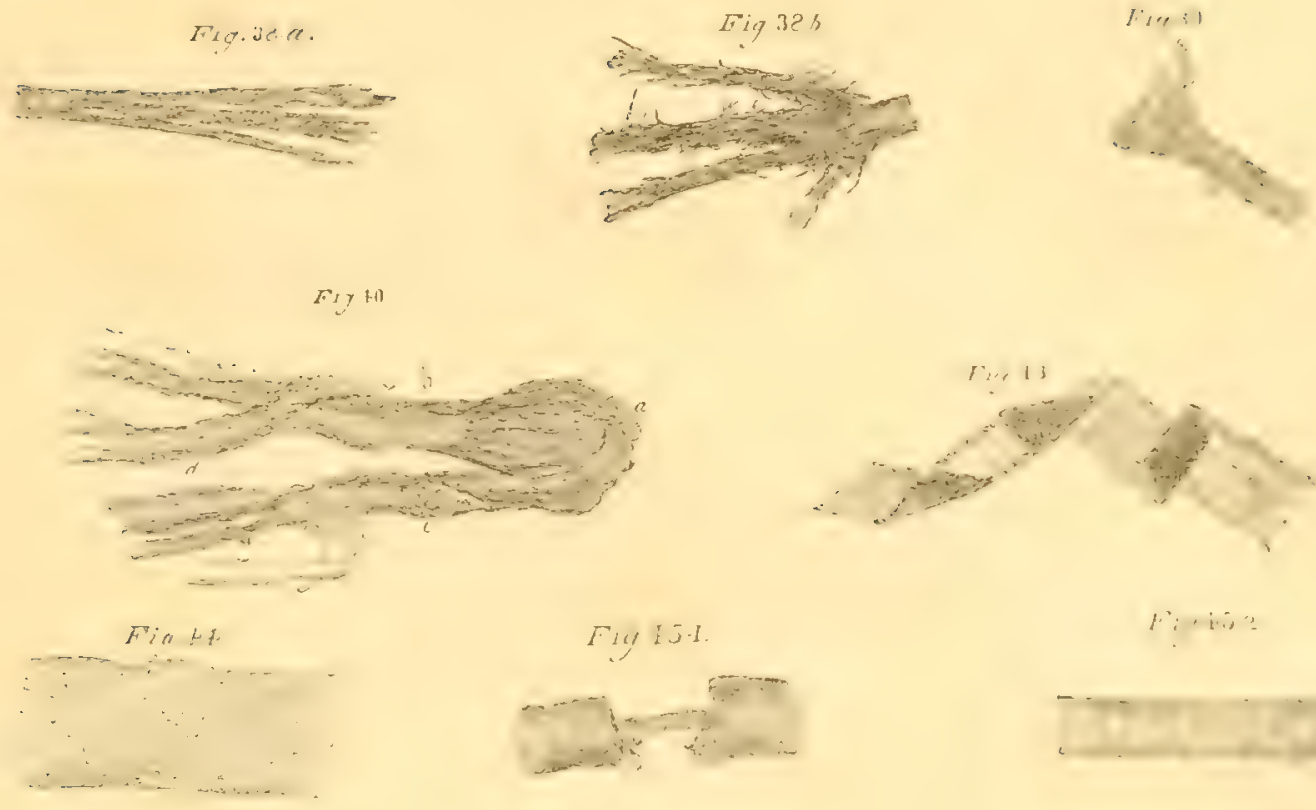

Fy :5-1.

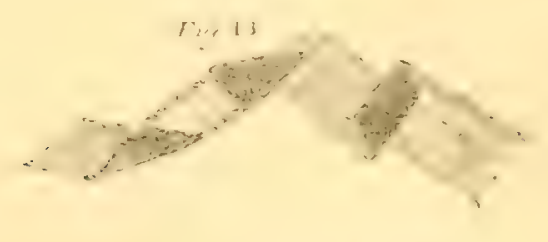

F.1. 5.5.3

$\therefore$ ?

Figt5+.

$\therefore$

(ख)

$i \cdot \cdots$
$\cdots$

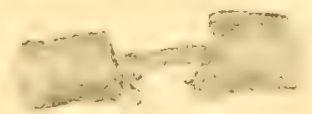

f: $: \mathrm{i}:=$

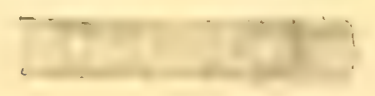

Fis? $1+$

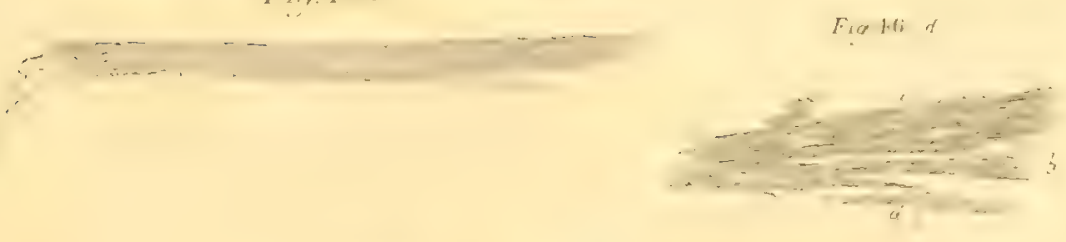

FIg.16 h
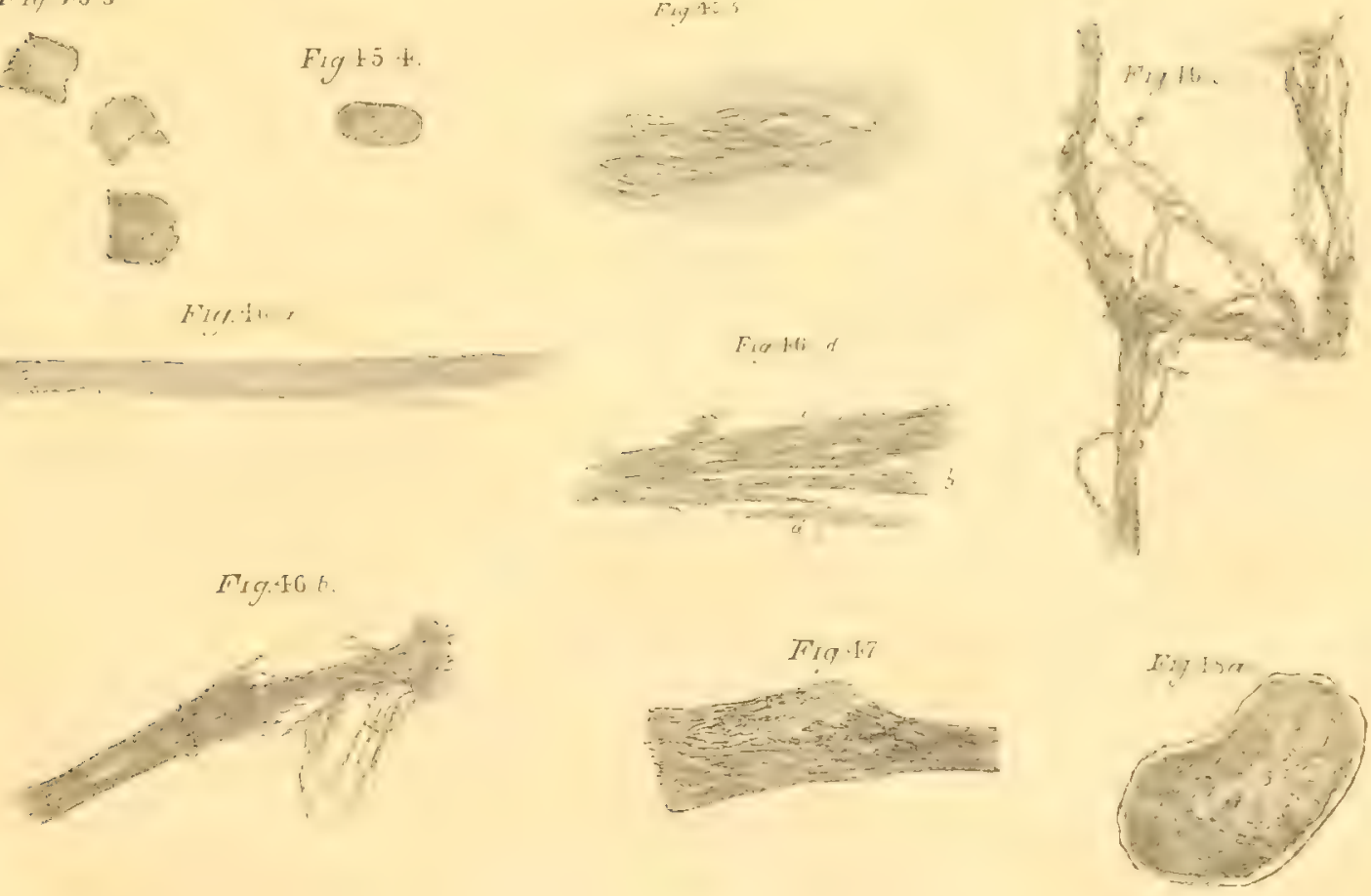



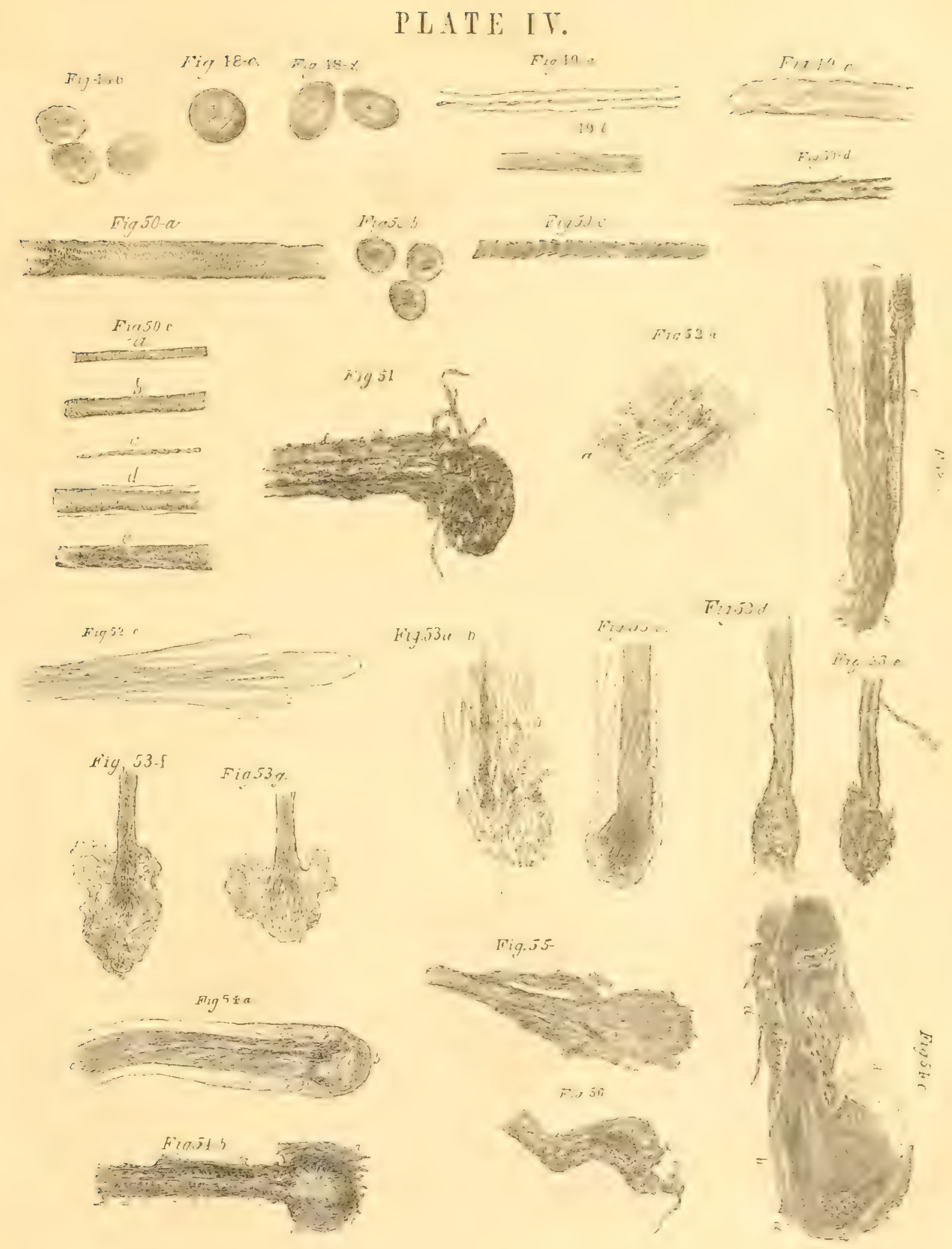

(6) 



\section{CHAPTER III.}

OF a PERfect Hair.-Eble is of opinion that the most perfect hair is the whistier of some of the lower animals, such as the seal, the lion, the rabbit, \&c.; but we (considering these whiskers as organs of touch) place the hair of the scalp of the white man, as regards perfection, at the head of the list of piles.

Of the Ciraracteristics of tire Pile of the Huilan Head.-These are the shape or form, the ductility, elasticity and tenacity, the direction, and the inclination, \&c., \&c.

Of the shape or Form of Pile of the Human Hewl.-The greatest number that have come under our notice, are either cylindrical, oval or eccentrically elliptical; we therefore call these the general forms of these piles.

Explanation of these Terms.-A cylinder, (from Kulindreo,) is a body formed by the rotation of a parallelogram about its own sides. If a cylinder be cut by a plane parallel to its base, the section will be a circle, equal to the base.

When a transverse section of a filiment of pile presents this circle, we call the pile "cylindrical." An oval, from ovum, an egg, is a curvilinear oblong figure.

When a transverse section of a filament of pile prosents a curvilinear oblong figure, the greatest diameter of which is $\frac{1}{3}$ more than its smallest, we call the pile "oval"

When a transverse section of a filament of pile presents a curvilinear oblong figure, the greatest diameter of which is $\frac{2}{3}$ more than its smallest, we call the pile "eccentrically elliptical."

\section{EXAMPLES OF THE THREE GENERAL FORMS.}

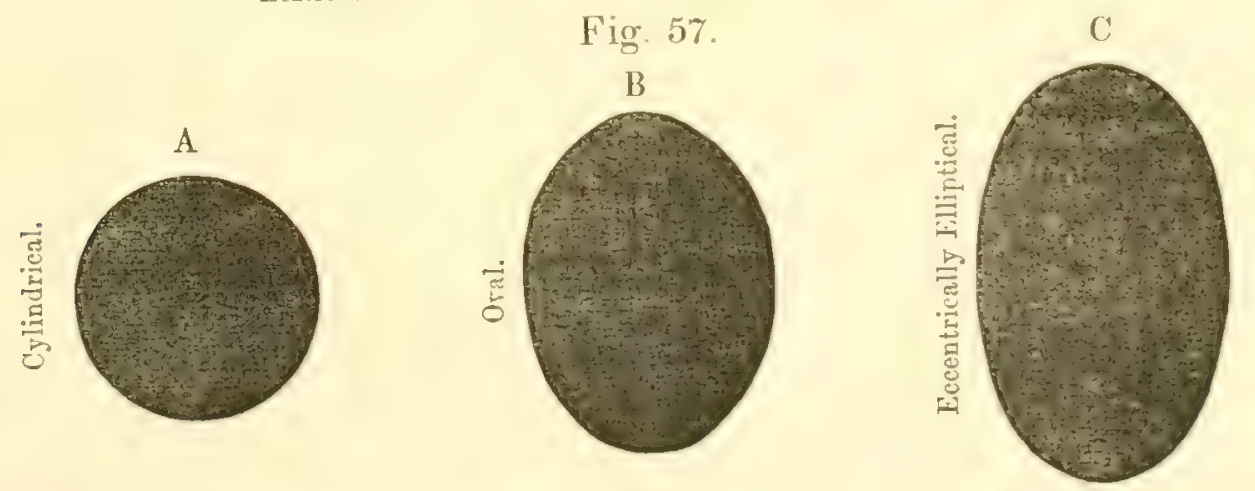

Of the Particular Forms.-But there are other shapes, less frequently met with, viz: the cylindroidal, the lesser ovoidal, the greater ovoidal, and the eccentrically elliptoidal, to which we give the name of "the particular forms of pile." 


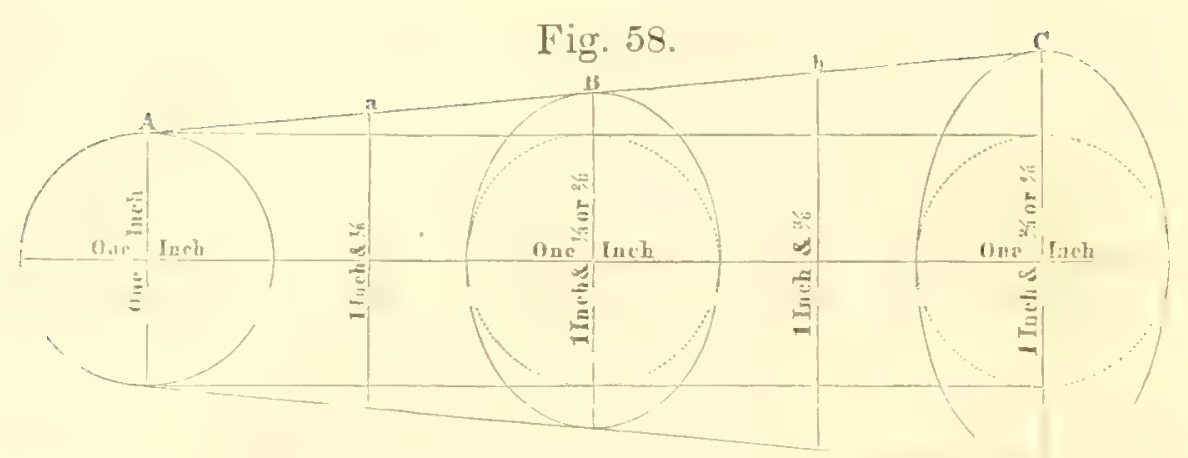

In this figure, $\mathrm{A}, \mathrm{B}$ and $\mathrm{C}$, represent, respectively, the cylindrical, the oval, and the eccentrically elliptical, as in the previous one. "a," marks a line half way between the cylinder and the oval. The pile belonging to this space, called "cylindroidal," have a form where one diameter exceeds the other by less than $\frac{1}{6}$. All pile belonging to the other half of the distance between the cylinder and the oval, viz: whose greatest diametcr exceeds that of its smallest $\frac{1}{6}$, but does not reach the $\frac{2}{6}$, are called the "lesser ovoidal." "b," marks a line equi-distant between the oval and the eccentrically elliptical. All pile on the oval side of this line, having its greatest diameter more than $\frac{2}{6}$ of its smallest, but less than $\frac{3}{6}$, we call "greater ovoidal;" and all pile on the other side of that line, where the greatest diameter exceeds its smallest by more than $\frac{3}{6}$, but by less than $\frac{4}{6}$, we call eccentrically elliptoidal. These dimensions have been explained, because they include all those known to belong to the hair of the human head. For practical purposes, it is not often necessary to regard any more than the three general forms; throwing the "oidals" into the classes from which they are derived.

To whom they belong. - The next step is to show to whom piles of these dimensions belong.

$A$ is a representation of the shape of a hair of the head of a full-blood Cloctaw Indian of 60 years of age, specimen presented by Dr. Nott, of Mobile. The original is black, straight, lank, and has a diameter of $\frac{1}{2} \frac{1}{7}$ of an inch.

$\mathrm{B}$ is a representation of the shape of a hair of the head of his Excellency General George Washington; the original is cololless and flowing, and has for its greatest diameter $\overline{3} \frac{1}{1} \overline{2}$, and its least, $\frac{1}{50} \overline{0}$ of an inch.

$\mathrm{C}$ is a representation of the shape of a filament of wool of the head of a pure negro; the original is black, crisped and frizzled and spira!ly curled, and has for its greatest diameter $\frac{1}{3} \overline{1}$, and for its least, $\frac{1}{3} \overline{0}$ of an inch.

The principal reason why hairs have been misrepresented in regard to shape, is the difficulty of ascertaining it in the way they have hitherto been examined. A hair is placed horizontally between two pieces of glass and examined under the microscope; but it is exceedingly difficult, if not impossible, to determine whether it is cylindrical or oval. Even if it is found that the diameters, in different parts, differ, you are at a loss to attribute this discrepancy to the shaft being oval or to tapering. But we have a machine with 
which we cut transverse sections or disks of pile, thereby completely obviating the dificulty.

Transverse Sections.-Figure $57 \mathrm{~A}$ is a representation of such a transverse section of the hair of the head of the Choctaw Indian. Figure 57 B is a representation of such a transverse section of the hair of the head of his Excellency General Washington.

The same difficulty does not exist to the same extent, in examining pile that is eccentrically elliptical; for if a spiral curl of this description is placed between two pieces of glass, and moderately pressed, a part of it will exhibit, under the microscope, the thin edge of the ellipse, and another portion will represent one of the flattened sides. I igure 59 is a representation of a single filament of a spiral curl of a pure negro head.

Of Ductility, Flemibility, Elasticity axd Tenacity of Pile. - Ductitity is that property of matter which allows of its being stretched or extended in length, upon the application of force or power, whether mechanically or chemically applied. Flexibitity is that which allows of its being bent, or moved in a lateral direction. Flexibility is always accompanied by ductitity on one side of the thing bent, and elusticity on the other side. Elasticity is the spontaneous returning to its original dimensions and juxtaposition of its particles, after the thing stretched or bent has been relieved from the force or chemical action. It depends upon a law in regard to the natural arrangement of the particles of matter, under which they exert a tendency to return to their normal juxtaposition, after having been partially separated; a tendency which pre-eminently distinguishes solids from fluids; which latter, conform to no such law. Elasticity does not belong, exclusively, to vitality; for it is traced to some minerals, as the elastic bitumen, \&c., \&c. It is found in the fibres of some plants, and remains there after their vitality has been destroyed. Tenacity is the adherence of the particles of matter, constituting strength. 'Tenacity may be accompanied by ductility, flexibility and elasticity, or it may not. When it is, the substance is said to be tough, when it is not, it is brittle.

Essential Properties.-Ductility, flexibility, elasticity and tenacity are the properties of pile, with such few (if any) exceptions, that they are deemed to be essential.

Of some supposed exceptions to the Rule.-The properties of ductility, elasticity and tenacity, are in the fibrous portion of the filament of pile, as we stated in a previous Chapter.

It has been supposed that the hair of the three-toed Sloth (Bradypus tridactilis) is destitute of ductility and elasticity, but it is so only in a degree; for one inch of the hair of this animal, with 240 grains, stretched $\frac{17}{9}$ of an inch, showed a loss of elasticity of $\frac{9}{90}$ with 240 grains, and was fractured with a weight of 250 grains. The cortex is irregular and inelastic; separates into amorphous brittle pieces, but will not divide into fibrils. Sometimes the shaft has deep fissures. 'The central portion is fibrous, the fibres having a diameter of $\frac{1}{2} \frac{1}{70}$ of an inch. (See ante, fig. 45.)

The hairs of those animals that have a paved cortex bend at a right angle, remain in that position, and also tie in a closed knot, (which is not the case with common hairs,) but 
they are not brille. One of these (Cervus elephus) has hair which stretches $\frac{50}{0}$ of an inch with a weight of 480 grains; retains its entire elasticity after stretching $\frac{6}{90}$ with 230 grains; loses $\frac{40}{9} 0$ with 480 grains, and fractures with 490 grains.

The hair of the Musk (Moschus pigmæus of Lin.) is said to be brittle. (See Elem. de Zoöl., p. 463.) We have no specimen in our cabinet.

Dr. Gross tells of a lady, the hair of whose head, without any assignable cause, became so brittle that it broke off in locks, about a quarter of an inch beyond the epidermis.

of the endurance of the essential properties of Pile-Long separation from the head or body of an animal may impair, but does not destroy, ductility, elasticity and tenacity of pile.

We have a lock of hair of the head of Prof. Benjamin Silliman, cut when he was twenty years of age, and another cut when he was over seventy. The greatest that one inch of a hair of the former stretches is (with 1,320 grains) $\frac{3}{9} \frac{0}{0}$ ths of an inch. The latter (with $1,7 \% 0$ grains) stretches $\frac{40}{9} 0$ ths. The former retains its entire elasticity at $\frac{2}{9} 0$, with 1,120 grains. The latter retains its entire elasticity at $\frac{5}{9} \overline{0}$, with 970 grains. The former loses $\frac{24}{90}$ of its elasticity with 1,770 grains. The latter loses $\frac{1}{9} \frac{6}{0}$ of its elasticity with 1,320 grains. The former breaks with 1,320 grains, and the latter with 1,520 .

The hair of His Excellency Gen. Washington had been upwards of fifty years severed from his head when examined, yet it stretched $\frac{35}{90}$ with 933 grains, and broke with 1,123 .

The hair of the Hon. John Sergeant has been cut thirty years and more, yet it stretches $\frac{2}{9} \frac{6}{0}$ with 710 grains, and breaks with 720 .

The Peruvian, Mexican and Brazilian mummy hairs (which are supposed to be from 2,500 to 3,000 years olı) stretch and bear considerable weight. (See Table.) And lastly, we have some of the hair of the Mammoth, found enveloped in ice near the mouth of the river Lena, in Siberia, which, with 4,029 grains, stretched $\frac{4}{90}$ of an inch, and broke with 4,669.**

\footnotetext{
* An Examination of the Hair of the Siturian Mammoth, founderveloped in ice, near the mouth of the river Lena, in Situeria. Specimen presented by Robert.W. Gibbs, M. D., of Columbia, South Carolina.

Our readers will recollect that the latter part of the summer of 1799 , a native fisherman of 'lungusia, who was in the habit of collecting tusks from among the blocks of ice and rubbish which fell from the cliffs, and were found on the banks of Lake Oncoul, near the mouth of the river Lena, saw, projecting from a great leight, a mass of unusual form, but of shapeless appearance. The year after, proceeding to his usual haunt, he noticed that this lump was somewhat disengaged and had two projecting parts; and, towards the summer of 1801, when he again looked at it, he found that it consisted of the whole side of a gigantic animal, having large tusks, one of which projected from the ice.

But so slowly do changes take place in this ice-bound district, that the next summer being rather colder than the preceding, no material alteration was noticcd. In 1803, a part of the ice between the earth and this monster was somewhat more melted, and at length the whole mass fell, by its own gravity, upon a bank of sand. Next year, in the month of March, the fisherman cut off the tusks, which he disposed of for fifty roubles, equal to abont $\$ 40$ of our money. Two years after this, and the seventh after the first discovery, these distant and deserted regions were traversed by Mr. Adams, an employee of the Court of Russia, and his account of the seruel is sufficiently interesting to be giren without abridgement.

IIe states that he found the mammoth in the position last indicated, but shockingly mutilated. It secms that some sickness which the Tungusian had experieneed, had been attributed to this bad omen, by his prejudiced countrymen; but with his recovery this prejudice had been dissipated, and no obstacle to approach the carenss remained.

The first discoverer was contented with his share of the profit arising from the sale of the tusks, and the Jakritski of the
} 
Of Contractibility. - We must he careful not to confound the property of clisticity with contractibitity, which belongs exchsively to vitality; elasticity, as we have said, is the spontaneous returning to its original dimensions and juxtaposition of its particles, and never exceeds the action of stretching; but contractibility is not subject to any such law.

neighborbood had proceeded to cut off the flesh to feed their dogs, and sundry wild beasts, such as white bears, wolves, wolverines and foses, must have partaken of it, as their footsteps were found aljundantly in the surrounding sand. By this means the skeleton had been almost entircly cleared of its flesh, but the bones were all there except one fore-leg, which was nowhere to be found. The heal was covered with a dry skin, and one of the ears was well preserved, and was furnisled with a tuft of hail. But it is to be regretted that these parts have been injured by transporting them to St. l'etersburg, a distanco of 7,330 miles. The eyes were preserved, and the pupil of one can yet be distinguished.

This mammoth was a male, and had a long mane on his neck. The tail and proboscis are unfortunately wanting. 'Iho skin, of which (says Mr. Adams) I possess three fourths, is of a dark srrey color, and is cocered with raldish wool and blach hair"; but the dampness of the spot where it had so long lain had, in some degree, destroyed (injured) the lair. 'lihe entire careass, of which I collected the bones, was 16 feet 4 inches long, and 9 fect 4 inches high. The tusks (not included in the above length) measured 9 feet 6 inches along the curre. The distance from the base or root of the tusk to the point, was 3 feet 7 inches. The two tusks weighed $360 \mathrm{ll} \mathrm{s}_{\text {ag }}$ and the hend $41.4 \mathrm{lbs}$. The skin was of such a wreight that it required ten persons to transport it to the shore. Upwards of $36 \mathrm{lbs}$. of hair and rool werecollected, and much more had been trodlen into the sand by wild beasts.

The integuments consisted of common hair, bristles and trool. The first was of different faricties, in regard to length and thickness. That remaining on the skin was thick-set and crisply curled, interspereod with a fow bristles about 3 inclues long, and of a dark redlish color. Some of the hair was about 4 inches long, and was more red than the short oues. Some of tho bristles were nearly black, and much thicker than lorse hair, and from 12 to 18 inches in length.

From the abore narrative, it is not easy to detemine from what part of the body of the animal the four hairs were taken, which are the subject of the following description. No. 1, is in length 6 inches and a half. It is eylindrical, and at the inferior extremity has a diameter of $\frac{1}{90}$ th of an inch, but gradually diminishes towarls the superior extrenity, where it has a diameter of $\frac{1}{1} \overline{0}$ of an inch.

It has no button, sheath, nor folliele. The shaft is black, passing into a blackish-bromn, opacuo, and deroid of lustre. The inferior extremity is broken aod uneren, exhibiting the intermediate fibrous sulstance. It is stiff and wiry, somerhat flexible, but brittle. March 21, 1849, one inch of it was submitted to the triebometer, (the Bar. being 29, Ther. 69, F. and Dew-point 60,) when the following were the results:-

It showed no ductility with a weight less than 3,300 grains, when it stretehed $\frac{t}{y}$ th of an inch, and upon remoring the weight, the clasticity was entire.

The weight was gradually increased to 4,300 grains, with which it extended $\frac{2}{9}$ ths of an inch, and the elasticity wasentire; with 4,500 grains it broke. The fracture was ragged, and exhibited three distinct substances, which appeared to hare parted in succession.

No. 2 , is 4 inches and $\frac{2}{10}$ ths in length; cylindrical, and $\frac{1}{8} \frac{1}{0}$ th of an inch in diameter; color, black, oparque, and deroid of lustre. Both terminations are abrupt; the anterior one furcated; has no button, sheath, nor follicle. It is much curled and bent, and the cortex has been fractured in two places. Upon this filament is the orum of a parasitic insect.

No. 3. This hair is in length $6 \frac{\pi}{2}$ inches, and las a diameter of $\frac{1}{8} \frac{1}{6}$ th of an inch. Has no button, sheath, nor follicle. Shaft, cylindrical, at the inferior cxtremity, but gradually passing into an oval at the superior extremity. Color, blackish brown, stiff, and slighitly undulated.

No.4. This hair is in length 8 inches and $T^{3} 0$ ths; diameter, $-\frac{1}{6} \frac{1}{0}$ th of an inch. No button, sheath, nor follicle. Shaftcortex, color, brown; intermediate sulstance, fibrous; coloring matter in the centre, dark brown. It is stiff and lrittle; inferior termination, abrupt; superior one, bifurcated.

Trial of this hair with the trichometer, same day as No. 1, with a weight of 1,070 grains it stretched $\frac{1}{9} 0$ th of an inch, and upon removing the weight, the elasticity was entire.

With 2,270 grains, its ductility was $\frac{2}{9} 0$ ths of an inch, and elasticity entire; with 3,820 grains its ductility was $\frac{3}{9} 0$ ths of an inch, and elasticity entire; with 4,029 grains its elasticity was $\frac{4}{9} 0$ ths of an inch, and clasticity entire; with 4,609 it broke.

The most remarkable circumstance in regard to these hairs is that, having lain in the ice for the immense period that the mammoth must have been there, has not impaired their ductility, clasticity and tenaeity more than it appears to have done. We cannot well account for the want of the buttons, sheaths and follicles upon these lairs; probably they were cut from the hille. We have no bristles or wool to examine. 
Table showing the Ductility, Elasticity and Tenacity of certain P'iles.

Hair of the head of a lady, which had laid 32 ? years in the grave,

Hair of the Sloth,

Mummy hair, from Thebes,

Ancient hair, from Pisco, Peru, " " Mexico,

President Madison's, (fallen out,)

Hair from the stomach of a Ruminant,

President Jackson's, (cut after death,

Hair of a compound Hybrid, (Hilton,

Hair of the Hon. Jno. Sergeant,

Hair of Prof. Jno K. Mitchell,

Ancient hair of a Mexican Mummy,

Hair of the Albino, Mrs. Williams,

Hair of R. Dividson, at 100 years old

Hair of the Elk,

Hair of the Grizzly Bear,

Hair of General Washington

Hair in 'T'inea Capitis

Hair of Choctaw Indian,

Hair of E. Hale, the Quaker Giant,

Another hair of the componmd Itybrid, IIillon, -

Hair of Mr. Swain,

Hair of Big-Water, Indian Chief,

German Bristle,

Hair of the Siberian Mammoth, found in Siberia,

Elephant's Beard,

Russian Bristle,

spine of the Pecary,

\begin{tabular}{|c|c|c|c|c|}
\hline $\begin{array}{l}\text { Weight in } \\
\text { grains. }\end{array}$ & $\begin{array}{l}\text { Duetility } \\
\text { in } 1-100 \\
\text { of an inch. }\end{array}$ & $\begin{array}{l}\text { Weight in } \\
\text { grains. }\end{array}$ & $\begin{array}{l}\text { Loss of } \\
\text { elasticity } \\
\text { in } 1-100 \text { of } \\
\text { an inch. }\end{array}$ & $\begin{array}{c}\text { Broke } \\
\text { with } \\
\text { weight in } \\
\text { grains. }\end{array}$ \\
\hline 1 & 0 & 1 & 0 & \\
\hline 240 & $\begin{array}{r}17 \\
0\end{array}$ & 240 & $\begin{array}{l}8 \\
0\end{array}$ & $\begin{array}{l}250 \\
320\end{array}$ \\
\hline 370 & 42 & 370 & 28 & 420 \\
\hline 470 & 3 & 470 & 0 & 820 \\
\hline-500 & 36 & 500 & 23 & $5: 0$ \\
\hline 573 & 8 & 473 & 3 & 673 \\
\hline 590 & 7 & 550 & 3 & 630 \\
\hline 760 & 39 & 760 & 19 & 781 \\
\hline 710 & 26 & 710 & 17. & 721 \\
\hline 813 & 37 & $81: 3$ & 25 & 8:: \\
\hline 853 & 5 & 470 & 1 & 893 \\
\hline 820 & 47 & $8: 0$ & 33 & 870 \\
\hline 973 & 45 & 973 & 25 & 1,023 \\
\hline 970 & 4 & 970 & 0 & 1,170 \\
\hline 1,070 & 10 & 1,070 & 7 & 1,120 \\
\hline 1,073 & 35 & 973 & 20 & 1,12 \\
\hline 1,020 & 55 & 1,020 & 34 & 1,07 \\
\hline 1,270 & 30 & 1,770 & 20 & 1,37 \\
\hline 1,273 & 30 & 1,273 & 13 & 1,37 \\
\hline 1,300 & .15 & 1,200 & 25 & 1.35 \\
\hline 1,473 & 47 & 1,473 & 29 & 1,57 \\
\hline 1,520 & 44 & 1,520 & 25 & 1,57 \\
\hline 1,770 & 40 & 1,770 & 24 & 1,821 \\
\hline 14,266 & 4 & 4,266 & 2 & 5,57 \\
\hline 4,300 & 2 & 4,300 & 0 & 4,50 \\
\hline 9,992 & 10 & 9,992 & 3 & 10,07 \\
\hline $14,85 \mathrm{~s}$ & 7 & 14,858 & 0 & 18,35 \\
\hline $\mathrm{J} 4,173$ & 30 & 14,173 & 18 & 14,65 \\
\hline
\end{tabular}


Description of an Instrument called a 'Trichometer, designed to measure the Ductility, Elasticity and Tenacity of Pile.-The accompanying figure represents a brass plate, 3 and $\frac{8}{10}$ inches long and $1_{\frac{7}{10}}$ wide. $A$, is an inch scale divided on the margin into parts of an inch. By means of a slide and groove this scale can be moved up and down, not exceeding one inch, the parts of which are marked on the brass plate; $B$, is a permanent clamp, and $\mathrm{C}$ a moveable one; $\mathrm{D}$, is a seprate clamp, with a hook by which the scale disk is suspended.

Modus operamli-Having ascertained the state of the barometer, thermometer and hygrometer, place one end of a hair, something more than an inch long, in the clamp $\mathrm{C}$, and the other end into clamp D; adjust, with the screw of C, until there is exactly one inch of hair from the points of clamp. D, (between which it passes,) and the jaws of clamp B; close both these clamps. Having placed the instrument in a vertical position, suspended the scale disk to the hook, and put into it as much weight as will cause the pile to stretch, note the amount, as indicated by the scale, $\dagger$ remove the weight, and ascertain to what degree the pile returns to its original length by means of its elasticity. Repeat the experiment with gradually increased

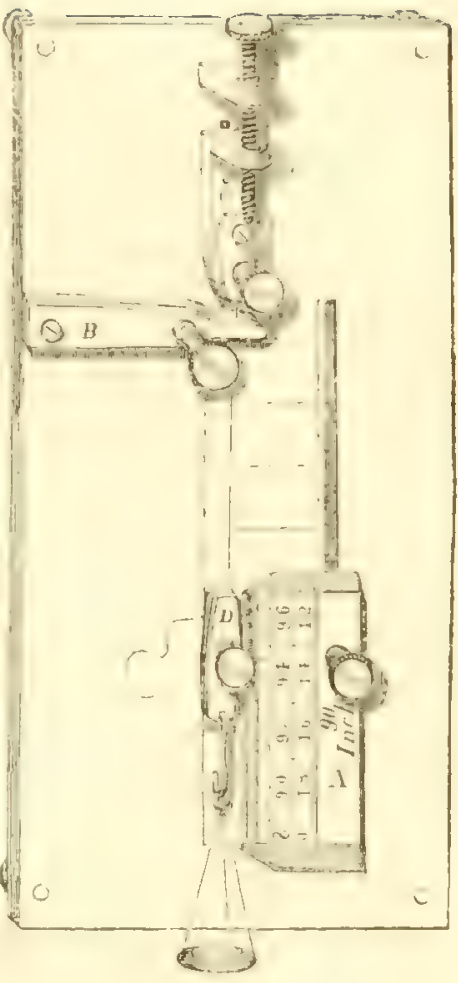
weights until the hair breaks. 'These results will show the ductility, elasticity and tenacity.

Of the Direction of Pile.-By direction we mean the conrse or path which a filament of pile pursues from the point where it pierces the epilermis to its apex. These directions are of three kinds, viz: 1st, the straight and lank; $2 d$, the flowing or curling; 3d, the crisped or frizzled, which is generally spirally curled.\$

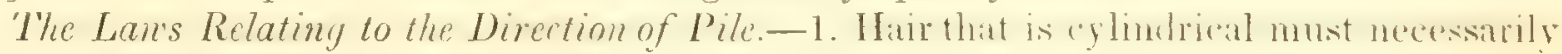
hang straightly and lankly from the head. 2. Hair that is oval must inevitably flow or curl. 3. Wont that is cecentrically elliptical must alwats be crispued or frizaled, and sometimes spirally curled.

The Reasons - Ductility and elasticity, (as before explained,) are essential properties of pile, and reside in the fibres. A hair that is cylindrical has just as many fibres, on all sides, from the centre to the periphery; and these fibres, being acted upon equally, when the hair is stretched or drawn up, the filament must necessarily stretch and draw up straightly, and the lankness be preserved. But an oval hair has a greater number of fibres on its two flattened sides than upon the ellipses; when, therefore, the stretching power is

\footnotetext{
* From "trix," a hair, and "metron," a mensurc.

† 'l'he weight of the climp I), and scale disk must be added.

+ "Lank:"-We know of no word in the Fuglish language which gives a better idea of the peculiar direction of this pile.

\& Qnery, whether crisped and frizzed pile is not spiral eurls drawn out und combul separate?
} 
exerted, it flows or curls in the direction of one of these flattened sides, in exact proportion to the eccentricity of the ellipse. An eccentrically elliptical filament of pile, being still flatter, the spiral curl is the necessary consequence.

Proofs.-Every one knows how easy it is to bend a spatula, (which is fibrous,) in the direction of either of its flattened surfaces, while his whole strength cannot make it bend in either of the contrary directions. Just so it is, (except in an inferior degree, with a flattened hair; a small degree of elastic force will cause it to flow towards one of its flattened sides, and a litule more will make it curl in the same direction; but no stretching or shrinking force ever makes it flow or curl edgenvise, or in the direction of its ellipse.

From a piece of wood, (where the fibres acting conjointly preserve the whole mass straight,) plane a thin shaving, and it will curl. It is the same force that preserves a watch-spring in a spiral curl, while an equal quantity of metal, in a cylindrical form, will be straight. Pass a cylindrical hair between rollers, flattening it, and it will flow, curl or form spiral curls in proportion to the flattening.

'The Consequences. - These laws being firmly established, we can judge of the direction of pile by its shape, and of the shape of pile by the direction.* We will recur to this subject again directly.

Of the inclination of Pile of the Head.-By the inclination of pile we mean the angle which the filament forms with the tegument from which it proceeds. This inclination does not depend upon the shape, nor upon the direction; nor does the direction depend at all upon the inclination; but it is due entirely to the angle which the root of the pile bears to the stin of the animal in which it is imbedded.

The roots of cylindrical and oval pile have an acute angle of inclination; for which reason those hairs do not grow out of the epidermis at a right angle thereto, but incline in a determinate manner; while the roots of eccentrically elliptical pile lie in the dermis perpendicularly, and hence the filaments pierce the epidermis at right angles thereto.

Of particular inclinations of Pile.-The foregoing description of the general inclination of pile of the head is governed by the following subordinate rules, viz: 1st. 'That of the anterior part of the cranium inclines obliquely in front, having a tendency to cover the forehead, and that of the posterior and inferior portions obliquely, transverse, so as to make the locks fall naturally along the posterior part of the neck; it is the same with the sides of the head, where the inclination carries this covering to the region of the ears. But these inclinations are, sometimes, partially artificially altered. Bichat ventured the opinion that these natural inclinations of the hair belong to the part of the bone which lies mendeneath; but of this we see no proof. The skull of the negro and that of the white man, are composed of the same number of pieces.

* It is true that sometimes the shrinking process of the two flattened sides alternate, when an exception, in the shape of the undulating hair is the consequenee; but generally, if the shrinking force of the fibre on one flattened side of the filament, gains the ascendaney over that of the other side, a curl in that direction is permanent; for the more the former is curved, the more foree will be reruired for its recursion, and the more the latter is stretched, the less will bo its power to return to its original cundition. 
2d. Of the inclination of the Hairs of the Body and Nemliers. Iryourastric hairs laver no determinate inclination; the hair of the navel inclines towards it; those anterior to the breasts and of the back descend; those of the neck incline upwards, while those of the members, generally, incline downwards; with the exception of those of the forearm, most of which incline towards the elbow.

Inclination of the Hair of the lower Animals.-A 'Treatise upon Milch Cows, recently published by M. Francis Guenen, wherein the quality and quantity of the milk they will give, \&c., is said to be determined by certain natural marks, contains some very curious remarks in respect to the inclination of their hair.

Tine Classification of Pile of the Head.-By the application of the foregoing laws, we will find no difficulty in separating pile of the head into three distinct classes, viz:

1. Hair that is in shape cylindrical, in direction straight and lanl, and in inclination at an acute angle.

2. Hair that is in shape oual, in direction flowing or curling, and in inclination at an acute angle.

3. Wool that is in shape eccentrically elliptical, in direction crisp or frizzled, and in inclination at a right angle.

Of the Classification of Man by tie Pile of tue Head.-Having shown that there are three distinct species of pile of the head, if we can prove that there are three portions of men who now exist, and who from time immemorial have existed, the covering of whose heads, respectively, do, and have, uniformly, corresponded with these three species of pile, there will be no difficulty in pronouncing that (judging from the pile of their heads) they belong to three distinct species of men.

1st. Of the Pile of the present American Indians.-We have, in our cabinet of national pile, the largest number and most carefully collected specimens in existence of hair of the head of the present American Indians of the pure blood, these we have examined with the utmost care and attention, and find them to be cylindrical.

2d. We invoke the aid of the law above laid down, viz: "that a hair that is cylindrical hangs straightly and lankly from the head, and that hair that hangs straightly and lankly must be cylindrical." 'This being admitted, enables us from the numerous descriptions of the American Indian hair, from the earliest discovery of this Continent, (all of which represent them as having straight, lank hair,) to pronounce that they have, for all that time, been cylindrical.

3d. Of Mound and Mummy American Indian Pile.-But we are enabled to trace this character to a much earlier date. We have, in our cabinet, the finest known collection of Anerican mound and mummy hair, to which we call particular attention, as they establish the antiquity and uniformity of this species of men.

No. 1. Examination and Description of hair and a portion of scalp from the sliull of a young American Indian, supposed to be a female of about ten years old, from Pachacamach, 'Temple of the Sun, fuve leagues from Lima, Sonth America.-I'his cemetery' has not been 
used since the Spanish Conquest, previously to which (according to Herrera) it was liept sacred for the nobles and other dignitaries of Peru. Specimen presented by Prof. S. Pancoast, M. D., of Philadelphia.

General Appearance.-Of the scalp, that of old tanned sheep skin. The hair has a dead, dry appearance. Ineneth, (natural,) about 2 inches; shates, cylindrical; diancher, $\frac{1}{36 \text { I }}$ of an inch; color, dark brown; no lustre; direction, straight; inclination, at an acute angle with the epidemis; duetility, with 470 grains one inch streteher an of an inch; elasticity, entire; tenacity, broke with 520 grains; fracture, the fibres drawn out of the cortex; button, when free, spindle-shaped, and split at the posterior extremity; sheath, none; follicle, none; the posterior termination of the hair in the scalp, chub-shaped aud black; length, $\frac{1}{2} \frac{1}{2}$; diameter, $\frac{1}{36} \overline{4}$; while the diameter of the shaft is $\frac{1}{50} \overline{0}$ of an inch; shaft, lown color; no lustre; colning matter, alparently in the cortex, in lines; intermediate fibres, white; diameter of one, $\frac{1}{15} 52$ of an inch; apex, inostly pointed; some few abrupt; no furcations; disk, of one uniform color.

No. 2. Examination and Description of hair and a small portion of scalp from a shull from Pachacamack, Peru, South America.-Specimen presented by Prof. S. G. Morton, M. D., of Philadelphia, being taken from a skull in the Academy of Natural Science, of Philadelphia.

General Appearance. - Of the scalp, of a light brown tanned sheep-skin; that of the hair, of dry, dead hair; length, (artificial,) eight inches; shape, cylindrical; diameter, 312 of an inch; color, dark brown; no luster; direction, stratight and lank; inclination, at an acute angle with the epidermis; ductility, with 170 grains one inch stretched $\frac{1}{90}$ of

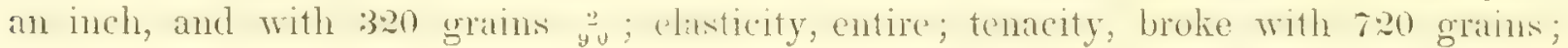
fracture, the cortex disrupted, and the fibres drawn out; button, spindle-shaped, dark colored, particularly at the proterion extremity; length, $12 ;$; dianeter, 312 ; the dianeter of the shaft being $\frac{1}{3} \frac{1}{2}$ of an inch; sheath, none; follicle, none.

(I) Iluirs imbedded in the partly decuynd Sculp - Thle postering portion of a wrown hair is spindle-shaped, with a ragged lower outline, below which is a mass of coloring matter, and under that again three or more vessels. The spindle is, in length, $\frac{1}{0}$, and diameter, $1 \frac{1}{7} ;$; that of the shaft being $\frac{1}{2} 5$ of an meh. The mass of coloring matter is of the length

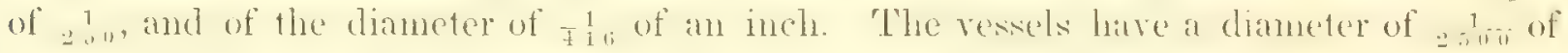
an inch. Alongside of this grown hair is a young one, which is now set in the dermis at. its posterior extremity, and free at its anterior one; but which has, between these two extremities, adhering to it, three separate pieces of decayed scalp, making it probable that, at the time of the death of this person, this hair had not pierced the epidermis. It has a diameter of only $\frac{1}{50}$ of an inch, is spindle-shaped at its posterior extremity, and is devoid of button, sheath and follicle,-the coloring matter being smaller in quantity, but located like that of the grown hair. Throughout the whole portion of scalp are spots of coloring matter, some of them too small for exact measurement.

Shaft-cortex, transversely striated, the scales easily removed by rolling the hair between two pieces of glas;; intermediate fibres, white, easily separated by crushing a hair; coloring matter in the cortex; apex, abrupt and pointed; disk, having a minute white central spot. 
No. 3. Examination and Description of hair from a shull from Arica, Peru, South America.-Specimen presented by Prof. S. G. Morton, M. D., of Philadelphia.

General Appearance, that of dead, dried, black hair; length, (artificial,) 3 inclies; shape, cylindrical; diameter, from $\frac{1}{3} \frac{1}{3}$ to $\frac{1}{3} \frac{1}{6}$ of an inch, i. e. of different filaments; color, very dark brown; no lustre; direction, straight and lank; inclination, unknown; ductility, with 420 grains one inch stretched $\frac{5}{90}$ of an inch; elasticity, minus $\frac{1}{9} \frac{1}{3}$ tenacity, broke with 470 grains; button, spindle-shaped, dark colored; length, $\frac{1}{500}$; diameter, $\frac{1}{100} \overline{0}$; while that of the shaft is $\frac{1}{50}$ of an inch; sheath, none; follicle, none; shaft-cortex, dark colored, the scales easily disengaged; intermediate fibres, white, translucent; diameter, from $\frac{1}{250}$ to $\frac{1}{1} \frac{1}{5} 5$ of an inch; easily separated by crushing the hair; apex, pointed and abrupt; one filament has a remarkable natural bifurcation; disks, uniformly colored; no central dot.

No. 4. Examination and Description of a portion of the scalp and hair from a sliull from Pisco, Peru, South America.-Specimen presented by Prof. S. G. Morton, M. D., of Philadelphia.

General Appearance.-The scalp is of a dark brown color, and resembles ancient tanned leather. It divides into layers, viz: layer immediately beneath that in which the hair is imbedeled, and that in which the hair is imbedded. The arrangement is in tufts, with interstices. Length, (artificial,) $3 \frac{1}{2}$ inches; shape, cylindrical; diameter, $\tau_{1}^{\frac{1}{16}}$ of an inch; color, dark brown, inclining to black; no lustre; direction, straight and lank; inclination, at an acute angle with the epidermis; ductility, with 370 grains one inch stretched $\frac{42}{90}$ of an inch; elasticity, with 370 grains one inch lost $\frac{2}{9} \frac{8}{0}$ of its length; tenacity, broke with 420 grains*; button, spindle, club and crook-shaped; sheath, none; follicle, none; shaft_cortex easily fractured; intermediate fibres, white, translucent; apex, abrupt and pointed; the point minute; disk, with a small central spot.

No. 5. Examination and Description of hair and portions of scalp from a slull of an Aztec, found in Mexico, North America.-Specimen presented by Prof. S. G. Morton, M. D., of Philadelphia, from a skull in the Academy of Natural Science, of Philadelphia.

General Appearance.-Of the scalp, that of dandruff; length, (artificial,) 3 inches; shape, cylindrical; diameter, $\frac{1}{6} \frac{1}{6}$ of an inch; color, dark brown; no lustre; direction, straight and lank; inclination, unknown; ductility, with 470 grains one inch stretched $\frac{3}{90}$ of an inch; elasticity-when the weight was removed, it had lost none of its elasticity;

\begin{tabular}{|c|c|c|c|}
\hline * Grains. & Stretched. & & Elasticity. \\
\hline 170 & $\frac{1}{2 \pi}$ & & entire. \\
\hline 225 & $\frac{2}{9} \delta$ & & " \\
\hline 270 & $\frac{2}{9} \frac{4}{0}$ & minus & $\frac{1}{3}{ }^{3}$ \\
\hline 320 & $\frac{37}{30}$ & $" 6$ & $\frac{2}{4} \frac{\pi}{6}$ \\
\hline 370 & $\frac{4}{3} 0$ & “ & $\frac{2}{9} 8$ \\
\hline
\end{tabular}


tenacity, broke with 820 grains; $*$ button, sometimes a mere swelling of the posterior extremity of the shaft, at others spindle or slightly hooked, and cracked at the lower extremity; sheath, none; follicle, none; shaft-cortex, friable; intermediate fibres, white; fibrils, very minute; one measured less than the $\frac{1}{500}$ of an inch; apex, pointed and abrupt; no furcations; disk, has a central white spot.

No.6. Examination and Description of hair and a portion of scalp of the skull of another Aztec, from Mexico, North America.-Specimen presented by Prof. S. G. Morton, M. D., of Philadelphia, being taken from a skull in the Academy of Natural Science, of Philadelphia.

General Appearance of the scalp, is that of dark colored, dried dirt; when rendered translucent, found to be set with hair in tufts; length, (artificial,) 1 inch; shape, cylindrical; diameter, $\frac{1}{3} \frac{1}{4}$ of an inch; color, dark brown; no lustre; button, spindle-shaped, dark colored, and divided in the centre; length, $\frac{1}{1} \frac{1}{2}$; diameter, $\frac{1}{2} \frac{1}{0}$; that of the shaft being $\frac{1}{1} \overline{5}_{5}$ of an inch; the button, of a young hair, measured in length, $\frac{1}{2} \frac{1}{2}$; in diameter, $\frac{1}{1} \frac{1}{8}$; that of the shaft being $\frac{1}{6} \frac{1}{5}$ of an inch; sheath, none; follicle, none; shaft-cortex, friable, easily removed; intermediate fibres, white; fibrils, very minute; one was less than the $\frac{1}{5000}$ of an inch; apex, pointed and abrupt; no furcation; disk, uniform color.

No. 7. Examination and Description of hair and a portion of the sca? $p$ of an ancient Indian, from a shull found in the interior of Brazit, South America.-Specimen presented by Prof. S. G. Morton, M. D., of Philadelphia.

General Appearance.-Of the scalp, that of granulated, black soil; of the pile, in tufts of coarse, black, dead hair; length, (artificial,) 5 inches; shape, cylindrical; diameter, $\frac{1}{2} 1$ of an inch; button, none-or a mere swelling of the posterior extremity of the shaft fractured; color, black; no lustre; sheath, none; follicle, none; shaft-cortex, black, opaque; direction and inclination, unknown; ductility, with 520 grains one inch stretched ii of an inch; elasticity, entire; tenacity, broke with 620 grains; intermediate fibres, discolored.

In one tuft the hairs were held together, at their posterior extremity, by small portions of decayed scalp, and a confused mass of young hairs, fibrils, vessels, and minute pieces of a feather. The diameter of the young hairs, fibrils and vessels, vary from $\frac{1}{2} \frac{1}{5} \overline{0}$ to $\frac{1}{2} \frac{1}{5} \overline{0}$, and smaller; one portion of feather measured, in length, $\frac{1}{6} \overline{1}$, and in diameter, $\frac{1}{6} \overline{5}$ of an inch.

A thin piece of scalp, which is rendered transparent, is composed of several layers of various thicknesses, and several shades of yellowish-brown color. It has, imbedded in it, young hairs, fibres, fibrils, and minute objects resembling the scales of the lepisma saccharina; one of these is in length, $\frac{1}{1} \frac{1}{2}$, and in diameter, $\frac{1}{50} \frac{1}{0}$ of an inch, and is marked longitudinally with minute parallel lines.

$\begin{array}{cc}\text { * Grains. } & \text { Stretclied. } \\ 170 & \frac{1}{90} \\ 370 & \frac{2}{90} \\ 470 & \frac{3}{9} \overline{0} \\ 820 & \text { broke }\end{array}$

Elasticity.

entire.

“"

، 
Among the hair is found a tragment of a feather, of a yellow color, and considerable lustre; in length, $\frac{2}{10}$; diameter, $\frac{1}{507}$, gradually tapering to $\frac{1}{5} \frac{1}{7}$ of an inch-the beard upon which varies in length from $\frac{1}{5} \frac{1}{5}$ to $\frac{1}{36}$ of an inch, and diameter, $-\frac{1}{3} \overline{3}$.

There is also found among the hair an insect.

Peculiarities and Affinities. - The peculiarties of this hair are its cylindrical shape, its straight and lank direction, its inclination at an acule angle to the epidermis, its coloring matter in the cortex, and as these constitute its affinities with the hair of the Choctaw, Cherokee and other tribes of existing American Indians, they determine all these nations to belong to one species, viz: "TUE CYLINDRICAL-IMALEI MAN."

From the uniformity of brown color in these six specimens, in their present fuded condition, and the black color of the seventh, it is probable that they were all originally black; like the hair of the present Indians. The want of the usual ductility, elasticity and tenacity is attributable to their partial state of decay; and their discrepancy in this respect is probably owing to the different periods that they have been inhumed. The total absence of sheath, and the distorted and disrupted state of the button, show that those parts are most liable to decay, and even the membranous intermediate fibres which are found more perfect, have parted with a portion of their essential properties by lapse of time.

The pointed apices to many of the filaments, are due to the constant supply of new hairs to make up the deficiency of those that are continually falling, and the abrupt termination of others, show that it was the practice then, as it is now, to cut the hair: 'I'he nit which is found on one of these hairs, is proof of the antiquity of the Aptera, of which they are the embryo. It is probable that the white centre, which is noticed in the disk of Nos 2,4 and 5 , is common to them all; but, being interrupted, is not seen in the rest.

Of Chinese PIL - Our collection of Chinese pile, although very respectable, is not equal to that of the American Indians; it is, however, ample for the determination that this numerous people belong to the cylindrical-haired species; and it is worthy of remark that the Chinese, in their earliest records, describe those who belong to this category by the term "le min," or "black-haired people," as contradistinguished from the "Yecchi," or foreign races with red or fair hair.

Of the Oval-Haired Spenes.-We have examined and measured countless numbers of hairs of the heads of Americans and Europeans, and have found them to be oval or ovoidal, with as few exceptions as are encountered to any other general rule in natural history. And here again, we invoke the description of the flowing and curling locks of our ancestors, with which history and poetry are overflowing.

Hair, which was the chief riches of mythology, was one of the attributes of Heathen Divinity. Phidias being asked by whom he had been inspired to make his statue of Jupiter Olympus, replied "that it was Homer;" and it requires one to be acpuainted with the poet to understand the sculptor. That terrible head of curling hair, the single movement of which made Olympus tremble.

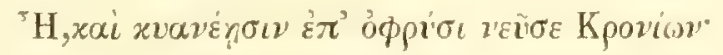

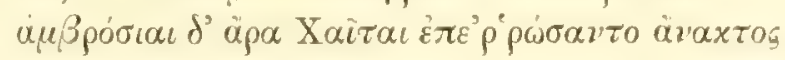

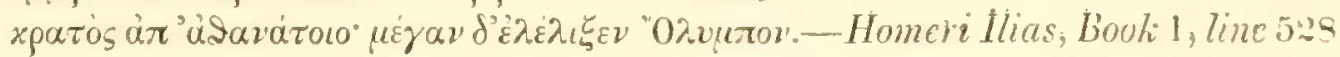


In this respect we are still heathens. What painter, even of the present day, would venture to depict the father of the gods with straight, lank hair? What poet would sing of Phobus without his long, gold-reflecting locks? We could not understand Venus without her flowing tresses, the only veil to cover her charms. Shall we deprive Isis of her portion of these fully developed integunents, or rob the muses of the name given by Simonides of "Kallikomai?" **

Achilles, who is represented as of Divine origin, and who by his beauty and audacity was almost a heathen god, is depicted as having an abundant head of hair; and when he flies, the wind agitates his brilliant golden locks, the rich curls of which seem to transform the head of the hero into a circle of glory. All these descriptions, although designed for a different purpose, are so many proofs of the antiquity of flowing, curling and consequently of oval hair.

Of Egyptian and Thebes Mummy Hair.-To which we will add that our cabinet of pile is enriched with two specimens (a male and female) of Ancient Egyptian Mummy hair, presented by Professor John K. Mitchell, M. D., of this city, and one specimen of Ancient Egyptian Mummy hair, of probably the Roman period, presented by George $R$. Gliddon, Esq., and another from the temple of Aman, at Thebes, from the same gentleman, all of which are oval. This last is worthy of being particularly described.

Examination and Description of the Hair of the head of the Mummy Got-mut-as-anch; the daughter of Got-har-as-anch, Priest and Scribe of the Sacred Signet in the Temple of Aman, at Thebes, who lived between the 21 st and 26 th dynasties, $i$. e. between the 650 and 1,000 before Christ; or about the lime of the Bubylonian captivity and the time of Solomon, say about 2,700 years ago.-This interesting lock of ancient pile contains nineteen hairs, their lengths varying from $2_{\frac{4}{10}}^{4}$ to $2 \frac{8}{10}$ of an inch. But this length must be considered as artificial, for the anterior extremities of the filaments are all abrupt; showing that her hair had been cut, probably in her lifetime; for if the length had been the natural one, that termination of some of the filaments would have been pointed. The shape of this hair is oval; the diameter, $\frac{1}{3} \frac{1}{4}$ by $\frac{1}{4} \frac{1}{16}$ of an inch; showing that the lady belonged to the oval-haired species; color, light brown; lustre, metallic; but both the color and the lustre may have been changed by time and the substances used, in embalming. This hair has no ductility nor elasticity, and its tenacity is very low, for it breaks with 320 grains! The fracture is abrupt, the fibres slightly obtruding beyond the cortex. There is not on any hair the slightest appearance of a button, sheath or follicle; all of which, being less durable than the shaft, having been destroyed by time and the materials used in cmbalming. The cortex is plainly distinguishable from the fibres, and is in diameter the $\frac{1}{5000}$ of an inch. The terminations of the fibres are dark colored and appear to occupy the whole interior of the shaft, except a central white spot. Many of the shafts are bent, some of them fractured, but none are furcated.

* Beautiful locks.

$\dagger$ A sound hair of that diameter mould have stretched $\frac{1}{5}$ of its length, and sustaincd some 800 grains. 
When artificially rendered transparent, the whole surface of the shaft is seen marked with longitudinal striæ, here and there interrupted, and of a dark color. This dry hair is easily crushed, when it becomes bright red, breaks into portions and separates into fibrils of extreme fineness.

Conclusion.-We do not apprehend that any one will deny that we have proven that the cylindrical and oval-haired species have existed for twenty-seven centuries.

Of the Eccentrically Ellipitical Species.-It might easily be supposed that in a city like Philadelphia, abounding in black faces, no difficulty would be encountered in procuring pure negro hair. It is quite the contrary, with great exertions we have becn able to obtain the following only:

1. Hair of the head of a negro, born in Congo, Africa, the manumitted slave of Colonel S. B. Davis, of Wilmington, Delaware; whom we call Congo Billy.

2. The Bushman boy from South Africa.

3. Pure negro wool, presented by Dr. Herring.

4. Pure negro wool from Wilmington, N. Carolina, presented by P. A. Marstellen, Esq., of Arrellton, Prince William County, Virginia.

5. Pure negro wool of Tom, and the same of Jenny, slaves belonging to Samucl Hodge, Little Pedee river, Marion District, South Carolina, presented by Mr. James Mullens.

6. Pure negro wool of a slave brought from Africa to Charleston, many years ago, now residing in Louisiana, presented by Dr. Marcus Taylor, of West Point, Georgia.

7. Pure African wool, presented by Dr. J. B. Baily, of Oxford, Georgia.

8 to 15. Eight specimens of pure negro wool from the Rev. Mr. Jno. S. Brooks, of Mendi Mission, Africa.

Upon a careful examination, all these have been found to be eccentrically elliptical, and to be spirally curled. We will notice more particularly some of these specimens.

1. The Bushman Boy.-The following is a description of this person from the pen of William F. Van Amringe, Esq., the author of the Natural History of Man.

"Accidentally hearing that a Bushman boy was in the Colored Orphan Asylum of New York, I visited the institution to see him. He is supposed to be about 18 years of age; but is not taller than our children of 9 or 10 , thick set, and well formed, without any indication of dwarfish peculiarities; that is, his developments are natural, not stunted. His complexion is light mullatto; eyes, deep set; cheek bones very prominent and projecting laterally; forehead low, very narrow, but not receding; comparison full, but causality deficient; caution very largely developed; combativeness full; his posterior or animal region of the skull was, I thought, disproportionably small, at which I was somewhat surprised. His pile is remarkably peculiar; each tuft on the head is perfectly isolated, exhibiting a distinct circle of yellow cuticle, or line of division from every other tuft. The tufts are remarkably small, and the hairs of each of them so ligbtly interwoven that each hair appears to be tightly drawn to a common centre."-MS.

The following brief sketch of his history is from the stme talented gentleman :

"Six years ago a trader from the Cape Colony was on an expedition in the Bushman 
Country, where he found this boy in a wretched condition; his parents having been killed by the Caffirs. He took the child with him to the Cape, and his business calling him again to the interior, he left him in charge of the American Consul. He did not return, and is supposed to have died. The Consul brought him to the United States and placed him in the Asylum. He learned to speak. English at the Cape, and he has since learned to read and write, and appears to possess at least ordinary capacity. His habits are mild and his spirit bold and fearless. His features are of an exaggerated negro type, and his chest is remarkably full and deep."-MS.

Description of the Wool of the Bushman Boy-Length, natural, when extended 1 inch $\frac{1}{10}$; shape, eccentrically elliptical; diameter, $\frac{1}{3} \frac{1}{2}$ by $\frac{1}{8} \frac{1}{5}$ of an inch, another $\frac{1}{3} \frac{1}{2}$ by $\frac{1}{9} \frac{1}{0}$ of an inch; color, black; button, sheath and follicle, had none to examine; direction very closely spirally curled; curl, $\frac{1}{2} \overline{0}$ of an inch in diameter; shaft, cortex, colored by minute longitudinal lines, the lines interrupted and the darkness of the shade depending upon their number and contiguity. Intermediate fibrous substance, white, with a white opaque or translucent ground upon which are a few minute longitudinal lines; no central canal nor central coloring matter. 'Transverse sections or disks show a continuous dark color.

The Wool of Congo Billy.-Description of the wool of a Congo negro. Specimen of a negro called Billy, the maumitted slave of Colonel Samuel B. Davis, of Wilmington, Delaware, aged 80 years, called by us Congo Billy. Length, 1 inch and $\frac{2}{10}$ when extended; shaft, eccentrically elliptical; greatest diameter, $\frac{1}{3} \frac{1}{0}$ of an inch; smallest, $\frac{1}{12} \frac{1}{50}$ of an inch; button, sheath and follicle had none to examine; spirally curled; color, black; shaft-cortex, transversely striated, the coloring matter disseminated in it by means of interrupted lines of various diameters. Intermediate fibrous substance, white, translucent or semi-transparent, the fibres when separated show dark, transverse divisions. There are a very few deep red hairs, which readily divide into fibrils that are very lustrous; no central canal or central coloring matter; apex, abrupt and often furcated.

Inferences.-We have thus shown, by the pile of the head, that there are three distinct species of human beings inhabiting this globe, and whose ancestors have been its inhabitants for at least from 2,700 to 3,000 years-probably from the first creation of man. These are:-

1. The Man with cylindrical or cylindroidal hais.-This pile is straight and lank; black; generally long; pierces the epidermis at an acute angle; has the coloring matter disseminated in the cortex and fibres; the seales are few in number, rounded at their anterior extremity, and invest closely the shaft.

2. 'The Man with oval or ovoidal hair. - This pile is either flowing or curling; of many shades of color; sometimes long; pierces the epidermis at an acute angle; has the coloring matter in a central canal; and the scales few in number, rounded at the anterior extremity, and invest the shaft closely.

3. The Man with eccentrically elliptical or ellip/oidal wool.-This pile is crisped and frizzled, and sometimes spirally curled; black; short; pierces the epidermis at right angles; has the coloring matter disseminated in the cortex and fibres, and the scales nume- 
rous; sharp at the anterior extremity; and not investing so closely the shaft. (See title page.)

Of Hrinios.-A hybrid is an animal whose parents, respectively, belong to different species; and if we have succeded in showing that in the human family there are three distinct species, it follows that, by the union of any two or more of them, a hybrid will be produced.

Of the division of Hybrids.-Hybrids are divisible into two classes, viz:-

Simple, being the product of the crossing of two of the three species only, and

Compound, being the product of the crossings of the three species.

Of the nomenclature of IIybrids. - The following tables of nomenclature relate to simple hybrids.

A, No. 1, shows the crossings of the two species, white and black.

A, No. 2, shows the crossings of black and Indian.

A, No. 3, shows the crossings of Indian and white.

A, No. 4, contains, in a condensed form, all that is contamed in Nos. 1, 2 and 3.

We preserve the names "whịte," "black" and "Indian," because they are short and familiar, giving notice that by white, we mean the oval-haired species; by black, the eccentrically elliptical-piled species; and by "Indian," the cylindrical-haired species.

By the term "mullatin," we distinguish all the mixtures of white and black; by "costin," all the mixtures of black and Indian; and by "mestisin," all the mixtures of Indian and white.

By the prefixes to be found in the third column, we distinguish the mixtures of the species, showing the degree of amalgamation; hepta, (from epta, seven,) being a mixture of seven; hexa, (from ex, six, being a mixture of six; penta, (from penta, five, being a mixture of five; tetra, (four,) being a mixture of four; tria, (from treis, three,) being a mixture of three; di, (from dis, two-fold,) being a mixture of two; and mono, (from monos, single, representing one.

The dots (...) on the lines and within brackets in the first column of table $A$, No. 4, represent the degree of mixture, whilst the termination of the brackets show the original sources. *

Examples._- "Hepta-Mulattin" is a two-fold mixture, only of white and black, in the proportions of $\frac{1}{1} \frac{4}{1}$ of the former, and $\frac{2}{16}$ of the latter.

"Hexa costin" is a two-fold mixture, only of black and Indian, in the proportions of $\frac{12}{16}$ of the former, and $\frac{4}{16}$ of the latter.

"Penta mestisin" is a two-fold mixture only, of Indian and white; in the proportions of $\frac{x}{1} \frac{0}{6}$ of the former, and $\frac{6}{16}$ of the latter.

* These tables may be adapted to express the crossings of animals inferior to man; proper names leing substituted. 17 
TABLE A, No. 1.

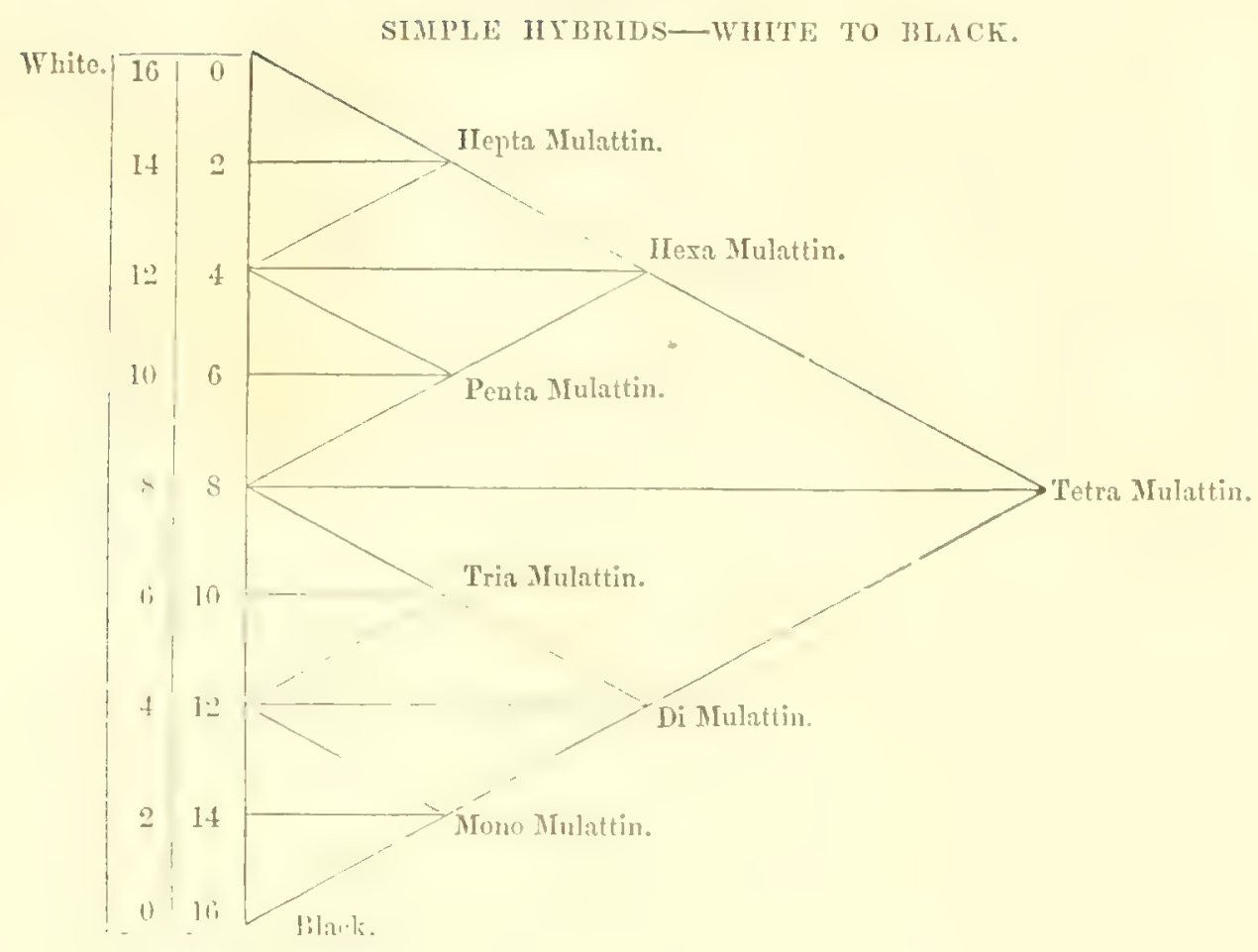

TABLE A, No. 2. SIVIPLE HYBRIDS-BLACK TO IXIDIAN.

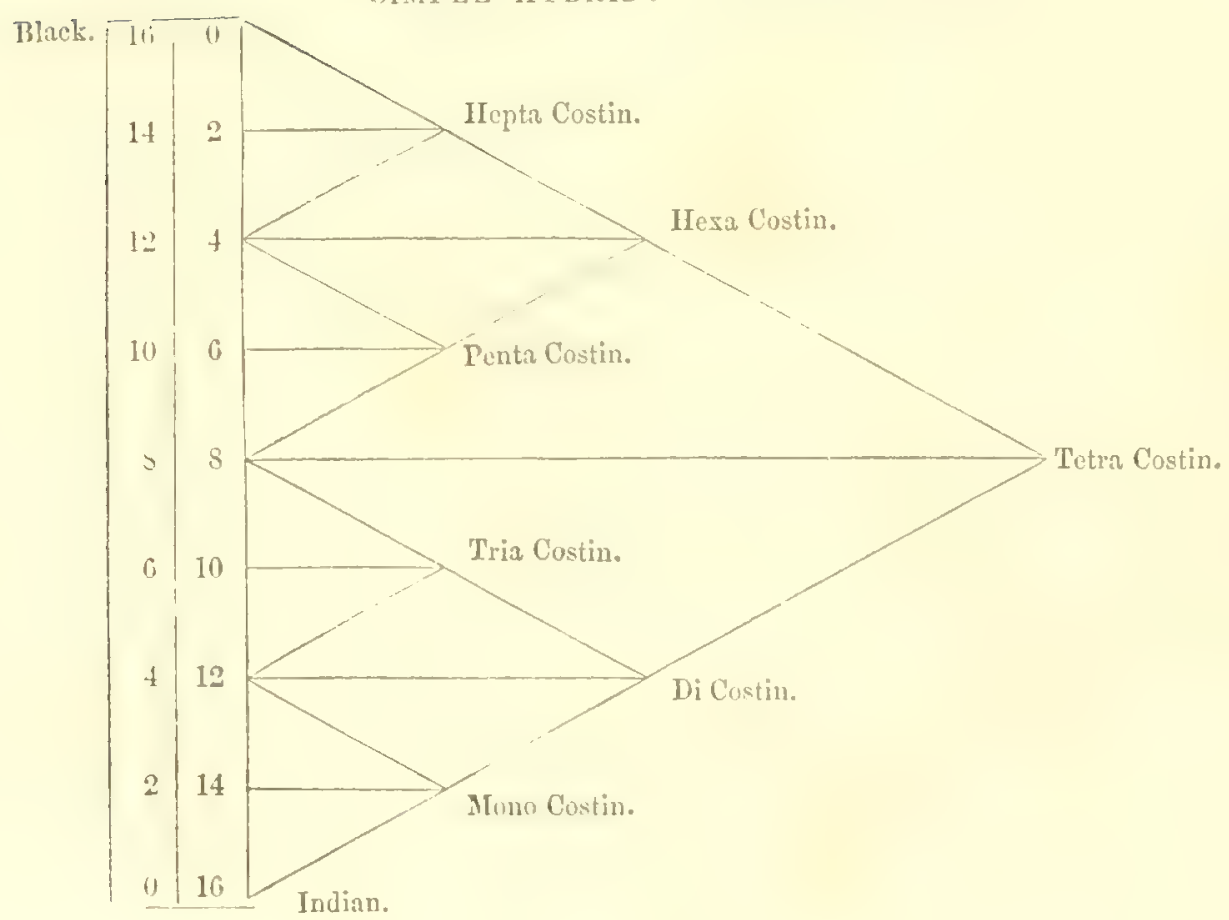


TABLE A, No. 3.

SIMPLE HYBRIDS-INDIAN TO WIITE.

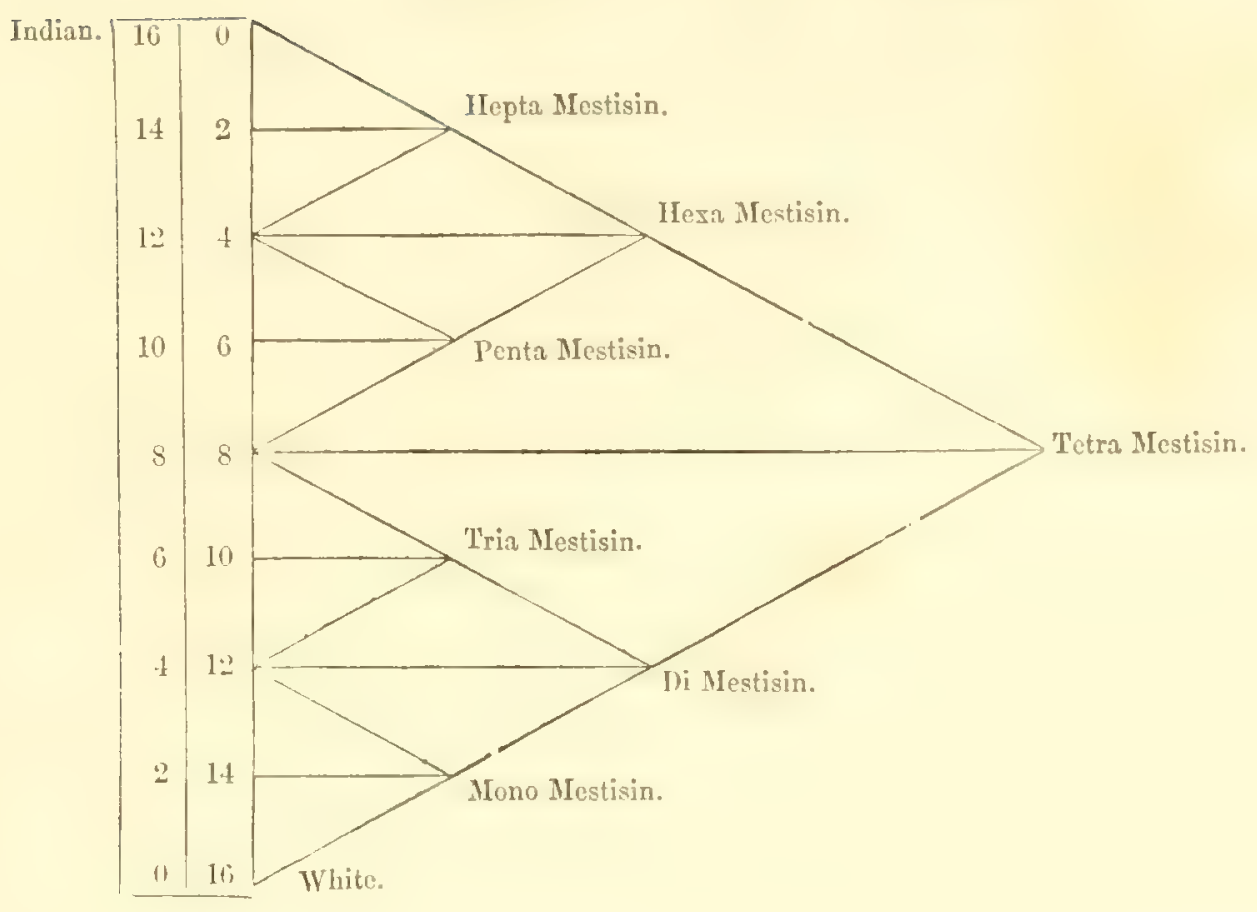

'TABLE A, No. 4.

Being a condensed table of Simple Hybrids, viz:-white, black and Indian; showing the various crossings of which any two of them, only, are susceptible.

It includes Tables A, Nos. 1, 2 and 3.

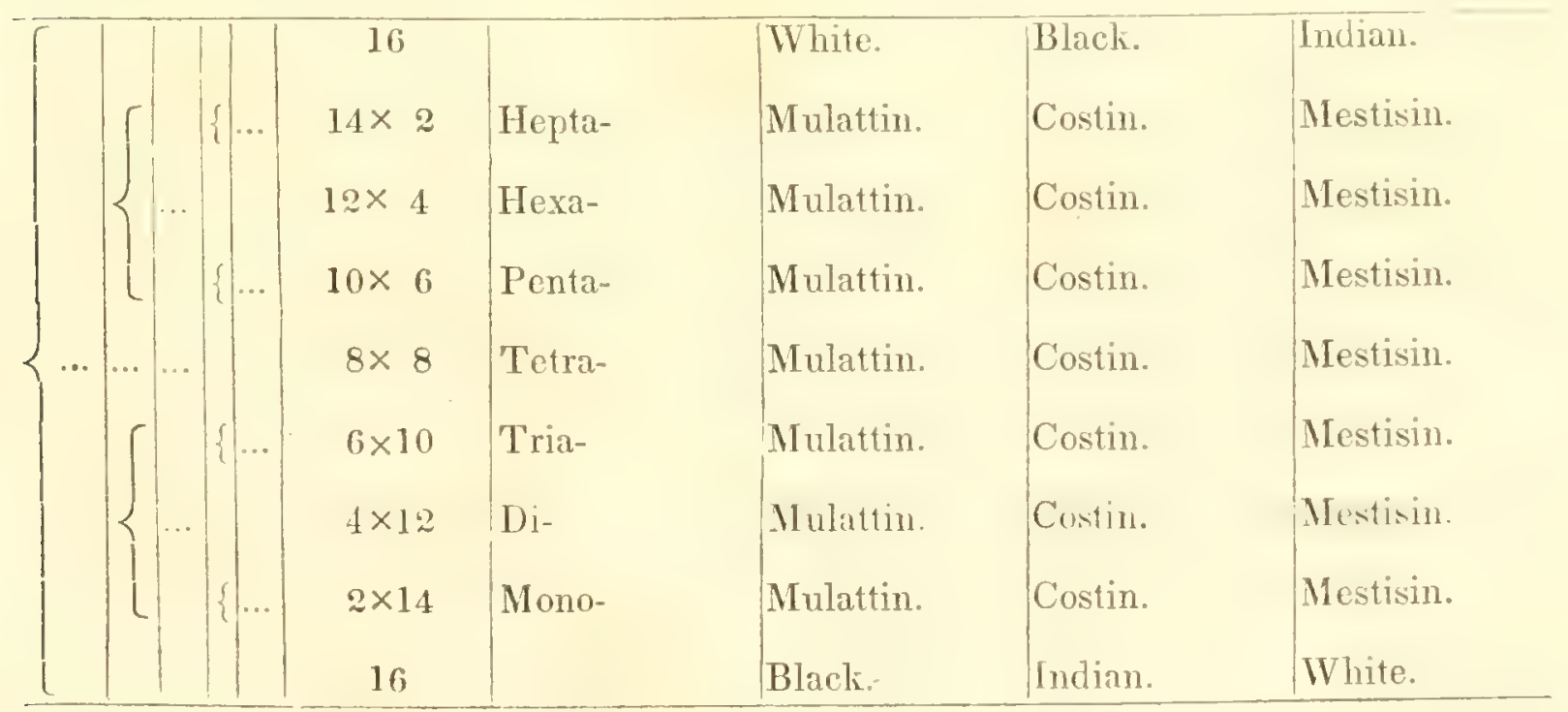


TABLE B, No. 1. COMPOUND HYBRIDS-WHITE TO TETRA-IIUATTIN.

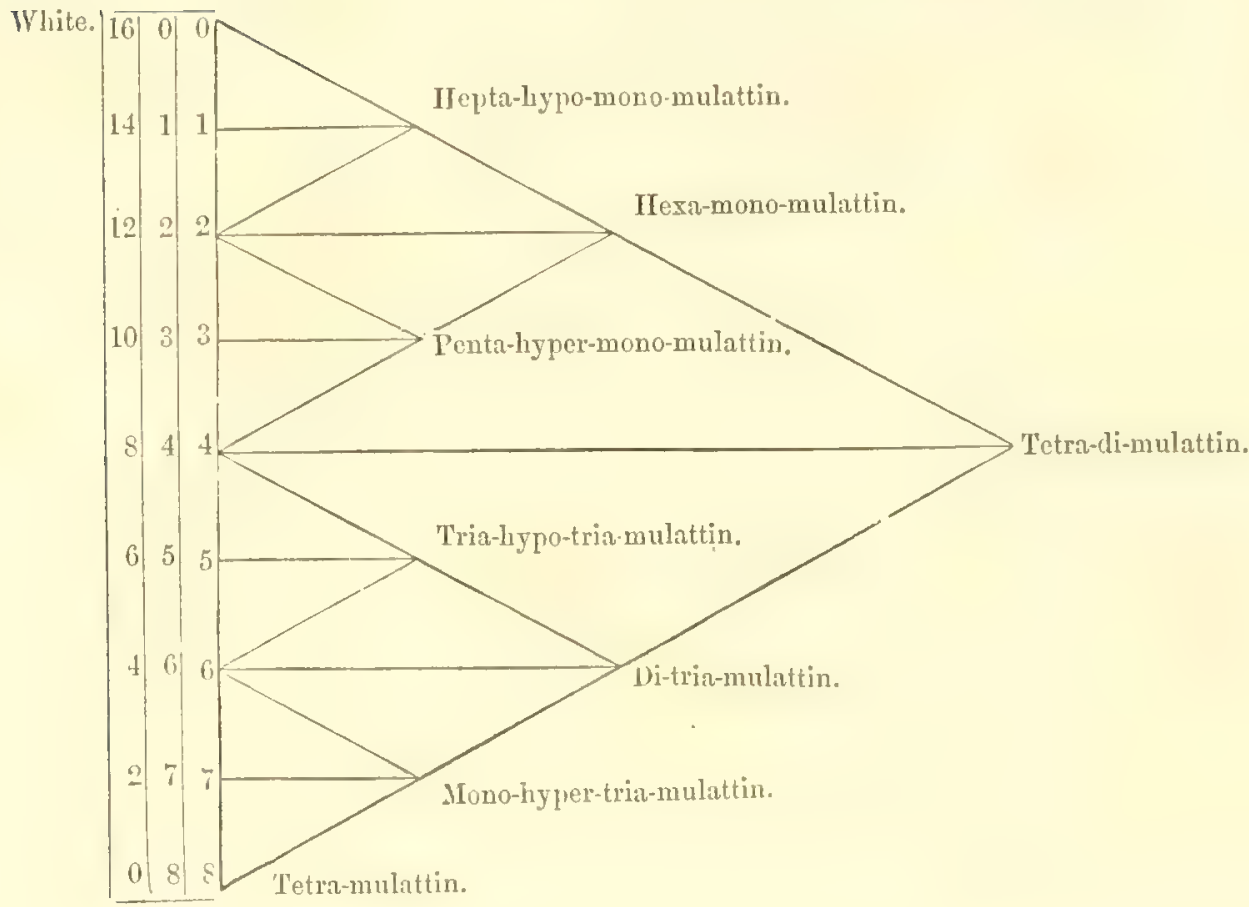

TABLE B, No. 2.

COMPOUND HYBRIDS-WHITE TO TE'TRA-COSIIN.

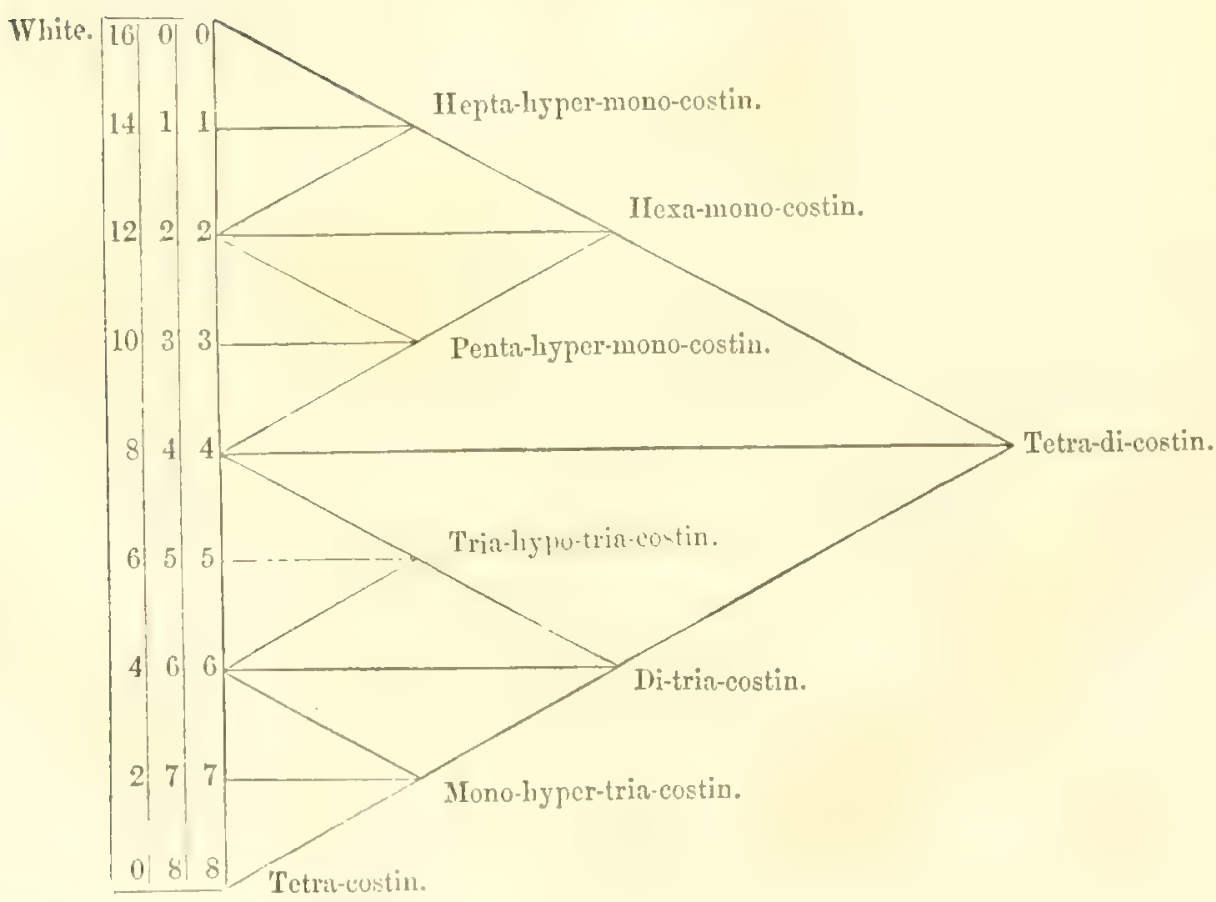


T'ABLE B, No. 3.

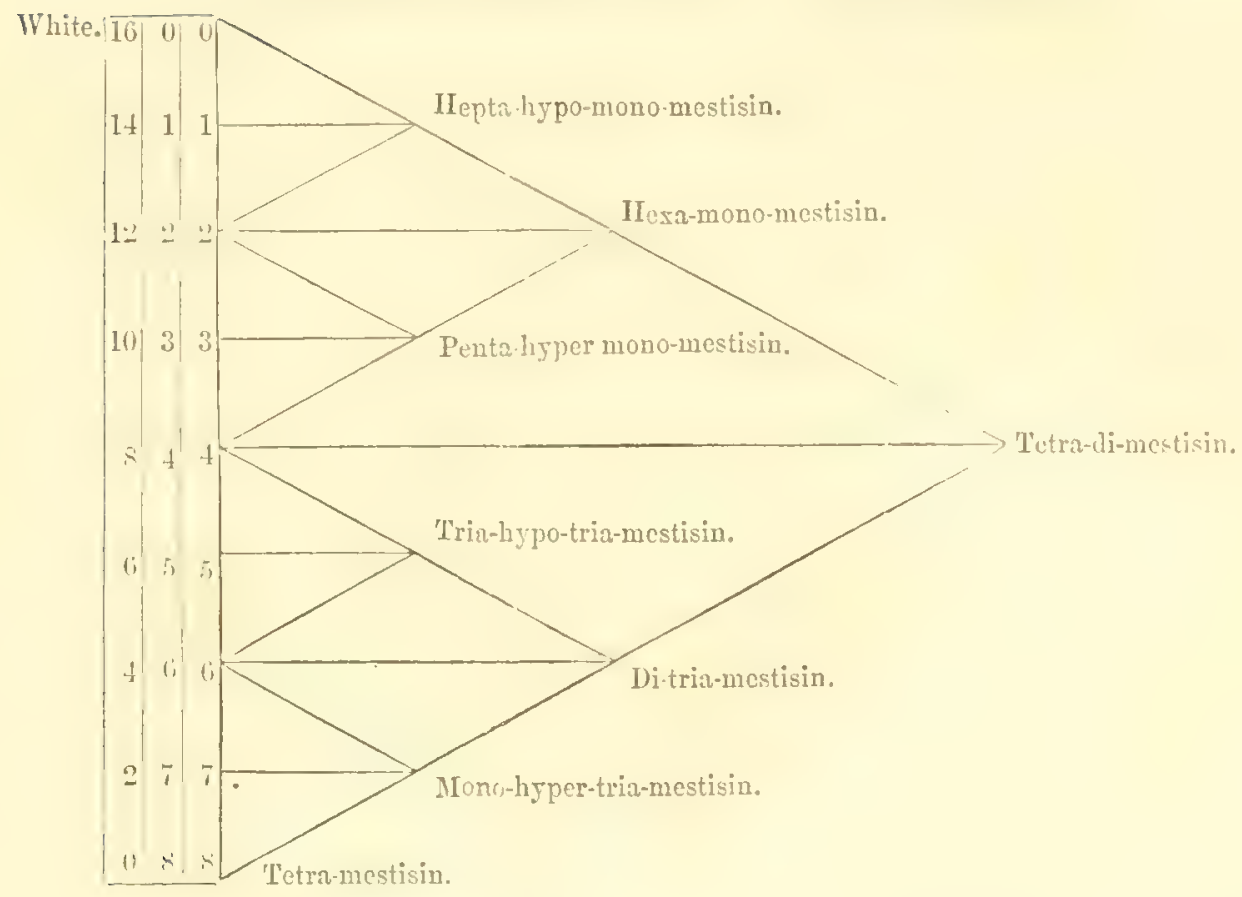

TABLE B, No. 4.

Condensed table of Compound Hybrids, showine the crossings of the three species, fiom white, Indian and black, respectively, to tetra-costin, tetra-mulattin and tetra-mestisin, respectively.

Note.-This table includes Tables B, Nos. 1, 2 and 3.

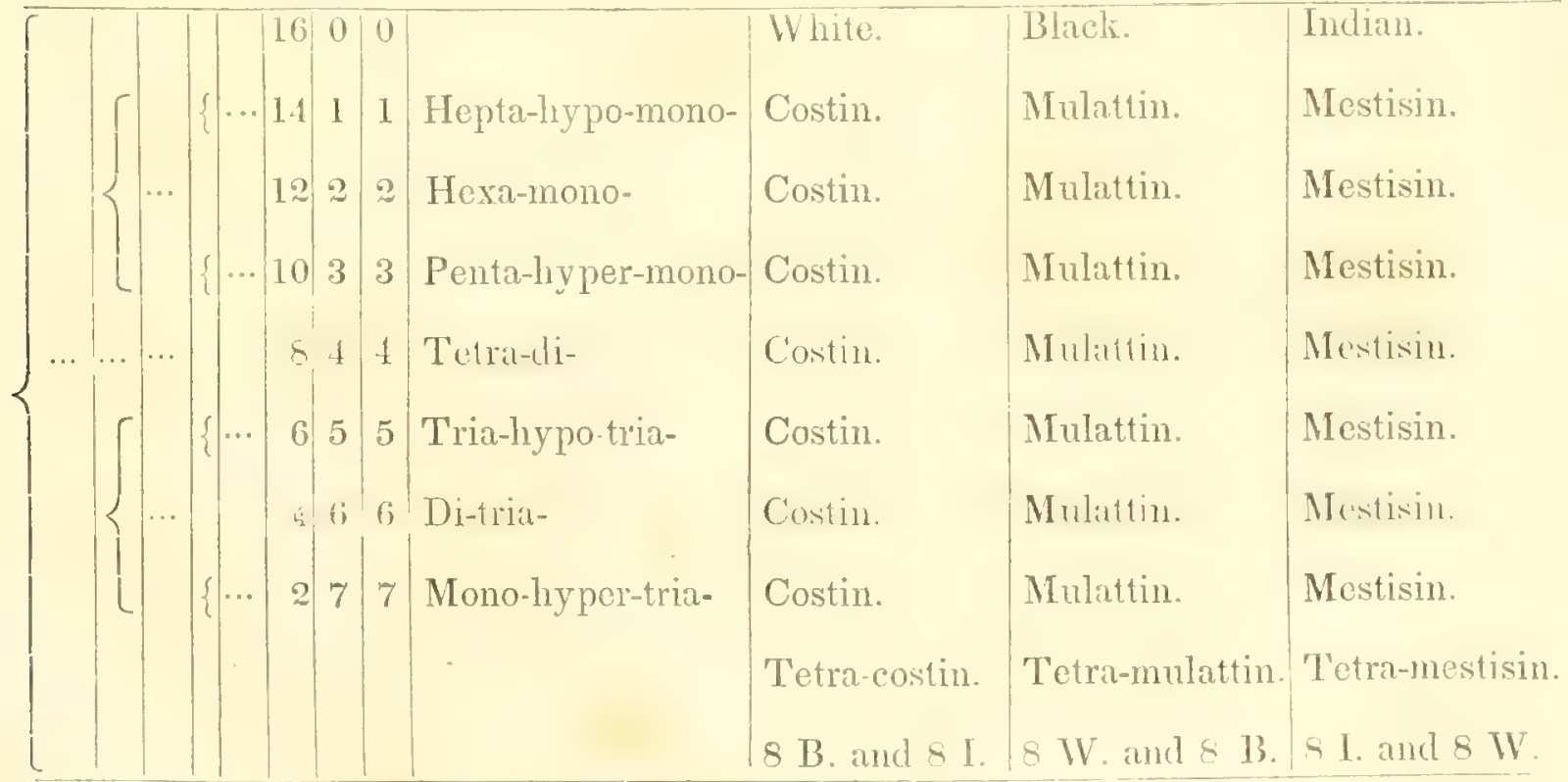


TABLE C.

Continuation of the condensed table of Compound Hybrids, showing all the crossings from tetra-costin, tetra-mulattin and tetra-mestisin.

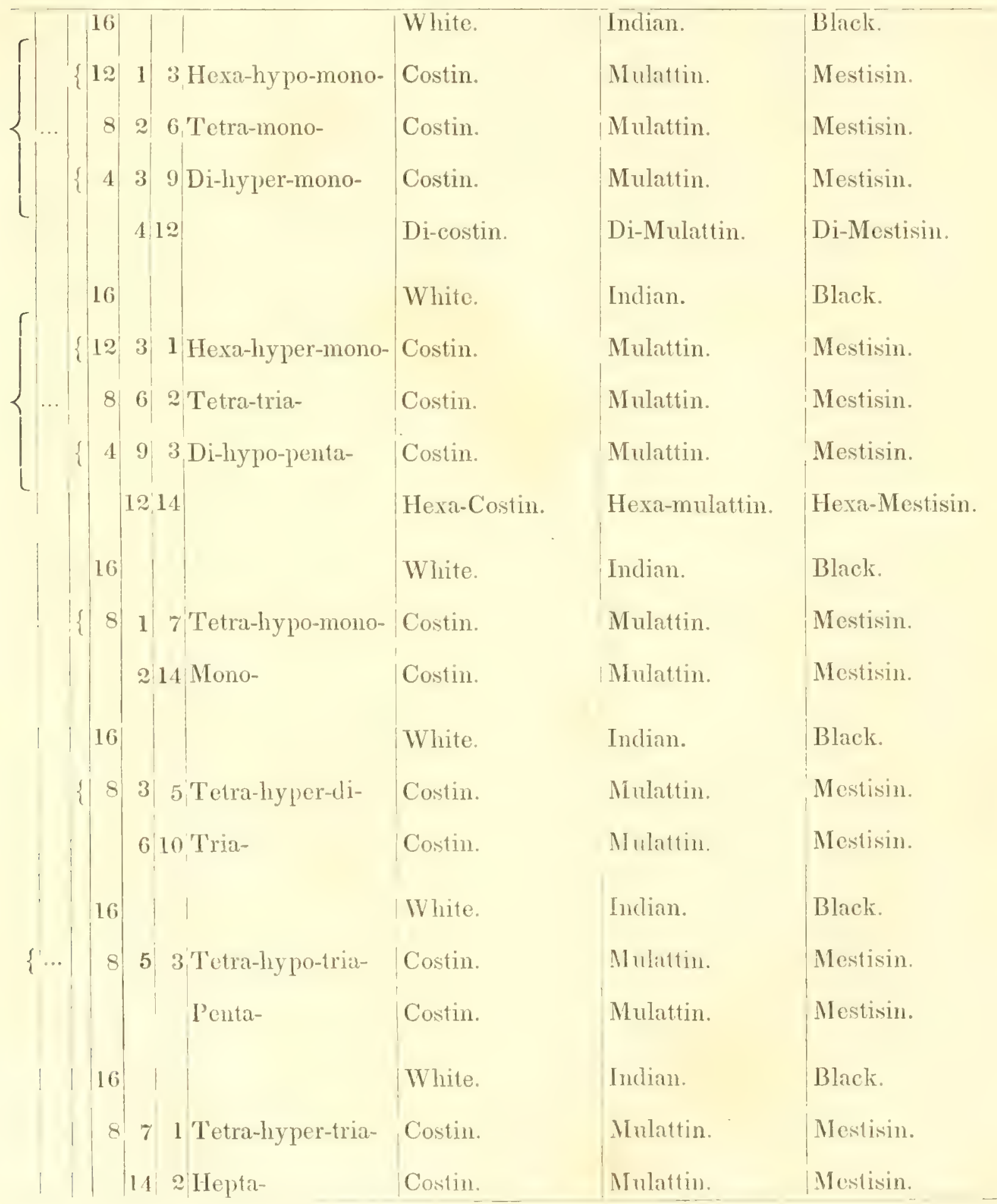


Note to Tables B, Nos. 1, 2, 3 and 4-All the terms used in these tables, which were previously used in Tables $\boldsymbol{A}$, have the meaning already explained.

h

The word "hypo" (from upo, under,) and hyper (from uper, above, are necessarily introduced into these tables, as they are based upon a division into 16 parts of blood; these words bringing 8 parts into 16 th.

The whole nomenclature has been fornded upon a division of eight, because it is not often desirable, or even practicable, to carry the division further.

Examples._"Tetra-di-costin." The tetra means $\frac{4}{8}$ or $\frac{8}{16}$; the di means $\frac{2}{8}$ or $\frac{4}{16}$, making together, $\frac{12}{16}$, the complement of which is, necessarily, $\frac{4}{16}$, which, therefore, need not be expressed.

Now, as "costin" means black and Indian, (not Indian and black, ) the "di," (i. e., the $\frac{2}{8}$ or $\frac{4}{16}$, ) must refer to the black portions; the term "tetra," (i. e., the $\frac{4}{8}$ or $\frac{8}{16}$, ) refers to the race mixed with the costin, and as this is bluck $x$ Inclian, the "tetra-di-costin" is a triple race in the proportions of $8 \times 4 \times 4 ; \mathrm{i}, \mathrm{e}, 8$ white, 4 black and 4 Indian.

Note to 'Table C.-All the terms used in this table have already been explained, and are used in the same senses.

There is an advantage obtained by making each species primary in its turn, as is done in all these tables; for example, take the name "hexa-hypo mono," which is a mixture of three species in the proportion of $12 \times 1 \times 3$, counting in 8 ths; the $\frac{12}{16}$ reads "hexa," the $\frac{1}{16}$, (being made from $\frac{2}{8}$ or "mono,") preceded by "hypo," indicating that it is less than $\frac{1}{4}$, that is to say, $\frac{1}{16}$, and the whole making "hexa-hypo-mono-costin." But if the order was from white to black, and also, from white to Tudian, the third number would have to be indicated; and then, instead of the word "hexa-hypo-mono," now used, it would be necessary to write "hexa-hypo-mono-hypo-mono," which would be unwieldy.

It is believed that the tables, as now presented, indicate all the shades in a distinct manner; and although some of the names may, at the first view, appear to be long, it is submitted that the sime complicated idea cannot be expressed in any shorter mamner.

The Covering of the Heads of Hybrids.-The pile of the head of human hybrids does not exhibit one uniform new variety, varying from that of both parents; but generally, perfect filaments which resemble that of the one parent, and other perfect filaments which resemble that of the other parent; for example, the progeny of a white and a black will have some perfect oval hairs, and some perfect eccentrically elliptical wool; so the progeny of a white and an Indian will have some perfect oval hairs and some perfect cylindrical hairs, and the progeny of an Indian and a black will have some perfect cylindrical hair, and some perfect eccentrically elliptical wool; and, even further, one who has in his veins the blood of all these species will generally have in his head pile belouging to all three. Sometimes, however, where the constitutional energy of one parent outweighs that of the other, only one species of pile will be found. 
This is in accordance with the general laws of hybridism, where the offsprings sometimes hold an imperfect intermediate place between both species, and at others they preponderate to one side. Where the progeny hold an intermediate place and they are bred together only, they gradually become less and less capable of reproduction, and after a few generations the race runs out. Where the constitutional energy of one parent outweighs that of the other, or the progeny is bred towards one side only, they pass over to that side, and the race becomes apparently extinct.

Some Examples of the Hair of the Head of Hybrids, belonging to our Cabinet of Pite:-

1. Of simple Hylrids.

Variety 1. Mixture of white and black.

1. 'The hair of the head of a jerion represented to be an crual mixture of hlack and white, 米 some $\frac{1}{3} \frac{1}{2}$ by $\frac{1}{190}$, others $\frac{1}{3} \frac{1}{16}$ by $\frac{1}{5} 2$.

Variety 2. Mixture of black and Indian.

1. The hair of the head of Bartola, the female Aztec dwarf, exhibited in New York, in February, 1552.† Specimen presented by Messis. Kettel \& Moore, of New York. Dianneters of some hairs, $\frac{1}{40}$, others $\frac{1}{2} \frac{1}{7}$ by $\frac{1}{5}$.

Variety 3. Indian and white.

Hair of the head of Lucy Chote, aged 11, Creek American Indian and white. $\$$ Specimen presented by the liev. R. M. Loughridge, of Tallahassee. Diameters of some hairs, $\frac{1}{1} \frac{1}{6}$, and others $\frac{1}{3} \frac{1}{6}$ by $\frac{1}{2} \overline{5}$

2. Compound Hybrids.

1. Hair of the head of William Hinten, late hair-dresser, of Philadelphia, whose father was white, and whose mother was the progeny of an Indian and negress. \$ Specimen presented by himself. Diameters of some hairs, $\frac{1}{3} \frac{1}{2}$, others $\frac{1}{2} \frac{1}{1}$ by $\frac{1}{1} \frac{1}{6}$, and others still ¿ $\frac{1}{5} 0$ by $\frac{1}{50}$.

2. Hair of the head of Tuh-duh-guh-mak-ke, a male Ottawa Indian, mixture with negro and white. Fipecinen presented hy he Rer. P. Dongherty, of Grand Travere, Michi-

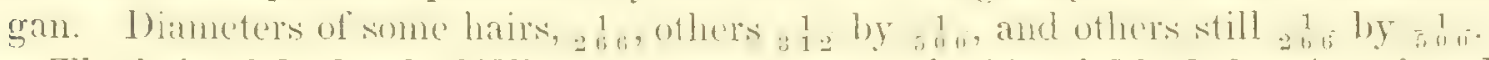

The hair of the head of Ellen Perryman, who is $\frac{1}{2}$ white, $\frac{1}{ \pm}$ Muskokee American Indian, and $\frac{1}{4}$ black. Specimen presented by the same. Diameters of some hairs, $\frac{1}{1} \frac{1}{6}$, others $\pm \frac{1}{1} \frac{1}{6}$ by $\frac{1}{3} \frac{1}{2}$, and others still $\frac{1}{5} \frac{1}{0}$ by $\frac{1}{3} \frac{1}{5}$.

Prue of Compound Hrbrins. Examination of the Hair of the Head of the Compound Ilybrid, the late William Hinten, Hair-dresser, of Philadelphia.-His grandfather was an Indian of nation, his grandmother was a negress and his father was a white man. Length, from 2 inches to 2 inches $\frac{2}{10}$; shapes, some oval, others cylindrical, and others still eccentrically elliptical; diameters, $\frac{1}{3} \frac{1}{3}-\frac{1}{8}-\frac{1}{4}+\frac{1}{16}-\frac{1}{2} \times_{5} \frac{1}{60}$ of an inch; directions, straight, undulated and curled; button, sheath and follicle had none to examine; colors, black, red and white (colorless); coloring matter, sometimes in the cortex, formed by means of minute gamphos, broken dark colored lines, which are divided 
transversely by lines still darker; intermediate fibres, slightly colored; a coloring matter also at other times in the centre, interrupted.

Trial with the Trichometer of one inch of an Oval Hair, April 1st, 1819.

With 270 grains it stretched $\frac{1}{90}$ of an inch, elisticity entire.

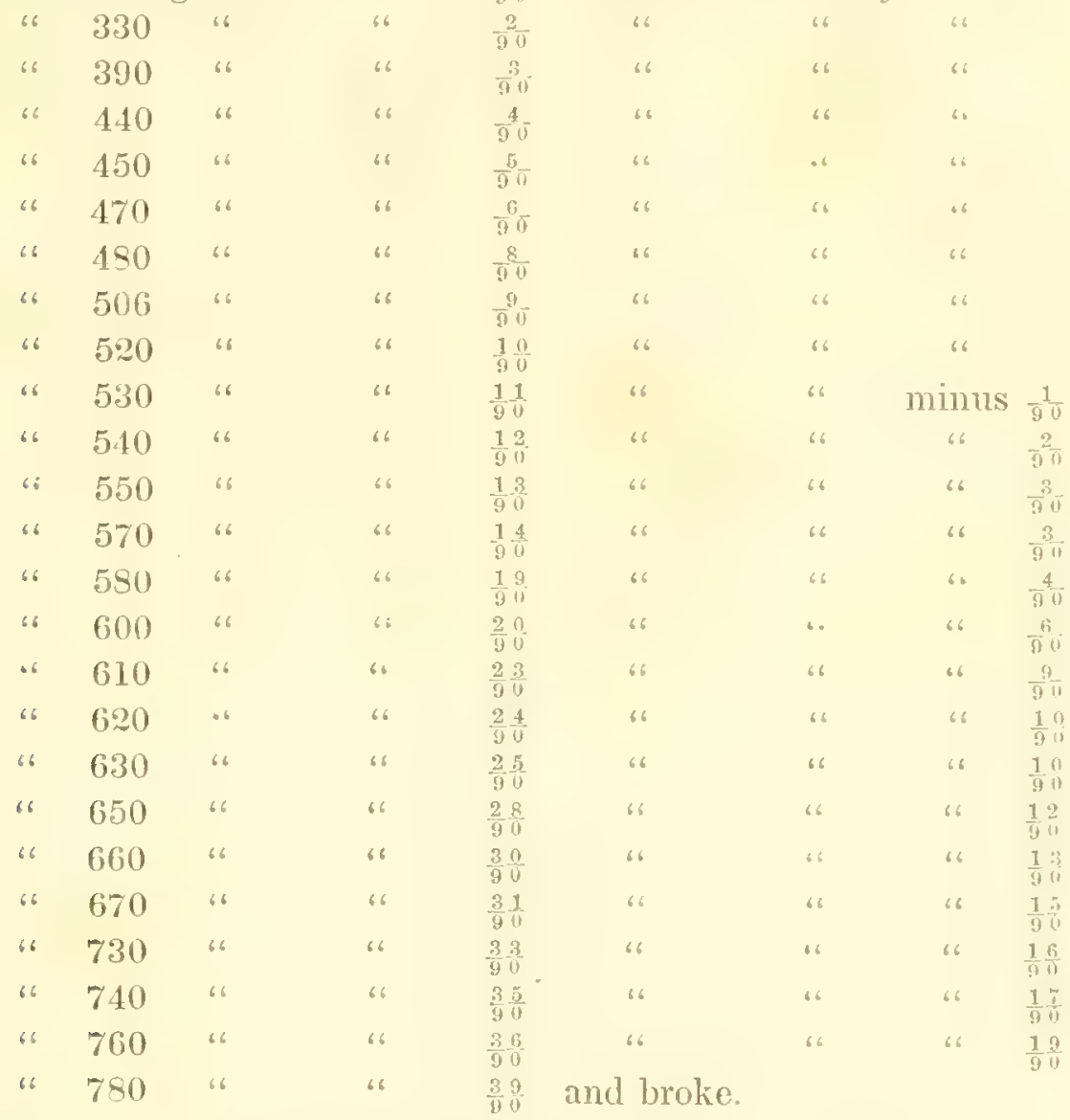

Fracture fibrous.

One inch of another hair from this specimen, which was cylindrical, was tried with the Trichometer immediately afterwards, with the following result:

With 100 grains it stretched $\frac{1}{90}$ of an inch, clasticity entire.

19

\begin{tabular}{|c|c|}
\hline 66 & 300 \\
\hline 66 & 400 \\
\hline 66 & 550 \\
\hline ، & 650 \\
\hline "6 & 700 \\
\hline$" 6$ & 750 \\
\hline 16 & $\$ 00$ \\
\hline 6 & 850 \\
\hline 16 & 900 \\
\hline
\end{tabular}




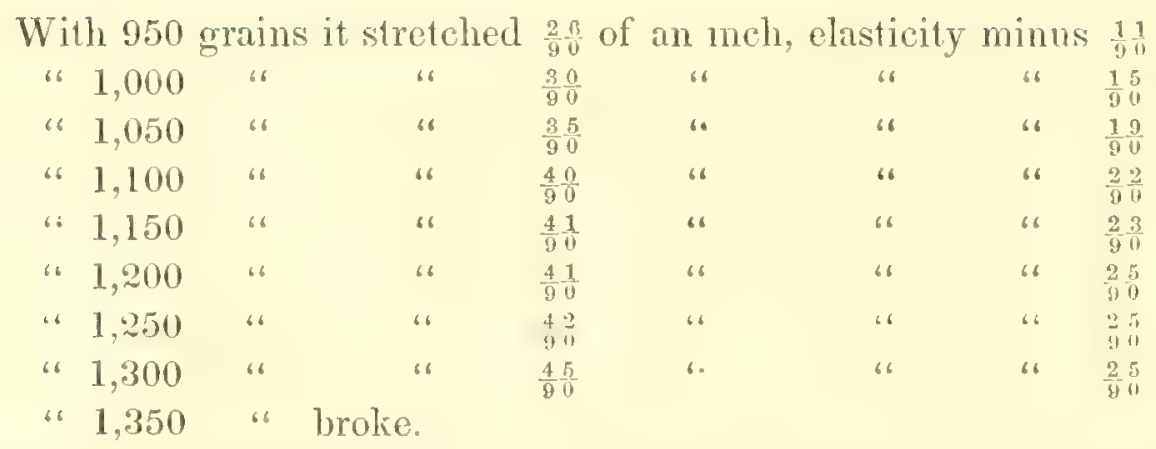

The peculiarity of these hairs is, that they separately partake of the characters of the three classes. The oval shape, the curled direction and central coloring matter, of the first class; the cylindrical shape, straight direction, and colored cortex, of the second class, and the undulated direction, black and red mixture of colors and colored fibres, of the third class. The very great discrepancy in their ductility, elasticity and tenacity is also very striking, as will be seen by the two above tables.

Of the Classification of the Lower Animals by thcir Plle.-We have a considerable amount of matter upon this subject, collected, but have not here room for its insertion.(See titles "Button," and "Coloring Matter.") 


\section{CHAPTER I V.}

OF THE COIOR of PIIE.-On the head of man there are various tints and shades of gradation from black to brown, red, yellow and white.

Of Melanic * or Black Hair.-Dr. Prichard, who contends for the unity of mankind, describes three varieties, viz: the melanic, or black-haired, the Xanthous, or yellow-haired, and the Albino, or white-haired. But he is entirely mistaken, for black hair belongs to the cylindrical and the eccentrically elliptical-piled man, and is found with the oval-haired, $†$ and the Albino is found in two if not all three of these species. (See post.)

Of tue Original Color of Harr.-Dr. Prichard considers the Melanic the natural and original color of hair of the head of man. $\neq$

Van Amringe, in answer, justly remarks, that the departure from the natural course of birth, among negroes, is always from black to white, so that, according to this theory, the red and yellow colors of hair are unaccounted for.

Buffon, with about as much reason, contended that white was the original color of pile, which (he says) has been varied by climate, food and manmers, to yellow, rel, brown and black. Other writers have imagined that originally there was but one colored fleece on sheep, and that was black; and, strange to say, they date the multiplication of colors to the time of the experiments of Jacob upon the sheep of Laban; overlooking the obvious objection, that the promise to give the ring-straked and grizzled implies that such varieties at that time existed.

A writer in an English annual of agriculture says that he has frequently had 12 to 14 black lambs in his flock, although he never kept a black ram or ewe, from which he draws the conclusion that the original color of sheep was black, and that art alone has produced vthite wool; and he opines that were these animals turned wild they would return again to their original color. A much more reasonable conclusion is, that his sheep are hybrids, and that one ancestor, in a remote degree, was black. It is a well ascertained fact that there are at the present time wild sheep that are white. No farmer purposely plants red Indian corn (zea maize,) yet we have never seen a field of Indian corn where there were not some red spikes. It is not an uncommon oceurrence for both parcuts of the oval-haired species, to have black hair, and for one of the children to have red hair.

\footnotetext{
* From "Mclas," Wlack or dark, neuter "melan."

+ Van Amringe is of opinion that ${ }_{10}^{7}$ ths of mankind hare black pile.

F 'This is not un original idea of this gentleman.
} 
Black Hatr no Mariz of Strtengtir.-Among the last mentioned species it is generally supposed that black hair is indicative of strength; but the strongest hairs we have found are brown. It took 1,323 grains to break the hair of the head of the Quaker giant who was exhibited in this city in 1848, and 1,373 to break his wife's. The brown hair of Mr. William Swain, took 1,573 grains to break it.

Of the Variance in Color between tite Hatr and Eres of Man.-Others have supposed that, in the same species, a predisposition to madness is to be found among those who have dark hair, especially if at the same time they have light eyos. Dr. Benjamin Rush, (in Med. Enq. and Observ, upon the Diseases of the Mind,) says, "Mr. Halsam informs us that this was the case in 205 out of 265 patients in the Bethlehem Hospital. He intimates that it was possibly from their consisting chiefly of the natives of England, in whom that color of the hair is general; but the same connection between madness and dark colored hair has been discovered in the maniacs of the Pennsylvania Hospital, who consist of persons from three or four different countries, or of descendants who inherit their various physical characters. Of nearly 70 patients who were examined at my request, by Dr. Van Dyke, in our Hospital, in the year 1810, with a reference to this fact, all except one had dark colored hair. In the month of April, 1812, I requested Dr. Van Dyke to direct his inquiries more particularly to the color of the eyes in the maniacal department of our Hospital. He executed my request with great care and correctness, and discovered that 56 out of 79 of them had light eyes, of which number but six had fair haire",

Hoping to obtain some useful information upon this subject, we addressed a circular to the heads of the various Lunatic Asylums in the United States, but we have received but one answer; which we here introduce.

My Dear Sir:-

$W_{\text {estern }}$ Asyluy, Va., June 15, 1850.

Yours, without date, was received some reeks since, and not anstrered earlior because of my many cngagements. I had not considered insanity in its connection with the color of the hair and eyes, and, of course, an not prepred to express

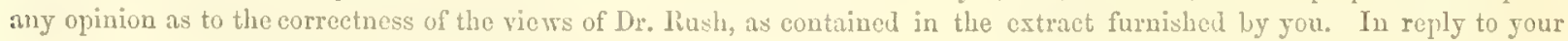
other quories I lave to answer as follows:

1. Patients now in this Institution. - _ _ _ _ _ $\quad$ - 265

But that you might lawe a larger number, from whom to derive your inferenees, I hape, in order to answer your $2 d$ and 3 dquestions, examined our register and find, that sineo the 16 th day of $\Lambda$ pril, 1816 , there have been reeeived into the Institution, (patients, )

Of these, dark hair and dark cjes, -

Dark hair and light oyes, 326

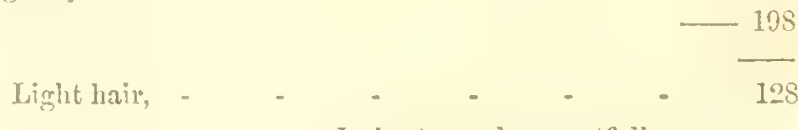

In laste, and respectfully yours,

Francis T. Stribling.

OF Brown PILE.-The English word brown, is from the Saxon, "brun," where it generally means the color produced upon the skin of a white man lyy the action of the sun. The French alio call it "brun." and define it to be. "le coleur tirans sur le noir"." 
Hair of some shades of this color is sometimes called "auburne," and at other times "chestnut." The black hair of the mound and mummy American Indians fades to brown.

Of Red Halr. - Smith, (in Nat Hist. of the Human Species, p. 288, in note, says that "red hair belongs exclusively to Northern Asia and Europe. 'This color is not much esteemed, and the number of persons belonging to the oval-haired species who have it is probably less than that of any other color.

Josephus tells us that the first man, Adam, was so called because he was made of red earth. It is quite as rational a conclusion that it was because he had red hair. Lisau, we are told, was red all over, like a hairy garment, and it is probable that he was red haired. The ancient Germans were celebrated for their red hair and blue eyes. Bichat says that the dislike to red hair is not only that it generally accompanies an unlappy temperament, but because the only humor which it exsudes is fetid.

OF YelLow Hair.-The word yellow is derived from the Belgian "ghcleuwe," where it means the color of gold. When yellow hair is very light it is called blonde or flaxen. An ancient painting found at Thebes, represents the shepherds or Hycksohos as having fair hair and blue eyes.

'The Celts, Ancient Saxons, Danes, Normans, Caledonians, and Gauls, had yellow and flaxen hair. The ancient Irish had fair hair; so had the Scots of king Malcolm's time. The prevailing color of the hair of the Northeru Russians is very fair. Penqueville speaks of the flaxen hair of the Spartan females, and of the blonde men. Blonde hair is generally (in adults) emblematic of feebleness and luxury.

OF WIITE IIIR.-There are two kinds of pile that is called "white," viz: that which" has a white coloring matter, and that which is colorless.

To the first of the above varieties belongs the pile of the Albinos, for l'Hereticr analyscel this pile, and found in it two kinds of fat, (as he calls it,) one liquid and destitute of color, and the other solid and mite, like stearine. The colorless pile is what is improperly called grey.

Of Albino Pile. - IVe have, in our cabinet, two varieties of the pile of the Albino; one of the oval-haired species, which is white with a very slight tinge of yellow; the other of the eccentrically elliptical species, which is dirty-white.

The word "Albino" was originally applied to some individuals found upon the coast of Africa, who, though descendants of negroes, are said to have had a pale, pinkey, and unnatural tint of skin, soft white pile, rose-colored iris and red pupil.* It is now extended

* "Albino." Nègre blane, Homme extrêmement blane, né de parents noir. (liuquette Dict. l'ortugais et Francais.)

"Albino." A term applied to white people begotten by a white man and a negress or mulatress. (Spauish and linglish Dictionary.)

"Albinos." Non donné par les Portugais à des hommes qui au caractère de figure de nègre joignent une hlancheur blasarde et hidieuse. (French Dictionary of the Academy, 1814.)

"Albino." Na adj. El que de padres negros ó de casta de ellos nace muy blanco y rubio. Ex nigra stirpe albus homo. Animal de pela blanco sobre piel rojiza ó blanca. Albineus.-Especie de hombres de carnes y pelo enterimente blancor, y (le vista muy debil albicolor. (Dict of the Spanish Acad.) 
to all persons of whatever nation or country who have silky, dirty or reddish-white colored pile, a pale reddish-white skin, red prupils and weak sight. The number of these individuals is not great; Van Amringe* computes that they do not exceed one in a million of the inhabitants of this earth; yet Dr. Prichard treats them as a distinct race. In his researches on the physical history of man, he divides the human family into the Melanic or blact-haired, the Xanthus or yellow-haired, and the Albino or white-haired!

No. 1. Examination and Description of the Pile of the head of the White Albino, Mary Mc Williams, aged twenty-five, born in Ireland.- Specimen presented by Dr. Klapp, of the Hennsylvania Hospital, in the city of Philadelphia, the 2d of March, 1849.

Length, (artificial, 4 inches; shape, oval, compressed, tapering; for example, a young filament, one inch long, has for its diameter, at the posterior extremity, $\frac{1}{4} \frac{1}{6}$ by $\frac{1}{2} \frac{1}{0}$, in the centre, $\frac{1}{2} 5$ by $\frac{1}{3}$, and at the apex, $\frac{1}{500}$ of an inch; color, white, with a slight tinge of yellow; lustre, considerable; direction, flowing; inclination, we had no means of ascertaining.

Ductility, Elasticity and 'T'nacity.-One inch of filament, (the Barometer being 39, the 'Thermometer being 72, and the Dew-point being 68,)

With 170 grains stretched $\frac{1}{90}$ of an inch, and when the weight was removed the elasticity was entire.

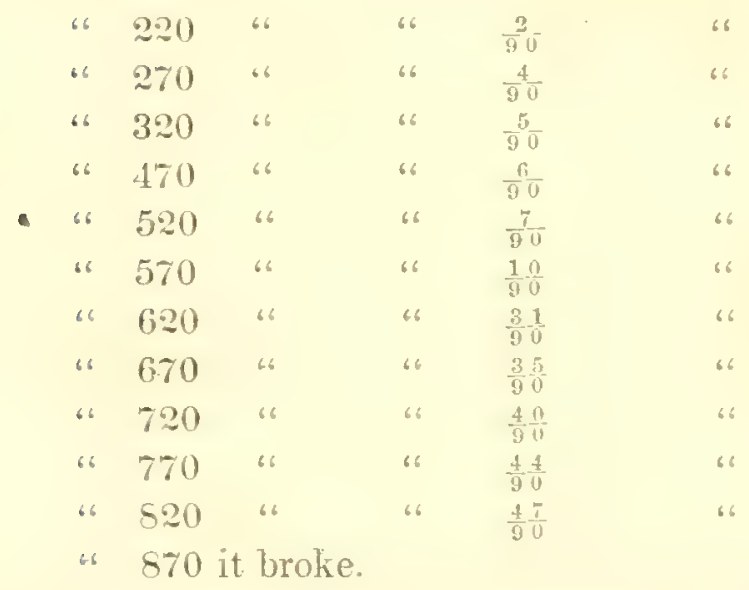

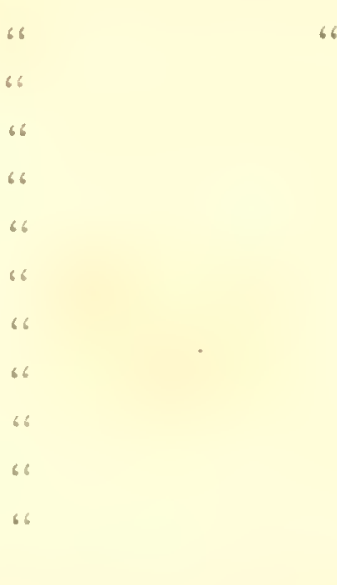

6 minus $\frac{1}{9} \overline{0}$ of an inch.

Fracture, abrupt; button, sheath and follicle, we had none to examine; shaft, uneven, bulged, flattened and sunken in different places; cortex, transversely striated the whole length of the shaft; ribbons of cortex, artificially detached from the body of the shaft, exhibit transverse divisions, the largest portion measuring $\frac{i}{2} \overline{0}$ of an inch; intermediate fibres, white, lustrous, and with a diameter of from $\frac{1}{5} 00$ to $\frac{\pi}{50} \overline{0}$ of an inch; the mass of fibres divided into sections or nodes; when the sluaft is artificially crushed, these fibres are distinctly seen; they are white, lustrous, and partially separated; but no canal or coloring matter is to be observed through the intersticest; centre, has a canal for the coloring

\footnotetext{
* In Natural History of Man, p. 71 .

†'The same experiment was tricd upon the other specimens, and the same iesults cusucd; Jut when the wool of a pure nuwro, or the black wool of sheep, was similarly treated, the piles were blect:
} 
matter, which is greenish.white, opaque and interrupted; when the cortex and intermediate fibres are artificially made transparent, the coloring matter is seen collected in spires and tangled threads of a plumbeous color, interrupted by vacant spaces in the canal; apex, very pointed-none furcated; disks or transverse sections, plumbeous colored, with sometimes a minute central speck, which is white and opaque.

No. 2. Examination and Description of the Pile of the head of the Altino of the white species, James Spencer, Esq., of Philadelphia, aged trenty-one years, nhose father had brown, and whose mother had black hair.-Specimen presented by himself, in 1819.

Length, (artificial,) 2! inches; shape, oval, $\frac{1}{1} \frac{1}{5} \overline{8}$ by $\overline{4} \frac{1}{3} \%$ of an inch; tituering; for example, a young filament, 1 inch long. measured, at its lower extremity, $\Sigma \frac{1}{i}$, in the? centre, $\frac{1}{36 \frac{1}{4}}$, and at the apex, $\frac{1}{5} \overline{0}$ of an inch; color, white, with a rery slight linge of straw color; lustre, considerable; direction, flowing.

Ductitity, Elasticity and Tenacity.-The Barometer, Thermometer and Dew-point being the same as before stated, one inch of filament

With 170 grains stretched $\frac{1}{90}$ of an inch, elasticity entire when the weight was removed.

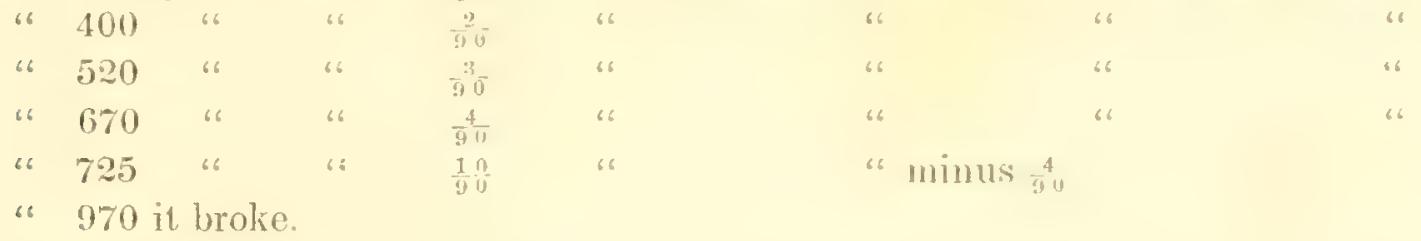

Fracture, abrupt, a small portion of the cortex being abraded; button, sheath and follicle, none; shaft, uneven, bulgred, Hattened and sunken; cortex, transwersely striated the length of the shaft, the strix numerous; intermediate fibres-having artificially removed the cortex, the intermediate fibres are exposed to view; they are divided transversely into sections or nodes, of the following lengths, riz: $\frac{1}{13}, \frac{1}{1} 5$ and $\frac{1}{50}$ of an inch; the interstices are bands which are originally white, but which, by exposure to the atmosphere, turn dark colored; central canal, upon artiticially rendering the cortex and intermediate fibres tramsparent, the coloring matter is seen consisting of portions of unequal sizes of spires or threars, of a plumbeous color; the mass has a diameter of $\frac{1}{2} \overline{5}$ of an inch, but the threads are too small for measurement; disks or transrerse sections, show a plumbeous color, either continuous or with a minute central speck.

No. 3 Examination and Description of the Pile of the head of the Albino Boy, of the black race, ten years old, both of whose parents are black._- Specimen presented by Doctor Nott, of Mobile, Alabama.

Length, (natural,) 1 inch and two-tenths; shape, eccentrically elliptical; diameter, $\Phi_{6}^{1} \overline{1}$ by $\frac{1}{62}$ of an inch; tapering; for instance, a young filament, measuring one inch and twotenths, had the following diameters, viz: at the lower extrenity, $\frac{1}{6} \frac{1}{5}$, in the centre, $\frac{1}{9} \frac{1}{5}$, and at the apex, $\frac{1}{12} \overline{5}_{0}$ of an inch; color, dirty, reddish-white; lustre, none; direction, crisped and frizzled, and spirally curled; diameter of the curls, $\frac{20}{10}$ of an inch; incluation, we had no means of ascertaining. 
Ductitity, Elasticity and Tenacity.-One inch of filament, the Barometer, 'Thermometer and Dew-point, being as above stated,

With 160 grains stretched $\frac{1}{90}$ of an inch, elasticity entire.

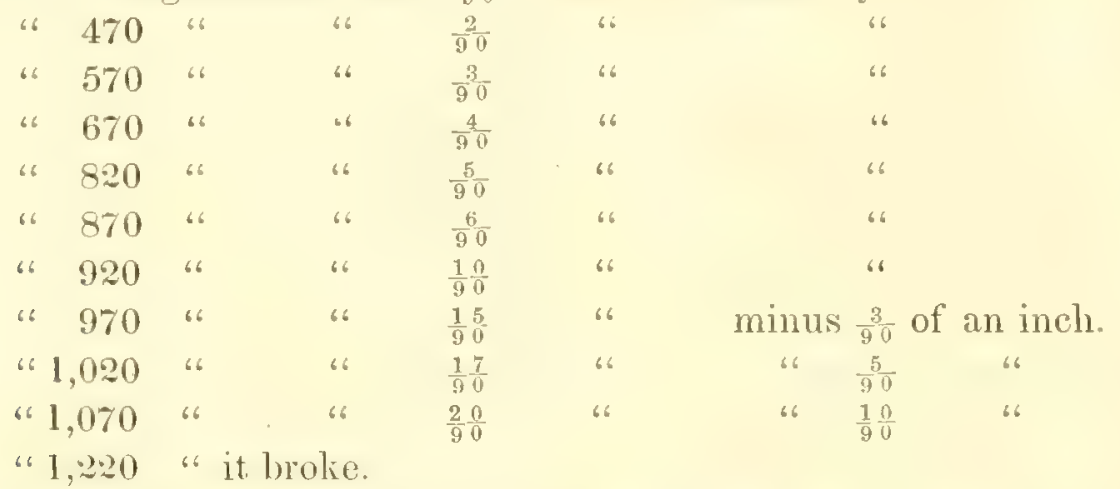

Fracture, splintery; button, hooked, knotied, and otherwise distorted; one of them, besides the main body, had two others of smaller dimensions; sheath, large, white, opaque, and sometimes divided; follicle, have none to examine; shaft, uneven, bulged, flattened and sunken; cortex, striated, striæ sometimes intersecting at right angles; intermediate fibres, white and lustrous; diameter of one of the smallest, $\frac{1}{2} \frac{1}{5} \overline{0}$ of an inch; central canal, with detached portions of plumbeous colored spires or threads of coloring matter; the greatest dimensious of a mass, $\frac{1}{250}$ of an inch; the threads too minute for measurement; apex, pointed, furcated, or bushy; disks, plumbeous color throughout.

No. 4. Examination and Description of the Pite of the Head of the Albino Boy, of the black race, of Cape May, New Jersey, aged 12 years. Specimen presented by Mrs. Garwood. His father is black and his mother a dark mulatto; they have five children, of whom three, viz: two males and a female, are Albinos, the other two are black and have negroes' wool. Length, (natural,) 2 inches and $\frac{1}{10}$; shape, eccentrically elliptical with a

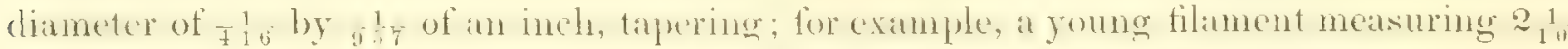

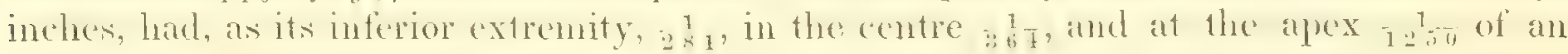
inch; color, dirty white; lustre, none; direction, frizzled and spirally curled; diameter of the curls, 10 of an inch; inclination, we have no means of ascertatining with certainty, but are informed that it is right-angled with the epidermis.

Ductitity, Elasticity and Tenacity.-One inch of filament, the Barometer, Thermometer and Dew-point being as before stated,

IVith 160 grains it stretched $\frac{1}{90}$ of an inch, elasticity entire.

\begin{tabular}{|c|c|c|c|c|c|}
\hline 220 & 66 & 66 & $\frac{2}{90}$ & 66 & 6 \\
\hline 270 & 66 & 66 & $\frac{3}{90}$ & 66 & 66 \\
\hline 370 & 66 & 66 & $\frac{4}{9}$ & 66 & 66 \\
\hline 420 & 66 & 66 & $\frac{5}{90}$ & 66 & 66 \\
\hline 470 & 66 & $"$ & $\frac{1}{9} \frac{0}{0}$ & 66 & minus \\
\hline 520 & 66 & 66 & $\frac{2}{30} 1$ & 66 & 66 \\
\hline 570 & $" 6$ & 6 & $\frac{34}{311}$ & 66 & 66 \\
\hline 620 & " & 66 & $\begin{array}{ll}4 & 0 \\
9 & 0\end{array}$ & 68 & $\cdots$ \\
\hline
\end{tabular}




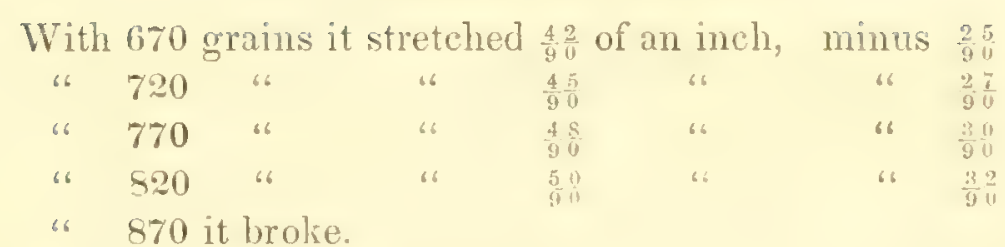

Fracture, bushy; button, sheath and follicle, have none to examine; sliaft, uneven, bulged, flattened and sunken; cortex, striated, striæ, numerous and confused; intermediate fibres, white, lustrous, diameter of one of the smallest $\frac{1}{5} 00$ of an inch; centre, a canal enclosing coloring matter which is white with a slight tinge of yellow; interrupted diameters, $\frac{1}{1} \frac{1}{8} 5$ of an inch; when the cortex and intermediate fibres are artificially made transparent, the coloring matter is seen in plumbeous masses of spires or threads; diameter of the masses, $\frac{1}{250}$ of an inch, the threads too minute for measurement; apex, very pointed; disks, plurnbeous colored with a minute light colored speck in the centre.

Albinos were, until lately, so little known in Europe, that Groldsmith describes two that he saw in London as "white negroes." He says lie found the color to be exactly like an European, the visage white and ruddy, and the lips of a proper redness; but that there were sufficient marks to convince him of its descent. The hair was white and woolly, and very unlike any thing he had before seen. The iris of the eye was yellow, inclining to red; the nose was flat, exactly resembling that of a negro; and the lips thick and prominent. No doubt therefore remained of the child having been born of negro parents; and the person who showed it had attestations to convince the most incredulous.

Whether any among the American Indiuns? - We inave no pile of an American Indian Albino, but notice that Wafer states, that he saw many of then among the native American Indians of the Isthmus of Darien. He says that they are not a distinct race, but they are descended from their copper-colored Indian parents. And in Latham, Nat. Hist. of the Varieties of Man, p. 395, it is said that many of the Luni Indians, of California, are Albinos; which he thinks is probably the origin of the report that there is a race of white Indians in that quarter.

Martin, (in Hist. of Man, p. 166, ) says that Albinos appear among all nations; they ocenr among the fairest of Europe and the darkest of Africa, in Java, Ceylon and the Continent of India. Captain Cook saw them in Tahiti, and Winterbottom mentions having seen them at Sierre Leone and the neighboring parts of the African Coast.**

Mr. Jefferson, $\uparrow$ mentioned forr cases of Albinos known to himself, and three others of whom he was informed, all of them descended from negro parents with no mixture of white blood. 'T'here are also Albinos among the lower animals. 'This pile it is our intention to examine and describe at some future day.

Inferences from Examinations.-It appears from the foregoing examinations :-1st. 'That

\footnotetext{
* Albinism is believed to be more frequent in the wooly-haired races of man: lut in the sandy plains of the North-West of Europe, the same appearances occur, though not quite with the marks of disease; it is mere absence of culoring matter in the system. Among IIongolic nations it is mknown, or very rare, and it is equally so with the aboriorial tribes of $A$ merica. (Smith's Nat. Hist. of the Human Species, 160.)

+ Nutes on Virginia, 159.
} 
the covering of the head of the Albinos is pile. Its general form, and its ductility and elasticity are sufficient to entitle it to a place in that category. 2d. That specimens No. 1 and 2 by their oval shape, flowing direction, acute inclination, and being formed of three distinct parts, (one of which is a central canal for the conveyance of coloring matter,) entitle the individual upon whom they grow, respectively, to be ranked with the ovalhaired species of men. But that the filaments gradually tapering from the inferior to the superior extremity, the unevenness of surface of the shaft, and the disposition of the coloring matter in the spires and threads, show that they are a distinct variety of that species. 3d. That specimens No. 3 and 4, by their eccentrically elliptical shape, crisped, frizzled, and spirally curled direction, and probably, by the inclination, entitle the individuals upon whose heads they grow, respectively, to be ranked with the eccentrically elliptical-haired species. But that their gradual tapering, their unevenness of surface, and the disposition of the coloring matter in a central canal, show that they are a distinct variety of that species.

The cause of the production of Albinos is unknown; but it is generally, (and we think erroneously,) attributed to imperfect generation, for the pile of the black Albino is, scientifically speaking, more perfect than the pile of the common negro, in having a distinct apparatus, viz: a central canal for the conveyance of the coloring matter.

L'Hóretier analysed the pile of the Albino, and found therein two kinds of fat, one liquid and destitute of color, and the other solid and white like stearine. (Traité. de Chem. Path.) It was, probably, the latter which we saw under the microscope.

Mr. Jefferson is of opinion that the cause which produces the Albino is more incident to the female than the male sex; but he was not acquainted with a sufficient number of cases to enable him to establish such a general rule, nor is he confirmed by succeeding observers.

Martin, (in Hist. of Man, p. 166, says, that "the constitution of the Albino is feeble." In examining the four specimens for ductility, elasticity and tenacity, we found that the filaments were possessed of a fair proportion of those properties which are considered as tests of vital strength.

This author also states, that their intellectual powers are often, if not always, of a comparative inferiority. We have no means of judging of the correctness of this remark. It is said that "Albinos breeding with Albinos produce their kind, but that where bred with the ordinary race the peculiarity disappears in the descendants; breaking out, horrever, now and then, as if the tendency lurked in the blood." (Martin, Hist. of Man, p. 166.)

Of the Cirange of Silade of Color at Puberty. - Hair of the head of the ovalhaired species is generally lighter colored in youth, than in after years; this change, probably, takes place at the period of puberty. Blonde liair becomes chestnut, chestnut turns nearly black, and red hair becomes several degrees darker shaded. The cause of this change is not known.

Of Monochromatic and Polychromatic Pile.-The hair of the head of man, before it becomes what is generally, but improperly, termed "grey," (i.e. Ioses its original color,) are con-colored; but there are occasionally exceptions. We have, in our collection, a lock from the hed of Dr. J. K. Potter, aged 28 , of Vermont, which contans four different colored 
hairs. Among the lower animals, variety in the color of pile, sometimes in difforent filaments upon the same animal, and at others exhibiting a variety of colors in the same filament, is not uncommon. The royal tiger of the cast has pile of a fawn-colored ground, striped cross-wise, with black; the jaguar has also a fawn-colored ground, but he has four ranges of black spots, in the form of eyes; the panther has sir or seven black spots; the leopard has ten rows; the guépard has small black spots; the zebra has transverse bands of blackish-brown color upon a fawn-colored ground; the conagge has the same bands, but they are confined to the shoulders and back. The silver fox has black hair, shightly tipped with white; the spines of the porcupine are black, brown and white; so are those of the pecary; the white hair of the possum and raccoon is tipped with black; the brown hair of a squirrel's tail is tipped with white, \&c., \&c. But the most extraordinary production of this kind is the golden mole, (chrysocholores,) which is said to have hair of a green color, changeable into a bronze or coppertingt. (See Eilem. de Zöol., p. 298.) We have had no opportunity of examining this pile, but conjecture that these changeable hues are occasioned by the various reflections of light from the scales of the cortex.

There appears to be much greater variety in the colors of domesticated animals than in wild ones, * and some are of opinion that, in regard to the wild ones, those which are incapable of being tamed, retain always the same color and markings.

Female domestic cats often have hai of three colors, but the males are limited to two. When an animal has two distinctly colored hairs, it is found, as a general rule, that. the darkest is above and the lightest below; but the badger (meles) is an exception, for he has grey above and black below.

\section{OF Changes in the color of PILE, at times other than puberti:}

"Can the leopard change his spots?"-Jer. 13: 23.

M. Destress reports the following singular case: "A young lady (only 13 years of age) who had never suffered except from temporary pains in the head, in the winter of 1817-18, discovered that many places on her head were becoming bald, and in six months she had not a single hair. In the month of January, 1-ls. fhere apperifed wpon the part of the scalp, which first became bald, a sort of biack wool, the rest had bromn hair. A part of this new integument fell out when it became two or three inches long; the rest changed [lost its] color, at a distance greater or less from the point, lecoming chestunt in the remaining part." The account continues with the remark that, "it was strange to sce a hair half white and half chestnut!" (Dict. des Sci. Med., v. 43, p. 502.)

The above report is too imperfect to afford much light to science. "A sort of black wool." We should have been informed what sort. It might have been domm hairs. From the arge, and a part of the new hair falling out, and the rest losing its color. we would attribute the phenomenon to the changes of puberty.

\footnotetext{
* Livingston says that the wild ones wear an unvaried uniform, with now and then such an exception as to afford a hint to man of the means of grafting a permanent change upon accidental variations. (Lisay upon Shcep.)

Van Amringe says that the California and South American wild ox and wild horse hides, hare less raricty of color than our dumestic ones.
} 
President Smith (in Essay on Man, p. 92,) tells of a negro whose skin, from a deep black, turned to a healtby white; the white color extending under the pile, where the woolly substance disappeared, and a fine, straight hair, of silky softness, succeeded. But Van Amringe thinks there must be some mistake in collecting the facts of this case; and we think that much allowance is to be made for one who was anxious to establish a favorite theory.

Of AтHipılié. - L'Héritier says, that "white or colorless hair sometimes becomes colored, which phenomenon he calls Athipitié; and that the assumed color is not always the same it was oliginally!" He says, that "sometimes this change is effected all over the scalp at the same time; at others it is progressive and gradual, as the black hair grows out from the root; so that you may see, on the same head, a hair partly white and partly colored." We have never witnessed any such phenomenon, unless he alludes to the young hairs which grow out of the skins of old heads, of the original color of the hair, and which turn white, (colorless,) commencing at the point.

Mr. Wm. H. Elsegood, of this city, sent us a lock of light brown hair, laken from his head, which he assures us grew upon a bald place from which his former grey hair fell, the skin having been stimulated by a wash of his own invention. We examined this new pile, and find it to be oval, with a diameter of $\frac{1}{4 \frac{1}{1}}$ by $\frac{1}{3} \frac{1}{1}$; sound and healthy.

OF Pile losing its color. - Hair sometimes loses its color suddenly, and at others gradually.

Of the sudden loss of colnr.-Fenchterstehen (in Med. Phy. Cho.) says, that as a special effect of grief, in excess, arises the well-known phenomenon, when the hair, more or less rapidly, turns grey. Lenhossek mentions the case of a philosopher who suddenly became grey, upon losing, by a storm at sea, an ancient manuscript which he had recently discovered. We have many instances (says Goldsmith) of persons who have grown grey in one night-time. (Hist. of Man, \&c., 33.) Bichat says that he was witness to six or seven cases where the hair turned white in less than eight days; and in one of them, an acquaintance of his, turned grey, almost entirely, in one night, owing to the receipt of bad news. It is true that Haller has expressed some doubts upon this sudden change; but we consider the testimony of Bichat as conclusive.

Several interesting cases.-Dr. Frederick A. Van Dyke, of this city, remembers a case which occurred some years ago, when a person, of rather weak mind, turned grey suddenly from fright, having been unexpectedly introduced into a dissecting chamber. We have, also, in our cabinet a lock of hair entirely white, which was cut from the head of a young lady, the rest of whose hair is chestmut colored. When she was between two and three years old, she was frightened by a boy with a mask over his face, and a lock of her hair turned white in the particular spot from which our specimen is taken. One-half of her left eye-brow, and one-half of the lashes of her left eye, underwent a similar change at the same time. The hair which has thus lost its color, has repeatedly been cut, and always sprouts out colorless. She is now 14 years of age, and her fumily, fiom whom we rcceived the information, is highly respectable and worthy of entire credit. 
We have, likewise, in our collection, a lock of white hair, taken from the head of $\mathrm{Wm}$. H. McCombe, of Lancaster county, Pa., now 15 years of age, who, three years ago, was kicked in the mouth by a horse, in consequence of which some hair on the left side of his head, above the temple, and of the size of half a dollar, turned grey in a few days. 'l'he rest of his hair remained brown.

Sometimes a sing'e white lock is found in the head without any assignable cause; the specimen of pile from the head of Mrs. - - , of Montgomery county, Pa., belongs to this category.

To these we might add the case of Her Majesty Maria Antoinette, whose beautiful blonde locks, history informs us, lost their color in one night.

The effects of Fear.-The following is quoted from the Boston. Medical and Surgical Journal, a periodical in which we should not look for a fietitious narrative, yet the story is wonderful :-

"A young man (23 years old) came from the mines to San Francisco, with the intention of soon leaving the latter place for home. On the evening of his arrival, he, with his companions, visited the gambling saloons. After watching for a time the varied fortunes of a table, supposed to be undergoing the process of 'tapping,' from the continued success of those betting against the bank, the excitement overthrew his better judgment, and he threw upon the 'seven spot' of a new deal, a bag which he said contained $\$ 1,100$, his allthe result of two years' privation and hard labos-exclaiming, with a voice trembling from intense excitement, 'My Home, or the Mines!'

"As the dealer slowly resumed the drawing of his cards, with his countenance livid from fear of the inevitable fate that seems ever attendant upon the tapping process when commenced, I turned my eyes upon the young man who had staked his whole gains upon a card; and never shall forget the impression made by his look of intense anxiety, as he watched the cards as they fell from the dealer's hands All the energies of his system seemed concentrated in the fixed gaze of his eyes, while the deadly pallor of his face bespoke the subdued action of his heart. All around seemed infected with the sympathetic powers of the spell-even the hitherto successful winners forgot their own stakes in the hazardous chance placed upon the issue of the bet. The cards are slowly told with the precision of high-wrought excitement. The seven spot wins. 'The spell is brokenreaction takes place. The winner exclaims, with a deep-drawn sigh, 'I will never gamble again,' and was carried from the room in a deep swoon, from which he did not fully recover until the next morning, and then to know that the equivalent surrendered for his gain was the color of his hair, now clianged to a perfect white."

It would seem that the frightful disease, leprossy, suddenly turns hair white. (See Levit, ch. xiii.) And the same has been said of the disease called scald-head, (Tinea capitis.) (See Dict. des Sci. Med., v. 43, p. 502.)

An Experiment.-Being desirous of ascertaining whether a sudden and violent dcath would effect this or any other change in hair, we, on the 12 th day of October, 181s; procured a lock of the hair of the head of Charles Langfeldt, the murderer; and on the 20th of the same month, immediately after his execution, by hanging: we procured another: 
these we have since examined and compared, under the microscope, but can discover no difference between them.

The cause of the sudden loss of color.-As to the manner in which colored hair becomes suddenly devoid of color, no satisfactory explanation is to be found in books. Vauquelain says "we must suppose that, in these critical moments, nature undergoes a revolution. and the natural functions are, in consequence, suspended or changed-some agent is developed in the animal economy, which, passing into the hair, decomposes the coloring matter," \&c., \&c. (See Nich. Dict. of Chem., title Hair.)

As to the cause of this phenomenon we know but little; probably, as we grow older, the vessels that convey the coloring matter become smaller and less capable of their office, and its cireulation is diminished, and finally entirely impeded.

Of the gradual loss of color in Pile.

"The glory of young men is their strength, and the beauty of old mon is the grey hend"-(Prov. 20: 20.)

Hair of the head begins to turn grey at thirty.

"Grey linirs are sprinkled upon him, lut he knoweth it not."-(Ilosea, $7: 9$. )

of the causes of turning grey.-Many causes may retard or advance it. We have a lock of hair of Robert Davidson, cut from his head the 9th of January, 1849, on which day he was one hundred years old. It is generally white, (i. e. colorless, but we find a few black hairs. We have another of a young lady, who is only thirteen; a large proportion of the filaments are brown; but there are many hairs eutirely colorless. * Jer grandmother informed us that she had grey hairs whon she was born.

Severe sickness is apt to hasten the whitening of the hair; and we have the authority of Rayner for saying, that long confinement in the dark will have the same effect. + (See Diseases of the skin.) But that light is not absolutely necessary to the existence of the blact color of hair. is shown by a lock in our collection, taken from a foetus of 9 months. It is as black as jet.

of the Indian tuming grey-Dr. J. Von Ischudi (in Travels in Peru) says, that "the hair of the head of the wild Indian is long, stiff, and of a brilliant black, (p. .90;) that some of them live to a great age, viz: 120 to 130 ; that generally they retain their teeth and hair in extreme old age, and that it is remarkable that their hair never becomes white, and very. seldom even grey." (p. 340.) "The ancient bodies, found preserved, have always the hair perfectly free from decay." (p. 352.)

We have, in our cabinet, sevcral specimens of colorless American Indian hair.

As it is upon the head of man that hair first appears, so it is there where it first loses its color; then the beard, and lastly the hypogastric hair. It is said that it commences to Inse color first at the temples-which are so called from the Latin tempus, to denote this primordial impress of lime. The last place is the lower part of the head and upper part of the neck.

Dr. Gross says that hair [the filament] turns white first at the loose [anterior]

\footnotetext{
* We possess a lock of brown hair of Mr. Wh. Duffey, nged 70 , in which very few grey can be found.

$\dagger$ Our American Mummy hair, which has heen so many hundred years in the dark, is turned from black to brown; but this may be owing to the eubstances used in its preservition.
} 
extremity, and that it is the same with the lower animals. (Elem. Phys. and Anat., p. 330. .)

We have, in our collection, a bristle of a Russian Hog, which is black at the posterior extremity for 2 inches and $\frac{2}{10}$ ths. and white for the remainder of the shaft, say 9 inches and $\frac{6}{10}$ ths. We have another that is tri-colored, viz: black, white and corneous colored.

'I 'here are, comnected with this subject of the coloring matter of pile, several interesting questions, as 1 st. Of the nature of the coloring matter. Of this we have disposed in the second Chapter, to which we refer. 2d. Of the seat of the coloring matter. This we have shown is, in a perfect hair, in a central canal; in an imperfect one, the coloring matter is sometimes confined to the cortex, and at others it is extended to the intermediate fibres. 'This distinction may have been before hinted, but has never been insisted on as an important specific difference, as it certainly is. 3d. Is the coloring matter of the slim and that of the hair identical? There are some writers, of high repute, who adrocate the? affirmative side of this question. (See Dict. of Sci. Med., v. 43, p. 170.) And there are others who even contend that the coloring matter of the skin is secreted in the bulhs [follicles] of the hair. Gaultier says that, upon removing the coloring matter of a negro's skin, with a blister, he saw it proceeding from the hair bulbs, one portion radiating until it met that of another hair bulb; and, finally, the whole surface becoming black.

'To this theory of "the skin of a negro being furnished with coloring matter from the bulbs [follicles] of his wool," there are two objections, which appear to be manswerable, viz: 1st. That the color of the negro's skin continues to be black, after his wool has become grey [white] for want of the coloring matter. 2d. 'That persons with blucli hair have nhite skins, and no appearance of a black colored rete mucostum.

It is true that Bichat says that it has been fregnently observed, that the red color of the hair accords with the spots of the same color found upon the skin of individuals. (See Anat. Gen., v. 2, p. 789.) But we answer that they are not always so found to agree, for we have in our collection specimens of the hair of Braddock Howard, who was cxhibited in Philadelphia in the winter of 1848-9, the whole of whose face, except a small seam upon his forehead, which has the appearance of a scar, is of a vivid murple; and this color, though not quite of so deep a hue, is traceable to the skin of his head, yet his hair is dark brown, fine and silky.

So Dr. Emery Bissell mentions the case of a very dark colored Tirdian, who gradually turned white after he had passed the age of sixty, the color of his pile undergoing no change other than that incident to old age. And in the Museum of Nat. IIst. of Paris is the portrait of a pie-bald negro, whose skin, in the changed part, is pale rose color, and whose wool is colorless.

Of the Rete Mucosun.-In regard to the experiments on the negro's skin and wool, through the agency of a blister, Cruikshank says, that when a blister is applied to the

\footnotetext{
* We are speaking of the hlack persons seen in all our country who are generally denominatel negrops, but which tre presume to be very far from being me negroes; and Gaultier, most probably, frerformed his experiment upon this kind of person.
} 
skin of a negro, if it has not been very stimulating, in twelve hours a thin, grey, transparent membrane will be raised, under which is found a fluid. This membrane, (says this author,) is the cuticle or scarf-skin; when this, with the fluid, is removed, the surface underneath appears black: But, if the blister has been stimulating, another membrane, in which this black color resides, will also be raised with the cuticle. This (he adds) is the rete mucosum; when this membrane is removed, the surface of the true skin comes into view, and it is white, like that of an European.

Mr. Flourens bas also examined this subject. (See Anmals di Sci. Nat., t. vii., p. 156.) He found four distinct layers between the cuticle and the cutis; the second of which (he says) is a mucous membrane, a distinclly organized body, underlaying the pigment and existing in persons of dark color only. Mr. Flourens sought in vain for this membrane, between the cutis and outer lamine of the epidermis of a white man; and yet this is the seat of the discoloration produced in his complexion by exposure to the sun.

From these examinations this distinguished naturalist and anatomist was able to pronounce, definitively, that the discoloration in the skin of the white man is totally different in lind from the cause of blackness in the negro, and he therefore concludes that the negro and the European are sEPARATE sPECIES of BEINGS.

We might add, that Henle, having examined the skin of a negro, found, besides the cells detected in the white man, others which contain a black pigment. (See Müller's Arch., 1840, Heft. 2, 180**) We, therefore, feel ourselves anthorised in inferring that the coloring matter of the stin, and that of the hair of man are not identical.

As to The Lower Anmals.-How this question is to be determined in regard to the hair and skin of the lower animals will, perhaps, depend upon other considerations; for while we find the blackest hair of the head of our species issuing out of a fair skin, we are credibly informed that the colored spots or portions of the hair of the lower animals, generally, if not always, correspond with a similar tint of the skin. Hence we find authors coupling these two integuments togother. Mr. Youatt, who tells us that he composed the $3 \mathrm{~d}$ chapter of his book with the assistance of several eminent gentlemen, whom he names, says therein that, in regard to sheep, the color of the skin and probably that of the hair and wool also, is determined by the rete mucosum; or, at least, the hair and wool are of the same color as this substance. (See Lib. of Usef. Know., p. 52.) And it must be borne in mind, that the coloring matter of a perfect hair, (i. e. of the head of the oval-haired man,) is confined to a central canal, while the coloring matter of the hair and wool of the lower animals, so far as our experience goes, is disseminated in the cortex and intermediate fibrous substance, or in the cortex alone.

4th. Is the color of the hair ever influenced by accidental, external or temporary causes? It is said in the Lond. and Edin. Jour. of Med. Sci., for 1841, p. 596, that the writer has a hair taken from the skin of a native New Zealander, whose face was closely tattooed, and

* P. Barnard, Prof of Physiology, in Pariw, says that the hair contains pigment grains lut no pigment cells. (260 Cour. Physi., 1848. 
which (hair) was of a bright blue color, owing to its having taken up some of the coloring matter used in the tattooing. We have repeatedly tried to inject a hair, but have never succeeded. Again, a woman, about thirty, became enciente, and at the seventh month, her skin of the face first assumed the color of oxide of iron; and afterwards it became black. On some days it was of a deeper shade than on others; her hair was naturally black, but it assumed a darker shade. The black of her face disappeared two days after her accouchement. Besides, Keidline mentions a case where the hair became bright yellow during a fit of jaundice; but he does not mention the original color, and Alibert tells of a blonde-haired woman whose hair became black after a severe accouchement. (See Dict. des Sci. Med., v. 43, p. 273.) A still more extraordinary case is mentioned in p. 503, of the same work, of a female whose hair, shortly before her death by consumption, changing from white to black. pile, sometimes is succeeded by white hairs, and sometimes, (though less frequently, by hair of the original color.

When a wound heals "by the first intention," the original skin closing and joining, hair grows and continues of the same color it was originally; but when it heals "by granulation," a new and imperfect skin is formed, with a very white hue and smooth surface, and upon this no hair will grow. Feeding an animal for some time upon madder turns the bones red, but it has no effect upon the hair. Dr. Belchier, an English physician, from seeing a pig which had been fed at a dyeing establishment have reddish colored bones, first discovered the phenomenon. He repeated the experiment upon other animals, and always with the same result.

Of tile Polarization of Ligitit by Pile.-Hairs polarize light. (Mandl, 'T'raité. Prac. du Microscope, p. 165.) Common light originates in vibratory motions in every direction transverse to the ray; but polarized light is caused by vibrations, transverse to the ray, and in one direction only. The part of the hair which is instrumental in producing this phenomenom is, probably, the cortex, which is scaly. Polarization may be caused by reflection, refraction or double refraction. $\dagger$

In viewing hairs under the microscope, we must remember the shape of the hair, for light impinging on its surface, being reflected according to the angle of incidence, will be reflected differently as the hair is cylindrical, oval or flat. We should also recollect that the rays of light which emanate from the reflector of the microscope, situated beyond or beneath the hair, being of different lengths, will canse a series of light and dark colored stripes and shadows, which, unless properly understood, will cause false impressions of the abject.

And, lastly, the rays of light, striking directly upon the hair, and those reflected by the reflector, which is beyond or below the object, may interfere and millify each other. 'This danger is increased when two reflectors, one above and one below the object, are used.

* May this not have been a falling out of the old colorless hair, and its place being supplied luy ner black ones?

† The shadow lines of light upon hairs, which, orring to their minuteness, are invisible to the naked eyo, become colored nuter the microscope, 
OF Dyeing Pile. - It is reasonable to suppose that, in the process of dyeing, the coloring matter enters between the scales of pile, and if this be the case, that wool, owing to the scales being more open, will take the dye with greater facility and in greater abundance than hair.

It is also probable, for a similar reason, that wool in the natural state, will take the dye more effectually than it will alter it has been felted or fulled. This may be the reason why "dyeing in grain," as it is termed, is preferred. Among a collection of pile specimens, presented by H. C. Merriam, Lsq., are some denominated "Black. Sea wool," to which is attached a memorandum that it will not talie colors. It is in three parcels, white, black and mixed; the first, when a transverse section is viewed under the microscope, shows two varieties, viz: an oval or an eccentrically elliptical shape, with an external white line, then a dark line and a centre of white fibrous substance; 2d, a cylinder with a white line enclosing a dark one, and a white fibrous centre; diameters, $\frac{1}{2} \frac{1}{0}$ by $\frac{1}{1} \frac{1}{2}$ and $\frac{1}{3} \frac{1}{2}$ by $2 \frac{1}{1}$. The $2 \mathrm{~d}$ parcel is cylindrical, or an ellipse slightly concave on its flats sides; colors the same as above, or black with a white centre; diameter, $\frac{1}{3}$. $^{\circ}$ "The $3 \mathrm{~d}$ parcel cylindrical, white or black external outline comparatively large, black intermediate substance with a minute white centre; diameter, $\frac{1}{6} ;$ 


\section{CHAPTER III.}

PLA T E I.

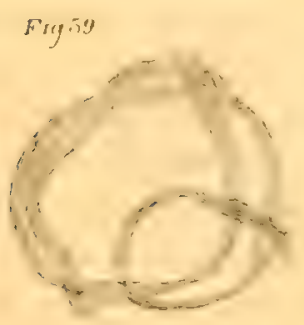

CHAPTER IV.

PLA T E I.

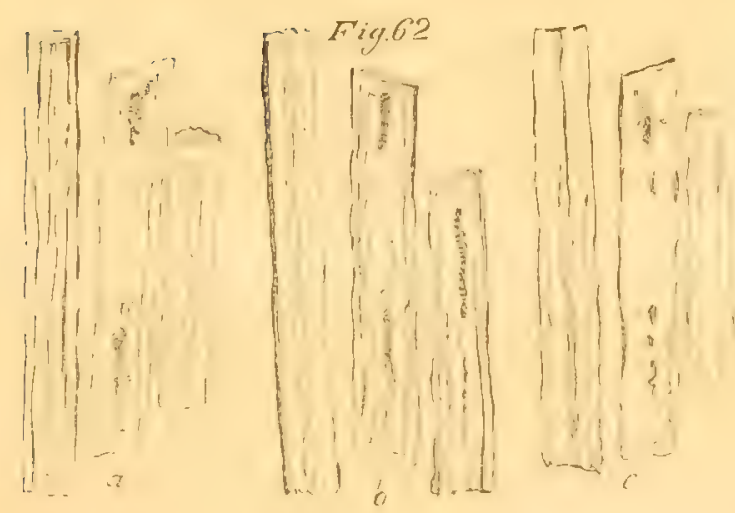

CHAPTER VI.

PLATE I.
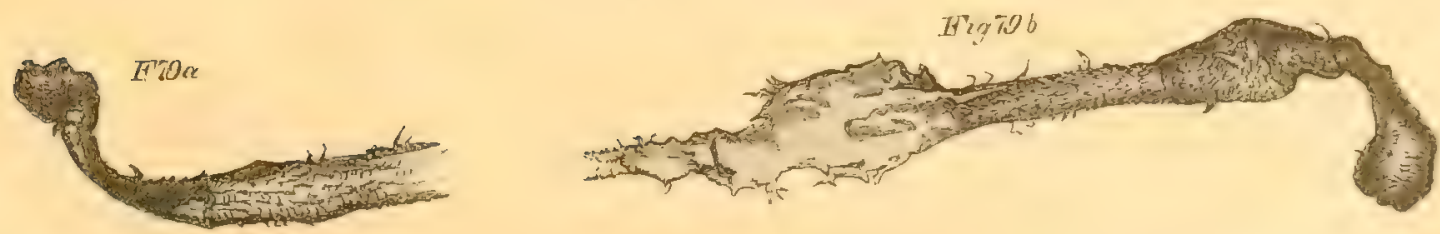



\section{CHA P T R V.}

Pile Belongs to the Dermis.-Pile belongs to the dermis and generally will persist in growing upon it. We are assured by one of the most eminent surgeons of this city that he has frequently, in different operations, turned flaps of skin in various cavities, to supply the place of the mucous membrane, and has observed that unless the piliferous bulbs (follicles) have been destroyed by a desquamating inflammation, or subsequently removed by excision, the hair natural to the skin continues to develope itself and sometimes becomes a source of considerable irritation.

On the other hand pile does not belong to the mucous membrane, and will not, generally, grow therein. We have often examined with admiration the minute line of demarcation, on the lips, between the skin of the mucous membrane, the former being covered with hair, while the latter will not produce a single filament.

But for the proluction of pile the dermis must be perfect; hence we find that where wounds heal by granulation, the cicatrix being an imperfect skin, no hair will grow upon it. It has been said, however, that where the mucous membrane has been left for a long time exposed, as in descents of the rectum and uterus, that hair will grow upon it.*

The notion of Oken, (in Elem. of Physiol., p. 394,) that hairs are dried bronchial filaments, and that, therefore, they continue to occupy in man those situations only where, in the lower animals, bronchia and tentaculæ are found, for example around the mouth, upon the head, in the axillw and around the sexual organs, is chimerical.

Some of the lower animals are entirely covered with hair, while others have so few, that they are called naked. Some are covered with a mantle and a few hairs, while others have scales in place of the mantle. All these different coverings might be made use of in their classification.

When Pile not usually found even in tie Derris. - Hail is not usually found in the superior eye-lids, palm of the hand, the soles of the feet, $f$ nor the dorsal face of the last phalanges of the fingers and of the great toe.

On the heads hair is found-pon the scalp-in the auditory passage-upon the eyebrows, (supercilium) -along the margin of the eye-lids, (cilium) -in the nares-on the

\footnotetext{
* Telle est l'analogies ontre ces deus membranes, que la peau, soumise au contact prolongé des matierc qui bainnent lit muqueuse, des larmes par example, prend bientôt l'aspect et les caractères de la muqueuse, de même que cello-ci, exposee au frottement des vétements et à l'action desséchante de l'air, se transforme bientôt en peau. (Un Mil. de fait, 1.513.)

† The mammalia are composed of, 1, a skelcton; 2, splanchnic eavities, of which there are three; 3, limbs; 4, ressels and nerres. All these are enclosed in an outer enrelope, called "the skin." It is to this latter that pile belongs.

$\ddagger$ froldsmith says that the Itare has hair upon the sole of the foot. (Nat IIist. of Man, v. 2, 137.)

2 1). Gross proposes to call the hair of the head "crin," from crinis, hair. The French have conferred this name upum the mane and tail of the pachydermata.
} 
cheeks and ontside of the upper lip, (whiskers)-and in and under the chin, (beard.) 'The first five are epicene; $*$ the two last belong to males only.

Of the Pile of the Scalp.-This, as we have before explained, is divided into two varieties of hair and wool; denoting three distinct species. It is upon the head of man that the epidermis has the least sensibility, and, owing to the convex form of the skull, it presents but a very small surface, at a time, to contact with external objects; it is, therefore, of very little inconvenience to the sense of touch to have the scalp entirely covered with hair, or wool, forming a soft cushion of defence against external violence. As to the face, although it is the seat of several other organs of sense, it does not require a high degree of tangibility; and hence we find it, also, plentifully provided with pile; but the prominent parts of the cheeks, and the environs of the eyes, (where the passions are principally depicted,) are left bare. Some rare instances occur where no hair is produced upon the head. There is a highly respectable gentleman, residing in this city, who has never had any hair on his head, nor, indeed, upon his body.

Much has been said in other parts of this work upon the hair and wool of the head, to which we refer, to avoid repetition.

OF Clinactric Hars.-That the generative organs exercise a general influence over the hairs of the beard and the hypogastric hairs, seems to be beyond a doubt. These hairs make their first appearance at the period of being marriageable, which is therefore termed the period of puherty. When, owing to any cause, the development of the sexual organs is interrupted, these hairs are defective; and, in like manner, any thing which destroys these hairs, or prevents their growth, acts detrimentally upon the sexual organs. The gentleman of this city, before alluded to, who has no hair, is married, but he has never had an offspring. In most of those cases of malconformation, commonly called hermaphrodite, there is a corresponding paucity of these hairs. Russel altered stags, and he informs us that in some their antlers grew irregularly, and in others not at all. Bichat says, that a cock with his comb cut languishes; which has probably given rise to the remark, often made, of such a one "having had his comb cut," when he is disconcerted or put down. The Lion, deprived of his mane, is said to lose part of his courage, and probably a part of his vitality. When Samson was betrayed by Delilah, he was bereaved of his pite; but when he was brought out to be sacrificed by the Philistines. his beard being grown, and his hair in a great measure restored, he laid hold of the two chief pillars and pulled the house down. $\uparrow$

Bichat condemns the practice of shaving the beard as injurious; and it is related of

\footnotetext{
* Epicene, from "epi," upon, and "hoinos," comuron; common to both seres.

$\uparrow$ "And she said unto him, Thou has mocked me three times, and hath not told me wherein thy great strength lieth. And he told her all his heart: and said untu her, There has not come a razor upon mine head; for I have been a Nazarite unto God from my mother's womb. If I be shaten, then my strength will go from me, and I shall become weak, and be like other men. And she made him sleep on her knees; and she called for a man, and she caused him to shave off the seven locks of his heal; and she began to attict him, and his strength went from him."
} 
Hans Adam, Baron of Oxensteirn, who was born in 1529, that he was renowned for bodily strength, and had a beard six feet two inches long! Two cases are recorded, one of a Monk who became blind upon cutting off a long beard, and the other of a Priest, who was extremely robust, but who suddenly became sick and weak from cutting his loug hair. (Dict. de Sci. Med., v. 43, p. 272.)

In Auverne, in France, they never cut the manes of their horses for fear of dimini-hing their strenglh.

A singular growth of beard on the chins of females; in decline of life, has been referred to the same category. (See Blumen’s Inst. Phys., \$660.) Bichat says that this is a new direction of vitality. Gross tells of a female, of 78, the mother of a large family, whose chin and lip was covered with a coarse beard, which obliged hei to shave once a week. (Elem. de Phys. and Anat., 227.)

WHEN IIIR FIRST MAIES ITS APPEARANCE.-The first development of hair, accolding to Valentin, [Entivi Chelangeschichte, p. 275,] is either at the end of the third, or the commencement or middle of the fourth month; but others think that it is not till the seventh month.* Bichat says that, "during the first months of the foctus, there is no hair upon the still gelatinous skin. That it is at the time of the production of the fibrous tissues that you purceive, upon the head, a fine down, indicative of the hair which is to succeed. "This down," he says, "is whitish, and is hidden in a greasy and unctuous substance, which covers the skin. Sholtly after it becomes colored; but palely so until birth."

The First appearance of Hlitr on time Possuni-Prof. Charles Meigs, M. D., of this city, watched the progress of development of a brood of possums, and there was no appearance of hair until the seventy-second day after they were first discovered in the pouch of their mother. (MS.) +

Some [hybrid] lambs are provided, at birth, with hair, which is soft, short and pointed, and which falls out, luving the place for wool. (Fleishman.)

We have obtained, through the kindness of the IIon. Jonathan Roberts, of Montgomery county, Pa., some of this lamb's hair. In Mr. Roberts' note, he says, some varieties of stock show little or no signs of hair in their first stages-such as the Merinos, for the most part, and in a good degree so are the Southdowns, on which we now pretty much run. And so of the Dishleys. We have had them sometimes very hairy, and there are instances where it never assumes the perfect state of woolly fibres. (MS.)

Of the three varieties of the Harr of the Head of Max.-All organized beings have their periods or ages of existence. In general the form is at first simple, and becomes

\footnotetext{
* We hare, in our collection, a foctus of three months, upon which there is not a single bair; and we have a specimen of a portion of a scalp of another of five months, upon which there is hair.

I With birds, towards the end of the ninth day of incubation, on the skin of the embryo are seen little pores, which are tho openings of capsules destined to secrete feathers, which begin to show themselves at the end of the tenth day, and to cover the body in the course of twenty-four hours. (Elem. de Zool., 215.)

The cub Lion has no mane when horn.
} 
successively more and more complicated-sometimes by metamorphoses, and at others without them. Haring arrived at complete development, the period of decline commences; for there is nothing stationary in their existence. 'lhere appears to be three distinct varieties of hair of the head of man, referable to three as distinct periods of production, viz:-

Ist. The primitive hair, spoken of by Valentin and Bichat, as above quoted. These fall off, mixing with the envelope of the foetus, and are never found except in the meconium.* We have never been able to obtain any of these hairs.

2d. The transitive variety, which succeeds to the primitive, and which is found upon the newly-born infant; but which generally falls out a few weeks after birth.

3d. The permanent hair; if permanent may be called hairs which are being continually renewed during life.

1th. 'The hairs of puberty.

It would be rery interesting to ascertain whether the three first rarieties are not progressive in the order of their perfection of organization, as they are in their order of time of production. In order to determine this question, we have made several unsuccessful exertions to obtain the pile of the first variety. With regarl to the second, we think that we have shown that it is less perfect than the third. (See title Follicle.)

Of Accinextal Hairs.- Hair is, occasionally, developed in unusual places, as in the cystis of oraries-on moles- on nari materni-on freckles-on the mucous membrane of the conjunctiva-on the intestines-on the gall bladder-in the stomach-on steatomatous and encysted tumors-on the tongue and in the uterus.

Homer tallis of the hairy heart of Achilles, and Pliny speaks of hair upon the heart, but we have never witnessed any such phenomenon. Dr. Gross sirys that hair can be produced in unusual places by constant fiction. (Elem. of Phys. and Anat.p. 330.) (Sed quxere?)

of the Huir found in Ovaries.-Among hairs that are denominated "accidental," because they are found occasionally, only, being dereloped in unusual places, the most remarkable are those discovered in the cystis of oraries. Bichat gives the following account of these anomalies:-

"A sack, sufficiently roluminous, contained a multitude of rery distinct little balls, resembling the excrement of sheep; they were formed of a white, greasy, unctuous substance, rery different in aspect from common grease. On the internal surface of each of these were planted a great many hairs, which the least movement was sufficient to displace. The hair was black." He also found some hairs, entirely detached, which were interlaced in rarious degress of compactness in little balls. (Anat. Genl., r. ?. p. 799.) $\dagger$

\footnotetext{
* Excrément noir et epais amasé d.uns les iutestins cì un eniunt naissant.
}

i For orary hairs see Meckl. Memoire sur les poils et les dents qui se derelop accidentellemeot dans le corps. (Seo Jour.

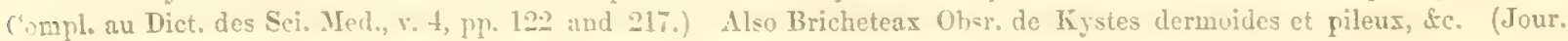
Compl. des Sci. Hed., r. 15, p.298.) Hairs have been found in the testicles. (Meckl.) 
So far as our researches have enabled us to ascertain, the following is the first microscopic examination and description of these hairs:-

No. 1 Examination and Description of Hairs from Ovariss. Name and description of the person from whom it came unlinown._- Specimen presented by Prof. Paul B. Goddard, M. D., of Philadelphia. (See fir. 33.)

Length, 3를 inches; shape, cylindroidal; diameter, $\frac{1}{2} \frac{1}{5}$ hy $\frac{1}{2} \frac{1}{5}$ of an inch; color, pale reddish-brown; dark brown; not lustrous; direction, slightly flowing, with a tendency to a stiff eurl; inclination, unknown; ductility, with 870 grains one inch stretched $\frac{2}{20}$ of an inch, elasticity entire; tenacity, broke with 1,000 grains; b:tton, a mere swelling of the posterior extremity of the shaft; sheath, length, $\frac{1}{10}$ of an inch; diameter, $\frac{1}{8}$; white, opaque, investing closely the shaft; follicle, had none to examine; shaft, partially injured in places, as if it had been acted upon by some corrosive substance; intermediate fibres. (exhibited when a hail is crushed,) coarse; one of them measured $\frac{1}{1} \frac{1}{5} 0$ part of an inch: a darker colored hair, when crushed, showed a light-colored cortex and white intermediate fibres; apex, rounded; none furcated; disks, mniformly colored; no central canal discovered.

In general outward appearance this hail resembles that of the head of the oval-haires species; but it differs from it in its deficiency of ductility, in its cylindroidal shape, in its being injured in places in the shaft as if corroded, in the coloring matter being in the cortex, and in the absence of a central canal.

No. 2. Examination and Description of Hair of an Ovary.-Name and description of the person from whom it came unlinown. Specimen presented by Prof. Horner, M. D , of Philadelphia.

Length, from $1 \frac{1}{2}$ to 2 inches; shape, cylindrical; diameters, one $\frac{1}{3} \frac{1}{5}$, another $\frac{1}{2} \frac{1}{1}$, and another still, $\frac{-1}{2} \frac{1}{7}$ of an inch; color, generally very light, no lustre; direction, crisped; inclination, unknown; ductility, with 190 grains stretched $\frac{1}{90}$ of an inch, elasticity entire; tenacity, broke with 893 grains; button, sheath, and follicle, had none to examine; shaft, deficient in uniformity, thinly covered in places by a white opaque substance; scales on the cortex very apparent, rounded and adhereing closely to the shaft; one hair, which was of rather a darker shade than the rest, notched as if it was corroded. Upon being rolled between two pieces of glass the scales disengage; being crushed, the cortex splits transversely, exhibiting the intermediate fibres, which are white and fine; one of them measures the $\frac{1}{2} \frac{1}{50}$ part of an inch; apex, sometimes pointed, and at others abrupt, none furcated; disk, uniform color; no central canal perceptible. 'The general appearance is that of the hair of the pubis of the oval-haired species. With this lock was a mass of tangled fibres of the size of $\frac{1}{2}$ of an inch, so much interlaced as to render it impossible to ascertain the length, but with various diameters fiom $\frac{1}{10 y 0}$ to $\frac{1}{500}$ of an inch, some that and others rounded, all white and opaque but one, and that is bhe.* The peculiarities of this hair are its deficiency in ductility, its cylindrical shape, its notched appearance. its deficiency in a central canal, and the blue color of the fibre above mentioned.

* We found a similar colored fibre among the hair of Joln Dennis (Aarrood, which gren after death. 
Remarks.-Ductility being one of the essential properties of pile, we are constrained to pronounce these either not to be true hairs, or to believe that they have been changed in this respect by some fluid with which they have come in contact, most probably the latter, for the corroded state of the shaft would render that probable. But a difficully still remains, that while these specimens, respectively, resemble in some respects the hair of the head and of the pubis of the oval-haired man the cylindroidal shape and deficiency in canal, negatives the idea of such an identity with the former and the cylindrical shape with the latter of these integuments.

Of Pile from tie Uterus.-In the 61h vol. of the West. Jour. of Med. and Surgery, p. 217 , is an account of the expulsion of a mass of a dark color. from the uterus of a black woman; which, upon examination, proved to be pile. It was deposited in the Museum of the Medical College of South Carolina, and we are indebted to Dr. Henry R. Frost, of Charleston, for a specimen.

Examination and Description of Wool from the Uterus of a Black Woman, made 10th of April, 1849.-Length, 10 inches and $\frac{8}{10}$, eccentrically elliptical; diameter, greatest, $\frac{1}{2} \frac{1}{30}$ of an inch, smallest $\frac{1}{50}$ of an inch; crisped; color, dark brown, no lustre; harsh and dry to the touch; no button, sheath, nor follicle; shaft, lower extremity quill-shaped, somewhat blanched and perforated; in some places encrusted with a whitish cellular substance, and in others fractured so as to display the fibres.

Trial of one inch with the Trichometer. Bar. 29, Ther. 70, F., Dew-Point 67.

With 100 grains it stretched $\frac{1}{90}$ of an inch, elasticity entire.

\begin{tabular}{|c|c|c|c|c|c|c|c|}
\hline "6 & 300 & "6 & 66 & $\frac{2}{3 \pi}$ & 66 & "6 & of \\
\hline . & 100 & .. & . & $\because \because 4$ & .. & & ،. \\
\hline " & 550 & 66 & 16 & $\frac{4}{90}$ & $6 !$ & 66 & 16 \\
\hline “ & 650 & "6 & 16 & $\frac{5}{9} \overline{0}$ & $\bullet$ & 16 & 66 \\
\hline " & 700 & 66 & $\therefore$ & $\frac{6}{90}$ & 66 & 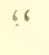 & 66 \\
\hline 66 & 750 & 16 & 66 & $\frac{1}{9} \frac{0}{0}$ & 66 & 66 & minus \\
\hline “ & 800 & 6 & 6 & $\frac{1}{9} \frac{5}{0}$ & $" 6$ & 6 & 16 \\
\hline 66 & 850 & 66 & 66 & $\frac{20}{9} \frac{0}{0}$ & 66 & $" 4$ & 16 \\
\hline "6 & 900 & 66 & 66 & $\frac{2}{9} \frac{5}{0}$ & 6 & 66 & "6 \\
\hline "6 & 950 & 66 & 66 & $\frac{2}{9} \frac{6}{0}$ & 66 & 16 & 66 \\
\hline 66 & 1,000 & 66 & 16 & $\frac{3}{9} \frac{0}{0}$ & "6 & 6 & \\
\hline 66 & 1,050 & $"$ & 66 & $\frac{3}{9} \frac{5}{11}$ & 66 & 66 & 66 \\
\hline 66 & 1,100 & 66 & 6 & $\frac{4}{9} \frac{0}{0}$ & "6 & 6 & 16 \\
\hline 68 & 1,150 & 66 & 66 & $\frac{4}{9} \frac{1}{0}$ & 66 & 66 & 66 \\
\hline 16 & 1,200 & 66 & 6 & $\frac{4}{9} \frac{1}{0}$ & "6 & 66 & 16 \\
\hline “6 & 1,250 & 66 & $"$ & $\frac{4}{8} \frac{2}{10}$ & 66 & 66 & 66 \\
\hline 66 & 1,300 & $" 6$ & 66 & $\frac{4}{3} \frac{5}{10}$ & 66 & "6 & 66 \\
\hline & 1,350 & 66 & & & & & \\
\hline
\end{tabular}

Whence came this pile? Are we to presume that its germ came from one of her parents, that it was transported by the circulation and absorbed in the placenta by the 
radicules of the ambicular vein? for there is no direct communication between the maternal and foecal circulation. Or was it a spontaneous generation? Or was it forced in from without? (See Berard's Cours. de Physio., p. 99 of I vol.)

Hair from the Stomach.-Dr. F. A. Vandyke told us of a case of a female lunatic, who extracted her hypogastric hair and swallowed it. Upon a post mortem examination, had for another purpose, they were found in her stomach in the form of a ball.

We have in our cabinet quite a variety of hair-balls extracted from the stomach of Ruminants, many of which we have examined.

Examination and Description of Hair from the Stomach of a Ruminant, Warch 14th, 1849.-Presented by Prof. John K. Mitchell, M. D., of this city. Length, $z_{z}$ of an inch; shape, cylindrical; diameter, $\frac{1}{5} \frac{1}{5}$ of an inch; color, dirty brown; no lustre, no button, sheath, nor follicle; apex, some abrupt and others pointed. In the general appearance resembling cow's hair.

Trial of $\frac{3}{4}$ of an inch with the Trichometer.

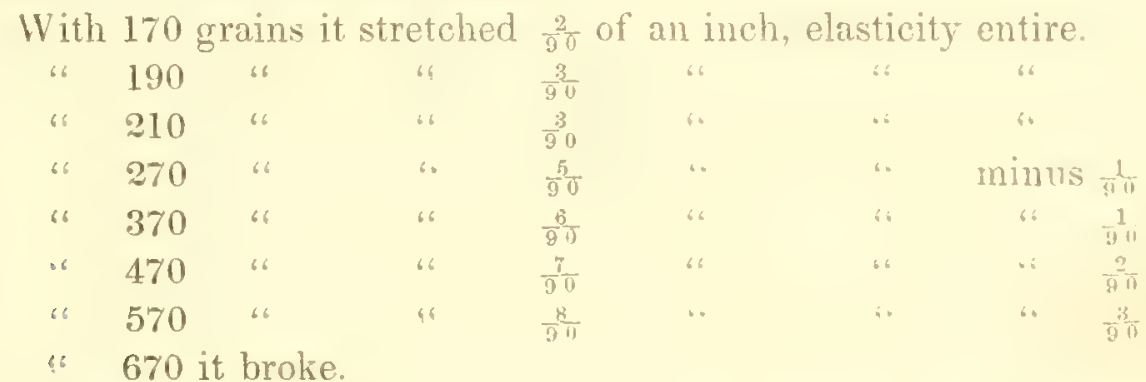

Dr. Rogers, speaking of these hair-balls found in the stomach and alimentary canal of Cows, \&c., says that the animals lick the hairs from the skin and swallow them with the saliva; that they concrete, forming a ball. (Prin and Prac. of Med., 18.1, p. 934.) In Youatt's Essay on Sheep, in Lib. of Usf. Know. 139, will be found an account of these balls by the name of Bezeors or Calculi in the abemasum of these animals. From a note affixed it seoms that they are found likerise in every species of Deer and Antelope, in the Elephant, the Rhinoceros, the Porcupine and some other animals.

Hair on the Tongue.-The second volume of the Medical Examiner, 1846, p. 266, mentions several cases of hairy productions on the surface of the tongue. (Med. 'Times. v. 13, p. 148.)

Of Pile which Appears to Grow out of the Interior Surface of the SixinSome of the skins of the lower animals, tanned with the pile on, have filaments which appear to be growing ont of the interior surface of the skin. The first one upon which we noticed this phenomenon was the skin of an Otter. It was about one foot in length and about seven inches wide, and there was a spot near the centre, of about five by three inches, where the pile grew sparsely upon the imer surface. The animal was, as usual, covered with a dense, fine wool, with long hairs above, but none but the hairs were to be seen on the inner surface. The hairs on the back of the animal have the usual acute angle, which obliged them to lie smoothly, inclining from the head towards the tail; but these 
hairs incline in the opposite divection. The hairs of the animal are, in color, dark brown, inclining to black; light brown, incling to fawn; and hairs of both these colors were to be seen in the interior surface, but a large majority of them were blackish brown.

From information received from dealers in furs, it would appear that these hairs are to be seen on the skins as soon as they are taken from the body of the animal, that they are confined to the skins of animals killed in the summer season, and that they are left upon the pelt from an opinion that to pull them out injures the aspect of the fur on the other side.

Explanation. - The projecting terminations of these hairs upon the reverse side of the skin, are the roots, the points of the filament remaining in the skin. 


\section{CHAPTER VI.}

OF the Dimensions of PiL. - The length and thickness of pile are important matters to be observed and remarked.

Of the length of Pile. - There is a bony, fibrous substance found in the mouth of the Whale, which, in commerce and the arts, is called whalebone. It is the fanon of the French. This substance is represented by some writers to be the beard, and by others to be the whiskers of this animal; and if it were hair, it would be a specimen of the greatest length of that integument found upon the mammalia; for it measures from two to ten feet. But we have ascertained that it is not pile. (See Chapter I )

On onr species the longest hair is mpon the scalp, and females have generally longer hair upon their heads than males, as if it were to compensate for the comparative deficiency of it upon their bodies.

"Doth not even Nature itself teach you that if a man have long hair, it is a shame unto him?" "But if a woman have long hair, it is a glory unto her, for her hair is given her for a covering." (1 Cor. xi: 14, 15.)

Among the female sex, it is said, some have been known to have hair extending to the hecls; sometimes males, also, have long hair. We have, in our cabinet, the hair of the male Chinese, Tsow Chaoong, which is four feet long.

As a general rule, the hair of the head of the cylimdricil-hatiod mant is the longestthen that of the oval-haired man, and the wool of the eccentrically elliptical is the shortest.

Next in length to the hair of the head comes, generally, the beard of man; which not unfrequently reaches to the waist. The sbortest hairs of the body of man are the downy hairs, (lanugo.) Hairs of a medium length are found in the axillz and the hypogastric hairs of both sexes. Some men have long hairs upon the breast, and even upon the limbs; women are, in general, less hairy.

It is said that the growth of hair is, sometimes, increased by certain discases; for instance, Dr. Green assures us that, in plica polonica, the hypogastric hair bas been known to grow down to the knees. (!)

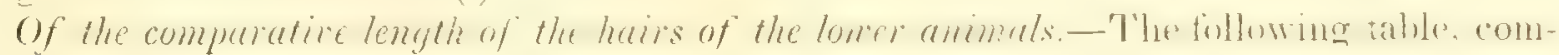
piled from specimens in our cabinet, may be regarded as at least an approach towards the truth:-

The tail of the horse, from 3 to 4 feet.

The mane of the same, from 12 to 15 inches.

The tail of the Elephant, 1 foot 1 inch.

'The tail of the Yak, or Horse-Tailed Buffalo, 10 inches.

'The tail of the Zebra, 9 inches. 
'The mane of the Lion, 5 inches.

'The bristle of the Russian Hog, $12 \frac{1}{2}$ inches.

The hair on the side of the Asiatic Bear, 10 inches.

The hair on the side of the Goat, 9 inches.

The hair on the breast of the Canadian Elk, 7 inches.

The hair on the side of the White or Polar Bear, 6 inches

The hair on the back of the Egyptian Sheep, $5 \frac{1}{2}$ inches.

'The beard of the same, 5 inches.

The hair on the back of the Grizzly Bear, it inches.

The hair from the back of the Striped Hyena, $3 \frac{1}{2}$ inches.

The hair upon the back of the Prairie Wolf, 3 inches.

'The hair upon the back of the Ichneuman, 21 inches.

'The wool on the body of the Buffalo, 2 inches.

The hair fiom the side of the African Leopard, 2 inches.

'The long hairs on the back of the Raccoon, 2 inches.

The long hairs on the Ferret, the Possum and the Stone Marten, $1_{\frac{1}{10}}$ of an inch.

The hair on the back of the Hudson Bay Marten, the Lynx and the Kangaroo, $1 \frac{3}{10}$ of an inch.

'The hair of the Kangaroo Rat, $1 \frac{2}{10}$ of an inch.

'T'he fur of the Chinchilli, $1 \frac{2}{10}$ of an inch,

The fur of the English Rabbit, 1 inch.

The fur of the Blue Jennet, $\frac{9}{10}$ of an inch.

The fur of the Black Jennet, $\frac{8}{10}$ of an inch.

'The fur of the White Mink, $\frac{7}{10}$ of an inch.

The fur of the Ermine, $\frac{4}{1 \pi}$ of an inch.

The fur of the Mole, $\frac{3}{10}$ of an inch.

Some writers are of opinion that the length of hair is indicative of the strength of the animal, but we believe that this is an error; it is its tenacily which is the test.

Of the Manner of Ascertaining the Diameter of Pile.-The diameter of pile is ascertained by the microscope and micrometer. Of this latter instrument there are several kinds, some of which are well described in Quekett on the Microscope, from page 189 to 196. Before the discovery of this instrument, the fineness (diameter) of wool was a mere guess, founded upon the experience of the wool stapler; now it is a matter of mathematical certainty. But, in order so to render it, the filaments must not be measured while lying horizontally upon the stage of the microscope; but disks must be cut in the manner described in this work. A microscope and micrometer is a very expensive apparatus, and moreover $\mathrm{it}$ is not every possessor who can use them effectually without considerable experience; it therefore struck us that a cheap and simple instrument, which will enable the sheep-breeder to ascertain the relative fineness of feece, would be a valuable acquisition, and we believe that such a one can be suggested. There is a point of approximation to the eye where objects can be distinctly seen, this point is different in differentindividuals, necording as they are long or short sighted, or have sight of the usual and medium kind, 
where it is about eight inches. To the later, as a grencral rule, it may be observed that the smallest square magnitude visible to the naked eye, either of white particles upon a black ground, or of black particles upon a white ground, is $\frac{1}{45}$ of an inch, but when the substance is in lines instead of particles, it may be seen, if held towards the light, when only $\frac{1}{490}$ of an inch in diameter. The finest wool that we have examined, coming from the body of a sheep, is $\frac{1}{1} \overline{6}$ part of an inch, which, according to the above rule, can be seen with the naked eye. There is a point beyond which an object cannot be seen; owing, perhaps, to the light being absorbed before it reaches the retina. 'This point, (which is called the "vanishing point,") must, of course, depend upon the eye, the light, the color and the size of the object; where the light, the color and the size of two or mole objects, are alike the distance of the vanishing point, to the same eye, must always be identic 1 . Now we propose that a series of tubes, to draw out one from another, like those of a telescope, be constructed of suficient length that, when fully drawn, they are equal to the vanishing point of the coarsest wool desired to be examined. Upon a picce of card arrange a series of strands of wool, in the order of fineness, the diameters of which liave been previously ascertained with the microscope and micrometer. Upon a similar card stretch a strand of the wool, the relative diameter of which it is required to ascertain, and, mpon fixing it near one end of the tube, (one eye to the other end,) draw out till you find the vanishing point of the strand. Remove this card and put the other one in its place, when it will be perceived which of the filaments upon it is at its vanishing point, and the diameter of that strand will be the one required. The tubes may be made of tin or even of pasteboard, but ought to be blackened inside. The measured wool upon the cards can be procured in this city for a trifle.

Of Hypertrophy or Unnatural Growth of Hatr.- When hair grows to such an unnatural length as to cause disease, it is called "hypertrophy." Dr. Gross tells of a young lady who died of this disease She had always experienced an unusual growth of hair, and generally kept it cut short; but, a few montlss before her death, it grew down to her heels. It was flaxen and had a soft oily feeling. 'The account concludes with the remark that a post-mortem examination showed that the unnatural growth of hair had caused her death.

Of Depilation. - Some Malays destroy the hair with quick-lime, the isolated ones being plucked out with tweezers. (Latham, Nat. IIist. of Var. of Men, 145.) Most American Indian tribes pluck out their beards.

Of the Discotone.-Description of a very conventent instrmmenf for cutting transterse sections or disks of hair, which we call a Discotome.

\section{1}

* From hyper uper, ar abore, and trix, hair.

f The corrosive medicines used to take nway supertluous luair are called "Ectillotice," from "ck," out, and "lillo," to pluck.

f From riseos, a disk, and temmo, to cut. 
It consists of a cylindrical metal box, (ours is of brass, ) of a convenient size to hold in the hand, (ours is $1 \frac{3}{4}$ of an inch in diameter, and two inches in length.) The bottom is permanent, but the top screws on. In the centre of each end is a circular opening of the diameter of $\frac{1}{4}$ of an inch. A cylinder of this last diameter, extends from the interior surface of the bottom of the box to that of its top. 'This eylinder', when the top of the box is minscrewed, can be taken out, but when the top is screwed down, remains fixed by a shoulder directly opposite to the openings. In the opening at the bottom of the box is a screw thread, into which fits a screw $1 \frac{1}{2}$ inches long; this screw, which is turned by the agency of a millhead, and which is seen below the bottom of the box, passes up the small cylinder, its end pushing forward every object resting upon it, forcing the other end of the object through the superior opening of the box. The thread of the screw and the circumference of the milhead are so graduated, that one revolution of the latter advances the screw just $\frac{1}{100}$ of an inch. Nieces of cork are cut so as to fit the small cylinder; through the centre of one of these pieces of cork is passed a fine needle carrying a thread, by returning it again through the same perforation a loop is formed, through this loop pass the hair from which the disk is required to be cut, then draw the other end of the thread until the hair doubles and passes down through the perforation in the cork. After having applied a very small quantity of gum to the perforation around the hair to keep it perpendicular in its place, put the cork into the small cylinder, one end of it resting upon the serew, and the other passing through the opening in the top of the box, and remaining exactly level therewith. 'This done, turn the millhead in proportion to the thickness of the disk required to be cut, and when the cork makes its appearance above the top of the box the distance required, cut off a disk of the cork, with the hair enclosed in it, with a sharp razor, ground flat on one side only. 'These disks nay be placed under the microscope in the cork, or they may be extracted and viewed separately, as desired. In either method the shape of the pile may be seen, and the diameter taken with the utmost accuracy.

The diameters of pile have been varionsly estimated by different authors, say, by Haller and Musscnchenbroech at $\frac{1}{7} \frac{1}{0}$ of an inch, by Robinson at $\frac{1}{3} \frac{1}{8}$ to $\frac{1}{3} \frac{1}{5}$ of an inch, by Withof at, black, $\frac{1}{5} \overline{5}$, brown, $\frac{1}{6} \bar{s}$, and blonde, at $\frac{1}{7} \frac{1}{5}$ of an inch.

So the sane pile has been said to vary in thickness. 'Thus, according to Weber, the thickness of a negro's wool was, at one point, 0.019 lines in its least diameter, and 0.038 in its greatest diameter, and, at another point, $0.023 \mathrm{in}$ its least and $0.038 \mathrm{in}$ its greatest diameter. Another fibre of negro's wool is said to have measured, upon four points, as follows:

Greatest diametcr.

0.0425

0.0470

0.0425

0.0410
Least diameter.

0.0310

0.0340

0.0295

0.0340

Of Tapering Hair.-Having found that the hair of Albinos was very tapering, from root to point, we took the diameters which were as follows:

The hair of Mary M. Williams, greatest diameter $\frac{1}{3}$, least $\frac{1}{6} \frac{1}{5}$ 
The hair of Mr. Spence, greatest diameter $\frac{1}{416}$, least $\frac{1}{5} \pi^{-}$

Dr. Ure gives the following dimmeters of wool:

Finest Saxon, at $5 \mathrm{~s}$ per $1 \mathrm{~b} ., \frac{1}{1} \overline{1}_{0}$ of an inch.

Second Saxon, at $3 \mathrm{~s}$ per lb. $\frac{1}{1} \frac{1}{1} \overline{0}$ of an inch.

Spanish wool, 3s $6 \mathrm{~d}$ per $1 \mathrm{~b}$., from $\frac{1}{100}$ to $\frac{1}{15} \frac{1}{10}$ of an inch.

Mr. Youatt gives the following as the scale of fineness of wools. Coarse, when more than $\frac{1}{500}$ of an inch; fine, when not exceeding $5 \frac{1}{9}$, and very fine, when it does not exceed $\frac{1}{1} \overline{0}$ part of an inch.

We have found the finest Saxony wool of the United States to be $\frac{i}{i} \bar{x}$

The finest wool of Sasony and Prussia, - _ _ $\quad$ - $\frac{1}{2} \frac{1}{1} \overline{6}$

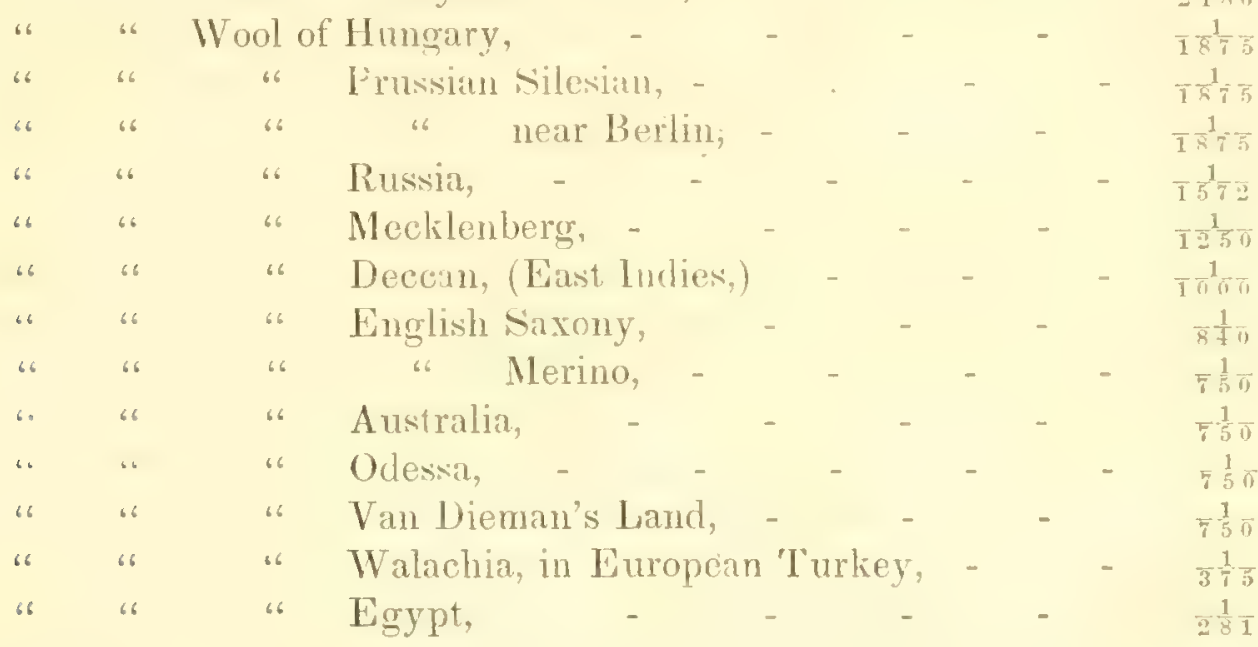

Of Hair Manipulations. - Those who are desirous of making manipulation of hair, (or, indeed, of any thing else,) without the microscope, but under a moderate magnifying power, should provide themselves with a pair of microscopic spectacles, the bridge of the frame of which, resting on the nose, while the lenses are at the proper focal distance from the eye; leave both hands of the manipulator at liberty, instead of obliging him to hold the magnifier in one hand and to work with the other only, in the usual manner. 'These spectacles are as simple in their construction as they are useful in practice. The magnifying glass has a linge, and opens inwards from the spectacle glass, so that it can, at pleasure, in a moment, be either placed or removed: By this arrangement you may use these spectacles as a microscope of moderate power, or as a common pair of spectacles.

Of the Exuberance of Pile.-

"But even the rery hairs of your head are all numbered."-Luke, 12: 7.

Withof found upon $\frac{1}{4}$ of a square inch of a male, moderately hairy, from the synciput, 293 hairs; chin; 39 ; pubis, 34; forearm, 23; at the exterior border of the back of the hand, 19; at the anterior side of the thigh, 13. Upon the same amount of surface the hairs varied in number, according to color, thus: black, 117 ; brown, 162 ; blonde, 182. 
Goldsmith says that it is observable among quadrupeds, as well as among the human species itself, that a thin, spuring diet is apt to produce hair; children that have been ill-fed, famished dogs and horses are more hairy than others whose food has been more plentiful.[!] (Nat. Hist. of Man, 2 v., p. 106.)

The Hindoos undertake to enumerate the hairs upon one of onr species. A woman who, upon the death of her husband, (says Unggira,) ascends the burning pile along with him, is exalted to heaven for as many years as there are hairs on the human body, that is, $35,000,000$.

OF HaIR GRowing in T'uFts.-Hairs (which are seen upon the foctus) are rarely isolated, but are found disposed of, sometimes in duplicates, sometimes in 1riplicates, and at others in quadruplicates, or even quintubles. (Eschricht in Muller, Arch., 1837, p. 43.) And it is very probable that the same arrangement may exist in regard to the hair of the lower animals; for while examining the skin of a Russian Dog, tamed with the lair on, with another object in vicw, we observed that the follicles were in tripticates. We have also observed that the fur of the Mole grows in tufts, and so does the wool of the Bushman boy, as has been noticed. (See post, wool staple.) And it is also beautifully shown in the skin of the Platyphus Ornithorinchus. (See Chapier I.) **

We have, in our cabinet, a specimen of hair which grew in tufts upon a gentleman's shonkler.

Of tue rapin growtin of Pile.- Withof found that the beard grows a line in a week, or 4 inches in a year, which, in a life of fifty years, would make upwards of 16 feet of beard.

W'e found the beard to grow, upon a male adult of 60 , in good health, $\frac{1}{9} 0$ of an inch in 21 hours.

Absalom polled his hair once a year, "becanse it was heavy upon him," and it weighed 200 shekels, after the king's weight. $\dagger$

Hair is said to grow more rapidly in summer than in vinter. (Dict. Des. Sci. Med., v. 43, p. 496.) Sed quire?

'The fur upon the abdomen of amphitious fur-bearing animals is the finest, and that on the back is the coarsest. With land fur-bearing animals, it is the very reverse.

'The finest wool is on the back of the sheep, and is called "picklock."

The specimens of Saxony wool, presented to us by the King of Saxony, represent the filaments from the shoulders, the back, under the belly, the tail and the legs-so that from the specinens you may form an opinion of the whole flcece.

OF tile regenera'tion of Pite. - Of the fall and regeneration of hair in the footus, we

\footnotetext{
* Hair of the limbs of the body of sume of the Piphums, of Darnly Islind, grow in small tufts. (Lathan, Nat. Hist. of Var., \&e., 215.)

† Shekel, ancient Hebrew weight, 0.032086 puunds. (Alexander.)
} 
speak in another place, and what is there said need not be here repented. (see Chapter $\mathrm{V}$.) But, besides what is there noticed, it is worthy of observation that, during our whole lives, there is an almost insensible regeneration of hair. We may, in almost every hairy region, find long and short hairs, and, upon dissection, hairs are always found beneuth the epidermis, not having yet pierced that integument. 'This regeneration, as we have elsewhere remarked, is a portion of the law of living organism, and not a peculiar property of pile.

On the regeneration of pile after having been dram out, Heusinger observes, that thero is found, in the follicle first, a thin, reddish, or flesh-red colored liquid; afterward, and deeper, a soft, reddish, fleshy substance, which adheres to the sheath and to the bottom of the follicle, but which holds only here and there to the sides of the latter. The hair passes through the middle of this stbstance. After the shaft has been dram out, the lleshy substance* swells, and is filled with blood In three days it returns again to its natural state. In its midst is then discovered a dark, clotted mass, rising from the bottom of the follicle. Five days after the hair has been drawn out, a hair, of the length of two millimeters, is produced. Heusinger adds, that he has scen, in the same follicle, alongsicle of the old

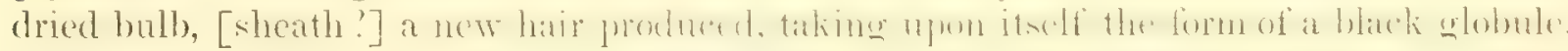
The new hair (he says) grows immediately upon the old one, [the sheath?] and pierces the skin right alongside of it.

This wonderful power to produce a new hair ought not to excite surprise, when we call to mind the reproductive power of some of the crustacea. A Crab or Lobster, which has been deprived of a leg or an antena, can, in a short space of time, replace it by a new onc, which proceeds from the stump. So the antler of the Stag (which sometimes weighs 30 pounds) is reproduced in ten weeks. The old ones, having artived at maturity, no longer receive the same nourishment from the powerful vessels which were instrumental in their production; still, for a limited time, they continue to live at the expense of their interior ressels; but these gradually diminish in capacity, and the necessary blood diminishes, until eventually they die and fall.

Bichat justly remarks, that the season of regeneration of all these integuments is one of much bodily weakness, and is sometimes of incipient disease. He attributes this to the unusual attraction of the products of nutrition, to the exterior, at the expense of the vital functions. This is a valuable hint to the owners of horses, sheep and other domestic animals, to be tender to them when they are renewing their coats.

\footnotetext{
"A merciful man is merciful to his beasts."
}

It ought also to teach parents to be very careful of their children at the season of puberty.

Of the gradual and perioticil decidence of Pile.-There are some witers who entertain the opinion that pile, at certain periods, attains the maximum of its development when the stalk becomes a dead mass, like the horms of the Stag, liable to be separated from 
its root by the slightest force. Against this opinion it has been urged, that the hair of the head has been known to suddenly become grey, [colorless;] which (they say) is proof that it still retains a secretion from its proper vessels. It is replied, that this sudden change (or, more properly spealing, loss) of color is due to chemical action. But this latter position is, in its turn, met by the rejoinder that the grey [white] color commences, in general, at the point [?] of the hair; and, also, that sometimes it does not act on all the hairs simultaneously, which it ought to do if it were a chemical change.

These are all very curious questions: but it is believed that we have not, at present, sufficient knowledge of the modus operaudi to discuss them to any advantage.

However, one thing is certain, that in regard to pile generally, if not universally, there is a decidence, which is sometimes gradual, and at others periodical. 'The former may be remarked in the slow and constant manner in which the hair of our heads falls out and is renewed; and is, most probably, due to a general law of our nature causing production, perfection, decay, and renewal of tissues. The latter appears to be a wise provision to secure the animal who depends upon his natural clothing, from suffering from the changes of seasons. Most animals, whose covering is hain, renew their coats at least once a year; in the Horse it is shed twice, viz: in the spring and the autumn, as may be observed in his wild state; when domesticated and stabled, it is transformed somewhat into a gradual decidence. In the Deer tribe there is a regular period; less so in the $\mathrm{Ox}_{x}$, and least of all in the Dog.

Goldsmith tells us, that when the hair of the Reindeer drops, it is not from the root, as in other quadrupeds, but that it seems to be broken short near the bottom. (Nat. Hist. of Man, \&c., 319.) We have had no means of examining this phenomenon.

For this natural falling of the wool in the case of Sheep, shearing has been substituted. But there are some notable cases which would appear to be exceptions to the law. One of these, namely, a Merino of Lord Western, is noticed in the English books, where the fleece was retained, without the slightest disposition to separate from the animal, for three years. (See Lib. of Usf. Know., p. 63.) And we have, in our cabinet, a specimen of Merino wool, presented by Mr. Aaron Clements, of this city, which was the first shearing of a three years' old Merino ram, and which is 18 inches long without being stretched. (See upon this point, Luccock on Sheep, p; 118.)

OF the restoration of Pile, tilat has been deteriorated, to its original INTEGRITY.-Prichard relates, that the wild hogs of "the new world, the descendants of" the animals left there by Europeans, bear a resemblance to the Wild Boar of Francethe skin being covered with thick fur, [wool,] often somewhat crisp, beneath which, in some individuals, is a species of wool. **

If these animals are so much like the Wild Boar of France, why may they not have descended from a wild species of America?

\footnotetext{
" Thete maly be cariclies, but there is but one species of wool.
} 
Of tile Endurance and Eremacausis of Pile- Raspail says, that cold checks the development of organized beings, but that it preserves organized substances, indefinitely, without alteration. In proof of the second branch of the proposition, he refers to the Nammoth that was found enveloped in ice, near the mouth of the river Lena, and to the bodies of the Spaniards which have lain, unchanged, on the iey summits of the Coldilleras, from the time of the first conquest of Peru. He also observes, that when they are afterwards thawed, these organized bodies putrefy more rapidly than those that have not been exposed to the influence of a low temperature. 'This last remark is, perhaps, less correct in regard to pile than some other organized substances, for we have, in om collection, specimens of the hair of the Mammoth, above alluded to, which has suffered very little, comparatively, from being thawed. Having, in a provious Chapter, $\nmid$ given a full description of that hair, we will, in this place, merely notice that one inch of it showed considerable ductility and elasticity, and required, to break it, from 4,500 to 4,600 grains.

In 1774, an apparently deserted ship was met in the Polar Sea, encumbered with snow and ice. On boarding her, a solitiry man was found in the cabin, his fingers holding a pen, while before him laid the record which lie had traced twelve years before. No appearance of decay was visible, except a little green mould upon his forehead.

Bichat attributes the great endurance of pile to its exterior envelope [cortex.] He says that when pile is deprived of the action of air, ages may pass away without any exhibition of alteration. (Anat. Gen., r. 2, p. 756.)

Ile further remarks, that "pile does not contain the principle of decomposition which belongs to other animal substances." Vedouht whether we understand what this learned anatomist means by "the principle of decomposition," since no one knows belter than he did that pile consists, essentially, of a substance allied to gelatino and bistulphuret of proteine.f

Bichat still further remarks, that "pile never rots, neither in air nor in water; that its endurance is superior to the epidermis, as may be proved by boiling or macerating them together." That pile has a greater endurance than the epidermis or dermis, we have, 11 our cabinet, several specimens which will furnish ample proofs; as a small piece of the skin and a portion of hair, from the skull of a Mummy, from Pisco, Peru, presented by Prof. Samuel G. Morton, M. D.; a piece of the skin with a portion of the hair attached, from the skull of a young Indian from the Temple of the Sun, at Pachacamack, five leagues from Lima, presented by Prof. Joseph Pancoast, M. D. 'This cemetery has not been used since the Spanish Conquest, previously to which (according to Herrera) it was kept sacred for the nobility of Peru. The skins, in both these cases, are much more decayed

* Eremacausis includes putrefaction, fermentrtion and decay; it is from "cremos," destitute, and "licu," to dry up or" wither. † See Chapter III.

t This substance has for formula, Carbon, 13; Iydrogen, 10; Nitrogen, 3 ; Oxygen, 5; and Gelatine (which is tho form of gelatine which is obtained from the skin, serous-membrane, hoof, bone, tendon and cartilage, having the furmulit of Carbon, 13; Hydrogen, 10; Nitrogen, 2, and Oxygsen, 5. (Van Lacr.) 
than the hair. In the last one the epidermis has the appearance of tanned leather, partly decayed.

We have a lock of hair, taken from the head of an infant who was buried twenty-one years, which is in a tolerable state of preservation, while the skin is entirely decayed. We might as well also notice again, the instances of hair found in the stomach of Ruminants, and expelled from the uterus, which, except that the button is decayed or not to be found, is not very much injured.

We have some hair from the head of a lady, that was in the grave thirty-two years. It has lost its ductility, elasticity and tenacity.

Of tile Transplanting of Hair.-Dieffenbach* and Weismant assert that a hair may be drawn out of one place and transplanted in another. Muller admits the possibility but denies the probability of this statement. (See Elem. Phys., 119.)

OF the EFfect of Diseases of tile Boty upon Hair.-For much information upon this head, see Rayer and Wilson upon Diseases of the Skin. See also Traité des Maladie du Cuir Chevelu par Cazenave, 1850. Dr. Green, (in Diseases of the Skin, p. 286, ) says that the secreting bulbs (follicles) of the hair, are secondarily or primarily affected in several diseases; that exanthematoust ferers are particularly apt to cause a temporary suspension of their functions, so that the hair is generally shed on the return of convalescence. In some instances (he adds) it amounts to a complete annihilation of their office, when permanent baldness is the consequence.

In such cases we suppose that the follicle is destroyed. It has been remarked that the wool of sickly or murrain sheep is finer, though it has less tenacity and possesses no lustre. And Mr. Luccock (speaking of the wool of old sheep which had lost their yolk) says that it "dies in the bowl," i. e. that it sinks in the water in which it is washed.

Of Disenses of Pii..-Bichat was of opinion that the exterior envelope of the hair (the cortex) is lifeless and insensible, and that therefore it cannot be the seat of any disease, either acute or chronic; from which he leaped to the conclusion that grey (colorless) hair, cannot be the subject of disease. (See Anat. Genl., 2 v., p. 796.) But when Bichat wrote this passage, it was supposed that a hair was composed of a cortex and medula (coloring matter) only.

Of Plica Polonica.§-A monstrous deal has been written upon this diseasé; nevertheless, there are some authors who doubt its existence. It is said that hair, under its influence, is enlarged in bulk, and that a passage is formed for red blood, which exudes,

\footnotetext{
* Nonn. de Regen, et transplan., Wurzlouro, 1832.

$\dagger$ De colitum partium, Leipzick, 1824, p. 33 .

\$ Hrom exanthemeta, eruption.

"From plico, to knit, and Pulonica, of Poland, "the Pblish knit," henuse the disease was thought to be peculiar to Poland, and that it caused the lair to linit en colcurgle.
} 
when the stalk is cut. (See Good's Study of Nature, v. 5, p. 675; Lib. of Usf. Kinow.. 56, and Bichat's Anat. Geul., v. 2, p. 789, \&c., \&c.) The most complete stmmary of Plica Polonica, will be found in Dict. des Sci. Med., Paris, 1820, v. 43, p. 226, 1it. "Llique," where all that had been previously written upon the subject by fifteen preceding anthors, is collected and arranged under appropriate heads. From this compendium it would seem that there are five varieties of this disease, to which man is subject at all ages, and that if has been traced to the lower animals when they are domesticated. That it is not confined to the hair of the head, but extends to all the hair of the body, \&c.; that sometimes it causes the hair to grow to an extraordinary length; that it makes its appearance moru frequently among those persons who are the worst fed, the worst clothed and the worst lodged, and, particularly, if they are uncleanly; that the seat of the disease is the follicle, but that its effects extend to the stalk; that the fluid which exmdes is not blood; that it has been known to attack the bulbs of the hair of shaven heads; that the matting of the hair is not a felting of the filaments but their glutination. 'This is the pith and marrow of the information.

$\Lambda$ case of incipient Plica Polonica having lately been discovered, in this city, we procured some of the pile, through Prof. John K. Mitchell, M. D.

Examination of the Irair of Annette Engle, aged 11, born in Poland of Jewish parents, laboring under incipient Plica Polonica.-Length, artificial, $1 \frac{1}{10}$ of an inch; shape, generally oval; mesne diameter, $\frac{1}{50}$ to $\frac{1}{5} \bar{z}$ of an inch; colors, brown and black; lustre, very feeble.

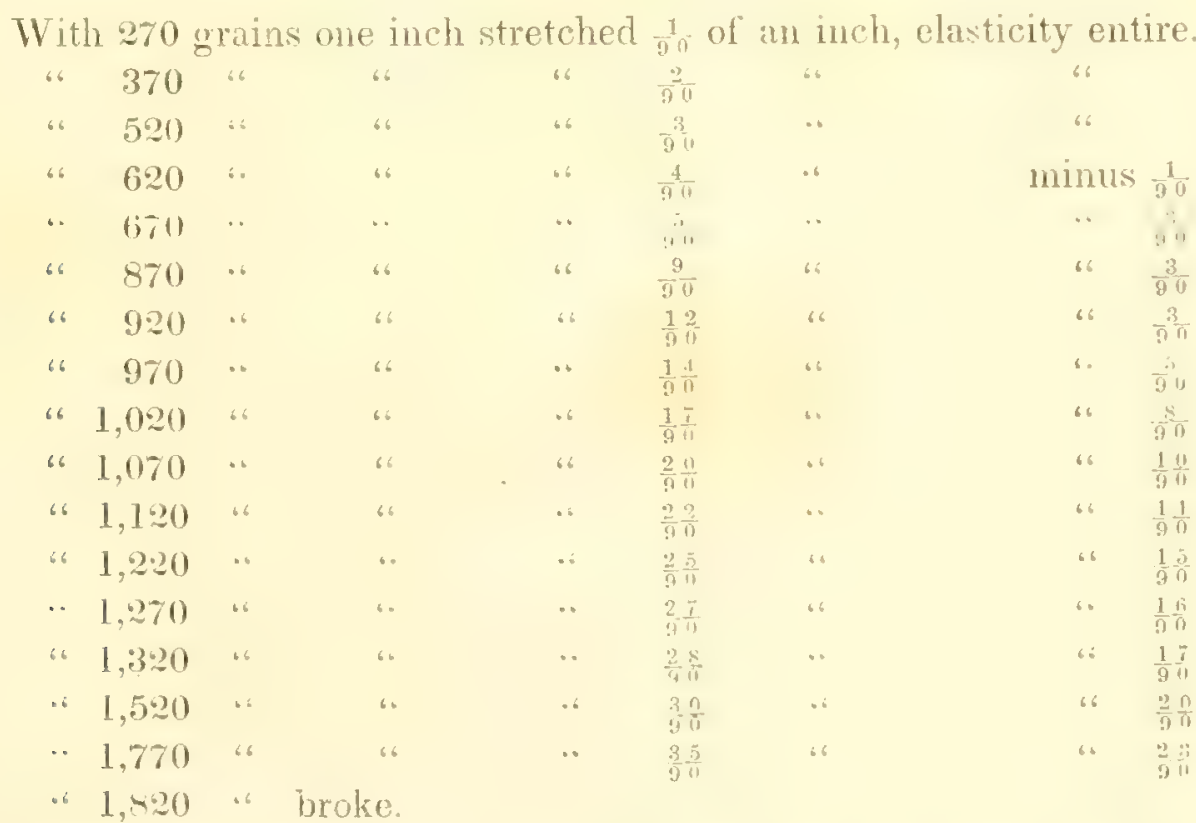

Fracture, complicated, the cortex having parted and the fibres being forn out and lacerated; buttom, black, sometimes club-shaped, and at others hamate. (See fig. 79.) Sheath, swollen and extending beyond the button, partly white and oparue, and partly translucent; shaft, varying in color; shape and diameter, for example, one shaft, which is of a brown color and of an imperfect shape, has a diameter of $3 \frac{1}{6}$, while another, which is black, and of a sub-trian!nlar shape, has a diameter of 
$\frac{1}{50}$ of an inch; cortex, dark-colored and opaque; when treated with terebinthus, becomes partially tianslucent, and a greatly interrupted dark coloring matter is then seen in the centre of the filament. Transverse sections, viewed as opaque objects, show a dark surfice, with a minute white central spot; disks, viewed as transparent objects, show a much larger white, (or motley,) irregularly shaped centre, in which are perceived the ends of fibrils and a dark central spot.

Having removed the cortex, fibres of a pure white and lustrous are seen. These are separable into fibrils, one of which measured the $\frac{1}{1000}$ of an inch. Direction, at an acute angle; inclination, crisped, frizzled and spirally curled; diameter of the curl, $\frac{3}{10}$ of an inch; apex, mostly abrupt, (artificial.)

Of the Hair in Tinea Capitis, or Favus.-Hair of Mary O'Donnell, aged five years, supposed to be laboring under Tinea Capitis, or Favus._Length, about 2 inches; shape, oval; diameter of some, $\frac{1}{56}$ by $\frac{1}{3} \frac{1}{3}$ of an inch, others $\frac{1}{500}$ by $\frac{1}{2} \frac{1}{7}$. 'The diameter of the sime filament sometimes varying in diameter the $\frac{1}{93} \overline{7}$ part of an inch; color, somerimes dark brown, at others horn-colored; no lustre; direction, at an acute angle; inclination, stinly bending at nearly a right angle.* (See fig. 80.)

Duclility, Elasticity and Tenacily.-

With 370 grains one inch stretehed $\frac{1}{90}$ of an inch, elasticity entire.

\begin{tabular}{|c|c|c|c|}
\hline 66 & 570 & 66 & 6 \\
\hline 66 & 720 & 16 & 66 \\
\hline 36 & 770 & 65 & 66 \\
\hline “6 & 820 & 66 & 66 \\
\hline 66 & 870 & 6 & "6 \\
\hline .6 & 920 & "6 & " \\
\hline . & 970 & 66 & b6 \\
\hline$\because 6$ & 1,120 & 6 & 16 \\
\hline .. & 1,170 & $\cdots$ & . \\
\hline 16 & 1,220 & .6 & " \\
\hline 16 & 1,320 & "6 & 66 \\
\hline 66 & 1,370 & 66 & 66 \\
\hline “6 & 1.120 & “. & " \\
\hline .. & 1,170 & .. & broks \\
\hline
\end{tabular}

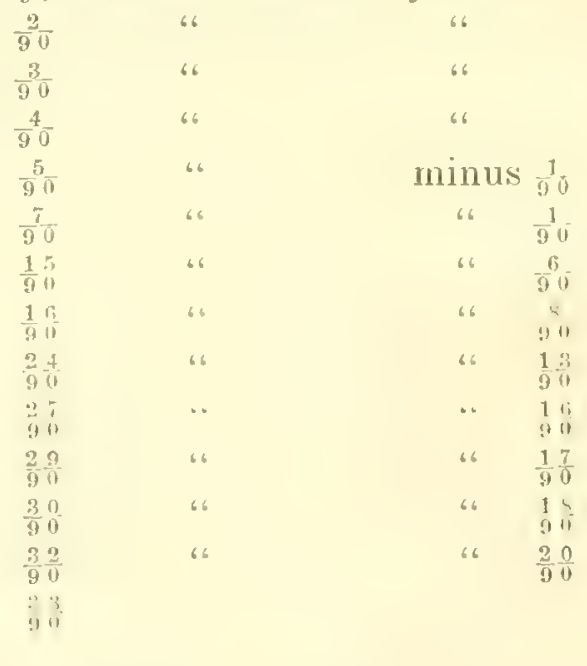

Fracture, abrupt; button, mostly obliterated, leaving the end of the shaft crooked, raggad and discolored, two buttons found sometimes adhering, enclosed in the same shatt; sheath, very much elongated and ragged, vessels adhering of the diameter of $\frac{1}{1} \frac{1}{5}$ of an inch; shaft, varying in diameter and color, bending abruptly when on the head, but expanding when put into water; apices, all abrupt.

Remarks. - This pile is so completely diseased that the button and the inferior portion of the shaft are destroyed. The shaft, bending at nearly a right angle, is an unfavorable

* Resembling in this respect the pile of sume of the species of animals who have the pared cortex. 
symptom, as it slows that its llexibility is inpaired. This cxamination shows that there is no probability of enring this disease without shaving the head and administering to the follicle.

Of Pile in Softening of tile Brain.-Examination and Description of the haiv of the head of a male, aged 60 years, laboring under Softening of the Brain, from the saturation of the system by the syphititic virus. - Specimen presented by D. I. Cain, M. I)., Charleston, South Carolina, A pril, 1552. General appearance, nothing remarkable; length, abont four inches; shape, oval, some of them slightly flattened on one of the extremities of the conjugate axis; diameter, $\frac{1}{2} \frac{1}{5} x_{\frac{1}{4}} \frac{1}{0}$ of an inch; color, of 20 hairs in the lock, seven are dark colored, the remainder are colorless, apparently from age; lustre, considerable; direction, flowing, slightly curled; inclination, no opportunity of examining, but presumed, from the shape, to be at an acute angle with the epidermis. (See fig. 81.)

\section{Ductility, Elasticity and 'Tenacity.-}

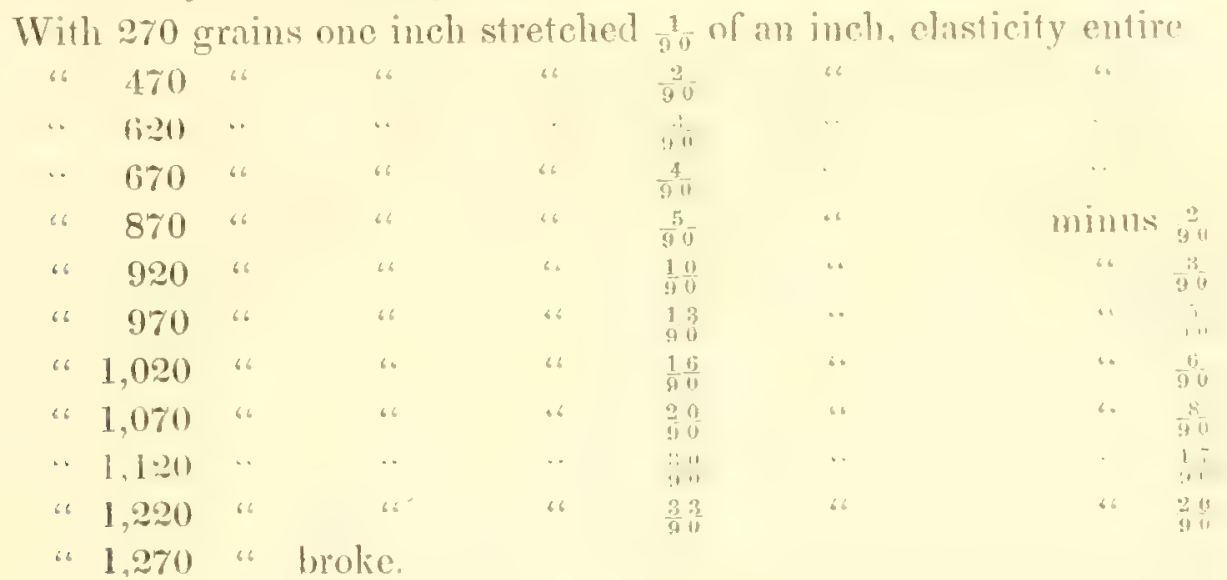

Fracture, abrupt; button, enveloped in a white, cellular substance which extends a considerable distance up and down the shaft, and prevents the button from being defined. This substance may, however, be rendered transparent or removed by maceration, when the button is seen, reduced to a mere knob. The matter removed by maceration imparts to the water a milky hue; shaft, cortex squamose; central canal, interupted; fibres, very apparent, when the shaft is crushed; disk, some dark colored throughout, others having a minute, white, central spot.

Remarks. - The part of this hair which is in an abnormal condition is the button and posterior termination of the shaft. 'The former, which in a healthy subject is naked, and is the shape of an oil flask and transparent or translucent, in this is covered with the white substance above described, and has lost is normal shape and transparency. In the white matter of one of these hairs are detected minute, highly colored, either fibres or vessels, for they are so small that it is difficult to determine their character with the highest powers of the microscope. 
The Examination of twenty-four Specmens of Diseased Praf.-Presented by Dr. William Pepper, of this city:

No. 1. Of the Hair in the last stage of Coxalgia, (hip-disease.)-Specimen presented by Dr. William Pepper. F'emale. Color, light brown; length, about 4 inches; mesne diameter, $\frac{1}{4} \frac{1}{6}$. All but one hair has the natural point; diameter, $\frac{2}{2} \frac{1}{50}$; none furcated.

With 230 grains one inch stretched $\frac{1}{90}$ of an inch, elasticity entire.

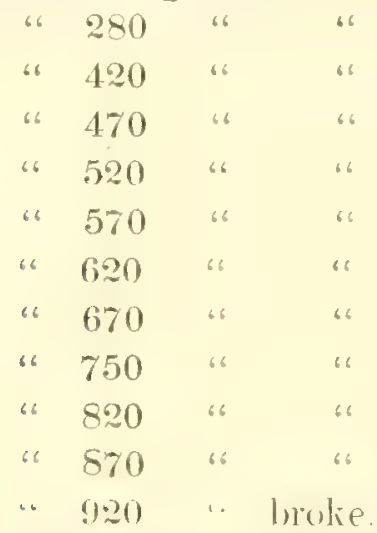

$\begin{array}{ll}\text { 6 } & \frac{5}{90} \\ 6 & \frac{6}{90} \\ 6 & \frac{7}{90} \\ 6 & \frac{10}{90} \\ 6 & \frac{1}{50} \\ 6 & \frac{20}{90} \\ 6 & \frac{25}{90} \\ 6 & \frac{30}{90} \\ 6 & \frac{35}{90} \\ 6 & \frac{37}{90}\end{array}$

minus $\frac{1}{9} \overline{0}$

"6 $\frac{2}{90}$

" $\frac{3}{911}$

“6 $\quad \frac{5}{9} 0$

"c $\quad \frac{9}{90}$

"6 $\quad \frac{1}{9} \frac{2}{0}$

6 $\quad \frac{17}{9} \frac{7}{0}$

6 $\quad \frac{2}{9} \frac{1}{0}$

" $\quad \frac{2}{9} \frac{2}{0}$

Firacture, abrupt; button, normal shape; translucent.

No. 2. Scrofula, (Caries.)-(Ulceration of Bone.)-Female-age 19. Color, light brown; length, about 6 inches; mesne diameter, $\frac{1}{2} \frac{1}{7}$. One of these hairs, drawn out of the button, singularly disrupted. (See fig. $46 \mathrm{c}$.) Buttons, distorted.

With 320 grains one inch stretched $\frac{1}{90}$ of an inch, elasticity entire.

\begin{tabular}{|c|c|c|}
\hline 68 & 370 & 66 \\
\hline 66 & 470 & 6: \\
\hline "6 & 570 & "6 \\
\hline 66 & 670 & 66 \\
\hline "6 & 720 & $\cdot 6$ \\
\hline 66 & 770 & 66 \\
\hline
\end{tabular}

No. 3. Phthisis, (Consumption of the Lungs.)-Male. Color, brown; length, 6 inches; mesne diameter, $\frac{1}{3} \frac{1}{12}$. Some of the apices pointed, but mostly abrupt; none furcated; buttons, normal.

With 170 grains one inch stretched $\frac{2}{90}$ of an inch, elasticity entire.

\begin{tabular}{|c|c|}
\hline 66 & 220 \\
\hline 68 & 270 \\
\hline 66 & 370 \\
\hline "6 & 670 \\
\hline 16 & 720 \\
\hline 66 & 8.20 \\
\hline 66 & 870 \\
\hline 66 & 920 \\
\hline$" 6$ & 970 \\
\hline 68 & \\
\hline$i b$ & $0 \div 0$ \\
\hline
\end{tabular}

$\begin{array}{lll}66 & 66 & \frac{3}{9} \\ 66 & 66 & \frac{8}{9} \\ 6 . & 66 & \frac{1}{9} \\ 66 & 6 & \frac{1}{9} \\ 66 & 66 & \frac{1}{9} \\ 66 & 66 & \frac{2}{9} \\ 6 & 6 & \frac{3}{9} \\ 6 & 6 & \frac{3}{9} \\ 6 & 6 & \frac{3}{9} \\ 6 & 6 & \end{array}$

\begin{tabular}{|c|c|}
\hline 66 & minus \\
\hline "6 & 66 \\
\hline "6 & 66 \\
\hline "6 & "6 \\
\hline "6 & 16 \\
\hline 66 & 66 \\
\hline$\Leftrightarrow$ & "6 \\
\hline .6 & 66 \\
\hline 66 & 86 \\
\hline "6 & 66 \\
\hline 66 & .6 \\
\hline
\end{tabular}


With 1,120 grains one inch stretched $\frac{402}{y}$ of an inch, elasticity minus action

" 1,230 " broke.

No.4. Advanced Phthisis, (Cavernis.)-Advanced Consumption, mith cavity in lungs.Male-age 20. Color, brown; length, 6 inches; mesne diameter, $\frac{1}{3} \frac{5}{3}$; buttons, hamate.

With 170 grains one inch stretched $\frac{2}{90}$ of an inch, elasticity entire.

\begin{tabular}{|c|c|c|c|c|c|c|c|}
\hline 66 & 270 & 66 & 6 & 6 & $\frac{3}{90}$ & 66 & 6 \\
\hline "6 & 320 & 6 & "6 & " & $\frac{5}{90}$ & & \\
\hline ، & 420 & 6 & " & " & $\frac{6}{90}$ & “" & minus \\
\hline “ & 470 & " & 66 & " & $\frac{\bar{i}}{9^{\prime}}$ & " & $\because \quad 9$ \\
\hline “6 & 520 & 16 & " & 6 & $\frac{15}{90}$ & $"$ & $" 6$ \\
\hline "6 & 570 & 66 & $" 6$ & 6 & $\begin{array}{l}20 \\
90\end{array}$ & 6 & 66 \\
\hline .. & 600 & .. & .. & . & 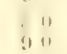 & & .. \\
\hline “ & 670 & $"$ " & "6 & " & $\frac{3}{9} \frac{5}{0}$ & 6 & 6 \\
\hline “ & 720 & "6 & " & $"$ & $\frac{38}{9} \frac{8}{10}$ & $"$ & " \\
\hline .. & 370 & .. & .. & .. & 4.7 & .. & $\cdot \cdot$ \\
\hline
\end{tabular}

" 820 " fracture.

No. 5. Chronic Pleurisy, extensive effusion.-Male-age 22. Color, brown; lenglh, '1 inches; mesne diameter, $\frac{1}{2} \frac{1}{5}$; buttons, distorted and discolored.

With 220 grains one inch stretched $\frac{1}{90}$ of an inch, elasticity entire.

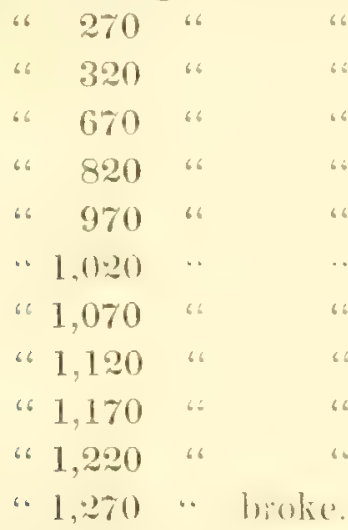

No.6. African Fever, 10 months, (very fatal.) - Male-age 42. Color, some brown and others without color; length, 4 inches; mesne diameter, $\frac{1}{2} \frac{1}{7}$. One of these hairs is bi-colored, and its anterior extremity is very unusual. 'The anterior extremity of another is remarkable.

With 220 grains one inch stretched $\frac{3}{30}$ of an inch, elasticity minus $\frac{1}{90}$

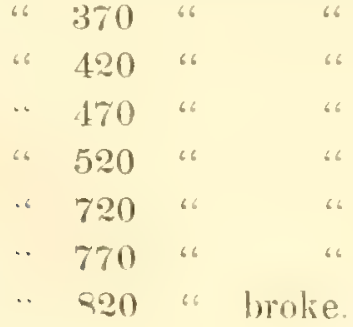

\begin{tabular}{|c|c|c|}
\hline 5 & 66 & 66 \\
\hline$\frac{6}{90}$ & "6 & 66 \\
\hline$\frac{1}{9} \frac{0}{10}$ & 66 & 66 \\
\hline$\frac{1}{9} \frac{2}{10}$ & "6 & 66 \\
\hline$\frac{3}{9} \frac{8}{11}$ & 66 & 66 \\
\hline$\frac{4}{4} 5$ & 6. & 6 \\
\hline
\end{tabular}


No. 7. Intermiltenl lever, 6 weeks, (Fever and Agne.)-Male-ige as. Color, brown; length, 3 inches; mesne diameter, $\frac{1}{2} \frac{1}{1}$; buttons, small and distorted.

No. 8. Acute Rheumatism, 2 weeks-Male-age 20. Color, brown; length, 6 inches; mesne diameter, $\frac{1}{50}$; buttons, hamate.

With 220 grains one inch stretched $\frac{1}{90}$ of an inch, elasticity entire.

\begin{tabular}{|c|c|c|c|c|}
\hline ". & 370 & "6 & "6 & 16 \\
\hline$"$ & 520 & $"$ & "6 & "6 \\
\hline 66 & 780 & " & " & 6 \\
\hline " & 820 & ، & 66 & a \\
\hline 66 & 870 & " & " & "6 \\
\hline " & 920 & .. & ، & “" \\
\hline . & 970 & . & . & . \\
\hline
\end{tabular}

No. 9. Albumimurea, 6 weeks, (Disease of the Kidneys.)-Mrate-age 21. Color, light brown; length, 3 inches; mesne diameter, $\frac{1}{8} \frac{1}{1} ;$ hutton, normal.

With 470 grains one inch stretched $\frac{1}{90}$ of an inch, elasticity entire.

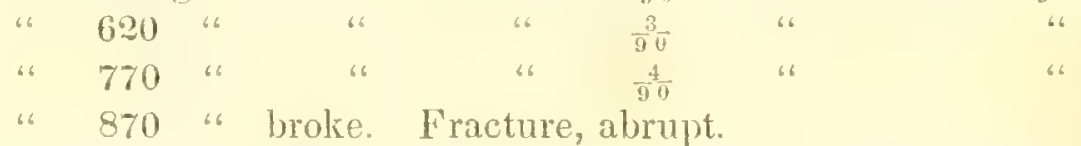

No. 10. Scrofula.-Female-age 26. Color, brown; length, 7 inches; mesne diameter, $\overline{3} \frac{1}{2} \overline{2}$. One button normal, the remainder distorted and discolored; some fureated.

With 270 grains one inch stretched $\frac{1}{90}$ of an inch, clasticity entire.

\begin{tabular}{|c|c|c|c|c|c|c|c|}
\hline 6. & $: 370$ & & ". & .. & 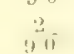 & ". & ". \\
\hline 66 & 520 & "، & " & 66 & $\frac{3}{90}$ & " & minus \\
\hline ، & 870 & “" & “" & ، & $\frac{4}{90}$ & " & $6 \quad 9$ \\
\hline 66 & 920 & "6 & "6 & "6 & $\frac{50}{90}$ & " & "6 \\
\hline “ & 1,070 & $"$ & "6 & 66 & $\frac{6}{90}$ & ، & 66 \\
\hline ، & 1,220 & $" 6$ & "6 & 6 & ${ }_{9}^{1} \frac{10}{0}$ & $" 6$ & "6 \\
\hline 16 & $1,: 320$ & “ & "6 & 6 & $\frac{15}{9}$ & "6 & ، \\
\hline “6 & 1,420 & $" 6$ & " & "6 & $\frac{24}{90}$ & " & 66 \\
\hline '. & 1,180 & .. & ". & ". & 30 & ". & " \\
\hline “ & 1,520 & $" ،$ & " & 6 & $\frac{2}{9} 7$ & " & 6 \\
\hline . & 1,570 & " & "6 & ." & 30 & .. & ، \\
\hline . & 1,620 & 66 & "6 & " & $\frac{3}{3} \frac{1}{0}$ & 66 & "6 \\
\hline & 1,670 & 66 & & tur & & ted. & \\
\hline
\end{tabular}

No. 11. 'Typleoid Fever, 2 weeks-Male-age 21. Color, dark; length,-32 inches; mesne diameter, $\overline{3} \cdot 5 ;$; buttons, some normal and others abnormal; none furcated.

With 520 grains one inch stretched $\frac{1}{00}$ of an inch, elasticity entire.

\begin{tabular}{|c|c|c|c|c|c|c|}
\hline 620 & "6 & 66 & " & $\frac{2}{0} \overline{0}$ & " & " \\
\hline 820 & " & 66 & 66 & $\frac{5}{90}$ & 6 & minus $\frac{1}{10}$ \\
\hline 920 & “" & " & " & $\frac{6}{90}$ & “ & $16 \quad \frac{1}{90}$ \\
\hline 970 & “ & “" & $6:$ & $\frac{7}{10}$ & “ & $\frac{1}{9 \pi}$ \\
\hline "1,020 & " & 6 & . & 9 & ". & 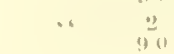 \\
\hline
\end{tabular}


With 1,070 grains one inch stretched $\frac{1}{9} \frac{1}{10}$ of an inch, elast. mints $\frac{2}{31}$

\begin{tabular}{|c|c|}
\hline $6 \quad 1,170$ & $" 6$ \\
\hline “6 $\quad 1,220$ & " \\
\hline 1,270 & "6 \\
\hline 1,320 & 6 \\
\hline
\end{tabular}

No. 12. Intermittent Fever.-Male-age 37. Color, brown; length, 1 inches; mesne diameter, $\frac{1}{30}$; buttons, some normal and others chu-shaped.

With 220 grains one inch stretched $\frac{1}{20}$ of an inch, elasticity entirc.

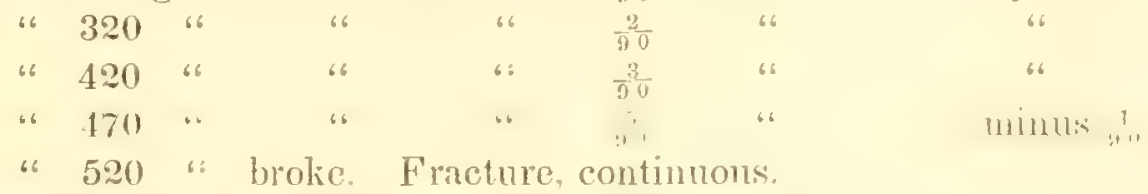

No. 13. Anomia.-Femalc-age 26. Color, blonde; length, 3 inches; mesne diameter, $5 \frac{1}{51}$; buttous, normal.

With 170 grains one inch stretehed $\frac{1}{30}$ of an inch, clasticity entire.

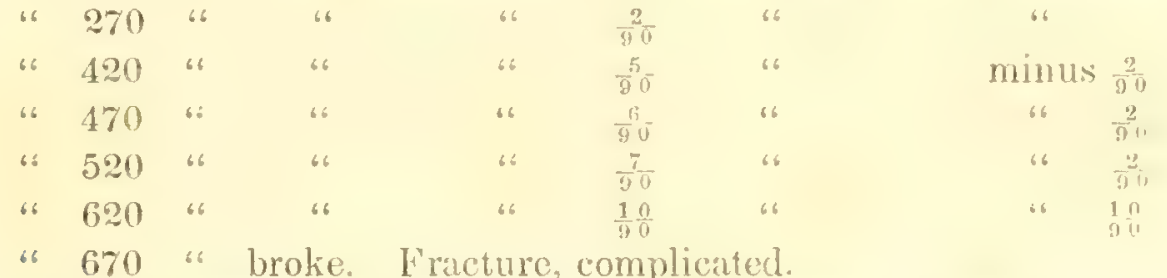

No. 14. Phthisis Tuberculosis, 32 months, (Consumption.)-Finale--age 22. Color, light; length, 6 inches; mesne diameter, $\frac{1}{5} \frac{1}{2}$; button, normal; apices, fureated.

With 220 grains one inch stretehed $\frac{1}{30}$ of an inch, clasticity entire.

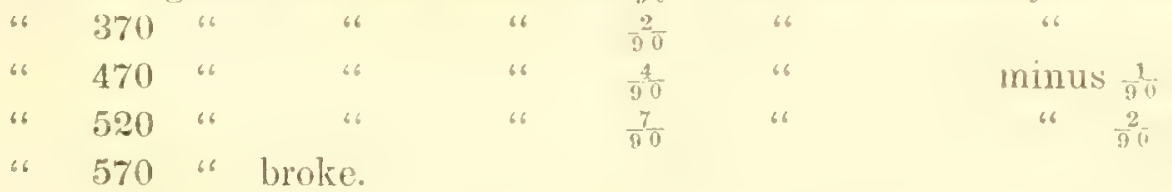

No. 15. Syphilis, Bubo, 4 months, (Venereal Discuse.)-Male-age 27. Color, brown; length, 4 inches; mesne diameter, $\frac{1}{1} \frac{1}{6}$; buttons, normal; apices, furcated.

No. 16. Syphitis, Second Stage, advanced to Ulceration, 7 months--Male-agre 38. Color, blonde; length, 4 inches; mesne diameter, $\frac{1}{16} ;$ buttons, small, distorted and discolored, club-shaped, one hair drawn out of the button.

With 170 grains one inch stretched $\frac{1}{90}$ of an inch, clasticity entire.

\begin{tabular}{|c|c|c|c|c|c|c|}
\hline "6 220 & 6 & " & 66 & $\frac{3}{90}$ & " & minus \\
\hline 320 & $"$ & " & “6 & $\frac{4}{90}$ & “ & " \\
\hline 420 & "6 & $66^{\circ}$ & ، & $\frac{5}{80}$ & "6 & "، \\
\hline 520 & 6 & “ & “ & $\frac{6}{90}$ & ‘. & “ \\
\hline 570 & 66 & “ & “ & $\frac{18}{9}$ & 6 & 6 \\
\hline 620 & ، & ، & “ & $\frac{17}{90}$ & & "، \\
\hline 670 & .6 & ، & "، & $\frac{2}{9} \frac{\hbar}{0}$ & ‘ & $" 6$ \\
\hline 720 & " & “" & "6 & 35 & 。 & $\cdots$ \\
\hline
\end{tabular}


No. 17. Syphitis, Eruptive, 6 months, (still further advanced.)-Male-age 39. Color, light; length, 4 inches; inesine diameter, $\frac{1}{2} \frac{1}{8}$; buttons, normal.

With 320 grains one inch stretched $\frac{1}{9} \sigma$ of an inch, elasticity entire.

\begin{tabular}{|c|c|c|c|c|c|c|c|}
\hline 16 & 520 & 66 & 66 & 66 & $\overline{2}^{2} \overline{0}$ & 66 & minus \\
\hline 66 & 670 & 66 & 66 & 66 & $\frac{3}{90}$ & 66 & 66 \\
\hline 6 & 820 & 66 & 16 & 66 & $\frac{5}{90}$ & 66 & 66 \\
\hline 16 & 920 & 66 & 66 & 66 & $\frac{6}{90}$ & 66 & 6 \\
\hline *. & 1781 & * & ." & $"$ & $\begin{array}{lll}1 & 11 \\
1 & 11\end{array}$ & " & " \\
\hline 6 & 1,020 & 66 & 66 & 66 & $\frac{1}{9} \frac{5}{0}$ & 66 & “" \\
\hline “6 & 1,070 & 66 & 66 & 66 & $-\frac{1}{9} \frac{7}{0}$ & 16 & 16 \\
\hline “6 & 1,120 & 66 & 86 & 66 & $\frac{2}{10}$ & 16 & 66 \\
\hline 6 & 1,170 & 66 & 6 & 66 & $\frac{2}{9} \frac{5}{10}$ & 6 & 66 \\
\hline 36 & 1,220 & 66 & 66 & 66 & $\frac{2}{3} \frac{8}{0}$ & 66 & 66 \\
\hline 66 & 1,270 & 16 & 66 & 66 & $\frac{1}{90}$ & 66 & 16 \\
\hline
\end{tabular}

No. 13. Chronic Bronchitis, 2 months.-Male-age 54. Light and without color; buttons, some normal and others distorted.

With 170 grains one inch strotehed $\frac{1}{30}$ of an inch, elasticity entire.

\begin{tabular}{|c|c|c|}
\hline 16 & 220 & 16 \\
\hline 66 & 370 & 66 \\
\hline 16 & 520 & 66 \\
\hline 16 & 620 & 66 \\
\hline 66 & 670 & 16 \\
\hline "6 & 720 & 66 \\
\hline .6 & 770 & 6 \\
\hline ".t & 820 & 66 \\
\hline " & 870 & 66 \\
\hline
\end{tabular}

No. 19. Hair of four Women advanced from cight to nine months in pregnancy.Diameter, $\frac{1}{8}-\frac{1}{5} \overline{1}-\frac{1}{3} \overline{1}$ and $\frac{1}{3} \frac{1}{9} \overline{0}$; butions, distorted.

No. 20. Acute Rhcumatism, 2 weeks.-Male, 25; color, light; mesne diameter, $\frac{1}{2} \frac{1}{3}$; buttons, normal ; no furcations.

No. 21. Neuralgia, 15 months.-Female-age 28. Length, six inches; color, dark; mesne diameter, $\frac{1}{1}$; generally but one hair is eccentrically elliptical, spirally curled and fureated; buttons of the natural shape but covered with a white substance.

With 170 grains one inch stretched $9^{\frac{3}{0}}$ of an inch, elasticity entire.

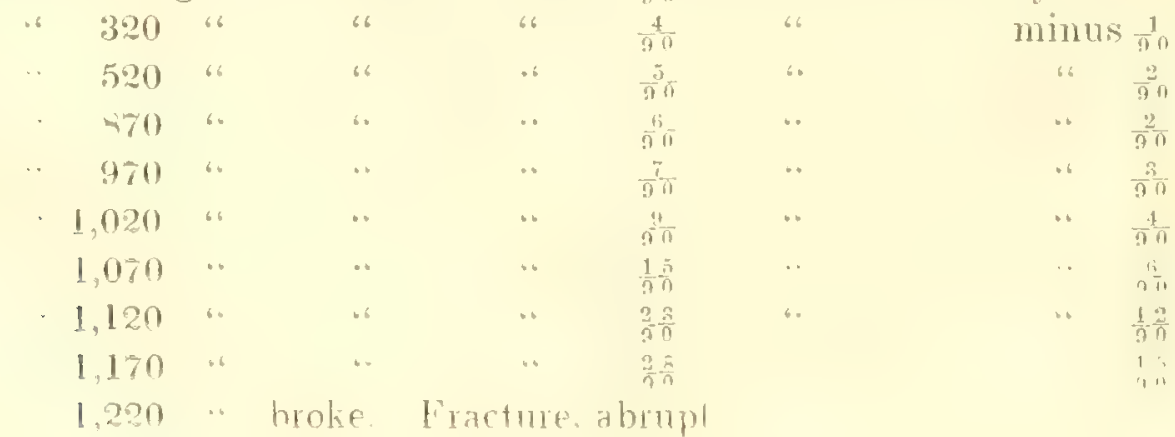


No. 22. Amenorrhaa, 1 year, (whites.)-Female, 17. Color, brown; length, 1: inches; mesne diameter, $\frac{1}{2} \frac{1}{1}$, generally; near the apex, $\frac{1}{5} \frac{1}{8}$; furcated; button, normal.

With 170 grains one inch stretched $\frac{1}{90}$ of an inch, elasticity entire.

\begin{tabular}{|c|c|c|c|c|c|c|}
\hline 720 & 6 & 6 & 66 & $\frac{2}{30}$ & 66 & 16 \\
\hline 870 & “" & " & " & $\frac{4}{90}$ & " & .. \\
\hline 1.070 & $" 6$ & 6 & 6 & $\frac{9}{3}$ & 66 & 6 \\
\hline 1,170 & 6 & $"$ & " & $\frac{1}{9} \frac{7}{11}$ & 6 & 66 \\
\hline
\end{tabular}

No. 23. Albuminurice, 14 months, (Disease of the Kidneys.)-Female-age 24. Color, light; length, 5 inches; mesne diameter, $\frac{1}{2} \frac{1}{8}$; button, decayed.

With 220 grains one inch stretched $\frac{2}{30}$ of an inch, elasticity entire.

.. $4: 0$ ". broke. Fricture.

No. 24. Typhoid Fever, 5 weeks.-Female-Color, browin; length, 8 inches; mesne diameter, $\frac{1}{4} \frac{1}{1}$; button, of the normal shape, but with a white substance adhering.

With 220 grains one inch stretched $\frac{1}{90}$ of an inch, elasticity entire.

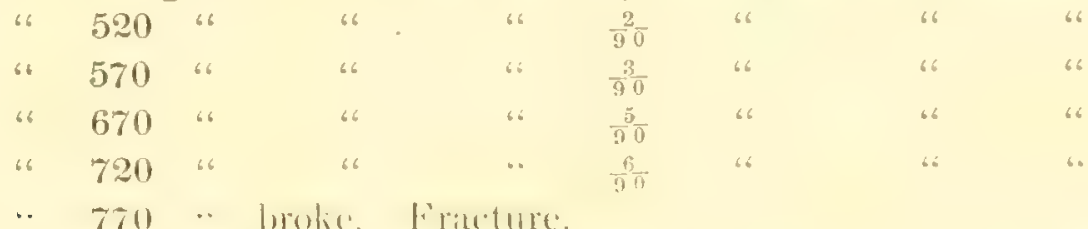

The above specimens of diseased hair were presented by us to the Jefferson Medical College of Philadelphia.

Of the Pile of Lunatics.**-After having, for a considerable time, been engaged in examining the hairs and wools of the Mammalia, it occurred to us to endeavor to discover whether there is any difference between the hairs of lunatics and those of the sane. With this object in view, we applied to Dr. Kirkbride of the Pennsylvania Insane Hospital, who politely sent us twenty specinens of these tegumentary appendages, cut from the scalps of as many unfortunate beings, both male and female, of various ages, and laboring under different kinds of insanity. All these we submitted to the most rigorous examinations with the trichometer, and under the microscope, but conld elicit nothing material, except that we thought the coloring matter was rather more confused than usmal. We next applied to the same gentleman for some drawn hairs, and he sent us over one hundred, extracted from the heads of different persons, all old cases of lunacy, but more than half of them were without button, and the whole were unaccompanied by designations of the age, sex, the kind of insanity, or term of suffering.

Not wishing to trespass upon the kindness of the same gentleman a third time, we applied to a friend, through whom we obtained from Dl: Evans, of the Frankford Insane Asylum, twenty-one specimens, all carefully drawn and marked; these, with the latter parcel, presented by Dr. Kirkbride, enabled us to arrive at rather more satisfactory results.

An Examination of 21 Specimens of the Hair of Lanatics, presented by Dr. Evans, made in August and September, 1849 : 
No. 1. Marked, "Female, aged 45, dementia 20 years."-This lock contains ten rather coarse hairs, of which six are colorless, and the remainder dark brown; one of the dark brown has its natural pointed apex, all the rest terminate abruptly; one bifurcated; seven of the ten are devoid of button; one has the button of the usual shape, and two, (one brown and the other colorless, ) have the button dark colored and distorled; the filaments are inclined to curl.

No. 2. Marked, "Female, aged 30, dementia 14 years."-In this lock there are seven hairs, all brown colored; two of them without button; of the remaining five, two have the usual button, and the other three are dark colored, opaque and distorted. The apices are all pointed and the filaments inclined to curl; none furcated.

No. 3. Marlied "Female, aged 42 , imbecility 13 years."-This lock contains nineteen fine, brown, straight hairs; seventeen of them without button; of the remaining two, one has the button, as usual, and in the other it is dart colored and distorled. Terminations, generally abrupt; a few pointed; none furcated.

No. 4. Marked "Female, aged 32 years, dementia 10 years."-This lock contains four dark colored hairs; all pointed, but with no button; none furcated.

No. 5. Marked "Femate, aged 25, dementia 5 years."-There are only eight hairs in this lock of dark hair; all but one abruptly terminated; two without button; of the remaining six, two have the usual, and 4 dark colored listorled buttons.

No. 6. Marked "Female, aged 27, mania paroxysmal."-There are in this lock ten hairs; all brown, and very fine, but without button; terminations, abrupt; none furcated.

No. 7. Marked "Female, mania, convalescent, aged 66 years."-Where are, in this, lock, eight colorless hairs, with abrupt terminations, but without buttons; none furcated

No. 8. Marked "Male, aged 32, imbecile from childhood."-T here are, in this lock, sixteen fine, brown colored hairs; six of them without button; on five of the remainder there are the usual button, and on five the buttons are distorted. The hair is flowing, and apices ubrupt, except two, which are pointed. The distorted buttons are opaque, and dark colored at the extremity; none furcated.

No. 9. Marlied "Male, aged 49, dementia 29 years."-This lock has twenty-seven hairs, but only seven of them have a button; of these, three are in the common form, and four are dart colored and distorted. 'The filaments were, originally, light brown colored, but are now mostly colorless; one (colored) hair is pointed; the rest terminate abruptly.

No. 10. Marked "Nale, aged 40, dementia 20 years."--This lock contaius twenty-five hairs, of which eighteen have no button ; of the remaining seven, four are of the ordinary shape, and three are distorted and dark colored. The hairs are dark brown color, and fine; have the apices abrupt, except in a single instance, and in that the point is colorless; none furcated.

No. 11. Nartied "Male, aged 38, epileptic from puberty; incurable."-This specimen is in two parcels; parcel " $a$ " has thirty-seven hairs, of which thirty-three have no button; of the remaining four, all are dark colored and distorted; parcel " $b$ " has thirteen hairs, and one only with a button, which is of the ordinary shape. The hair is dark colored; apices, abrupt; none furcated.

No. 13. Nartied "Date aged 5\%, cpileptic 9 years."-There are, in this lock, fourteen 
hairs, thirteen of which have no button; the fourteenth is dark colored and distorted: twelve of the hairs are dark brown, and two colorless; the apices are all abrupt; none furcated.

No 14. Marked "Male, aged 25 , dementia $2 \frac{1}{2}$ years." - There are, in this parcel, thirti hairs; but only four of them have buttons; and they are all dark colored and distorterl. The lock is brown, and the apices abrupt of termination; none furcated.

No. 15. Marked "Male, aged 59, dementia, from paralysis, 2 years."-There are, in this lock, fifteen hairs, only four of which have a button; they are all darts colored and distorted. The hair is brown and fine; the terminations abrupt; none furcated.

No. 16. Marked "Male, mania 1 year; incurable." - There are, in this lock, twenty hairs; but not one of them has a button; none furcated.

No. 17. Marked "Male, aged 56, hypochondria 10 months."-This lock has fwenty-four hairs, all but six cololed; but two have buttons, and they are diminutive, opaque and not very regularly formed; apices, abrupt; none furcated.

No. 18. Marked "Male, ager. 54, acute mania 1 month."-'There are, in this lock, eighteen hairs, and byt three of them with buttons; one of them white and opaque, and of the ordinary shape; hair, brown and colorless; apices, abrupt.

No. 19. Marticd "Male, aged 35, mental depression; convalescent."-There are twentyfour hairs in this parcel, only two of which have a button; and they are white, opague, and in the ordinnry form. The hair is dark colored; the apices abrupt; none furcated.

No. 20. Marked "Male, aged 21, congential imbecility; incurable." - There are twentyfour hairs in this lock, fifteen of which have dark colored and distorted buttons; and two white, ordinary shaped ones. Color of hair, brown; and all the apices, except one, abrupt.

No. 21. Murked "Male, aged 65, dementia; incurable." - There are, in this parcel, sixteen hairs, all but three of which are colorless; there is one diminutive button, slightly distorted; none furcated.

RFCAPITULATION IN TABLISAR FOIM.

\begin{tabular}{|c|c|c|c|c|c|}
\hline $\begin{array}{l}\text { Examination of the spe- } \\
\text { cimens. }\end{array}$ & Number of IIairs. & $\begin{array}{c}\text { Number of Hails with } \\
\text { Buttons. }\end{array}$ & $\begin{array}{c}\text { Number of regularly } \\
\text { shaped Buttons. }\end{array}$ & $\begin{array}{l}\text { Number of distorted } \\
\text { Buttons. }\end{array}$ & $\begin{array}{c}\text { Number of lissolored } \\
\text { Buttons. }\end{array}$ \\
\hline 1 & 10) & 3 & 1 & 2 & 2 \\
\hline 2 & 7 & 5 & 2 & 3 & 3 \\
\hline 3 & 19 & 2 & 1 & 1 & 1 \\
\hline 4 & + & 0 & 0 & 0 & 0 \\
\hline 5 & 8 & 6 & 2 & 4 & 4 \\
\hline 6 & 1i) & 0 & 0 & 0 & 0 \\
\hline 7 & 8 & 0 & ก & 0 & 0 \\
\hline 8 & 16 & 111 & 5 & 5 & 5 \\
\hline 9 & 27 & 7 & 3 & 4 & 4 \\
\hline 10 & 25 & 7 & 4 & 3 & 3 \\
\hline 11 & $3 T$ & 4 & $n$ & 4 & 4 \\
\hline 12 & 13 & 1 & 1 & 0 & 0 \\
\hline $1: "$ & 14 & 1 & 0 & 1 & 1 \\
\hline 14 & 80 & + & 1) & 4 & +1 \\
\hline 15 & 15 & $i$ & 11 & 4 & 4 \\
\hline 16 & 20 & 1) & 11 & (1) & 11 \\
\hline 17 & 24 & 2 & 2 & 0 & 0 \\
\hline ls & 18 & $\therefore$ & $\because$ & 0 & 0 \\
\hline 19 & 24 & 2 & 2 & () & 1) \\
\hline 20 & 24 & 17 & $\because$ & 15 & 15 \\
\hline 21 & 16 & 1 & 0 & 1 & () \\
\hline 'lutal. 21 & 454 & $\because !$ & $2 \pi$ & 52 & it \\
\hline
\end{tabular}


Examination of the second parcel of hairs, presented by Dr. Kirkbride, marked "Drawn Ilairs of Lunaties-mostly old cases."-There are, in this parcel, one hundred and fiftyeight hairs; of these, ninety-eight have no button, ten have the ordinary button, and fifty have the button distorted and discolored.

From the whole of these examinations, we feel satisfied that if there exists any difference between the hairs of the sane and the insane, it must be sought for in the button. It will be recollected, that this portion of a perfect hair of the head of a sane white person is translucent, and of a regular shape-generally that of a pestle. (See Figs. 16 and 17.)

When a hair is drawn out of the head, we sometimes have the stalk only-the button, sheath and follicle, being all left behind. This is more generally the case when the dermis or epidermis, owing to discase or any other cause, is contracted; and this, probably, will account for the large proportion of hairs of the insane, which came under examination, being without a button. U pon three hnundre.I and sixty-nine hairs, presented by Dr. Evans, we found but seventy-nine buttons-and this occurred after a careful drawing; and upon one hundred and fifty-eight hairs, obtained from Dr. Kirkbride, there were but fifty buttons. Upon an equal number of hairs, carefully drawn from the head of a sane, healthy white person, probably there would have been three-fourths with a button.

It will be perceived that out of 139 buttons examined by us, thirty-eight had the ordinary, and 101 distorted and discolored buttons. The distortions hitve no general character, some of them are flattened, others are crooked, curved or twisted and there are a few that are hamate. There is a loss of the translucency, which is chracteristic of the button of a sound hair.* We do not, nevertheless, pretend to have extended our examinations to the length that would authorise the enunciation of a theory; but, on the contrary, make the result of our labors known, merely to attract the attention of medical gentlemen, and particularly those who are connected with insane asylums, to the subject. Should future inquiries confirm our views, it will appear that in lnnacy the slin and its appendages are affected, and these distortions and discolorations of the button may become valuable diagnosties. It has been shown that the bution and follicle, as well as the shaft of the hair are continually forming from cells, to supply the deficiency caused by gradual waste from hairs falling ont; and this explains why a part only of the hairs examined were distorted and discolored, while the remainder were in the ordinary state.

The hairs of lunatics were the first diseased ones which came under our examination, and it is possible that we may have mistaken for the signs of hunacy what were the marks of disease only. If this shall turn out to be the case, the error can easily be corrected by comparison with other diseased hairs.

We are assured by Professor Dunylison, (in Hum. Philos., p. 277, ) that, "Mania never occurs without the physical condition of the brain undergoing some change, directly

\footnotetext{
* Since mriting the foregoirg, we have cxamined a great many hairs cillunatice from the $\boldsymbol{A s y l u m}$ in Staunton, Western Virginia, and from two lunatic asylums in Ohio, and found the results always the same.
} 
or indirectly," and that, also, "the cranium is often affected, seeming, for example, to be musually thick, dense and heary." Then, what is there incredible in the idea that it affects the skin and hair of the head.

All that we have to say, in conclusion 1s-do not decide upon the merit of onr discovery until you have examined the subject.

$$
\text { "Finis coronat opus." }
$$

Of the Decay and Deatu of Pile.-It has been decreed by the Mighty Power which confers vitality upon organism, that there shall always be a limit to its endurance; and hence we find that even where dissolution is not hastened by violence or disease, time never fails gradually to bring life to a close. Whenever the comection between pile and its vessels is in any way severed, the former dies, and then, like all effete matter, it inclines to separate from the living organism. But the stalk of the hair nay die, and the follicle survive; in which case the hair may fall out, and a new one be produced. Whether the follicle, after having been separated from its vessels, is ever resuscitated, or a new one produced, are (to say the least of them) doubtul questions, notwithstanding all that has been asserted in books about the transplanting of hair.

Hair which falls out of itself is dry, and ordinarily colorless, even when it has been previously colored. Henlé seems to think that we know nothing of the canses which determine hair. But, admitting our knowledge upon that point to be scanty, still we may reason upon the facts in relation to it, which experience has brought to light. We read of a boy who was found wild, and his body is said to have been entirely covered with hair, like one of the lower animals; $*$ and among the savage race of Kurlians, there are individuals who have hair growing down the back and covering nearly the whole body. From

* Tre Wild Woman of tue Navidad. - About a year since an aceount was published in the Victoria Adrocate respecting a strange creature, whose tracks hal been discovered on the banks of the Navidad, near Texana. The footmarks of this creature resembled those of a moman, and a report was circulated to the effect that a wild woman had made her retreat in the forests of the Navidad. Within a few weeks several attempts have been made to capture this singular being. Mr. Glascoek pursued it for sereral days with dogs, and at one time approached so near it as to cast a lasso upon its shoulders. It, however, with great adroitness, eluded the snare, and fled to a dense thicket where it could not be traced. Mr. Glascoek states that he was near a small prairie enclosed by the border forests of the river, when the creature emerged from the woods and ran across the prairie in full vietr. It was about five feet high, resembling a lhuman being, but corered with hair of reddish-brown color. In its hand it held a stick about six feet long, which it flourished from side to side, as if to regulate its motions, and aid it when running at full speed. Its head and neck are covered with rery long hair, wluich streamed l,ackward in the wind. It ran with the speed of a deer and was soon out of sight. Ihe dogs pursued it, and came so close upon it at a small ereek, that it was compelled to drop its stick, which was taken by its pursucrs. This stick is alout six fect long, straight and smooth as if polished with glass. Several other persons hare repeatedly seen the creature, and they all concur in representing it as a human being, but so covered with shagre hair as to resemble an ourang outang. It has frequently approached the houses of the settlers in that neighborhood during the night and stole various articles; among other things it carricd off a quantity of towels, one or two books, and has taken several pigs. One of its nests was found in the forest, in which were sereral napkins, folded upjust as they were taken. $\Lambda$ bill for washing was also enclosed in the Bible. The foomarks of this strange beint have often been traced in the bottom of the Naridad, hut it has eluded all attempts to capture it. The old settlers in that section say that thesc footmarks have been noticed for ten or twelve years, and that several years ago there were other footmarks, indicating that three of these creatures were in eompany. Within the last vear" the footmarks of only one have been noticel. Mr. Glascoek intends to collect a jack of good hounds and resume the pursuit. and he is confident that he will sueceed in capturing it. - [From the Houston (Texes) Teleyraph.] 
these facts, and others of a like nature, we may conclude that hair was intended to protect us from violence and the inclemencies of seasons. By its division into filaments, which, (especially in regard to those of the head,) spread and flow, catching every breeze, it exposes the largest possible exient of surface to the actions of light, of the atmosphere and of electricity, which, doubtless, act upon its fluids, promoting their motions.

OF Baldness.-Savages, who never wear hats or caps, retain their hair ; but civilized man covers his head and becomes bald. It is painful to see the glowing and graceful locks of children suffering false imprisonment in paper curls, put into the stocks of unnatural plaits, or smothered under imperious head-gear, to the manifest injury of its growth and destruction of its beauty.

Every one must have remarked that females do not become bald as often as males, which may be accounted for by their wearing less dense coverings on their heads than our felted hats.

These considerations teach us what are the general causes of baldness; nevertheless, there are others which may conspire to the same effect. It has already been shown that the hair of the head of the oval-haired man, has an inclination of obliquity with the epidermis through which it pierces; and any forcible change of this divection will have a tendency to loosen the hair in its sheath, or in its sheath and in the follicle, and will cause it prematurely to fall out. The disagreeable feeling which we experience when our hair is combed "the wrong way," as it is generally termed, that is, contrary to its natural inclination, is not at all owing to any feeling in the shaft, but to this disturbance of the sheath, or sheath and follicie, which is experienced by the nerves, and this disagreeable feeling is a warning that we are warring against a law of nature. The effect of this practice is most injurions when the operation of altering the inclination is done with a stiff brush; each bristle, at its extremity, is placed against the lower end of the shaft of the hair, and when the brush is turned outward and upwards, acts as a lever, prying out the filament, which had been previously loosened. Dr. Gross says, that baldness generally commences at the crown of the head, + and this is the place which is generally most brushed.

Another fruitful source of baldness is the too free use, in anointing the head, of aqueous or alcoholic essences, which remove the natural grease designed to preserve the hair. To which we might add that some persons, when colorless hairs make their first appearauce in their heads, pluck them out.

Julia, the daughter of Aupustus, celebrated for the unbridled license of her manners, was early visitel with gley hairs, which she pulled out in secret. One day she was surprised by the sudden appearance of the Emperor, who saw several of the drawn hairs upon her robe. Augustus, dissimulating at first, led the conversation to age, and inquired of his daughter which she would prefer, baldness, or grey hair. "The latter," she promptly "nnswered. "Why, then," asked the Emperor, "do you allow your women to make you bald?"

\footnotetext{
* 'The old sarages of Vanikoro Island (Australia) become balıl! (Latham, Nat. Ilist. of Var., de., 223.)

t lilem. of Path. and Anat., 328.
} 
Of Pile Growing after Deatri-Among the elder writers upon this subject, we find several accounts, apparently well authenticated, of hair growing after death; but Bostock does not consider them worthy of credit. (See Syst. of Physi., p. 53.) Bichat, however, assures us of one case, which came under his immediate notice, and his word is not to be doubted. It was the beard of a chin of a subject preparing for anatomical examination, it had been closely shaven, and after maceration for about eight days, in a cellar of the dissecting-room, the beard was discovered to be grown, (how long we are not told.)

We have, in our collection of specimens of pile, a lock of fine, dark brown hair from the head of the gallant Lientenant Ayres, who died in Mexico during the late war. The body was buried in that country, but being disinhumed, after the lapse of a few months, it was found that the hair had grown upon his head, which, during his illness, had been shaved in oriler to apply blisters.

We have also a lock of the head of John Dennis Garwood, an infant son of Mr. John Garwood, of this city. This little innocent died and was buried, and disinterred after a lapse of twenty-one years; when alive, it had a remarkable long lock of hair, which projected from a peculiar spot on its head; this, when the child died, was cut off and preserved by the mother, and, when the cofin was opened, after having lain for this long period in the earth, this lock had been renewed, and had sprouted beyond the rest of the hair.

Examination and Description of the Hair of John Dennis Garwood, which grew after Death.-Length, 4 inches ; shape, oval ; greatest diameter varying from $\frac{1}{9} \frac{1}{7}$ to $\frac{1}{12} 50$ of an inch ; color, brown, no lustre; direction, flowing, slightly curling; inclination, unknown.

Ductility, Elasticity and Tenacity.-

With 220 grains one inch stretched $\frac{1}{0}$ of an inch, elasticity entire.

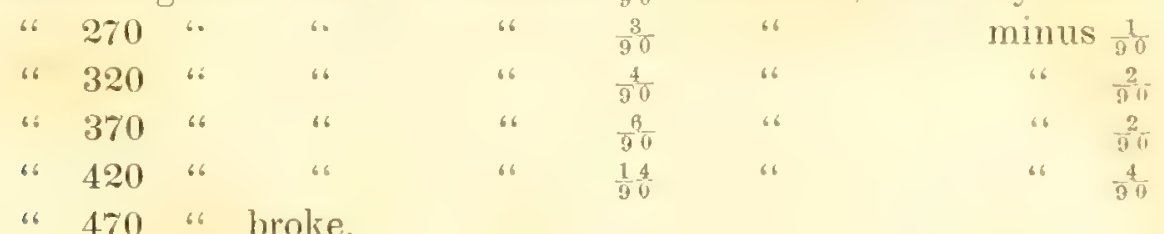

Button, very rare and thin, diminutive; sheath, none; follicle, none; shaft, very unequal in diameter, of different filaments; upon rubbing between two pieces of glass the scales disengage, the cortex separates from the fibres which are white; no central canal perceptible; coloring matter in lines in the cortex; apex, pointed, none furcated; among the fibres was discovered one that was blue.

Remark.-This is an imperfect hair.

We have heard it asserted that sheep's wool, left in its grease, (that is its yolk, or natural soap,) after having been separated from the body, will increase in weight; but we regard this as a popular error. In an Essay upon Sheep, * it is said that it may increase in weight for a few days, especially if lept in a damp place, but after that it rapidly

* Library of Useful linowledgc, p. Tt. 
becomes lighter, ending in considerable loss. When wool has been long kept a dust may be shaken from it. 'This is probably the decomposed yolk.

Kraft,* (in Nov. Com. Petrop., v. 2, p. 24, ) says that hairs lengthen after they are detached from the body. We know nothing of this phenomenon. (See Meckel, Man. of Anat, v. 1, p. 320.)

* Having understood that Dr. Coates had seen some hair grown after death, we wrote to him upon the subject, and suljoin his answer:

Philadelphia, Novemuer 13th, 1851.

Dear Sir:-I have received your polite favor respecting instances of hair growing on anatomical preparations while preserved in spirits. I can bardly believe that this plenomenon is very rare. The specimen to which I referred Dr. Chaloner, was a tumour remored by Dr. Physick, at an early period of his practice, from bebind and below the angle of the jaw of a man, with ultimate success. Part of the patient's whiskers had grown from the portion of the skin which was remored. The case is in the Hospital Case Book, with a drawing; and, I think, was published in the journals of the day. In such cases, hair was uniformly shaved off before making the incisions; and I remember, in addition, hearing my father say that he saw this opreation, and that it was dun so in this instaner. The hatr, in the ghas far of spirits, when $I$ satw it, appears to my recollection, above 11 inches long, probally nearer 2 inches; all which had grown in the spirits.

I believe that the specimen is now in the Museum of the Unirersity. Dr. Leidy has the control of that institution, and will, I am sure, be glad to show it to you. I should suppose that the hair ou ght now to be much longer.

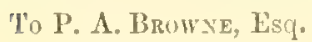

I am, rery respectfully and sincerely yours, \&c., \&e.,

* Dr. Leidy was unable to find this specimem.

B. II. Coates. 


\section{CIIA P'H R VII.}

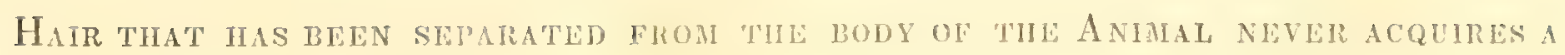
Distinct LIFE.- It has been supposed that a hair, laid for some time in a stream or pool of water, is transformed into a worm; but this is a popular error. It will appear to be animated; but that is owing to animalcules with which it becomes invested. There is an annelida called "the hair-worm," (Gordius Aquaticus,) which is found in stagnant pools, and this name has probably aided in propagating this error. Such a transmigration as a hair of a mammalia into a worm, which belongs to another class of animals, is unnatural, and should not obtain credence except upon positive testimony. *

Of the Electricity of Pile.-Pile, when dry, is electric, and by rubbing it, sparks and even detonations may be produced.

L'Héritier says, that many sick persons have died from cutting or sharing the hair of the head, and he attributes it to the disturbance of the currents of electricity. (Traite de Chem. Path., p.616.)

* In the Life and Correspondence of Robert Southey, p. 296, is a letter from him to Dl. Southey, dated "Kesmick, June 6th, 1813," in which he siys:-

"Mix Dear Harry :-Do you want to make your fortune in tho philosophical worle? If so, you may thank Owen Lloyd for the happiest opportunity that was crer put into an aspirant's hands. Iou uust have heard the rulgar notiou that a horse hair, plucked out by the root and put into water, becomes alive in a few days. The boys at brathay repeatedly told their mother it was true-that they had tried it themselves, and seen it tried. Ifer reply was, "Show it me, and 1 will believe it.' While we were there, last weck, in eame Owen with two of these ereatures in a bottle. Wordsworth was there; and to our utter and unutterable astonishment did the boys, to convince us that these long, thin black worms, were of their own manufactory by the old receipt, lay hold of them by the midlle, while they writhed like eels, and stripping them with their anils down each side, actually lay bare the horse hair in the middle, which scemed to serwe as the buti-boncuf the creature, or the substratum of the living matter which had collected around it.

"Wordsworth and I should both have supposed that it was a collection of animalcula round the hair, (which, howerer, would only be changing the nature of the wonder, ) if tre could, in any way, have aceounted for the motion upon this theory; lut the motion was that of a snake. Wo could perceiro no bead; but something very like the root of the hair; and, for want of glasses, could distinguish no parts. 'Tho creature, or whatercr else you may please to call it, is blinek or dark brown, and about the girth of a fiddle-string.

"As soon as you have read this, draw upon your horse's mane and tail for half a dozcn hairs; be surc that they bare roots to them; bottle them separately in water, and when they are alive and kicking, call in Gooch, and make the fact known to the philosophical world. Never in my life was I so astonished as at secing, what even in the act of seeing I could scarcely believe, and now almost doubt. If you verify tbe experiment, as Owen and all his lrethren will swear must bo the case, you will be able to throw some light upon the origin of Jour friend the tape-worm, and his diabolical family.

"No doubt you will laugh and disbelive this, and half suspect that I am jesting. But, indeed, I larve only told you the fact as it occurred; and you will at once see its whole importance in philosophy, and the use which you and Gooch may derive from it, coming forth with a series of experiments, and with such deductions as jour grey-hound sight and beagle scent will soon start and pursue.

"And, if the horse's hair succeels, Sir Domine, by parallel reasoning, you know, try one of your own.

li. S."

* We presume that tho horse's hair disl not stececd. for we hear no more of the matler 
Goldsmith is of opinion, that the reason why the hair of the cat kind of animals [Felis] is more electric, is because it is sleeti and glossy.* (Nat. Hist of Man., \&c., v. ", p 7.)

If you rub the back of a person, standing upon a stool with gliss fect, with the skin of an inimal tanned with the fur on, for a few nunutes, he may light a gas-hurner with his finger:

Pile as a CONDUCTOR or von-CONDUCTOR OF CALOTIC.--Pile is a non-conductcr of caloric. According to the experiments of Count Rumford, it depends upon the degree of looseness or tightness with which the hairy or woolly filaments are compacted; hence, it would seem that those wools which are capable of being felted or fulled into the least space, will be the most effectual in retaining the animal heat. But a late learned writer upon this subject considers the atmosphere, which is confined within the interstices, equally as good a nonconductor as the pile.

Of the efrect of clidite and seasons upon Pile.-Nature, like a kind mother, adapts the clothing of wild animals to the climates and to seasons to which they originally belong. In Guinea, dogs and sheep are almost naked, while the Siberian Dog and Iceland 5 heep are provided with warm clothing. Swine, in high latitudes, have bristles only, or brinles and hair of a similar texture; but the same species of animal, in colder regions, has atided to their coats a vest of fine frizzled wool. The present race of elephants, inhabiting warm latitudes, lias scarcely any hair, and no wool-a few hairs on the lower jaw, the ear and tail, heing all of which they can boast; whereas, the Mammotll, found envelope.I in ice on the banks of the river Lena, in Russia, had long hairs and narm nool. In like nammer (as it is said) some animals taken from one climate to another, exchange their coats for one more suited to their change of situation. In regard to Sheep, we feel ourselves warranted in announcing the following roles, viz: 1st, that a pure woolly Sheep cannot become a hairy sheep by change of clinate, nor can a pure hairy Sheep become a woully one by such change; 2d, a hybrid (which is already partly hairy and partly woolly) may partially change its coat by the one kind of integument falling out and being replaced by the other kind; 3d, a filament of hair cannot be changed into a strand of wool, nor a strand of wool be trausformed into a filament of hair, by any change of climate.

The variation of seasons affects the natural clothing of wild as well as the domesticated animals 'The trapper, suffering from the extreme cold of an uncommonly severe winter, consoles himself with the reflection that his stock of furs will be valuable in the same proportion. And the experienced furrier, from the examination of his pelts, is able to judge of the severity of the weather during which they were produced.

Leuwenhoeck tells of a man whose hair changed with the seasons, like one of the lower animals, $\nmid$ but we have never witnessed any such phenomenon.

Of the effects of tile Sity upon Pile-Mir. Livingston (in his Essay upon Shecp)

* Is it unore electric than other animals with hair and wool?

† Cullect. I'lilos., ite. dic., 1681. 
rentures the opinion, that pile is affected by the tissue of the skin through which it passes. "In warm climates (he says) the hair of man is generally black and coarse; in cold ones we find flaxen, yellow, and various shades of brown. And eren when the hair takes in deeper shade, (he says,) that it is finer than the lank, black hair of the South." He inquires, "may not this be owing, in some sort, to the slin being more braced in the one and more lax in the other!" In applying the same rule to wool, he opines that "its fineness may be affected by the state of the themometer when the young wool obtrudes through the stim." "If it is compressed (he says) it will be fine-if it finds an easy passage, it will be coarse." (See p. 124.)*

To those who are in the habit of examining the different parts of pile, under tho microscope, this notion of Mr. Livingston's will appear to be fanciful; and it would not have been noticed, but for the great respectability of the author, and the importance of understanding correctly every thing which relates to wool.

The shaft of a mature hair, from its posterior cxtrenity to the point where it penetrates the epidermis, is enclosed in a sheuth, which (according to llenle) is composed of an internal and external layer; which (sheath) effectually protects the shaft of the hair from any such pressure as is smpposed on behalf of the dermis; $†$ and, as to the epidermis, it is too thin and porous to aflord any sucli obstructing and condensing power.

It is true that Mr Livingston, in a subsequent page of his essay, admits that "men of high latitudes have hair similar to that of those near the line"-an admission which (in our opinion) is destructive to his theory; but he endeavors to explain this contradiction by saying, "that the smoky huts, slender" diet, and habit of greasing the hair, in high latitudes, have precisely the same eflect in relaxing the skin as the continual expostuc to the rays of a tropical sun." A non sequitur, which will be apparent to the learned reader.

But there is another and a conclusive answer to this theory of Mr. Livingston's, iz: that a filiment of hair or wool grown partly in a warm and paxtly in a cold scason, ony hit 10 vary in its dianeter, according to his reasoning; whereas, in Gill's 'Technical Repository for 1528, v. 2, p. 72, will be found a letter from Mr. Charles C. Western, accompanying specimens of wool of his own laising, one of them of the growth of nearly three years, upon which that gentleman remarks, that "there is no possititity of discovering the difference in the annual growths." And we have, in onx collection of specimens of wool, one eighteen inches long, taken from a Merino ram, being his first shearing in three ycurs' growth, and not the slightest indication of there having a pressure and relaxation of the skin can be detected.

Of tire specific gravity of l'ile-- In the Philosophy of Manufactures, p. 97, Doctor

\footnotetext{
* Mr. Youatt advanees a similar opiniou in regard to wool. (Sec Lilo of Use. Tisuwl., GT; also, Audersen on Wool, 124.) Col. Randall, while he admits tho fact of wool being fincr in colk "climates. (?) denies tlese inferences. "I am rather disposed (says this gentleman) to look for the cause of this phonomenon in the amount and quality of the mutriment received by the animal." (See Sheep IIusbandry in the South, p. 23.)

it besides, there is found a liquid grease helween the exterior enat of the sheath and the interine of the follicle.
} 
Ure gives the specific gravities of cotton, 1.t7 to 1.50; of linen, 1.50; of silk, 1.30; mummy cloth, 1.50; wool, 1.26. The Doctor found some difficulty in taking the specific gravity of mool, owing to its greasy nature, which prevented it from sinking in water.*

Our phial, for taking the specific gravities, when empty weighs 373 grains; when filled with distilled water, at $60^{\circ} \mathrm{F}$., up to two marks made upon its neck, (one to note the upper, and the other to note the lower surface of the concavity formed by capillary attraction,) it holds 1,000 grains. We have a thermometer tube (with no mounting) small enough to enter the phial. Upon this tube is marked, with a diamond, the single point of $60^{\circ} \mathrm{F}$.; when we are about to perform the experiment upon wool, we weigh the quantity required, and boil it 11 a weak solution of sola, to extract the grease of the exterior. After having dried it again, and re-weighed it, (in order to ascertain the loss sustained, we proceed in the way directed by Dr. Uro.

Dr. John Davy (in Researches Phys. and Anat, p. 138, 1840,) gives the following specific gravities of hair : $1,280,1,393,1,278,1,290,1,275,1,315,1,328$, and 1,300 .

Of the incineration of Pile.-In Graham's Elem. of Chem., 702, it is stated that hair of the beard left 0.72 per cent of ashes. "Blonde colored hair of the head. 0.3 per cent.; black hair of a Mexican, 2 per cent.

Achard found from the combustion of one pound of hair, the following cinders, viz:Hair of the head of Man, - 1 drachm 20 grains.

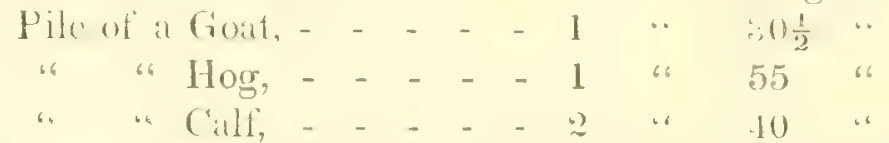

* "I'o ascertain with precision the specific gravity of textile fibres (he says) is a more troublesome experiment than would at first sight appear, and the point has, for this reason probalyly, been left hitherto undetermined. IIaring bestowed some pains upon the sulject, and having contriced a simple method susceptible of giving exact results, I sball here state it in detril. I take a taper-neckel phial, capaljle of holding nearly 2,000 grains of distilled water-poise it when so filled, mark the line of the neek where the water stands, and then pour out exactly 200 grains of the water. I next meigh out 300 grains of the textile substance, lay thes on a clean tray, and proceed sluwly to introduce them into the phinl, in swall quantities at a time, pressing each portion down with a wire, so as thoroughly to wet it and to extrude every particle of the entangled air. Whenever so much fibrons matter has been introduced as to raise the water-line to its primilive malk in the aeck, there has obviously been added a volume of the matter cyual to that of 200 grains of water; and the additional weight communicated to tho phial being divided by trm, will therefore be the quotiont, cxpressing the specific grarity of the sulustance compred to the water reckoned, 100. From the sponsy nature of cotton, whol, flax and silk, much water is alsorised into their pores, and this is movided for in the 1,800 grains, or therealsonts, which are jormosely left in the phial at tho beginning of the experiment. If the raw filaments of cutton, wonl, flax se silk, alre male the sulject of this experiment, they are apt to retain so uany minute particles of air as to cause fallicious results. 'thus, after the labor of sereral hours in filling the vacant space of the phial with woollen fibres, and in churuing then, so to speak, under mater, to expel the air alhering to them, I have found it impossible to introduce 500 grains of wool; and I miglit thence have concluded, that 206 grains of wool oceupy a greater space than 200 grains of water. But if we talio shrels of flumel, frect from grease by washing, which are readily moistened, we then find that 252 grains of it may lo introdued into lle space of 200 grains of water; and we are entitled to affirm, that the true specifie grarity of wool is $1.26 \mathrm{compared}$ to water $100-01^{\circ} 1,260$ by the ordinary notation. By a similar procedure, I have fornd the specific gravity of cotton to be from $1.4 \bar{t}$ to 1.50 ; of linen, 1.50; of silk, 1.30 ; of mummy eloth, 1.50. It was stated that a definite weight (300 grains) of each substance was weighed out at the commencement of each experiment-a precaution taken for the purpose of verifying the result-since that weight, minus the weight of the residuary portion, onght to be erual to the increase of weight in the phial. If these two rumtities differed, the experiment was considered to he inoxact, and to recuire repetition." (Phiłos, of Manuf, 1. 47.) 
Pile of a Dog, - - - - 2 drachms 56 grains.

Mane of a Horse, - $\quad \ldots \quad-34012$ " 30

Wool of a Sheep, - - -1 " 1 " 32 "

(See Dict. de Chem. of Klitproth, 1810, p. .)

Modus Operandi.-A platina crucible, being carefully weighed, and the weight noted, place therein a given weight of pile; submit the crucible and its contents to heat until incineration of the pile takes place. Weigh the crucible with the residue, from which deduct the weight of the empty crucible, and the quotient is the weight of the cinders.

But pile requires an intense heat for complete incincration. WV burnt one grain of hair of the head of an American Indian by the heat of a spirit lamp, in a platina crucible, and the residue was 0.750 grains. But Prof. Boyer subjected this residue to completo incineration, leaving only 0.0077 grains.

Of Fossilized Pile.-Hair never becomes fossitized in the proper sense of that term. Neither the pile found in the envelopes of mummies, nor that found on the Mammoth discovered near the bank of the river Lena, enveloped in ice, were fossilized.

Of the Hrgroscopic Property of PILE.-Pile, like some other animal membranes, absorbs moisture from the atmosphere, causing it to elongate, and to contract agrain by evaporation; this is called its hygroscopic property.

Taking advantage of this property, an instrument has been invented which is called a hygroseope, to show the different degrees of moisture in the air. But from a great variety of experiments that we have made, we have ascertained that pile frequently extended, even though in a small degree, gradually loses a portion of its clasticily; wherefore it appears that it is not to be relied upon for the construction of hygroscopes.

When Capt. Bligh made his perilous voyage, in an open boat, over three thousand miles of the ocean, he and his companions used to dip their clothes in the sea and wear them damp, to allay the desire for drink. It is generally supposed that the moisture was absorbed through the pores of the stin. We would rather ascribe the quenching of the thirst to the inhalation of the aqueous vapor, caused by the heat of the body, but think it possible that a very small portion may be absorbed by the hair.

OF tue Analisis of PiLe.-Thenle remarks, that we are still in want of an analysis of hair, in which regard shall be paid to the three substances which compose the stalk. That, according to those we possess, hair is a combination of fat and hormy substance; the first belonging to the centre, and the last to the cortex and intermediate fibrous substance. $\$$

\footnotetext{
li

* From ugros, moist.

† It is also called a hygrometer, from nigros, moist, and metren, to measure.

† Since writing the above, we have obsersed in Daniel's Introduction to Chemical Philosophy, a drawiug and deseription of Sinsom's hygrometer, used in the Puris Olscrvatory, and it is remarked that it cannot he depended on.

Henle is here speaking of a perfect har, which las these three distinct portions.
} 
The fat (siys this author) may be extracted by boiling the hair in alcohol; and is, ordinarily, acid, (the margaric and oléic.) It lias a blood-red tinge in red hair; greyish-grey in brown hair, and (according to Jahn's, in Der Haarartz, ti. p. 49, white hair* has a limpid oil.

After the extraction of the fat, brown hair becomes greyish-yellow, and then behaves like horn.

Hair is insoluble in water, whether cold or hot; but in Papin's Digester is dissolved (all except the fat) with a disengagement of sulphuretted hydrogen. 'The residue of the liquid, after evaporation, is viscous, and capable of being re-dissolved in water, when it does not become a jelly. From its watery solution a precipitate may be thrown down by concentrated acids-by chlorine-by the sub-acetate of lead, and by tamic acid.

When hair is dissolved in concentrated acids (particularly by the nitric) the colored oils separate, coagulate by cold, and become limpid

Chlorine whitens hair and produces, by its combination with it, a viscous transparent mass, which has a bitter taste, and dissolves in water and alcohol. Caustic potash, diluted, dissolves hair entirely.

Hair may be dyed, melted and distilled.-Hair may be colored by the metallic salts-both nitrate and sulphate; nitrate of silver blackens it When heated, hair melts, exhaling an odor of horn. It burns with a sooty flnme, leaving a bloated coal.

Upon dry distillation, hair gives off one-fourth of its weight of a carbon difficult to incinerate, the products being empyremmatic oil, water charged with ammonia, and combustible gases which contain sulphuretted hydrogen.

Van Laer is of opinion, that hair consists, essentially, of a substance nearly allied to gelatine and bisulphuret of proteinet This substance has the formula of carbon, 13; hydrogen, 10; nitrogen, 3; oxygen, 5, and gluttin (which is the form of gelatine which is obtained from the skin, from serous membrane, from hoof, from bone, from tendon, and from cartilage,) having the formula of carbon, 13; hydrogen, 10; nitrogen, 2, and oxygen, 5.

There have also been found in hair silica, iron and manganese.

The elements of Pile in the blood and in the mill. - That the blood contains all the elements of hair, is found by its being produced on the foetus; and that the mother's milk is equal, in this respect, is demonstrated by the growth of the hair while a child is receiving no other nourishment.

'The ancient practice of milking the ewes, to make butter-cheese, was believed to have injured the growth of the lamb's wool. (See Lib. of Use. Knowl., p. 48.)

Of examing Pile.-It often becomes necessary, while examining a hair under the microscope, to turn it over and back again, or hall way over-a task not easily performed.

* He here speaks of white (albinos) hair, and not grey (colorless) hair, as we renture to jresume.

+ Proteine is the name given to the substance which enters into the three important animal compoumls, album in, fibrin, aul cassin. 
It also is sometimes required to stretch a hair, and allow it to contract again, while under examination microscopically; to effect which no information is giren in the instructions how to use the microscope. We have invented and constructed a rery simple instrumont, by which both these objects can be attained.

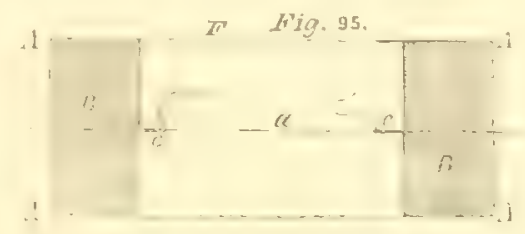

Upon an oblong piece of glass, $\mathrm{A} A, \mathbf{A} \mathrm{A}$, of the size of a common slide, fasten two pieces of cork, B B, one at each end of the glass. Through a perforation in the centre, crosswise of each cork, at the surface of the gliss, pass two sewing needles, $\mathrm{C}$, the eyes being inward and the points projecting a short distance outside of the cork. Fasten the ends of the hair, D, desired to be examined, on the eyes of the needles. When this instrument is placed on the object-holder of the microscope, the ends of the keeper resting respectively upon the corks, and the microscope is adjusted so that the hair comes into focus, by taking hold of the outer ends of the ncedles, you may turn the hair in any direction and to any extent of a revolution required. And by gently drawing the end of one needle, or both of them, you may stretch the hair while under examination, and by pushing back the ends of the needle or needles, allow it to draw up again to its original dimensions.

We propose to call it "a hair revolver and stretcher."

Of describing Pile.-By adopting some order in which pile is to be described, we incur less risk of omitting something which ought to be noticed. The following is recommended:-

1. Name, and short description of the animal.

2. Name and address of the donor of the specimen.

3. General appearance.

4. Length, (noting whether it is natural or artificial.)

5. Shape.

6. Diameter.

7. Color and lustre.

8. Direction.

9. Inclination.

10. Ductility, elasticity and tenacity.

11. Button-the dimensions and description.

12. Sheath,

"6 6

13. Follicle,

14. Shaft,

64

" 


\section{Cortex-}

Stria

Scales, or

Paved.

2. Intermediate fibres.

3. Centre-

\section{Coloring matter.}

4. Apex.

15. The appearance of disks or vertical sections

16. The same when the pile is crushed.

17. The same when treated with alteratives.

18. Peculiarities and affinities of the specimen.

19. Remarlss. 


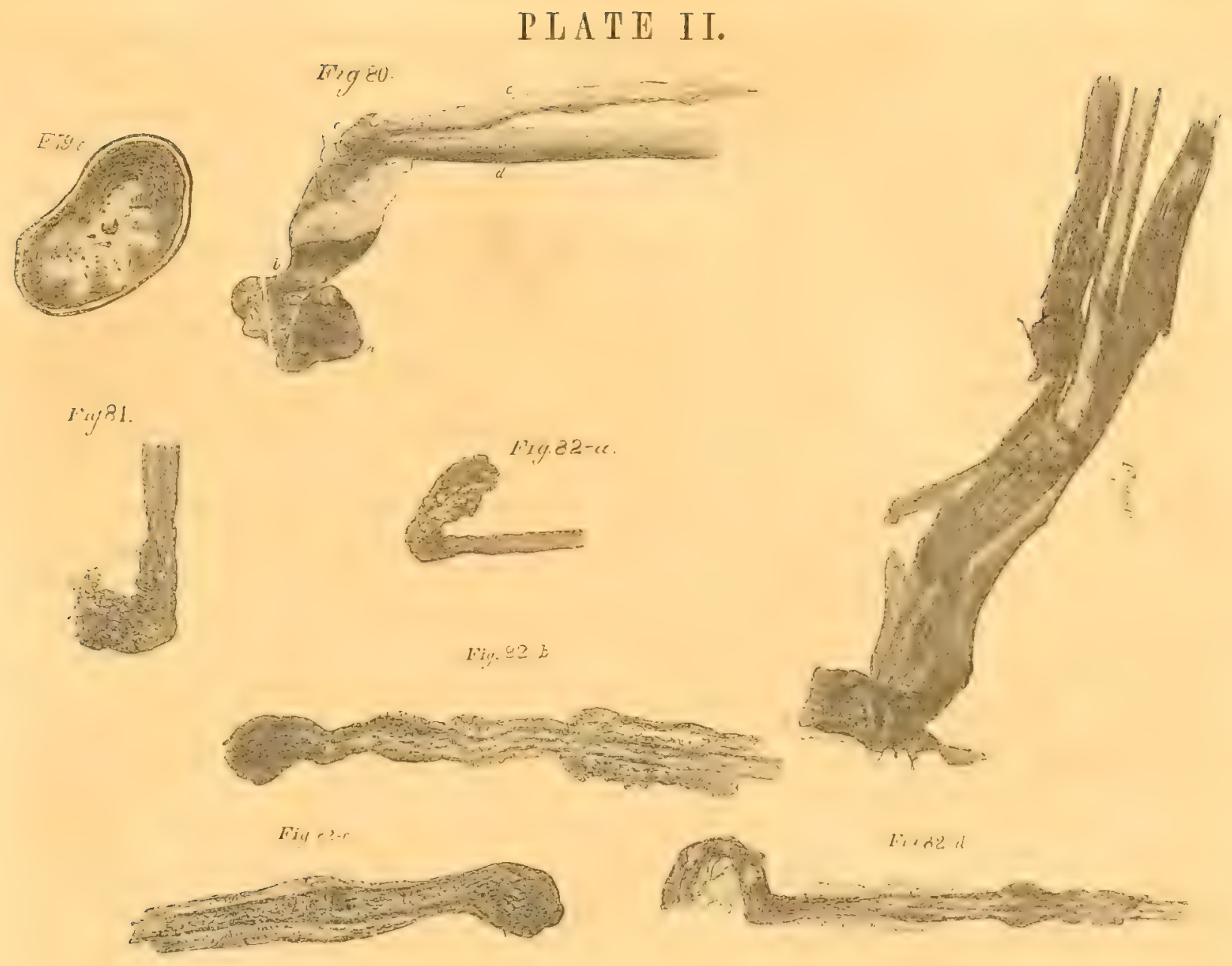

\section{CHAPTER VIII. \\ PL A TE I.}
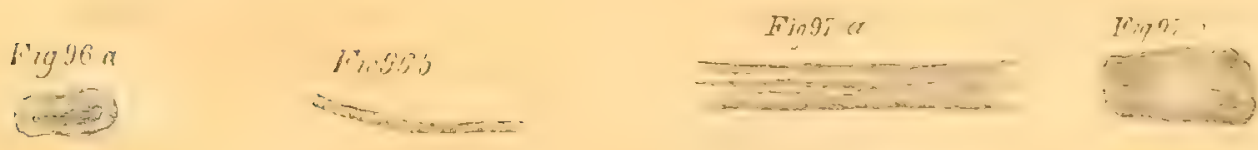



\section{CHAP'TER VIIL.}

Of the Beauty of Pile.-Hair was, doubtless, intended, in part, to beantify.

"Behold thou art fair, my love, -behold thou art firir. Thou last dore's eyes within thy locks, -ihy hair is us a fock of Goats that appear upon Mount Gilead, dec. (Song of Solomon,. . 1.)

So in describing the beauty of Absalom, his hair is mentioned. (2 Sam. xiv. 25 and 26.)

Hair was considered as the chieformament of the Eigyptian ladies. Ptolemy Evergetes, king of Egypt, had a rnost beautiful wife, "Berenice;" who, being alarmed for his safety, during his absence in war with Antiochus, king of Syria, made a vow to consecrate her hair in the "Temple of Venus, if he returned safely. By some accident these locks soon became lost; and the Astronomer, "Conon," did not hesitate to assert that they had been translated to the firmament and formed a constellation in the Heavens!

Hearken to Apuleius: - "But because it is a crime for me to say so and give no example thereof. Know yee, that if you spoyle and cut off the haire of any woman, or deprive her of the colour of her face, though shee were never so excellent in beauty, though shee were thrown down from leaven, sprung of the seas, nourished of the flonds, though shee were Venus herselfe, though shee were accompanied with the Graces, though shee were waited upon of all the Court of Cupid, though shee were girded with her beautiful Skarfe of Love, and though shee smelled of perfumes and musks, yet, if shee appeared bald, she could in no wise please, no not her own Vulcanus.

"O ! how well doth a fire colour and a shining face agree with glittering haire. Behold it encountereth with the beams of the sunne and pleaseth the eye marvellously. Sometimes the beauty of the haire resembleth the colour of gold and honey, sometimes the blew plumes and azured feathers about the neckes of Doves, especially when it is either anointed with the gumme of Arabia, or trimmely tufted out with the teeth of a fine combe; which, if it be tyed up in the pole of the necke, it seemeth to the lover that beholdeth the same, as a glasse, that yieldeth forth a more pleasint and gracious comelinesse, than if it should be sparsed abroad on the shoulders of the woman, or hang downe scattering behind. Finally, there is such a dignity in the haire, that whatsoever shee be, though shee be never so bravely attyred with gold, silkes, pretions stones, and other rich and gorgeous ornuments, yet if her haire be not curiously set forth, shee camnot seem faire." (Adlington's Translation, (A. D. 1639, page 27,) of the Golden Asse of Apuleius.)

The Uses of Pile to the Animal upon whom it Grows.- T'he first and most obvions use of pile is to prevent the animal heat from escaping, thereby preserving an equili-

\footnotetext{
* Apuleius was born at Madura, in Afriea. He studied at Uarthane, Athens and liome. Ilis Gulden Ass, in 11 books, is an allegorical production, replete with morality.
} 
brium of bodily temperature. For this purpose pile has been formed, a non-conductor of caloric. The "downy hairs" distributed over our bodies cannot be expected to contribute largely to this end; and, consequently, we find that whenever a part of the person requires more than ordinary protection from cold, a greater abundance of hair is produced. Hair may also have been intended to preserve the epidermis from the injurious effects of too much friction, from contact with hard external objects; each hair, upon such occasions, acting the part of a friction roller. This may, also, be one of the uses of the long hairs found, still more plentifully upon the head, body and limbs of some of the lower mammalia; they prevent their wool, which is mderneath, from being torn out by the roots, and their skin from being lacerated in their daily rambles through forests, their clambering up trees, and their burrowing in the earth. The Mole (Tatpa Europea, has a short, soft, smooth fur, offering little or no resistance or adhesion to the moist earth, through which he burrows; and it is a coincidence, no less remarkable than instructive, that the insect, "Mole Cricket," (Gryllo Talpar,) who worlis his way under ground in the same manner, is covered with a fone domm, which has corresponding properties. In the order "Pachydermata," such as the Elephant, Rhinoceros and Hippopotamus, the skin is so thick and tough as to be impregnable, and no protecting hairs are required; and, therefore, nature (who never labors in vain) has provided none.* If man has fewer hairs upon his body, generally, than some of the lower animals, he is, consequently, less impeded than they are in the refined sense of feeling, possessed through the dermis and epidermis; a sense so necessary to his enjoyment, but which would be an incumbrance to inferior classes of animals. At other times hair is accumulated to act as a cushion of protection, as in the case of that of our heids, where it acts, in concert with the bony fortress of the skull, to preserve the brain from external injuries.t

Another use of pile to the animal, is to protect the part upon which it is produced from the injurious effects of superabundant moisture; the hair collecting the fluid and repelling it from the part. Insects which, like grats, walk upon the surface of water, have, at the extremity of each foot, a brush of fine, hair-like processcs, (which, however, are not true hairs, ) the dry points of which repel fluids and lieep the foot and legdry. And some of the hairy-footed manmalia, who inhabit the water, are provided with a still further means of protection from the action of moisture, by an adipose sccretion, with which this legumentary appendage is profusely anointed.

Hair, being olectric, subserves the purpose of attracting that fluid from the atmosphere, thereby keeping up a healthy circulation and preserving a proper equilibrium, notwith-

\footnotetext{
* The few hairs found in the Elephant's ear, and on his jaw and tail, are noticed in another place.

† The hair of the head deadens the concussion which the brain would experience from the infliction of heary blows; and rrevents the skin of the scaly from being injured by the attrition of bodies. In military service the former of these uses has been taken advantage of, and an arrangement somewhat similar to that which exists naturally on the bead, has been adopted with regard to the helmet. The metallic substance of which the ancient and modern helmets are formed, is readily thrown into vibrations, which being communicated to the brain, might, after heavy blows, derange its functions, more even than the wound inflicted by a sharp instrument. 'T'o obviate this, the helmet is covered with horse hair. 'This arrangement prevaled with the Roman soldier. (Dunglison IIum. Physio., 55.)
} 
standing the boty is constantly imparting it to the earth.* This will, in part at least, explain why fur-bearing animals are provided with long hairs as well as short wool. Each projecting hair is a lightning rod, (if one may so speak, ) to extract electricity from the atmosphere; at the same time that every movement of the animal, causes the hair and wool to rub together, and forming currents of electricity. There is not (as every one knows) a more effectual method of exciting electricity than by rubbing together hair and wool, as is done when the hand is passed briskly over the back of a cat; but all the friction you can bestow upon the short hair of a dog will be attended with no such result.

The hairs of the eye-brows shadow the eyes and preserve them from too great a glare of light; for the effectual performance of which function, the brows upon which they grow are provided with muscles, which are under the control of the will. The eye-brow hairs (supercilium) also protect the eye fiom the moisture which collects on the forehead, and which would otherwise run into the eyes.

The hairs of the eye-lids (cilia) are bow-shaped, and crossing each other, form a sereen, which prevents insects and fine particles of matter, which float in the atmosphere, from entering the eye.

The hairs of the nasal passage and of the ears, also, prevent the ingress of insects. When in health the principal part of the air we breathe passes through the nose, the shape of which is well calculated for its conveyance to the lungs. 'The sense of smell would appear to be placed in the nasal fossi, to give notice of the presence of any deleterious vapor, and the hair to prevent insects from obtruding. Hypogastric hairs subserve the same purpose, and in females particularly, to conduct off the moisture of the body.

Sometimes the uses of hair are more temporary, and, in those cases, their endurance is; of the same limited character. Of such, is the velvet coat, (as it is called, which covers and protects the large vessels on the summit of the head of the Stag, previously to the sprouting of his antlers.

Besiles these, which are the direct and palpable uses of hair, there are others of an indirect and latent character, such as for secretion and insensible perspiration; with the functions of which we yet know too little to make them objects of purticular discussion.

Bostock is of opinion that the skin is the seat of an extensive system of exhanstion and absorption; although he acknowledges that it may be very difficult to delermine the actual termination of the vessels, or the exact apparatus by which these functions are performed. (Syst. of Physig., p.50.) With these systems, (if they do exist,) pile is, doubtless, connected.t

We believe that the question has never been decided, whether the stin of our species has a chemical action upon the atmosphere; in the case of the lower animals the affirmative seems to be admitted; and, therefore, we think that we may be warranted in sugrestIng that another use of hair to them, may be to modify that action. We have rery high authority for considering hairs as emunctories. Boerhave, Knophof, Haller, Blumenback

\footnotetext{
* Magendie, (Précis Élem. 177.) very erroneously states that liair is a lad conductor of electricity.

$\div$ But see Bichat in Anat. Gen. 7.s, as to absorption of hair; alko, Wilson on the Skin.
} 
and Schlegel, have been advocates of this opinion. This tegumentary appendage (they say) acts as a universal purifier of the humors; disencumbering the body from a variety of matters, which are of no use, and which, therefore, are likely to become injurious. Haller and Schlegel contend that it transpires by its superior extremity, if not by its whole cortex. 'The bulb (follicle) is represented as secreting, besides the substance which forms the stalk, a particular humor, which circulates through its fibres, and exhales between its scales; and the opinion is ventured that the more a person perspires the shorter will be his hair, and vice versa. This rule, if true, ought (all other things being equal) to make the inhabitants of warm countries have the shortest, and those of cold countries have the longest hair. But the whole of this theory is doubted, ${ }^{*}$ and does not seem to be confirmed by experience.

Of the uses of Pile in Manufactures and tire Arts.-Of the uses of Hair.-Human hair, taken from the heads of persons slain in battle, is made a considerable object of commerce and profit, being used to manufacture wigs, scratches, toupées, curls, \&c., \&c., to adorn the living.

The hair of some of the lower animals, such as the Horse, Ox, \&c., is used to increase the tenacity of plastering mortar.

The hair of the tail and mane of the Horse has long been woven into a cloth, extensively used in covering sofas and chairs; it is called "hair-cloth." It is also used for making sieves, \&c. The hair of the Horse and of Hogs is, moreover, used for stufing cushions of all kinds, and is preferable to moss, which, when it becomes old, fills into a powder, and penetrating the covering, soils the exterior of the cushion. But of all hair, that of the hairy Sheep is the most valuable, being admirably adapted, on account of its not possessing the shrinking property, to manufacture tiannels, hose, blankets, \&c., \&c. (See Chapter IX.)

The skins of some of the lower animals are tanned with the hair on, or the hair and wool on, and the fur is taken from others for making pelts.

The following are among those in common use in this country: The Buffalo, the Bear, the Leopard, the Dog, the Raccoon, the Badger, the Glutton, the Skunk, the Polecat, the Fitch or Ferret, the Weasel, the Ermine, the Marten, the Sable, the Mink, the Otter, the Beaver, the Wolf, the Fox, the Jackal, the Jenet, the Tiger, the Panther, the Lynx, the Cat, the Seal, the Squirrel, the Rabbit, the Hare, the Chinchilli, the Possum, the Kangaroo, the Stag, the Elk, the Antelope, the Sheep, the Goat, \&c., \&c. Of all these we have specimens in our cabinet, and design to examine and describe them in their appropriate places.

In some countries, by a moderate degree of labor, the skins of Lambs which are intended for slaughter are converted into a splendid fabric, which commands a high price. As soon

* See Dict. des Sci. Med. v. 43, p. 275 and 502.

$\dagger$ The word pelt, from the Saxon, (where it means simply a hide or skin,) is used to designate skins of the lower animals, that are tanned with the hair on or the fur on, for the purpose of being manufactured into muffs, tippets, \&c., and for lining and trimming garments worn in cold conntries. Those who deal in them are called pelterers and furriers. 
as the Tamb is dropt, it is clothed with a coarse linen garment calculated to keep a gentle but constant pressure on the wool. Warm water is also poured over it every day. By' these simple means the softness, sleekness, and beautiful waves of the fleece of the newborn Lamb, are preserved. By paying attention to these directions, hundreds-we might say thousands, of Lamb skins, which are now almost valueless, might be disposed of for prices higher than the carcasses command.

There are also some varieties of Dog skins, among the hundreds of those animals that we are obliged annually to destroy, that might be tanned with the hair on, and which would sell for very high prices. It is confidently believed, that their extirpation might be converted from a charge to a source of profit.

We will here add, that it is from the skin of the Wild Ass that the grained leather, called chagrin, is manufactured; and we respectfully suggest to the ingenious American manufacturers, that the slim of the Wild Horse of our prairies* might be appropriated to the same purposes with equal advantages.

Of the uses of Wool.-Wool is used for felts for the manufacture of hats, and for the manufacture of cloth.

Of the Wool of Sheep.-Of all animals the Sheep furnishes the most valuable wool, (as will be shown in the next Chapter upon the raising and breeding of Sheep;) consequently the raising and breeding of Sheep has, in all countries and in all ages, been encouraged. Anciently, the great wealth of lings and princes consisted of Sheep and Goats.

"And Mesha, king of Moab, Tas a sheep-master", and rendered unto the king of Israel 100,000 lambs and 100,000 rams, with the mool." (2 Kings, iii : 4.)

And even in modern times we read that a clan of Turks, neal Aleppo, were seen by Chardin, who had 3,000,000 of Sheep and Goats.

In the kinglom of Saxory they raise an immense number of Sheep, bearing fine wool; their woollen manufactories employ 25,000 people, besides which a large quantity of wool and a considerable number of breeding sheep are amually sold and exported.

In the United States every man, woman and child, should, during the winter season, wear flamnel next the skin; and those who follow occupations which cause them to perspire freely, had better wear it during the summer likewise.

The following valuable advice is from a late French work:-

"Vêtements.-L'usage des vêtements de laine est nécessaire à tous en hiver, du moins pour la partiè supérieure du corps; et même, pendant l'été, l'homme que sa profession oblige de travailler dans les lieux humide et à des courants d'air, ne devra pas porter du vêtements légers et surtout s'en dépouiller lorsqu'il sera en suer.

"Les bas de laine détermine vers les jambes un afflux de sang trop considérable; ̀̀ moins que leur usage ne soit réclaimé par des conditions de santé particulière, on doit le rejeter dams la jeunesse ct l'âge mûr; mais c'est une ressource próciense dans la vieillesse; car alors il faut surtout empêcher le sang de se porter vers la tète, et d'ailleurs les vieillards ne sauraient être trop chaudement vêtus. 
"Chausson de laine devraient être adoptés par tout le monde; car c'est presque toujours par le froid aux pieds que l'on s'enrhume, et l'on voit souvent une toux opiniâtre céder au seul usage de cette chaussure essentiellement hygiénique.

"En général on ne court aucun risque, etl'on trouve au contraire de grands avantages, sous le rapport de la santé à vêtir chaudement.

"Les marins de nos climats portent tous de la laine sur la peau et des vêtements de laine épais et nombreux, - on observe presque pas d'example de phthisie parmi les marins.

"On ne gagne que des maladies de poitrine à braver le froid avec des vêtements insuffisants. Parmi les enfants de 1 à 15 mois que meurent en hiver, la plupart sont tués par le froid ou par des maladies qui en sont de la conséquence.

"Les sauvages du nord de l'Amérique vont nue dès leur enfance, et a 30 ans ils sont, pour la plupart torturés par les rheumatismes.

"En Angleterre, où les enfants vont demi-nu, où les servantes font leur travails au matin les bras nus jusqu'aux épaules, où les femmes sont toujours légerèrement vêtus, on observe la phthisie pulmonaire dans une proportion énorme. A Londres, un quart des morts ont. lieu par suite de phthisie.

"La phthisic chez les femmes, n'a jamais été plus fréquente en France qu'apres l'Empire, époque où les femmes portaient les cheveux à la Titus, les bras nu el la poitrine forte découverte.

"C'est donc un préjugé meutrier que celui des parents qui, pendant l'hiver, promènent leur enfants les épaules, les bras et les jambes nus, sou prétexte de fortifier leur constitution." (An. D'Hygiène.)

Of the Mountain Sireep.-TEspecial care must be taken not to confound the Masama with the Mountain Sheep, (Ovis Montana, of Desm,) which is extensively distributed through North America, along the highlands of the Rocky Mountains, the hair of which is coarse and brittle, while that of the Mazama is fine and soft.

Examination and Description of the Pile of the Monntain Sheep, (Ovis Montana.)Specimen presented by the late Dr. Samuel George Morton, of this city.

General appearance, that of dried vegetable fibres; length, (natural,) from 2 to 3 inches; shape, a compressed and irregular oval; diameter, from $\frac{21}{100}$ to $\frac{28}{100}$ of a millimeter; color, cinereus; no lustre; direction, at an acute angle; inclination, slightly undulated; no sensible ductility nor elasticity; tenacity, broke with 170 grains; button, pestle-shaped, white and opaque, succeeded by a neck which is white and opaque also, and which separates the button from the shaft; length of the button, $\frac{1}{4}$ of a millimeter; that of the neck, 3 of a millimeter; diameter of the button, $\frac{7}{1} \frac{7}{0}$ of a millimeter, and that of the neck, $\frac{5}{10}$; that of the shaft being $\frac{21}{100}$; shaft, cortex paved, white, and compressed, quadrilateral and pentagonal figures, some of which measure less than $\frac{i}{0} 0$ of a millimeter; intermediate substance, white, opaque and granular; centre, white, translucent and granular; the shaft is easily crushed.

It will be seen, by the above description, that this pile can be of no use in manufactures 
OF tine Goat.-C. 1. Quadrupedia, O. VI., Pecora G., Capra of Lin. Horns, concare, inclined upwards, straight and rough; teeth, fore, eight; lower, shorter, more acute; canine, none. The great Swedish Naturalist enumerates eleven species of Goats.

Buffon considers the Ibex, the Chamois and the domestic Goat, as one specics. (Sec Nat. Hist., v. 3, p. 218.)

Milne Edwards (who follows Cuvier) places the Goat in the order of "Ruminants," in the division of " $R$. with horns," in the tribe of "hollow horns," and the genus of "Capra;" and points out two wild species, the "Agagre" and the "Bouquetin." He is of opinion, that the domestic Goat is a descendant of these two wild species. The three races of Goats most esteemed, are the Goats of Thibet, (also called the Cashmere Goat, ) the Angora and the Kirguis.

Goats must have been domesticated at a very early period; for, in the Song of Solomon, written 1014 years B. C., mention is lamiliarly made of "feeding the kids before the shepherd's tents; but, as most things are judged of by comparison, the Goat has ever been regarded with less respect, because he is supposed to be inferior to the Sheep; as the humble Ass is treated with contempt when compared with the noble Horse. It is possible that religious impressions may have, unwittingly, kept alive this feeling, owing to the purity always attributed to the Lamb, and the wicked being compared with the Goat.

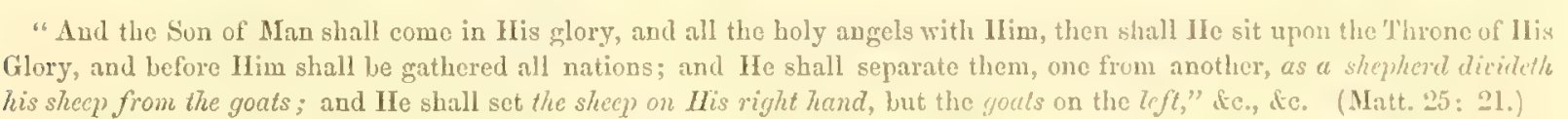

Nevertheless there are, as we shall perceive in the sequel, some races of Gouts whosc fleece is quite as valuable as that of the Sheep; and we shall, notwithstanding the severe sentence, figuratively, denounced by the Apostle upon the poor Goat, of "curses and everlasting fire," venture to commend this animal to the especial attention of the Amcrican agriculturists.

OF the Goat of Tinbet.-Thibet, in Asia, extends from the source of the Indus to the borders of China, and from Hindoostan to the Desert of Cobi-a distance of 1,500 miles. The capital is Lassa. Thibet is mountainous, and intersected by very large rivers; the climate is cold, the soil sterile, and vegetation scanty. The principal wealth of the inhabitants consists of cattle, among which is the Goat, which fumishes the fine fleece from which are manufactured the vahuable shamls of Castmere.

Cashmere is a province of India, belonging to Hindoostan, and this fine fleece of Thibet is taken there and manufactured into shawls, whence the animal is sometines, but very improperly, called "the Cashmere Goat." They are said to employ in this inanufacture $\mathbf{1 6 , 0 0 0}$ looms, and that 80,000 shawls are anmually produced.

Of tile Argora Goat.-Natolia (or Anatolia) is a province of Asiatic Turkey, extending from the Black Sea to the Mediterranean, and from Caramania to the Archipelago and the Sea of Marmora. In this province are raised another fine breed of Goats, called the "Angora," from the city where the wool is manufactured into shawls, which are said to 
rival those of Cashmere. Each Goat is represented to yield from 200 to 300 drachms of wool at each shearing, which takes place twice a year.

OF Tue Goat of Kirguis. - T'he immense plains of Kirguis, in Independent 'T'artary, are inhabited by a people who raise a third kind of valuable Goat, which produces wool of great fineness.

The Introduction of these Goats into the United States.-Exertions have been made to introduce some of these valuable Guats into France, which, we regret to say, have not been attended with success; but this ought not to discourage the enterprising American Agriculturist, who is aware of the fact, that the raising and breeding of the fine woolled Saxon Merino Sheep has here succeeded to admiration, while in France it has proved to be a comparative failure.

We will first enumerate some of the inducements to introduce fine breeds of Goats into our country, and will then show what has already been done. 'The Goat is a cosmopolitan, he is found rambling amidst the snows of Norway, and basking in the burning sun of Africa. Lven the fine varieties, to which we have above alluded, brave the mountainous, cold climate of 'Thibet; feeding upon the scanty vegetation of that sterile soil, or luxuriating in the fertile district of Natolia. He is easily sustained,-as the Sheep follows the Ox, fattening upon the gleanings, so the Goat prospers upon the scanty remains of vegetation left by the Sheep, or in worn out and neglected fields; in some places, as for instance, in Norway, feeding, like the Reindeer, upon simple moss.

He is a most valuable companion of the pioneer to the "far west" thriving upon boughs, and even upon the bark of trees eut down in clearing, or for fuel, where all other domestic animals would starve. The Goat is less liable to diseases than the Sheep. He naturally attaches himself to man, and appears to be grateful for the very few favors he receives at his hand.

The female Goat commences breeding when only one year or eighteen months old, and continues until she is seven; she produces, in temperate climates, one, two and three at a birth; and in warmer ones, three, four and five. She may be milked in fifteen days after parturition; the milk is sweet, nourishing, and medicinal; not apt to curdle on the stomach, as much as that of the Cow, for which reason it is recommended to those whose digestion is imperfect. It has an agrecable flavor, imparted, no doubt, by the wild food upon which the animal delights to feed. This quality renders it peculiarly appropriate to the manufacture of butter and chesse. The suet of the Goat makes candles superior in whiteness and goodness to that of the $\mathrm{Ox}$ or Sheep.

The skins of the Goat are useful in the manufacture of morocco leather, parchment and vellum; we are told that from Norway 80,000 raw Goat hides are annually exported. In Turkey and the Crimea, morocco leather is made from the hide of the male Goat, which is highly prized all over the world. The skin of the Kid is made into glores of the besi. quality, and always commands the highest prices. The horns are extensively used for handles to took of many kinds. Of the pile are made various articles of clothing, from the luxurious shaw, to the humbler but more useful camblet. 
The Goat lives from 11 to 12 years, its flesh is used as food; that of the kid being esteemed to be more delicate than that of the lamb. In several parts of Ireland and the Highlands of Scotland the Goat constitutes the chief agricultural riches. The Welsh goats are also much celebrated.

Having endeavored to retrieve the character of the goat, we will next show what has been done, and what can be done to render him a valuable animal in the United States.

Colonel Wade Hampton, of South Carolina, has introduced upon his farm the Thibet Goats. He kindly sent us a number of specimens of their fleece, which are fine and silky. When we recommend the agriculturists of the United States to introduce upon their farms the Thibet Goat, it is not as a mere experiment, and we refer them with confidence to the patriotic and scientific gentleman whose name we have just quoted; who, we are sure will take pleasure in imparting any information he may possess in the premises, upon a proper application.

We notice that two of the specimens are marked "hnif breed, between the Cashmere and common Goat." We have also in our collection of pile one specimen marked "Angora Goat," obtained through the politeness of R. C. Weightman, Esq., of the United States Patent Office, but where it was raised we have not leained.

Of the Mazaia, (of RaF。) the Rocky Mountaln Goat of Harlax axd Schintz.The Examination and Description of the Pile of the Mazama (Raf.) Americana, the Rocky Mountain Goat of Harlan and Schintz.-Specimens presented by Professor Samuel S. Haldeman. This pile is of two kinds, one longer and coarser than the other. "The general apearance of the first is of lamb's hair-of the second, of the under coat of the poodle dog. The first is in length about four inches, but it appears to have been cut, not drawn out of the shin of the animal. Shape, eccentrically elliptical; depressed in the centre, tapering from the inferior to the superior extremities. The diameters of four filaments, taken in three places of each:

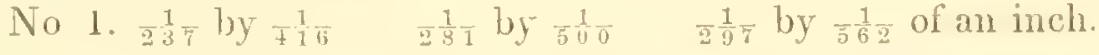

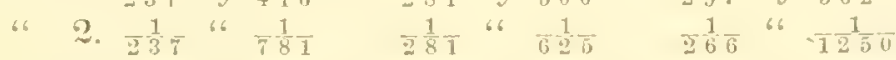

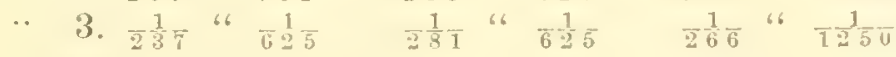

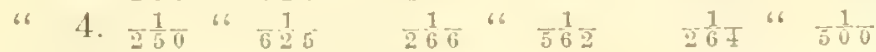

Color, white; direction, straight, but undulated.

Ductility, Elasticity and 'T'enacily.-

With 170 grains one inch stretched $\frac{3}{0}$ of an inch, elasticity entire.

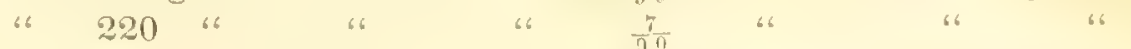

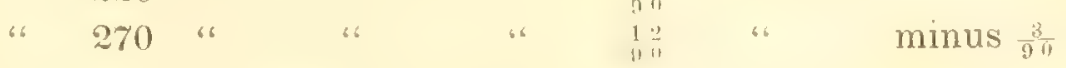

$$
\begin{aligned}
& \text { " } 320 \text { " broke. }
\end{aligned}
$$

Fracture, abrupt; shaft, composed of three parts, viz: 1st, a cortex which is white and too thin to be measured; $2 \mathrm{~d}$, a black, fibrous band, of the thickness of $\frac{1}{82} \overline{1}$ of an inch; 3d, a white, opaque, granular centre, which has a fleecy appearance; apex, sometimes abrupt, but mostly pointed; none furcated; transverse sections or disks exhibit plainly, the shape and three parts above enumerated. (See fig. 96.) 
When a filment is crushed, the fibres readily separate. They have a diameter of $\frac{1}{6} 5$ of an inch, but nay be divided into fibrils of from $\frac{x}{2} \frac{x}{0}$ to $\frac{7}{50} \overline{0}$ of an inch. The central matter which oozes out from the interior, is white, opaque, and granular; the grains of an irrezular and heterogenents shinge; the smatlest less thin the wowo of an inch.

The Small Pile.-Length, $1_{\frac{1}{4}}$ inch ; shape, oval; diameter, from $\frac{1}{15} \frac{1}{5}$ to $\frac{1}{18} 5$ of an inch. The shaft consists of three parts, like the first described, but the cortex is comparatively thicker. It is undulated and slightly frizzled; no furcations.

Ductitity, Elasticily and 'T'nacity. - With 12 grains one inch parted with its undulations and elongated $\frac{2}{30}$ of an inch.

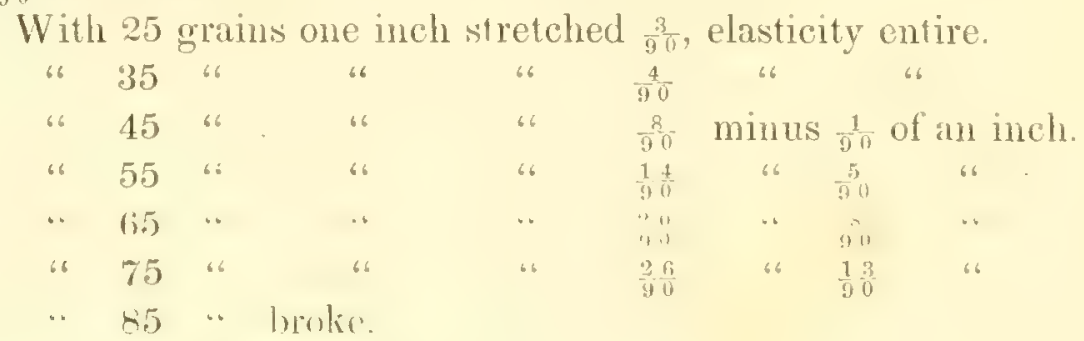

Scales upon the cortex, 3,500 upon one inch of length.

Tile Pile of the Comion Gost. - The skin of the common Goat is peculiarly well adapted to the manufacture of gloves, and is used to make morocco leather. From their hair is also made camlet, which for beauty those of Syria are much esteemed. The fleece of the Russian Goat is much extolled as consisting of, first, a short stiff hair, and sccondly, a fine soft wool which grows at the roots of the other pile. Some of the latter was sent to England to be manufactured, the quantity was so small that the chain was made of silk, and the fabric is represented to have been equal to the finest Indian shawls. 'This induced Dr. Anderson to examine the pile of the common Lnglish Goat, among which it is said he found the very same substance. From this experiment the author of Illus. of Nat. Hist. ventures the assertion, that a variety of the goat species in Great Britain does actually produce a wool of perhaps finer quality than that which is yielded by any sheep whatever. (See Andersou's Recreat. in Agric. v. 2, p. 231.) We earnestly recommend to the enterprising American farmers to try the experiment of raising and breeding the common Goal of this country for the fleece.

UF rne Canel.-This animal, according to Edwards, (Elem. de Züol., 432, belongs to the eighth order, viz:-_"Ruminants"- the section "without horns" -and the tribe "Camel." 'There are seven species, viz: 1st, the Arabian Camel or Dromedary, (the Camelus Dromedarius of Limn., ancl Le Dromédaire of Buff.; 2d, the Bactrian Camel, (C. Bactrianus of Linn., the Chameau of Buff.;) 3d, the Lama, Camelus (Glama of Limn., the Lama of Buff.;) 4th, the Guanaco or Huanaco of Molina, (see Nat. Hist. of Chili;) 5th, the L'eruvian Camel, (C. Arcuanus of Linn., found in Peru and Chili;) 6th, the Vicumna, (the C. Vicugna of Linn., the Vicunna of Pennant;) 7th, the Paco or $\Lambda$ lpaca, (the C. Paco of Limn., and P'acos of Pemant.) 
The Arabian Camel or Dromedary, or Camel with but one hunch, belongs originally to A rabia, as one of its names imports; it is smaller than the other species; there are several varieties, as the Turkman, which is the largest and strongest; the Arabian, which is hardy, and the Maihany and Raguahl, which is swift. The Camel is capable of traveling cight or ten days upon a few dates and a little flour; it being generally supposed that, on such occasions, the fat of the hump administers to its support.

The hair is soft; longest about the neck, under the throat and about the hunch; the color of that on the protuberance is dusky; that on the other parts, of a reddish-ash color: The Camel is used as a beast of burthen in Egypt, and along the Mediterranean Sea, in Morocco, Sara and Ethiopia. It lives from forty to fifty years. Its flesh and milk are esteemed for food, and its pile is used in the manufacture of rich shawls, hats, cloth, carpets, \&c. It is provided with a bag, serving as a reservoir of pure water, which it cau pour into the stomach or raise even to the throat, at pleasure. It will carry a weight of 1,000 to 1,200 pounds. In Upper Egypt a Camel is worth from 200 to 300 lives.

Examination and Description of the Pite of the Camel. Specimen presented by Mr. Darid Samuels, of Philadelphia, dealer in furs and pelts.

The long Pile.-Length, from $\frac{1}{10}$ to $\frac{1}{12}$ of a meter; shape, cylintrical and cylindroidal; greatest diameter, $\frac{5}{10}$ of a millimeter; color, dark brown; lustre, considerable.

Ductility, Elasticity and Tenacity.-

With 170 grains one inch stretched $\frac{1}{30}$ of an inch, elasticity entire.

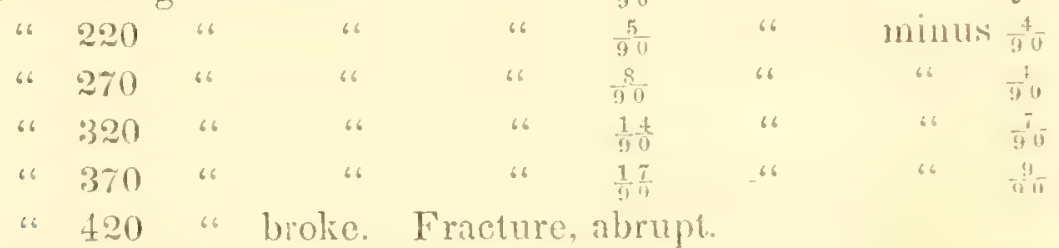

Button, sometimes white and spindle-shaped, at others trumpet-shaped, dark colored, and angled; length, $\frac{18}{10}$, and diameter, $\frac{7}{10} \overline{0}$ of a millimeter; sheath, white, transparent and librous; leneth, $\frac{2}{3}$ of a nillimeter; diameter, $\frac{1}{1} \frac{3}{0}$; shaft, tapering; diameters, at the sheatl, $\tau_{i}^{5}$, but gradually widens to $\frac{-7}{1} \overline{0}$, and gradually narrows to the apex, where it is only $\frac{2}{1} \overline{0}$ of a millimeter; cortex, dark brown; the coloring matter in transverse lines, which appear to be formed by a succession of dark colored rings, occupying about $\frac{1}{3}$ of the diameter of the shaft. When a filament is wetted and pressed between two pieces of glass, these rings fide away, but re-appear when the pressure is removed. When the pile is imbected in Canada balsam, the rings sometimes disappear entirely, leaving the curtex light fuwn colored, with transverse stria of specks of light. At other times the cortex becomes entirely transparent, except some broken lines of colnoug matter in the centre. Fibres, white, transluccnt, coarse. and diflicult to separate.

The short Pile.-Staple, $2_{1}^{1}$ inches; shape, cylindroidal; diameter, varies from $1 \&$ to Tin of a millimeter; button, spindle-shaped, white and opaque; length, $\frac{1}{11} \overline{0}$, and diameter.

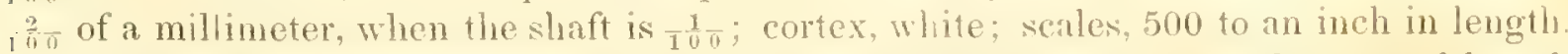

This Heece, owing to its great fineness, recommends itself to the manufacturer, althougls fiom its shape and small number of scales, we would conjecture that its felting and fulling 
properties are not very great. But as the Camel is, in other respects, a highly useful animal, it might be as well to try to domesticate it in the United States.

Of the Lama, (Anchenia,) "Camel of the New World," of Edwards.-This animal belongs to the tribe "Camel," of the section "without horns," of the eighth order, viz: "Ruminantia;" Camelus Glama, of Linn., and Lama of Buff. He is about 4 feet high; his body, comprehending his head and neck, 5 feet 6 inches-the neck alone being nearly 3 feet. Peru is said to be his native country, where his race is found in the greatest abundance, and is much esteemed for the flesh as well as the pile, which latter is converted into beautiful clothing. The Lama is also used as a beast of burthen, being very strong and sure-footed. He will travel with 200 to 250 pounds weight upon his back. In the time of Bolivar, upwards of 300,000 of these animals were employed at the mines of Potosi.* Some Lamas are black, others brown; and a white one (probably an Albino, (was exhibited at the London Zöological Garden. The one from which our specimens of pile were taken, was shown at the Zöological Institute in Philadelphia, in 1848. It was brown, paler on the under parts. The Lama is not as long lived as the Camelhis existence being limited to 15 or 20 years.

Examination and Description of the Pile of the Lama.-The Pile of the Chest.-Length, 11 inches; shape, oval; diameter, $\frac{10}{1} \frac{0}{0}$ of a millimeter by $\frac{7}{10} \overline{0}$; color, light brown; no lustre; inclination, straight.

Ductitity, Elasticity and Tenacity of one inch.-

With 170 grains it stretched $\frac{1}{90}$ of an inch, elasticity entire.

\begin{tabular}{|c|c|c|c|c|c|c|c|}
\hline 220 & 46 & 66 & $\frac{3}{9} 0$ & 66 & & 66 & \\
\hline 270 & 66 & "6 & $\frac{4}{90}$ & 16 & minus & $\frac{1}{90}$ of & an inch. \\
\hline 320 & 6 & 66 & $\frac{5}{90}$ & 16 & 66 & $\frac{2}{90}$ & 6 \\
\hline 370 & 66 & 66 & $\frac{5}{9} \overline{0}$ & 6 & 66 & $\frac{2}{90}$ & 66 \\
\hline 420 & 66 & 66 & $\frac{6}{90}$ & 66 & 66 & $\frac{3}{90}$ & 6 \\
\hline 470 & 66 & 66 & $\frac{7}{9} 0$ & 66 & 6 & $\frac{3}{90}$ & 6 \\
\hline 520 & 66 & 6 & $\frac{8}{9} \overline{0}$ & "6 & 6 & $\frac{4}{9}$ & 66 \\
\hline 570 & 66 & $\therefore$ & $\frac{1}{9} \frac{9}{0}$ & 66 & 66 & $\frac{5}{90}$ & 66 \\
\hline 620 & 66 & 16 & $\frac{1}{9} \frac{1}{0}$ & 66 & 16 & $\frac{6}{96}$ & .6 \\
\hline 720 & ". & “. & $\begin{array}{ll}15 \\
40\end{array}$ & . & 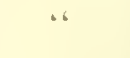 & $9 \overline{0}$ & $" 6$ \\
\hline$x: 0$ & 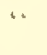 & "، & 199 & . & $\because$ & 5 & 6. \\
\hline 870 & 66 & 66 & $\frac{2}{9} \frac{5}{0}$ & "6 & 66 & $\frac{1}{9} \frac{1}{0}$ & 6 \\
\hline $9: \geq 0$ & “ & . & $\begin{array}{lll}3 & 4 \\
\vdots & 0\end{array}$ & . & .. & $\begin{array}{ll}i & 4 \\
4 & 0\end{array}$ & . \\
\hline 970 & 66 & 6 & $4 \frac{n}{n}$ & 6 & - 66 & $\frac{2}{9} \frac{11}{11}$ & "6 \\
\hline 1,020 & 16 & $6:$ & $\frac{4}{9} \frac{4}{0}$ & " & 66 & $\frac{2}{9} \frac{3}{0}$ & 16 \\
\hline 1,070 & 6 & $\because:$ & $\frac{4}{9} \frac{6}{0}$ & . & 66 & $\frac{2}{9} \frac{5}{0}$ & "6 \\
\hline 1,120 & $\cdots$ & $\cdots$ & $\frac{4}{3} \frac{8}{0}$ & . & $\because$ & $\frac{2}{9} \frac{8}{0}$ & 6. \\
\hline 1,170 & $\cdots$ & $\cdots$ & $\begin{array}{lll}3 & 10 \\
9 & 0\end{array}$ & . & $\cdot$ & $\because \begin{array}{ll}\because & 11 \\
3 & 1\end{array}$ & 6. \\
\hline
\end{tabular}

"1,220 " broke. Fracture, abrupt.

* Lamas are still used in Yeru as beasts of burthen. At the Salines, near Huacho, they are employed in carrying lumps of solid salt-oach one carrying. 100 pounds on his lonck. (T'sehudi's 'Travels in Peru.) 
Button, little more than a swelling; length, $\frac{31}{100}$; greatest dianeter, $\frac{10}{10}$ - that of the shaft being $\frac{7}{100}$ of a millimeter; a slight club at the lower extremity; sheath, white, transparent; length, $\frac{2}{3}$; diameter, $\frac{1}{5}$ of a millimeter; shaft, uniform in shape and diameter; cortex, white, fibrous, transversely striated and transparent; fibres, white, transparent; disks, exhibit a white centre, which is sometimes eccentrically elliptical, being $\frac{5}{10}$ by $\overline{1}^{2} \overline{0}$ of a millimeter; at others, the shape of a chain shot, and at others, strix irregular; apex, pointed. (See fig. 97.)

The Pile of the Back.-Length, 3를 inches; shape, imperfectly cylindrical; compressed on three sides; diameter, $1 \frac{9}{10}$ of a millimeter; shaft, irregular; color, light brown; slightly undulated; apex, pointed.

Ductility, Elasticity and Tenacity.-

With 170 grains one inch stretched $\frac{2}{90}$ of an inch, elasticity entire.

\begin{tabular}{|c|c|c|c|c|c|c|}
\hline "6 & 220 & 6 & 66 & $\frac{4}{90}$ & 6 & minus \\
\hline 6 & 270 & 66 & 66 & $\frac{5}{90}$ & 66 & 16 \\
\hline 66 & 470 & 66 & 66 & $\frac{6}{9} 0$ & 66 & 66 \\
\hline "6 & 520 & 68 & 66 & $\frac{7}{9} 0$ & " & 16 \\
\hline 66 & 570 & 66 & i: & $\frac{0}{90}$ & 16 & 66 \\
\hline "6 & 620 & 66 & 66 & $\frac{1}{9} \frac{1}{0}$ & 66 & 6 \\
\hline 66 & 670 & 66 & 66 & $\frac{1}{9} \frac{6}{10}$ & 66 & 16 \\
\hline 66 & 720 & .6 & $\because 6$ & $\frac{1}{9} \frac{g}{0}$ & 66 & 6 \\
\hline
\end{tabular}

Disk, exhibits a dark colored white, of a compressed cylinder, with a white centre formed by the union of three white dots, so arranged as to form together a compressed right angle triangle. The great ductility of this pile, especially that of the breast, indicates a great degree of softness, which compensates for its comparative coarseness. (See fig. 97.)

Of the Vicunia, (Camelus Vicugna.) - This animal also belongs to the genus Lama, and the tribe of "Camels." He is about as large as a Sheep, and is equally remarkable for his fawn colored wool of an admirable fineness and softness. He inhabits the heights of the Andes in Peru and Chili; where he is sought for his wool, to be fabricated into precious stuffs. (Elem. de Zöol., 435.)

The animal from which our specimens were taken was from Buenos Ayres. He is smaller than the Lama Anchenia, his limbs more neatly formed, and no protuberance on the breast. He is of a reddish-brown color on the upper part of the body, and whitishbrown below. Dr. Von Tschudi says, that in Tarma and its neighborhood the natives weave an exquisitely fine description of woollen cloth from the fleece of the Vicunia and Alpaca. A poncho, made of these materials, will sell for one hundred to one hundred and twenty dollars. The hairs are the long and short, from the back and sides.

Of The Paca or AlPaCA.- This is the vulgar name of one variety of another species of the Lama, viz: the L. Guanaco. The Guanaco is found in all the ligh mountains of 
Sontl America. He is as tall as a Deer, and his covering is chesinut color, and coarse; but the Paca or Alpaca is domesticated, and his covering (it is said) is composed of a woolly hair, *w which is very long, and which, for fineness and elasticity, ranks next to the most beautiful wool of the Groats of Thibet. (Flem. de Zöol., 435.)

We have seen none of this fieece.

OF Staple.-When specimens of wool, especially of the Merino and Saxony Merino are examined, it is perceived that the filaments do not hang independently, side by side, as do hairs in a lock; but that certain of them unite at their anterior extremities, forming tufts ; and these tufts are again partially united, forming locks. With a pair of tweezers and under a magnifying glass, we separated these filaments of a lock, one by one, thus ascertaining that each was distinct. In not a single instance did we discover that "branching from the main trunk like boughs from the principal stem," described by some observers. (See Lib. of Usf. Know., 6,5.) These tufts and locks are what Mr. Fleishinan calls "the staple." (See Report of the Commis'r. of Patents, 1847, p. 271.) Above the junction, the filaments have somewhat the appearance of a web, but, upon close examination, it is found to be a tangling of the filaments only; which is owing, probably, to the spiral curls. The terminations of these tufts have been the subject of examination and animadversion, and the result may be seen by referring to the book and page last cited.

Dr. Ure remarks, that the best length of staple, for cloth, is from two to three inches. But Merino Saxony wool has fiom four to five, and is in high estimation. (Philos. of Manf., p. 129.)

Of Stapling.-The "middle man," between the breeder and the manufacturer, whose business it is to assort the wool, is called the mool-stapler."

Formerly, all wools were distinguished into fine and coarse, these (which are at best vagne and indefinito terms) become more so when it is recollected that often fine fleeces have some coarse filaments, and coarse fleeces some fine ones. Wool is now divided according to the following: 1 , fine; 2 , pure; 3 , straight; 4, elasticity; 5 , staple; 6 , color; 7 , mixture of coarse and fine; 8, tenacity; 9 , freedom from stains.

Nicholson (in Dictionary of Chem., title Wool, ) says that simple inspection may easily lead to error in wool stapling, and recommends the use of the microscope and michrometer; but a good microscope costs a large sum of money, and when possessed, requires sorne practice before it can be used with success. The stapler, being familiar with the qualities of fleece, with an accuracy which requires a delicate sense of touch, a quick eye and long training and experience, divides the fleece into nine parcels: the picklock, the prime, the choice, the super, the head, the downright, the seconds, the abb, and the livery.t But the breeder and mamfacturer ought, also, to have at least a moderate knowledge of

* This is a very rague description!

† Staple, (Staple Belg.,) originally signified a pulblic place or market where gnorls werc cxposed for sale. "Staple commodities," are those upon which a country chiefly depends. Wool wasone of the staplo commoditicis of England, and hence he who assorted it for market was called "a wool-stapler."

+ In Spain the Merino wool is separated into form pareela only. (Sec Lib. Us. Linow., p. 154.) 
flece; how is this to be obtained? Let him practice with the michrometer that we have proposed, until he is able to ascertain the relative fineness of wool; that will answer all his purposes. Let him then practice with the trichometer, until he is able to determine its ductitity, elcsticity and tenacity, He will then be enabled to defermine the four most essential properties of fleece, and will never be at a loss to judge of its value, for himsell. It is to this platform of independence that we desire to elevate the $\Lambda$ merican farmer and manufacturer.

OF THE STRENGII OF PILE.- That the strength of pile depends, in a great measure, upon the vitality of the animal upon whose body it grows, camot, we think, adnit of at doubt. Having, by repeated experiments, ascertained the average strength of the liail of the head of oval-haired men, we compared that with the hair of persons of linown vital power, and also with the hair of others ascertained to be defective in vitality, and we found that the strength of the hair corresponds with the vital power in a remarkable manner.

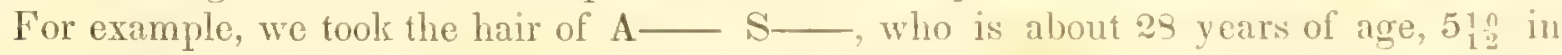
height, in health, but who has ever been remarkable for a deficiency of vital powers; ons: lock of filament, being tried with the trichometer, broke with a weight of 470 grains.

One inch of the hair of the head of J_L K. M___, who is 35 years of age, 6 feet high, of a good constitution, and in health, broke witl 823 grains.

One inch of the hair of the head of William M. Swain, Esq., who is 39 ycars of anc, $5 \mathrm{ft} . \frac{10}{100}$ high, weighs 210 lbs., and very remarkable for vilal porer; broke with 157:3 grains.

'That the strength of the filament does not depend upon the size and weight of the animal, unless they are accompanied with a corresponding vital poncr, would appear from the following experiments:

One inch of the hair of the head of the Quaker Giantess, Mrs. Elizaboth Hales, who is nearly eight feet high, and weighs 337 pounds, broke with 200 grains less than Mr. Swain, say 1373. And one inch of the hair of the head of her husband, Robert Hales, tho Quaker Giant, who is 29 years of agre, weighs 505 pounds, and measures eight feet, broke with 250 grains less than Mr. Swain, say 1323.

'That the strength of the integument does not depend entircly upon the diancter of tho filament, is also apparent from the examination of the hair of the head of Professor Silliman. One inch of his hair, taken when he was go years old, and in the full vigor of manhood, broke with 1820 grains. But one inch taken in the year 184 , when he was in the neighborhood of 70 , broke with 1370. Besides which, the actual diameters of the hairs upon which the above mentioned six experiments were made, did not correspond with their strength, for the hair of A. S., is $\frac{1}{5} 0$ of an inch; that of J. K. M. $\frac{1}{5} \frac{1}{8}$ of an inch. Mr. Swain's is $\frac{1}{3} \bar{g}$ of an inch. Elizabeth Hales' is $\frac{1}{3} \frac{1}{1}$ of an inch. Robert IIales' is $\frac{1}{1} 10$ of an inch, and Prof. Silliman's is from $\frac{1}{20} \frac{1}{8}$ to $\frac{1}{3} \overline{7}$ of an inch. We have also compred the 
diameters of the hair of the lead with the strength of it, in a few cases of diseases, of which the following are the results, viz:

1. Last stage of Coxalgia, 15 months, female, diameter $\frac{1}{4} \frac{1}{1}$, broke with 920 grains.

2. Scrofula, (caries,) " " " " " " " 7770 " "

3. Phthisis, " male, " " " " " " " 1,220 "

4. Advanced Phthisis, (cavernis,) " " " $\quad \frac{1}{3} \frac{1}{5}$ " " " 820 " "

5. Chronic Pleurisy, (extensive effusion,) male, " $\frac{1}{2} \overline{6}$ " " 1,270 " "

6. African Fever, white, " " " 820 " "

Nor does the strength of flece depend entirely upon the diameter of the filament, for 1. A filament of full blood saxony, from Saxony, whose diam. was $4, \frac{1}{3}$, of an inch, broke with

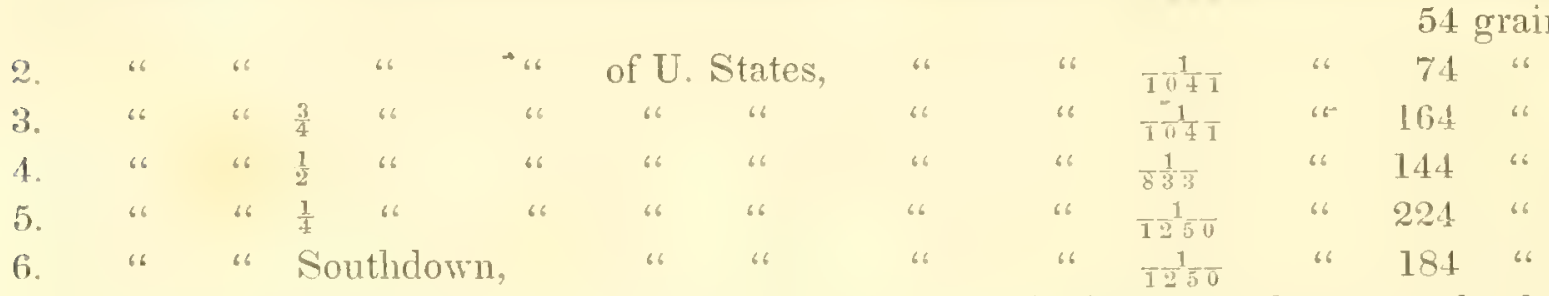

From all which we deem ourselves warranted in inferring, that the strength of pile depends, in a great measure, npon the vital power of the animal upon whom it grows, from which we deduce the following colollary, viz: that the breeder of sheep, who would require strong flecce, must, by attention to their food, cleanliness, and preservation from inclemencies of weather, endeavor to preserve, and, if possible, increase their VITAL PowER. A feeble Shcep cannot produce a strong wool; it is contrary to principle as well as our experiments, and must not be anticipated.

Combe, on the duration of human life, from tables of mortality in Ediuburg, shows that what he calls the gentry (by which he means the class between the nobility and the artisans) have a mesne average age of $43 \frac{1}{2}$ years; while artisans, laborers and servants, have an average age of only $27 \frac{1}{2}$ years; and we think that the reason of this disparity is to be traced, mainly, to premature loss of vital power by the reckless among the second classwhich loss would donbtless, by careful experiments, be discovered in their hair. The American Sheep breeder should have none but gentry in his flock.

OF THE FINENESS of FuEECE. - We entertain the opinion, that even the fineness of fleece may be increased by continued care and attention; good, wholesome food, in suff: cient quantity-preservation from the inclemencies, and particularly from the sudden changes, of the weather-and cleanliness; these are the means by which the integuments may be improved in fineness, as well as in other useful qualities; while starvation and exposure to cold, sudden changes, dampness and filth will, in time, show its effects in a contrary direction.

In turning over the leaves of oux book, which contains "locks of the hair of the heads of distinguished individuals," every one is struck with the fineness, the softness, and the lustre of a large majority of the specimens, when contrasted with our collection of hair of the inmates of the alms-houses and hospitals, i. e., of the unintelligent and reckless, who have been in the habit of living uncomfortably. From our examination of the pil 
of the lower animals, we entertain no doubt but that the rule extends to them. Ife recollect having heard the late much-respected Samuel Coats (who was one of the founders, and for many years one of the managers, of the Pennsylvania Hospital, ) say, that at one time they kept a few hors in the yard of that Institution, and that, in order to avoid the disagreeable effluvia generally arising from such animals and their pens, he had them both well scrubbed every morning, and that the hogs' hair became fine, soft and lustrous. And we, with confidence, refer the intelligent reader to the history of Cattle and shcep raising and breeding in every country where they have attained any celebrity, for the fact that success depends much upon the knowledge, the care, and the perseverance of the farmer. Bakewell, in 1789, was in the receipt of 3,000 guineas a year for the hire of rams, and seven of them sold for 2,000 guineas! But this was the result of unremitted

- care and attention to his flock for a long series of years. He commenced his experiments upon the old Leicester breed, and he continued them, without amy crossing matever. ending with the new Leicesters, of the value above mentioned. He paid too little attention to the wool, as we will hereafter notice; but, in other respects, his experiments were crowned with complete success.

Softness of STAPLE.-There is a delicate, silky, highly elastic feeling in wool that is very desirable. This softness of texture is usually judged by passing it through the fingers nr over the inside of the lips, but may be determined with the trichometer, it agreeing with the ductility and elasticity of the filament. The more ducti!e an't elastic the filament, the softer the wool; and the degree of ductility and elasticity can be measured with the utmost minuteness and certainty with the above named instrument.

OF breeding and Raising Swine for tire Bristles.-The following is a Statement of the quantity and ralue of Bristles imported ammully into the Cinited States, from the 1 st Octotier, 1s42, to the 30/h June, 1819.

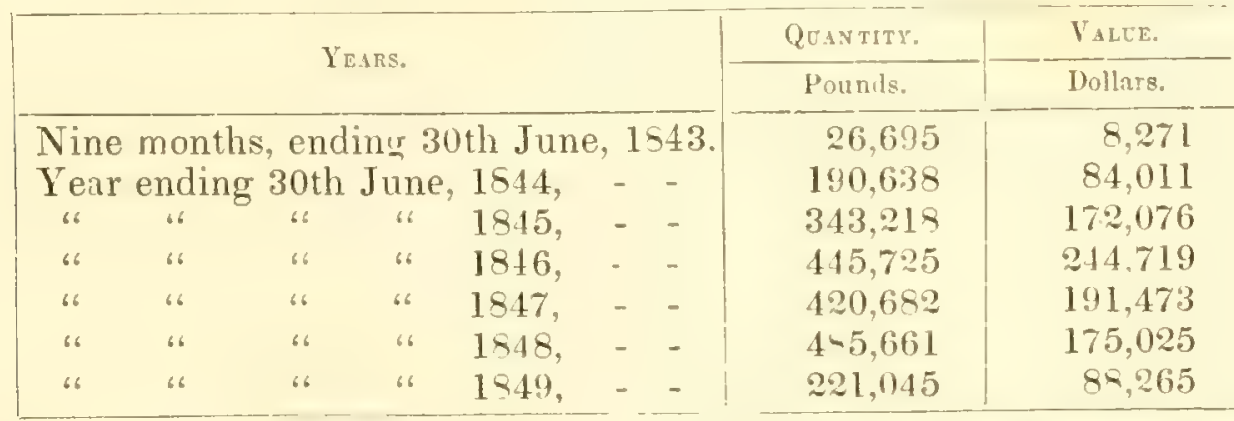

$$
\text { (sigued,) M. Nourse, Act'gReg. }
$$

Treasury Department, Register's Office, Oct. 12, 1850.

This furnishes an average of 380,264 lbs. per annum, worth $\$ 174,311$.

Now, if the United States were incapable of producing bristles enough for her own consumption, or if she was unable to furnish them of qualities adequate to her wants, there would be no ground of complaint; but, by a reference to the statistical table accompany- 
ing the last census, it will be seen that we raise swine in suflicient numbers to supply bristles for our own wants, leaving a large balance for exportation. How is it as to the quality of these tegumentary appendages? Upon referring to the table of dimensions of eleven varieties of bristle, found in our cabinet of pile, the specimens from Ohio measure $\frac{1}{30}$ and $\frac{1}{45}$ of an inch, and consequently are stouter than any that we import; and it requires to fracture one inch of one specimen the enormous weight of 35,874 grains.

It is true that the Ohio bristle is not as long as the French, but it is an indisputable fact that the qualities of bristles may be improved by breeding, as well as the hair and wool of Sheep, if proper means are resorted to by our agriculturists; and this, too, without injuring the quality of the meat.

We therefore earnestly recommend the improvement of our bristles, feeling perfectly certain that our farmers and planters will not find reason to regret taking the advice. 


\section{('H A P'TE I X.}

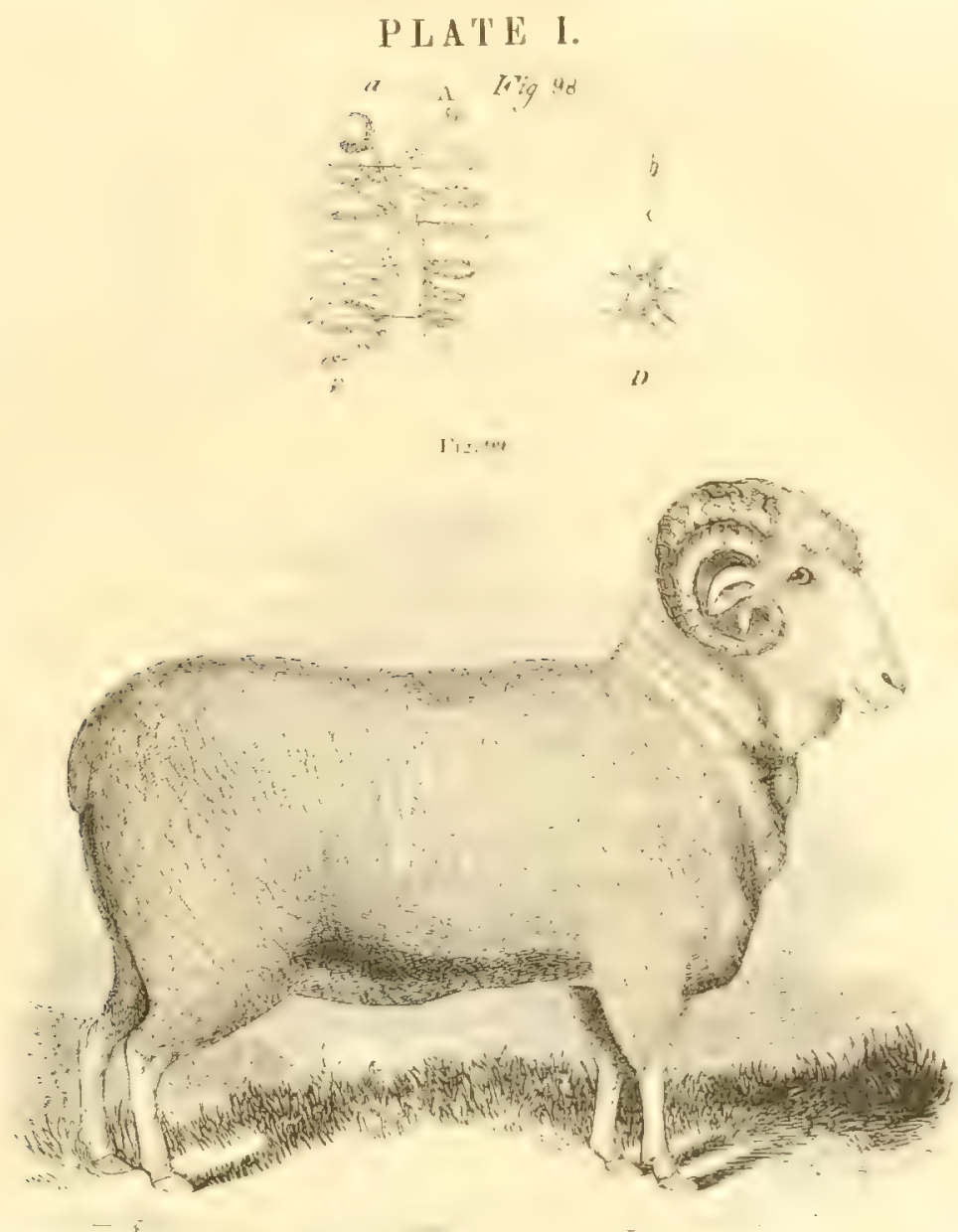

TII F WOI, I, S II F F F

Hig. I190.

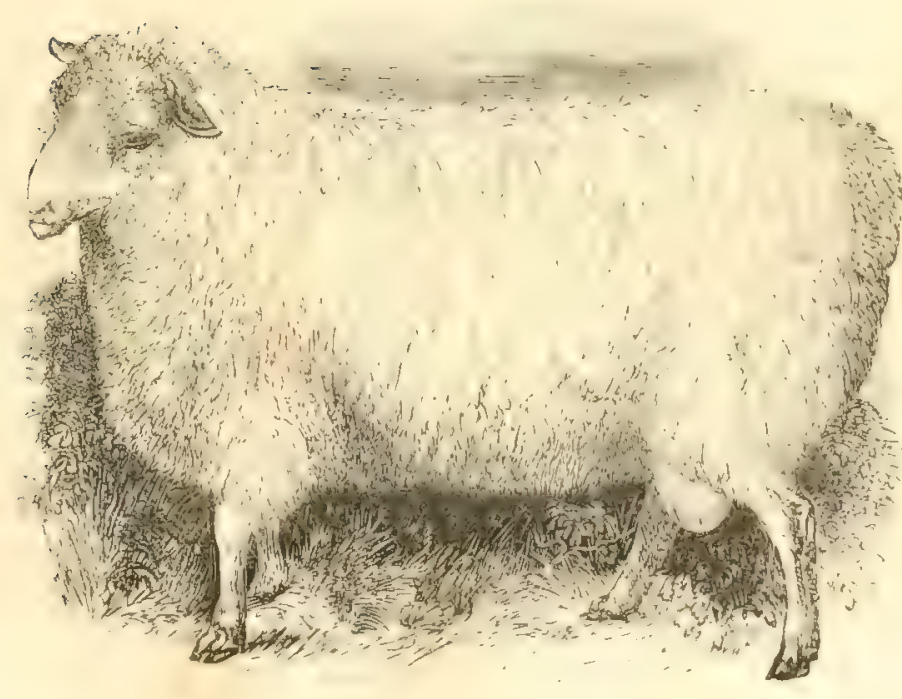

TII E II A I I 



\section{CHAPTER I X.}

Of the Raising and Breeding of Sheep.-Breeding and raising domestic animals includes, not only the multiplication of individuals, but the preservation and improvement of their species, so as to ensure some desirable end; which should always be kept fully in view.

'I'he design, in raising Sheep, should be to produce, with the least trouble and expense, the greatest quantity of the most valuable quality of fleece; and when this is done, and then only, is the system of Sheep breeding perfect.

We are aware that there are some persons who consider that the main object in raising Sheep, is to produce fine flesh, for food; and that others entertain the opinion that nocl and carcass are of equal importance and equally deserving of care and attention. But ne maintain that the matter which ought to absorb oul undivided attention is the fleece, and that the production of sufficiently good mutton will be a necessary consequence.

The most valuable propertics of fleece, as regards its usefulness in manufactures and the arts, are its fineness, its ductility, and its flexibility and elasticity, (indicating its softness, ) its strength, and either its capacity to felt and full in an eminent degree, or its being free from shrinting. Therefore, the greatest perfection in sherp breeding and raising, consists, in being able to produce an animal, whose wool is fine, soft, strong, and will felt and full perfectly; or one, whose fleece is fine, soft and strong and will rot shrink. And we propose to show that either of these objects can be effected, in diflerent regions of the United States, with one stock, and that both may be effected with lmo stocks, but that lcth cannot be done effectually and permanentily with one, nor in the same region of this country.

Upon examining the above mentioned propertics of llece, it is apparent that, inasmuch as these qualities depend upon specific differences of the animals, the same species cannot, by any management or skill of the breeder, be made to produce wool that will felt and full, and fleece that will not shrink; but that to vary the peculiar specific properties of either, (within the range of the specific characteristics of each species, is more or less under the control of the skilful breeder. Hor instance, the diameter of wool, taken from animals descended from the same parentage, may vary; so the ductility and elasticity of filament, (and consequently the softness of the fleece, may differ, although the race is identical; and the strength of the fibres is, doubtless, subject to the same law; but far different is the case with the property of felting, fulling and shrinting, which depends upon the shape, direction and inclination of the filament, and these upon its organization; all which in the fleeces that will felt, full and shrink, are different from those that will not. so much so, that we have ventured to call the one "WooL," and the other "HAIR," and so they are, in the proper understanding of those terms, for 
1st. Hair is, in shape, cylindrical or oval, but wool is eccentrically elliptical or flattened.

21. The direction of hair is either straight, flowing or curled; but wool is crisped and frizzled, and sometimes spirally curled.

3d. Hair issues out of the epidermis at an acute angle; but wool emerges at a right angle.

4th. The coloring matter of a perfect hair is contained in a central canal; but the most perfect wool has no such canal, the coloring matter being disseminated in the cortex, or the cortex and fibres.

5th. The scales of the cortex of hair are less numerous than those of wool, are less pointed and smoother, and they embrace the shaft more intimately than those of wool, causing wool to felt and full, while hair will not shrink.

These things surprise, on account of their novelty, but when they are perfectly understood, no one will any longer marvel why we say, that "there are two species of Sheep." Let us then, in the first place, examine the subject.

Of Felts and Felting.-The word felt, is from the Saxon "felt," from "fel," the hide or skin of an animal. The fabric is manufactured from wool of Sheep or other animals, the filaments of which are entangled and matted together, so as, without spinning or weaving, to form a compact mass. There is no doubt but that felting was practised at a very early day. It is true that the first impulse of uncivilized mind would be, to cover the body with the skins of animals rudely stitched together.*

"Unto Adam also, and his wife, did the Lord God make coats of skins, and clothed them." (Gen., ch. 3, 21.)†

But it could not have long escaped observation, that the filaments of the woolly covering of some animals, while yet growing upon their bodies, had a tendency to entangle and mat; and this natural felting was, doubtless, imitated by our earliest forefathers, probably long before spimning and weaving were known.f

Travelers tell us of Tartars manufacturing tent-covers and tent-carpets, by spreading two or three layers of wool on the wet ground, and treading them together, making a felt. But they have no idea of

The Feltiny Property.-Notwithstanding the great antiquity of felting, and the great perfection which it has attained, as a mechanical and manufacturing art, it was not until very recently, comparatively, that the property in the filament of wool, upon which it depends, was known, or even suspected. Fxperience taught that hair would not felt and that wool would; and, from the same great teacher, it was learned that among the last mentioned integuments there were various degrees of this matting and mass-making power, it requiring more matting power to felt than to full; but to explain the cause, or

* The Stare Indians, occupying the valley of the liver McKinzie, are cluthed in rabbit skins tagged together. (U. S. Exploring Expedition.)

$\dagger$ And see Lucretius, 1xi., v. 1011.

† Yet rearing seems to have been known in the time of $\mathrm{J} 0 \mathrm{~b}$, for he says, "my day's are swifter than a veater's shuttle." (viii. 6.) 
describe the modus operandi, the learned and the unlearned were equally at fault. 'The skilful operator has a mass of wool, which, with his magic bow, he has formed into the desired shape; this fleece, "light as the thistle-down that floats on the air," with no other agency than a damp linen cloth, and the pressure of his hands, , he, in a few moments, transforms into a firm cloth or felt; but neither he, nor the scientific looker-on, could explain the phenomenon. At length a filament of wool was placed under the microscope, and THE MYSTERY WAS REVEALED.

It is the scales of the cortex of pile that cause the filaments to folt. They are circularly disposed. Upon hair they are less numerous, smoother, rounder at the point, and embrace the stalk more intimately; upon wool they are more numerous, rougher, sharper at the point, and at their anterior extremities stand a little out from the shaft.

The scales from the different wools should be drawn, described and classified to understand perfectly their felting power.

The first attempt to count the number of these scales was mace by Mr. Youatt. He found upon a filament of Anglo-Nerino wool, 2,400 to a linear inch.

Let us here pause for reflection. If one inch, in length, of this wool has 2,400 sciles, and it is (as Mr. Youatt tells us) in ciameter $\frac{1}{50}$ of an inch, there are, upon the whole area of its contour, 23,040 scales, ever ready to hook and fusten into as many to be found upon every similur inch of filament with which it comes in contact! $\neq$ Mr. Youatt afterwards counted the scales of other wools, from the result of which we have made the following table:-

No. 1. Saxony, - _ _ _ _ _ $\quad 2,720$ scales on an inch in length.

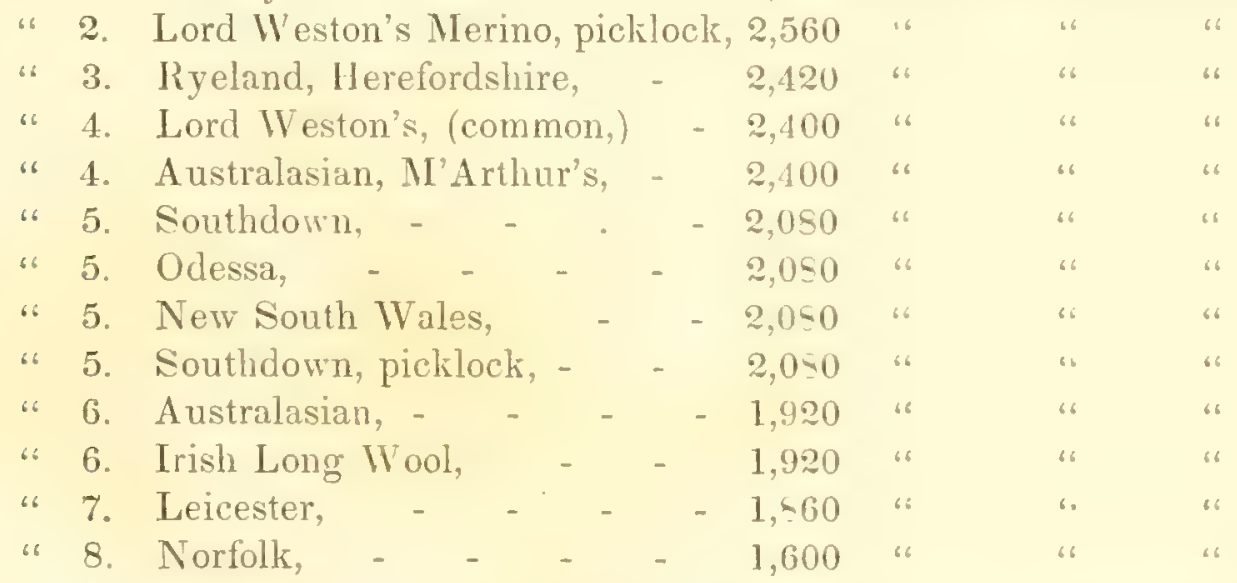

* The nitrate of mercury is sometimes used to facilitate the felting.

f In an article published in the Plough, the Loom and the Auril, for 1850, we hare giren a history of the discorery of the cause of felting, and endeavored to do justice to the memories of those concerned in its discorery.

¥ The following calculation was made for us by Ferdinand IIubbel, Esq. There are 2,400 points (which are the edges of scales) upon one inch in length of Nerino wool-assuming it to be of the same circumference, there were 2,100 in the contour, and multiplying $2,400 \mathrm{by}$ itself, will give $5,760,000$ for the number of points on the one inch of cylinder. But the filanent has a diameter of only $\frac{1}{750}$ of an inch $-7.22 \frac{7}{2} \frac{7}{50}: 0,004=\frac{4}{10} 0 \overline{0}=\frac{-1}{2} \frac{1}{50}$.

Diride $5,760,000$ by 250 , and you will hare 23,040 for the number of Ecales upon one inch in length of a filament of wool that has a diameter of $\frac{1}{5} \frac{1}{6}$ of an inch. 


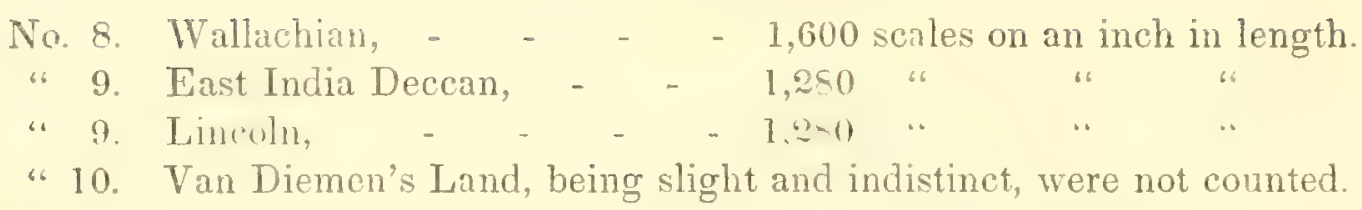

We must next speak

OF TIE SHape and position of THE Scales.-It will be obvious, that besides the number of the scales, their shapes and their positions upon the shaft may materially influence the felting power; for if the scales (although numerous) are smooth, rounded at their anterior extremities, and they adhere to the shaft, they will be less likely to entangle and mat together than under, opposite circumstances. Hence the necessity of examining them under a microsene of high power, and of depicting and describing them, as proposed to be done.

OF FULlisa-Wool, while being manufactured into cloth, is not felted, but scribbled,* carded, spun, wore, and then fulled; the latter process consisting in causing the filaments of fleece (after haring undergone all the other operations above enumerated) to entangle and mat together, thereby giving more compactness to the fabric.

It must be obvious that the same property in wool that causes it to felt, must also cause it to full. But there is another peculiarity in wool which is auxiliary to both these processes, namely, its tendency to form spral curls, which must now be explained.

Of Spiral Curds.-It is one of the consequences of the eccentrically elliptical shape of wool to form these curls. If a filament of Merino or Saxony wool be separated from the rest, it will be found to be contracted into these curls. If it is extended until it is straight, and then set at liberty, it will, spontaneously, return to its original spilally-curled condition. Now it is easy to conceive, that filaments in this spirally-curled state are more likely to entangle and mat together than they would have been were they straight, or even undulated. But, preliminary to spiming, the rool has (as above stated) to undergo the operations of scribbling and carding, by which these curled filaments are broken in to minute curves or sections of rings, and these interlock still more than the entire spiral curls, as will be obvious to the reader; for these curves and sections of rings, having been tossed about in every direction by the scribbling machine and cards, will present to the points of each other's scales opposite points of their own, which will be much more likely to interlock than when, on the unbroken filament, their points were all in one dircction. Let us endeavor to make this still more plain by the aid of diagrams. (See fig. 98, $a$ and $b$.)

Suppose A and B to be spirally-curled filaments of wool, presented to each other, root to point. The points of the scales being in opposite directions, confer a tendency to inter-

* The scribbler consists of a large number of wooden cylinders, placed horizontally on a frame, aimost touching each other, with small cylinders placed above them. The cylinders are corered with iron teeth, which, as they revolve in different directions, tear the wool into minute portions. After having been transferred from cylinder to cylinder, the wool is finaliy thrown off in a flake. It is then carded. 
lock. Now suppose these two spirally-curled filaments to be broken into curves and sections of rings, by the scribbling nachine and cards, at the places indicated by the horizontal lines upon the figure A, B, the tendency to entangle is, in the first place, increased in proportion to the mmber of these curves or sections of rings. But suppose, again, that these curves and sections of rings are presented to each other (as they will be after the wool is scribbled and carded) in the opposite direction of the points of their scales, as represented in the figure $\mathrm{C}, \mathrm{D}$, the tendency to entangle, and the mass to mat, will be still further increased, in proportion to the number of curves or scctions of rings that are thus oppositely presented.

From all which we learu, that although the scales are the principal cause of felting and fulling, yet that they receive considerable aid from the spiral curls.

Having discussed so much at length the properties of the wool that will felt and full, it now becomes us to say a few words respecting

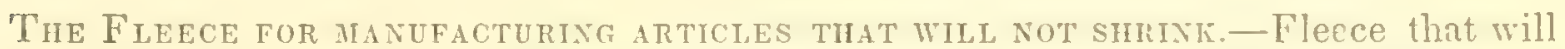
not shrink, or will not do so in an appreciable degree, is exceedingly valuable for the manufacture of flannel, worsted, * blankets, hose, \&c. \&c. Now we are to unterstand that "shrinting" (which is defined to be "the contracting into a smaller space") is only another word for "fulling," since it depends for its operations upon precisely the same properties of the fleece. $\dagger$ If wool, possessing the felting property, be manufactured into cloth, all but the fulling, it will afterwards, when used and washed, shrink. And so will Hannel, if made from the same material. On the other hand, cloth which is made from a fleece which has no felting property, will not full, and the only may to obtain flannel, of c., which will not shrink, is to use that material. This is correct in theory, and will hold equally good in practice, as any one will discover who will try the experiment; so that. nothing further remains to be known but whether the sheep-breeder can, at pleasure, produce one fleece that will felt and full, and another fleece that will not shrink; and this question we propose now to discuss.

OF SHEEP.- Wool grows upon a great many animals; hut our chicf supply is obtained from the Sheep.

Sheep (Ovis, O. 6, "Pecora" of Lin.,) belong to the tribe of hollow horns, of the order Ruminaxta, and are distinguished from the Goat, plincipally, by the direction of the horns.

We will not consume time by enumerating the different kinds of Sheep mentioned in books, nor by noticing the rain endeavors that have been made to refer all the domesticated varieties to some wild species. They were domesticated as early as the lime of Abel-

\footnotetext{
* Worsted is a thead spun of fleece that has been combed, and wbich, in the spinning, is twisted harder than ordinarily: Formerly it was chiefly used to be woren into stockings, caps, glores, \&e. The name is derired from that of the town in Eagland where it was first manufactured. (See Slater's Memoir, appt., p. 440, where will be found sume excellent remarks upon the manulacture of worsted.

+ The degree may tare.
} 
for he was "a keeper of Sheep;" but there were no doubt wild ones ever since, and even are at the present day, if we believe travelers.

Of the two Species of SHeEp.-It is very evident to us that there are two distinct species of Sheep, viz:-

1st. The HAIRY Sheep, and

2d. The wooluy Sheep.

The hairy Sheep (when perfect) has no mool, and the woolly Sheep (when perfect) has not a hair on it. We have already described hair and wool, and shown how the latter is admirably calculated for the manufacture of felts and all cloths which are required to full, and the former to the manufacture of flannel, worsted, blankets, hose, and all articles that are required not to shrink.

The fleece of the hairy Sheep has sometimes been called "long wool," and that of the woolly Sheep "short wool;" but the truth is, that the former is not wool at all, and these "long" and "short" names should be discontinued, being calculated to mislead.

In the manufacture of fabries that are required not to shrink, the hair should be combed and spun, but never scribbled nor carded. The object of this is to preserve the same direction of filaments that they had on the back of the animal, when the scales are not opposed to each other, and whence they have no tendency to entangle, even should they become loose.

But it will be objected that there are Sheep that have on them both hair and nool. We admit it, and shall now proceed to show that the existence of such mongrels is no objection whatever to our division into two pure species. But as the discussion of this point involves nearly the whole art of sheep-breeding, it is time that we should reduce what we have to say to order.

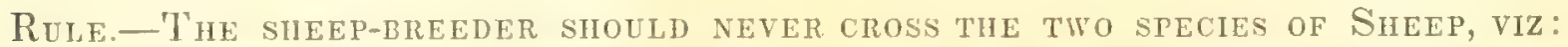
The Hary Eneep and the Wooluy Silep.-This is the most important direction we have to give-it is the golden mle - the primatus principatus-a rule, the more necessary to be dwelt upon, as its adverse has been countenanced by authority, and has been acted upon by those whose example has been deemed worthy of being followed. Its discussion divides into two questions, viz:-

1st. Whether the hairy Sheep and the woolly Sheep really belong to two distinct species? and

21. Whether, by the amalgamation of two distinct species of animals, a permanent, selfsupporting race, possessing equally the properties of both p/rents, can be produced?

The learned have not always agreed upon a definition of the term "species." On the contrary, it has been used in diflerent senses, according to the mode or subject, whether literary, popularly, logically, or zoölogically and physiologically. In its zoölogical and physiological meanmg, it is (according to the Rev. Thomas Smith) "a fixed principle, founded upon the indefinite varieties of which animal life is capable." In regard to proof, he considers common parentage as the best evidence which the nature of the case admits; but as this cannot alwars be traced, he does not exclude other pronf. 
We acknowledge that we prefer the definitions of species given respectively by Van Amringe and Nills; but we do not think that it would be hazarding too much to atlim, that under almost any other definition of it, 10 be found in the boolis, the modification of an animal from being entirely covered with hair to beines entirely covered mith wool, when permanently native in its race, is suficient ground for a specific distinction.

That this is the case with the most perfect kind of animal known, we think we bave proven in "The Classification of Mankind by the Hair and Wool of their Heads," 10 which we refer; and if we have, the argument from inalogy, in regard to the two species of sheep, is irresistible; but even if it shall not be conceded that we have heretofore shown, by th.o hair and wool, that man is not confined to one species, we shall contend, and shall endeavor to prove, that there are two species of sheep.

"Species (says Van Amringe) is a constitutional organization in a race of animals, producing a similarity of functions, in which they agree with all aninals of the same genus in generic character; but differ from races of the same genus, in modifications of generio character, in regard to form, color, instincts, or intellectual power, and which we have good reason to believe to be permanently native in the race."

Now, in cousidering the permanent modifications of generic character, as regards form, let.us see whether naturilists, generally, have not been influenced by discrepancies of a much less decided character than those which distiuguish the hairy Sheep from the woolly Sheep.

The general similitude between the Horse and the Ass is very striking, the difference betwean them (if we throw out of view a discrepancy in the dimensions of the head and ears) consisting in the color and marking of the pile; yet where is the naturalist who has put them in the same species?

The Zebra, which has pretty much the same form as the Horse and the Ass, is placed in another species, on account of the siugular disposition of the colors of his hair. ("Equus lineis transversis versicolor.")

The Quagga, the Onagga, and the Dziggtai, between whom and the Horse and the Ass there exists still slighter shades of difference, are all considered as distinet species.

The two species of Camel are distinguished by the first having one, and the second having two humps on the back, and they are never placed together."

There are two species of Rhinoceros, one having one, and the other having two homs.

There are several species of Deer-kind, which are known mainly by the difference in the horns.

Some species of Monkey are distinguished by the presence, and others by the absence of the tail.

Sloths are separated into species by the number of their toes.

And in Peru there are two species of Lizird, the only difference between which is, that the one has an orifice in the thighs for the passage of a gland, which the other has not.

* There are two species of Carabou, (Tarandus arcticus and T. hastalis, the difference betrecn them (aceording to Prof. Baird) consisting in sizc, difference and dimensions of the antlers, the existence of a gall-kladder foumd in one and not in the other, and different geographical distrilution. (Sec Patent Oflice liepurt of 1851, p. 105.) 
Why, then, hesilate to acknowledge two species of sheep, the race of one of which is permanently covered with hair, and that of the other as permanently covered with wool? Especially if, as has been shown, the difference between these integuments is not merely one of color and marking, (as in the cases of the Horse and the Ass, and the Horse and the Ass and the Zebra,) but where the shape, divection and inclination of the pile is different-where the disposition of the culoring matter is remarkably different; and, above all, where the number, shape, position and mode of adherence of the scales of the cortex are so entirely different as to render the one altogether unfit for felting and fulling, and not liable to shrink, while the other is admirably adapted to felting and fulling, and liable to shrink. Take a!l these things into consideration, and then say whether there is not, at least, as much ground for believing these two animals to constitute two species, as there exists in regard to the unity or plurality of the humps of the Camel, or of the horns of the Rhinoceros. And then, again, renember that, to establish this modification, there must be a difference of organization-a difference in the functions which the apparatus of each kind have, respectively, to perform; for instance, the fibres and cortex of the nool, while they subserve all the ordinary purposes which they do in hair, are also the medium of conveyance for the coloring matter of the former integument, while that of the latter flows in a central canal.

"Species of plants (says Mills) are not only realkinds, but are, probably, all of them real lowest kinds, or infince species." And he adds, "I say probably, (not certainly,) because this is not the consideration by which the botanist determines what shall or shall not be admitted as a species; but which, consistently with experience, might have been produced from the same stock." *

So that, in the present instance, (seeing that the same law prevails in the animal commonwealth,) where the inquiry is "whether the hairy Sheep and the woolly Sheep are or are not two distinct species?" we are not bound to show, absolutely, that they are descended from different parentages; but only that, consistently with experience, they might have been descended from different parentages. And after having shown the difference between hair and wool, and having pointed out the character of the discrepancies upon which zoölogisis have been in the habit of creating species, we would confidently inquire, whether any naturalist who had presented to him two newly-discovered wild animals, otherwise alike, but one of which had always produced wool and the other one hair, would hesitate to consign them to two specific departments? And if he would not, then why, in the case now before us, should we allow habit, born in ignorance and nurtured in stubborness, to prevail over the dictates of reason and experience?

Let it not be supposed, from what has been hitherto said, that too little attention has been paid to the laws of physiology, for we do not believe, that the zoological and physiological, and even the embryological meanings of the word species materially differ. 'The author last cited remarks that, "It reems to be a law of physiology that animals and plants

\footnotetext{
* By the adoption of this rule no inconsistency is introduced, for, (as this learned author shows, this distinction in most (aud probably in all) cases happily accords with the other.
} 
do really, in the physiological as well as in the popular sense, propagate their lind, transmitting to their descendants all the distinctions of kind, (down to the most special and lowest kind,) which they themselves possess." Now surely one of "the distinctions of kind," of the hairy Sheep is, "to produce hair," and one of "the distinctions of lind" of the woolly Sheep is, "to produce wool."

In like manner, Agassis, (in Prin. of Koöl. 43,) says, "the constancy of species is it phenomenon depending on immaterial nature. Animals (and plants also) produce their kind, generation after generation. We shall hereafter show, that all animals may be traced back, in the embryo, to a mere point upon the yolk of the egg, bearing no resemblance whatsoever to the future animal. But even here (he adds) an immaterial principle, which no external influence can prevent, or modify, is present, and determines its future form, so that the egg of the hen can produce nothing but the chicken, and the egrg of the codfish can produce only the cod. It may, therefore, be said with truth, that the chicken and the cod existed in the egg before their formation." Now, although this learned author has given us examples drawn from two classes of animals, viz: the chicken and the fish, it is fair to presume that he meant his observations to apply to animals of different species but of the same class and order, and therefore, that the hair of the hairy sheep and the wool of the woolly Sheep depends upon an immalerial principle, which no external inlluence can prevent or modify." The question of species, is, therefore, one of fact, and Dr. Morton was right when he said that "all circumstances which tend to establish analogies are proper and necessary for the determination." We admit, that where common parentage can be traced, with certainty, that it constitutes the best evicence that the nature of the case admits; but he who would reject secondary evidence, when prinary cannot be obtained, would place himself in the position of one who would shut his eyes to all other" light, because he cannot always bask in the rays of the sun.

Between animals of the same species nature throws no impediment whatever to free sexual intercourse, and the progeny form a permanent, self-supporing race of animals which inherit equally the properties of both parents. But with animals of different species there is a natural abhorrence to amalgamate, which sometimes cannot be overcome at all; and which at others exhibits itself in various ways and in various degrees; and the progeny is always incapable of securing a permanent and self-supporting race, in the proper sense of those terms. This is a most valuable rule for the determination of species, when properly understood and correctly applied; but from inattention and inadrentence, it his been converted into a fruitful hot-bed of error, as will be hereafter shown in the proper place.

The common Cow and the Buffalo have, we are told, a natural antipathy to each other. Such is the fixed aversion formed between these creatures, (as we are informed by Goldsmith,) that the Cow refuses to breed with the European Buffalo, which she nearly resembles.

Wild Asses, (as we are told by the same beautiful author, live in herds, but they will not allow a Horse to come among them; if, perchance, one strays into the boundary of their grazing ground, they fall upon him, and wilhont even giving him time to refreat. they kick and bite him until he is left exhansted on the spot 
'The Babyroussa, or East India IIow, is often secn with tho Wild Boar; with which, however, he is never known to engender. And the Pecary of South America, although he herds with the Wild Hog, which he so much resembles, has never been linown to breed with him. This is the voice of Nature, proclaiming in unmistakable terms, her abhorrence of the amalqamation of spEcies.

How is it where man exerts the powerful influence of domestication? Sometimes, even here, all efforts to subvert nature are abortive. Buffon for three years kept a male matin Dog and a she Wolf together, but they refised to have any intercourse. Goldsmith tells us that a similar experiment was tried with a Fox and a Dog, with the same result. And the Hare and the Rabbit, though so nearly resembling each other in form and disposition, refuse to hold any communication. Buffon bred up several of both kinds together; but from being at first indifferent, they soon became enemies, and they would sometimes combat until one was disabled or destroyed.

How is it (it may be asked) with the Horse and the Ass? The Mule, (it is asserted, ) may be engeidered by mixing either a Horse and a she Ass, or a Jack and a Mare. When the latter method, (which is the one preferred,) is resorted to, a IIorse is used as a teaser; and before the Jack is brought forward the Mare is hoodwinked! Is this the free sexual incercourse, spoken of in the rule above quoted? But we have another question to ask in regard to this connection, viz: is the Mule protific? Is he capable of continuing the race?

Goldsmith says, that "from the great resemblance between the Horse and the Ass, one would be led to suppose that they are of the same species; that the Ass was only a degenerate Horse; but that they are perfectly distinct, an inseparable line having been drawn between them." He adds that it had been said by Aristotle, that after 2000 years' expericnce this assertion had been modified. That others had said that in warm climates, female Mules are prolific; but that, upon examining the cases, it was found that such progeny were incapable of continumg the race.

Fortunately we have the reports of two cases which occurred in our own country, which, as they are exceedingly interesting, we will be excused for giving at large:-

"John Thompson Kilby, of Springhill, Nancomond county, Virginia, was the owner of a female Mule, which, on the $23 d$ of April, 1834, was delivered of a male young one. She was not suspected of being with foal, and therefore it was not known what animal was the father; but suspicion alighted upon a three-year old Colt, belonging to Mr. Kilby, which had been allowed to rum with the Minles on Sundays. Also, the young one resembled the Colt. When born, it was very lean, but its mother, although she had a small udder, having plenty of milk, it throve pretty well until the aoth of October, in the same year, when (having been previonsly weaned) it was taken sick and died, of lock-jaw, the following day."

"Another (female) young one was born of the sane Mule, on the same plantation, on the 13th of August, 1835, and ried on the 26th of Augus1, 1530, alter liaving been sick

\footnotetext{
* Hedied 3220 years 13.0 .
} 
two or three days only. It was in fme order, ran with its mother (who was doing nothing) in good pasture. When taken sick, had every medical attention paid it; but it mas found impossible to effect a passage through it, and, upon a post mortem examination, all the food and medicine was found in the stomach, none having ever passed into the intestincs."

We recollect how, at the times, these births respectively were dwelt upon as proving the Mule to be prolific. But we ask the intelligent reader whether they do not fall far short of the mark; they exhibit no ground to believe that such progeny can ever be the foundation of a permanent, self-supporting race, which (as we have secn) is one of the conditions of the rule above quoted.

We will next refer to some cases of intercourse, or supposed intercourse, between the Goat and the Sheep, premising that, although the evidence in these cases is somewhat contradictory, yet that its weight will lead us to a similar result.

Smith (in Hist. of Man, p. 117,) says, that "Goats and Sheep intermix, producing permanently fertile lybrids."* But Bcllchambers (in a note to Goldsmith's Nat. Hist. of Man, \&c., p. 245, qualifies the above broad assertion as follows: "The Sheep and the Goat propagate-the buck Goat is found to produce, with the ewe, an animal which, in two or three generations, returns to the Sheep, and seems to rotain no mark of its ancient progenitor." TVhere is the permanence?

How the breeding goes on during these "tmo or three generations," we are not informed; but we take it for granted that the progeny is bred tomarls the sheep. Surely no one would pretend, from this evidence, to arer that such hybrids were permanently fertile, much less that they constitute a self-supporting race!

Now let us see what the author of Cllustrations of Natural IIistory, (p. 151,) with all these remarks before him, has to say upon the subject. "Although the Goat is a distinct species, and possibly further removed fiom the Sheep than the Ilorse is from the Ass, yet the buck will propagate with the ewe. But, although these intercourses happen very frequently, and are sometimes prolific, yet no intermediale species has crer been formed between them. *** No new or middle race has arisen therefrom."

It seems, then, that all that we know with certainty is, that the Goat and the Sheep, in their domestic state, frequently have intercourse, and not that they have "free intercourse," as exists between members of the same species-that this intercourse is "sometimes" (not uniformly) prolific-and that here propagation, per se, ends; if you desire to continue the progeny, you must call in the aid of an animal belonging to the original parents.

And even this breeding is somewlat doubtful, for one of our correspondents, namely, Mr. Samuel Patterson, of Patterson's Mills, IVashington comnty, Pennsylvania, in a letter to us upon this subject, says: "I have made inquiry, but have heard of no case of intercourse between the Sheep and the Goat being prolific. I have tried the experiment to some extent, myself, with the Goat and the ewe, but without production. I liave never seen the ram having intercourse with the she Goat, although I llave had them running together at tupping time. Mr. Plummer, a neiglıbor of mine, has made the experi- 
ment more fully than I have, but with the same result. I am perfectly satisfied that the fine woolled Sheep [the woolly Sheep] and the Goat will not mix. I know of no case where it has been tried with the coarse hairy Sheep."

From all that has been said, we feel warranted in believing that the best rule we possess of discriminating between species, is to inquire whether NaTuRE has thrown any impediment between the animals to free sexual intercourse, and whether the progeny form a permanent, self-supporting race of animals, which inherit equally the properties of both parents. And we feel confident that a trial of the hairy Sheep and the woolly Sheep, by this law, in order to ascertain whether they are one and the same, or two distinct species, will result entirely in favor of the ground we have taken.

The reader will be so good as to remark that we do not admit, as proof of belonging to the same species, that animals, either domesticated or wild, will mix together-nor that they will have progeny incapable of continuing the breed-nor that they will have progeny capable of continuing the breed for a limited time, after which a new draft must be made upon one of the original parents to prevent the breed from rumning out-nor where they have progeny capable of continuing the breed for a limited time, after which it runs ont for want of power to continue it; but we admit, as proof of belonging to the same species, a breed where nature has thrown no impediment in the way of free sexual intercourse, and where the progeny constitute a permanent, self-supporting race, partaking equally of the properties of both parents.

Mr. Youatt, when speaking of the attempt, in England, to amalgamate the Southdown Sheep (which is itself a hybrid, being a mixture of the hairy and the woolly species,) with the Leicester sheep, (which belongs to the hairy species,) pronounces it "A FallurE." And he adds, that "the promised advantages to be derived from the mixture of the Southdown with the Merinos, "Were Delusive." (See Essay on Shcep, p. 233.)

It is true that this anthor does not appear to be aware of the cause. of this faiture, nor of the reason why the expectations, to which he has referred, were delusive; but he has furnished us with the facts, and the inferences to be adduced from them are irresistible.

Doctor Robert Knox, an English lecturer on anatomy, and corresponding member of the National Academy of Medicine, in France, in a recent work upon the Races of Men, (52,) says: "The theories put forth, from time to time, of the production of a new variety, permanent and self-supporting, independent of any drafts or supplies from the pure breeds, have been distinctly disproved. It holds neither in Sheep nor Cattle;" and again, (in page 68:) "But the statement in question is not even true of Sheep; for by no effort, saving that of constant, never-ceasing intermixture, or dranghts on the pure breeds, can a mixed breed be maintained."

So, Col. Rindall (in Sheep Husbandry in the South, p. 170,) admits, that any attempt to mite the Merinos and the Leicesters, by crosses, is AN UNQUALTFIED ABSURDITY.

It is true that this last gentleman, (incautiously, as we presume,) advises the crossing of the Southdown and the Merino; but such crossiug of a luybrid, formed from an amalgamation of the two species, with the pure race, of one of the species, is no less an "unqualified absurdity," although the reason may not, at first, be quite so apparent to every one. 
We have not only the pleasure to hope, but the vanity to anticipate, 保at Col. Randall, after further reflection upon this important question, will agree with us in opinion; if he does not, we would like to hear, from himself, why the crossing of the Southdown and the Merino merits his recommendation, while the mixture of the Merino and the Leicester is so inconsistent with reason and common sense.

Having satisfied ourselves that the hairy Sheep and the woolly Sheep are members of two species, the next step in the inquiry is, "what is the consequence of their amalgamation?" Will it promote, or mar, the great object of the American sheep breeder? Considering the very great extent to which Sheep are now raised in the United States, and the general prevalence of crossings, these are important questions.

The grand desideratum of the American Sheep breeder is, to form and preserve, either one permanent and self-supporting race of animals, which shall inherit equally the good qualities of both parents, which shall produce, with the least trouble and expense, either the greatest quantity of the finest quality of fine, soft, strong nool, which will felt and full in the greatest perfection, or the greatest quantity of the finest quality of fine, strong, soft fleece tlat will not shrink; or two races, one answering to either of these requirements Now to perform either, or both of these, he must (in each flock) confine himself to one species, for as often as the parents are of different species, the oflspring will be hylrids, none of which possess the power of permanently fixing and self-supporting a race, such as has been mentioned.

Among all animals, intelligent and instinctive, there exists a natural abhorrence to the amalgamation of species; but it is exhibited in diflerent ways. Sometimes the antipatly is so potent as to amount to an entire prohibition, as we have seen in the cases of the Cow and the European Buffilo, the Barbyroussa and the IVild Boar, and the Pecary and

* The experiments of Robert Wicklifte, Esq., of Lexingtun, Kentucky, in relation to the crossing of the American Butlilo (Bison Americanus,) with the domestic Con; are full of interest. (See Aud. and Back. Quad.)

"The herd Buffilo I possess, (says this gentleman,) hare descended from one or two Cows, that I purchased from a man who brought them from upper Missouri. I have had them about thirty fears; but fron giving them away, and the occasional killing of them by mischievous persons, as well as other causes, my whole stock at this time does not exced ten or trelve. I have sometimes confined them in separate packs from other cattle, hut generally they herd and feed with my stock or farm cattle. They graze in company with them as gently as the others. The Buftalo Cows, I think, go with young about the same time the common Cow does, and produce once a year. None of mine have ever had more than one at a birth. The approach of the sexes is similar to that of the common Bull and Cow, uncler all circumstauces, at all times, when the Cow is in heat-a period which seems, as with the common Cow, confined to neither day nor night, nor any particular seasou; and the Cow brings forth her young, of course, at different times and scasons of the jear, the same as our domestic cattle. I do not find my Buffiloes more furious or wild than the common cattle of the same age, that graze with them.

"Althongh the Bufillo, like the domestic Cow, brings furth its young at different scasons of the year, this I attribute to the effect of domestication, as it is different with all animals in a state of nature. I have always beard their time for calring in our latitude, was from March until July; and it is very obviously the season which nature assigns for the increase of both races, as most of my calres were from the Buffaloes and common Cows of this season. On getting possession of the tame Buffalo, I endearored to cross them as much as I could with my common Cors, to which experiment I found the tame or common Bull untrilling to accede; and he was always shy of a Buffalo Cow, lut the Buffilo Bull was willing to breed with the common Corv.

"From the common Cow I have several half breeds, one of which was a heifer; this I put with a domestic Bull and it produced a Bull Calf. This I castrated, and it made a rery tine steer, and when killed produced very finc beef. I broul 
Wild Hog, when in their native state; and the Dog and the Wolf, the Dog and the Fox, and the Hare and the Rabbit, even when domesticated. At other times the antipathy is partially subdued in a few instances out of many, by association, as in the rare cases of marriages between a white person and a negro. And here every one of us must have been witness of the almost universal natural feeling of abhorrence of the community disgraced by such an ontrage; often followed by an outbreak. That this is the effect of the natural feeling we have described, we rely upon Professor Samuel G. Morton, who tells us that it is not only proverbial among all European nations, but is evinced by Africans, in their own country, and upon Duncan, who, in his travels in Western Africa, relates several instances of the negresses rumning a way in apparent fright and disgust at the sight of a white man. At other times this natural abhorrence is overcome either by domestication alone, or by domestication aided by the artifices of man, as in the case with the Jackass and the Mare.

In like manner nature makes known her non-conformity to this mixture in various ways.

Sometimes the issue is absolutely sterile. At others the product is so mal-conformed that it camnot survive the period of lactation, as was the case with both the foals of $\mathrm{Mr}$. Kilby's Mule. Now the progreny is capable of bcing continued but only by new drafts or supplies from the pure breeds from which it sprung; as was the issue of the Sheep and the Goat, mentioned by Bellchambers. Then the progeny multiply among themselves for two or three generations only; and even during that time show no constancy of character, as mentioned by Van Amringe, in Nat. Hist. of Man, (p. 429,) who says: "We have devoted much attention to this subject, have examined a number of mulatto families, and are satisfied that the children seldom exhibit the medium color of their parents." And, in a

from this same heifer sereral calves, and then, that the experiment might he perfect, I put one of them to the Buffalo Bull, and she brought we a Bull Calf, which I raised to be a very fine, large animal-perhaps the only onc to be met with in the world, of this blood, viz: a $3^{3} \frac{3}{1} / 3-1 / 3$ of common blood.

"After making these experiments I have left them to propagate their blood themselres, so that I hare only had a fer half-breeds and they always prove the same eren by a Buffilo Bull."

Upon this statement of Mr. Wickliffe's we crave attention to the following comments:

1st. That his herd, which now numbers ten or twelve, commenced thirty yoars ago, with two pure female Buffaloes; Jet he endeavored, as much as he could, to cruss them with his common cattle.

2d. He found the tame or common Bull unwilling to copulate with the female Juffalo.

3d. One half-breed heifer produced a Bull Calf but he was castrated and killed, aud so ended that experiment.

4th. From the same heifer he bred sereral Calros, one of which was put to a Butfalo Bull, which produced a Bull Calf which was rised, and here this experiment ended. It stands thus:

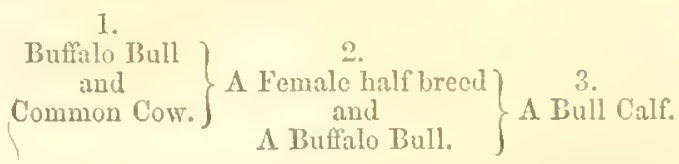

Now the reader will remark that No. 1, being a cross of two species the product was No. 2, a hybrid half-breed. But this hybrid half-breed was not cotapled with another of the same grade, but was bred toucards one of the original stock or parents, viz: a Bufialo Bull.

Mr. Wickliffe, therofore, very properly comes to the following conclusions, viz: that his experiments wore not satisfactory eridence that a half Buffulo will produce again; but only that a half-brecd heifer will be productive from breeding towards either original ruce. 
subsequent page, $(431$, ) he adds, "that in large families of mulathoes (of half-blood parents) it is quite common to find several of the children as light colored as if one parent was white, and another portion of the children as black as if one parent were a pure negro."

All these different phases speak in different languages, but they proclaim the samo sentiment of natural abhorrence to the amalgamation of species; while, by the connection of two individuals belonging to the same species, the stock is uniform, permanent, indestructible and ineffaceable-no change of time, food, climate, nor circumstances, can materially alter, much less sweep it away; as witness the cases of the Jews and the Gipsies, whose races have out-lived the records of the most ancient listory.

"It is by the exclusion of all foreign mixtures (says Humboldt) that species are preserved."

And even Dr. Prichard (who has shown such an anxiety to reduce the white man and the negro to the same category) tells us, (in Researches, \&c., v. : p. 341,) that "separate species of organized beings do not pass into each other by insensible degrees."

What Van Amringe has remarked in regard to the variation of the color of the slim of the children of mulattoes, we have found to correspond in the diversity in the organization of the pile, which is found sometimes corresponding with that of one parent, and at others with that of the other parent, and at others, still, resembling the pile of both, in differens filaments; thus furnishing ample proof that there does not there exist, that joint inheritance of the characteristics of both parents, so remarkable when the progeny is derived entirely from one species, though of different varieties. 'This experience ought to serve as a warning to the American Sheep breeder, whose object is to produce a race enjoying equally the good qualities of both parents.

The natural disgust planted in the minds of all animals to the mixture of specics, seems to have been wisely pre-ordained, in order to preserve the purity and beauty of creation. By the formation of species order was proclaimed, but it can be maintained by this natural feeling alone. Without such a feeling, the law of the harmony of species, throughont the immense varieties of created beings, which now people and beautify the carth, the air and the sea, would be utterly destroyed, and the whole animal commonwealth would be converted into a disgusting assemblage of unsightly monster's!

God has wisely and kindly given to each species of aninals the intelligence, the instinct, and the organs exactly fitted for their respective stations; but, by such a general amalgamation, his wisdom and kindness would be rendered entirely abortive, and his designs for the happiness of his creatures annulled. Organs would be taken atray from animals to whom they are invaluable, and conferred upon others to whom they would be an incumbrance. Propensities, which are the happiness of one species, would be torn from them to be imposed upon another to make them miserable.

It is no objection to our position that such crosses are sometimes allowed to be productive, to a limited extent; for, after the lapse of a few generations, the progeny either pass over to the side of one or other of the progenitors, and the abnormal race is thus expunged forever from that polluted page of the fair volume of nature, or the breed, from a natural 
defect, caused by this very amalgamation, runs out entirely, and is thus eventually atimglished."

Every practising physicim has had occasion to remark how much more mulattoes are liable to scrofulous and phthisical diseases, and similar wasting complaints, than either the whites or blacks from whom they are descended; $f$ and we have no doubt but that a similar law holds in regard to Sheep when species are amalgamated. Now this is destructive to the permanency of stock, which it is one great object of the American farmer to ensure. It little suits his purpose, after having paid for a high-priced ram, to have all his hopes of a stock blasted by an unwise crossing with a common country ewe.

It is true, that by a repetition of the same causes, that is to say, by similar amalgamations, new hybrids may sometimes be continually produced, as in the cases of mulattoes and mules; but they, in their turn, are subject to the same law of destruction, and are doomed to the same premature decay and denolition. "TVith the cessation of the supply of European blood (says Dr. Knox) the mulatto, of all shades, must cease." "He cannot extend his race, for he has no race;" "there is no place for him in nature." And Col. Smith (in Nat. Hist. of Man, p. 119,) says: "TVe doubt exceedingly if a mulatto fanily does exist, or could exist, in any part of the tropies, continued to the fonrth generalion, from any one slock; perhaps there is not one, even in five generations of positive mulattoes, but that all actually require, for continuity at least, a long previous succession of foreign influences, of white, or negro, or mestise, or quadroon, or sambo, or native Indian, or Malay blood, before the simew and substance of a durable, intermediate race can be reared." Then how can the American Sheep breeder reasonably expect, by crossing a Saxon ram with a common country ewe, to obtain a permanent stock of Merino

\footnotetext{
*The following case came within our own oljserration: An English gentleman, stout and healthy, went to one of the West Inlia Islands, where he had a son by a tetra-mulattin. He brought him to the United States, where he was brought up and eluented: Ilis skin was white, and he showed no indications of negro blood except that his black hair was slightly frizzled. When quite young he har an illergitimate child, by a white girl, which died in infancy. He was afterwards thrice married, and had 26 children. By his tirst wife he had thrce children,-two of them died in infuncy, the third lired to about 40 years of age. By his second wife he hat three children-one died in infancy, one lived to full age and died unmarried, and the third lived to full age, married and had children. By his third wife, who was young and healthy, he had 10 children-eight of whom died in infancy, and a ninth died of consumption just after he attained his age; a tenth, under 30, of consumption, learing three children, one of whom is sulject to tits; the elerenth died under 10 years; the twelfth, being a female, married, and had three children, one of whom died in infancy, and another is deformed: the thirteenth, being a female, and always weakly, married and had fire children-three of whom died in infancy, and tro alive are very delicatc; the fourteenth and fifteenth are females, unmarried; and the sixtecntl a male, who is married, and has three children.

† Vitai Statistics.-Dr. Pendleton, of Georgia, has published a raper on the vital statistics of IIancock county, in that State. By bis tables we learn, that during the last ten years, the increase of the white population has been 13.4 per cent., while that of the black has been 23.6 per cent. In the pure races the males numerically preponderate, while, in the mongrel race of mulattoes, the fomales are largely in the ascevdunt; which may possibly be explained on the theory that the mothers leing black, and the fathers white, in most cases, the former detemine the sex. It is also here shown that the mulatto is much shorter lived than either of the unmixed races. The comparative salubrity of the elimate of Georgia is shown, by a tabular exhibit, to be rastly greater than any other portion of our country, and eren superior to that of the rural districts of Fingland, and this, notwithstanding the fact that the blacks greatly outnumber the whites, while the former are much more short lived than the latter. The average mortality of New York, for seven years, from 1841 to $18+8$, is stated at 2.87 per cent., while that of six counties in Georgia, for the last year, was only 1.51 per cent. The fallacy, however, is apparent in cumpraing a country population in the interior, with a city containing balf a million of pouple, subject to impurtation of ship-ferer, small-pos, and other cpidenies, from which much of om mortility is elerived.
} 
Sheep? We know, that sometimes hybrids are purposely produces on account of an individual pecutiarity, which (notwithstanding their evanescent character) render them, in some respects, more valuable than either of their progenitors. 'This is the case of the Miule. But the same reason does not exist for producing the hybrid sheep, which possesses no such peculiarity, and is esteemed only in proportion to its similarity to its progenitors.

In page 120, Col. Smith says, that "war and slavery are the elements of amalgamation, where mixed races spring up, and are maintained, until the impure fall a prey to the pure races; the former falling before the victors until they are externinated, absorbed and perish by a kind of decreasing vitality, and are entirely obliterated.'

From hastily reading the passage last cited, the reader might, perhaps, be led to imagine that, in the end, no injury is done to the pure races, who are represented as "swallowing up the impure ones:" but this author adds, "yet this apparent obliteration must ever affect subsequent forms and mental conditions in the victors; which the physiologist ought to bear in mind, when known, or indicate, when only suspected."

Therefore, let no American Sheep breeder flatter himself with the hope or expectation that by breeding tomards a superior race, he will ever be able, entirely to obliterite the defects of an inferior one; if he does so, he will find, to his cost and discomfiture, (and that, perhaps, when he least expects it, ) that the obliteration is not real, but apparent; and that he has entailed a stigma upon his stock, which no art nor time can wholly cradicate.

In page 214, Col. Smith explains some of the names of hybrids from the crossing of white and black persons; he says "a black and white make a mulatto, a mulatto and white make a quadroon, a guadroon and a white a mestise, a mestise and a white a white." But what kind of white is thus manufactured out of black and white? He tells us, "Jut this last has black and curly hair; nails, dart and ill-shaped; feet, badly formed; and much of the negro propensities."

Now Col. Smith may call this a "white" if he chooses; but we would be very much afraid of marrying such a white, for fear of finding ourselves, some day, blessed with a black heir. And we think that, arguing from analogy, it would not be hazarding too much to predict, that if the (so called) "full-blooded Saxon Shcep," we read, and hear tell of, manufactured by breeding from an impure to a pure race, were critically examined, that the vestiges of their impurity would be found still lurking in their reius.* It is not in

\footnotetext{
* Our learned friend, Willian F. Van Amringe, to whom we loaned the MS. of this chapter, returned it with the fullowing valuable note:

"BtACK HEIR. - This unfortunate circumstance happened, recently, in —_. I gentleman of high respectability married a beautiful girl, whose first child was a negro! The fidelity of the rife mas beyond suspicion; but, on investigation, it was discorered that her mrandfather, or great grandfather, was a negro.

"Dr. White, a wealthy, educated physician and farmer of Duchess County, in this State, [New Iork, became posscssed of a full-hlooded Ayreshire Cow, which, about twenty years ago, he put to a full-blooded Durham white Bull. Subsequently he bred continually, "in and in," towards the Cow, and boasted that he was prictically disproring the doctrine of comstitutional impairment by "in and in" breeding, notwithstanding my prediction that it would ultimately fail. It was remarknble that, for many years, say 12 or 15 , the progeny uniformly leancd towards the Core, whose culor and type were frequently

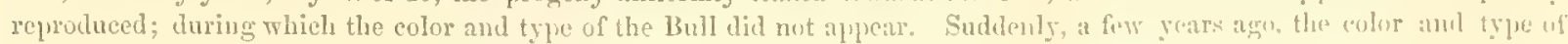


the nature of things, by adding purity to impurity to beget purity. Copper added to gold never yet made pure gold; nor will pure blood added to impure make pure blood.

"It is a law of nature (says Agassis) that animals, as well as plants, are preceded by individuals of the same species only; and reproduction in animals is almost universally accomplished by an association of indiriduals of two kinds, [sexes,] males and females." But those who contend for the breeding we ard now caling in question, act upon the principle that one find [sex] only can accomplish the reproduction. Nut only so, but they act upon the principle that they can select which of the two kinds [sexes] shall perpetuate its like, for if it is left to nature, and she selects the impure kind, then they admit that the stock is inretrievably destroyed.

"The law of species is so clearly laid down by Professor Wagner, that we cannot withstand the temptation of transcribing a part of his essay.

"Plants, produced from different varieties of the same species are FERTILE; while hybrids oither mevert to the original character, or become gradually less capable of reproduction, and within a few generations become entirely extinct."

Dr. Prichard copies this passage into his Nat. Hist. of Man, followed by the remark that "the same law prevails in the animal hingdom," and Van Amringe confirms the proposition in the most unqualified manner. So, you perceive, that it is the acknowledged law of Goul, who has conferred upon man, and other animals, the power of producing others of their kind, and of thus perpetuating their species, but not of forming a new race.

"And God wade the beasts of the cartl after his kind, and cattle after their kind, and every thing that creepeth upon the carth after his kinel, and God saw thit it wis good."

"I'he word "kind," here found repented, corresponds with the term "species." Thus it appears that God saw that it was good to create all animuls in species.

It is God's attribute to create! man's to mar and destroy! Such artificial varieties as we have been condemning are nahural deformities. Specific nniformity is beauty and belongs to nature-emanates from her laws, and is the work of her hands; every deviation from nature's type, must necessarily be a deformity. It is one which she (if left to herself) will throw off, cast from her, as unworthy of suppoit; Int if the deviation is persisted in, it terminates in ch:os!

As sometimes it is allowed to argue from extremes, let us suppose, for a moment, that nature were to resign the reigns of creation to man, what a picture wonld soon be presented-Cows rioting in blood, while Lions and Tigers were grazing and chewing the cud; Fishes clambering up trees, or building and inhabiting three-story brick houses;

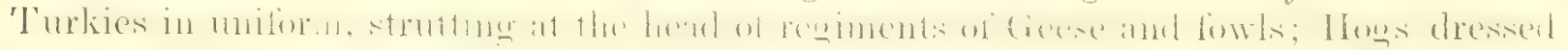
in brocades and adorned with pearls and diamonds, while woman, lovely woman, is grunting Italian airs, as she lies wallowing in mire!

the Bull exhibited themselves; and from that moment the impairment of constitution became wanifest, and the extinction of the stock hastened.

"Erom this remarkable example I infer that, in crosses, so long as the constitutional energy of either parent predominates over that of the less vigurous parent, and minifists itself in the comstitution of the progeny, propagation will contioue; but the moment the constitutional energy of the predominating parent becomes reduced, to arimit the alteration of the constitution of the less vigorous parent, the rapid extinction of the rare is indicated." 
And lastly, we must anticipate an objection which may possibly be made to our twofold division of Sheep, into the hairy Sheep and the woolly sheep, namely, that there are Sheep which have both lrair and wool. Now, suppose our opponents were able to demonstrate that these Sheep belonged to a third species; this would by no means invalidate the positions we have advanced. But we believe that the true answer to such an objection would be, that the "hairy and woolly Sheep" are hybrids, which, like the mulatto before noticed, exhibit the separate integuments bequeathed respectively by both their progenitors. And we might as well here notice, that it has been said that Shcep taken from one climate to another, will partly change their coats; portions of the hail of some falling out and being replaced by wool; and portions of wool of others falling out and being replaced by hair; for no one in his senses would contend that a single filament of either of these integuments can be transformed into the other.

Now this change of coat, if it ever takes place at all, $\uparrow$ never happens to either the pure hairy Sheep or the pure woolly Sheep, but is a condition of these hybrids who have already hair and wool.

From all which we are decidedly of opinion, that the $\Lambda$ merican Sheep breeder, whose object is to lay the foundation of a permanent, self-producing stock, or, if he will, of two such stocks, (in different places,) inheriting respectively and equally the good qualities of both their parents, should abstain from mingling together the lairy sheep and the woolly Sheep. He ought to do so as a measure of prudence, were it only that he incurred the rist of injuring his flock, a multo fortiori, after we have positively proved that such crosses are unmitigated evils.

Are crosses of hairy and woolly Sheep recommended to save expense of outfit? No outlay of capital can justly be considered as extravagant which has for its object to preserve a permanrnt purity of stock. Is it to save time? It is time lost, and not time saved, to commence by such an abnormal crossing.

When an architect is about to erect a noble superstructure, destined to last for generations, he commences by laying a perfectly solid foundation, regardless of a moderate expenditure of time and money. The breeding and raising of Sheep, and the production of tleece, promises to be, in this country, a great and important undertaking; let ns not then destroy it, in the beginning, by a hasty and inoperative plan of breeding.

Exampe of the wooldy Sineep species. - From what has been already said, it will be anticipated that the example of the mort-bearing species of Sheep is the breed some-

* Mr. Lathan, (in Nat. Ilist. of Var. of Man, p. 62, ) speaks of the hair "changing," but his riews are not explained,

$\dagger$ Lawrence says that it does not appear, that the change of climate will convert the wool of an individual Enclish Sheep into hair; and it is equally incapable of conferring a woolly covering on a hairy Sheep. Dr. Wright, who lived many years in Jamaica, speaking of the opiniou that the wool of Sheep becomes more hairy in warm climates, says that in the West Iudia Islands there is to be found a breed of Sheep, the origin of which he has not yet been able to trace, that carry very thin fleece of a coarse, shaggy kind of wool; which cireumstance, he thinks, may naturally have given rise to the report. But he never observed a Sheep that had been brousht from Fngland to carry wool of the same sort with these native Sheep; on the contrary, though he has known them live there several years, these English Sheep carried the same kind of close, burly fleece that is common in Fngland, and as fir as he could observe, it was erually free from liair." 
times denominated the Merino, and at others the Saxomy, which, when perfect, are entirely destiute of hair. (See fig. 99.)

This perfection the American wool grower should endeavor to attain; for "in all the energies, moral and physical, of man, the pursuit of absolute perfection is the only means of arriving at the nearest approximation to it, attainable by human power."

Example of the hatry Sheep species.- - It is not so easy to point out an example of a perfect hairy Sheep. (See fig. 100.)

'The old Leicester breed (as they once roarned in most of the midland counties of England) is now known to us as a matter of history only. Its description is found in Youatt's Essay upon Sheep, p. 313. 'The new Leicester, of Bakewell, (if it be true, as said of it, that it is derived from the old breed, without any crossing,) might be a good basis whereen to form a permanent and self-supporting stock for this country, if, by retracing the steps of Bakewell, so far as he transformed a hair-bearing animal into a mere beast of slaughter, we could restore the injured pile to its original integrity, pursuant to the principles laid down in the IVth Chapter of this work.

Of the fleece of the American new Leicester Mr. Randall remarks, that it is long, averaging, after the first shearing, about six inches; that it weighs about six pounds; that it is coarse, and little used in the manufacture of cloth, on account of its length and deficiency in felting properties; but as a combing wool (non-shrinking hair) it stands first, and is used in the manufacture of the finest roorsterls.

Mr. Randall adds, that this wool is not saleable, BECAUSE of THE DEARTI OF WorSTED MANUFACTORIES IN OUR COUNTRY; and when we inquire into the cause of this dearth of worsted manufactories in this country, we are told that it is because of the scarcity of the proper fleece. What is to be done? Are there never to be worsted manufactories in the United States because the proper fleece is not grown? and is the proper fleece never to be grown in the United States, because there is a dearth of worsted manufactories? Verily, this is arguing in a narrow circle!

It is a subject of general complaint, that the English flannels have greatly depreciated. After the sccond or third washing, they have shrunk to such a degree as to be almost valueless, and the consumer has lost not only the original cost of the material, but the price of making it into a garment. Why this is the case, has been disclosed in the testimony taken before the House of Lords, 1828, viz: that the Southdown wool, being unable to compete with foreign fleece, in the manufacture of cloth, has been appropriated to the manufacture of flannel. Now, if we turn to our table of the number of scales upon the different fleeces, we will find that the Southdown has, upon one inch in length, 2,080, while the Leicester has only 1,860 ; so that the shrinking of flannels made by the former lias been increased in the proportion that 2,080 is greater than 1,860. And it must be recollected, that we come to this important conclusion by merely counting the scales; and that if the differences in their shapes, sizes, roughness, pointedness and degree of adherence to the shaft, were taken into the acconnt, no doubt but much more light would be shed upon this hitherto obscure subject. 
But it is wisclom to profit by the errors of others. Let us take warning, and manufacture our flamels from a fleece that will not shrink. It can be produced in this country by selecting the best breed of hair-bearing Sheep, and taking care to keep them separate from the other species.

In turning his attention to this particular branch of industry, the American farmer will be without a competitor; for it is well known that in Russia, Prussia, Hungary, Saxony, \&c., \&c., where attention is paid to the raising of fine wools for cloth, the fleece for mantfacturing articles that are required not to shrink, is much neglected.* Here is a fine field open for American enterprise, in which the industrious farmer has only to walk the course and pocket the purse.

\footnotetext{
* Perhaps cannot be grown in perfection.
} 


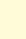




\section{I.TST AND DESCRIPTION OF PLATES}

\section{CHAPTER I.}

PAR' I.

Fig. 1, page 7.-A Hair of the Head of one of the Oval-Haired Species; $a$, the vessels; $b$, the follicle; $c$, the button; $d$, a part of the shaft, with the cortex; $e$, another part of the shaft, with the cortex removed, exposing the fibres; $f$, another still, with the cortex and fibres removed, exposing the central canal, interrupted.

Fig. 2, page 8.- Hair and Wool contrasted. A, hair, (the scales having the appearance of transverse striœ only;) $B$, wool, (with the scales more apparent.)

Fig. 3, page 9.-Outline of a Feather; $a$, the cylinder; $b$, the inferior navel; $c$, the superior navel; $d$, the stalk; $e$, the beard and steno-beard.

Fig. 4, page 11.-The Ostrich Feather.

Fig. 5, page 11.-The Eye-Lash of the Ostrich; $c$, the cylinder, and $a$, the inferior navel; $b$, the superior navel; $e$, the beard and steno-beard.

Fig. 6, page 12.-The Pile of the Ornithorynchus; $a$, the button; $b$, a part of the shaft, (marked with dark colored varying lines;) $c$, the neck; $d$, the broad portion of the shaft, (with disseminated coloring matter and the spire;) $e$, anterior part of the shaft, (gradually narrowing;) $f$, the apex.

\section{PART II}

Fig. 7, page 14.-The internal arrangement of one of the divisions of the Mantle of the Armadillo. $A$, the main arterial trunk; $B$, the fusiform follicles; $C$, the hair-like processes; $D$, the orbicular capsule. $1,2,3$ and 4 , horizontal limbs; 5 , inclined limb; 6 , anastomosing branches; 7 , the largest branch; 8, branches which do not anastomose; 9, interfolical vessels; 0 , culs de sac.

Fig. 8, page 16.-Hair-like Processes issuing from between and under the Scales of the Manis, (showing its shape, coloring matter in irregular lines and dots, and a wart-like protuberance.)

Fig. 9, page 16.-.Scales upon the Prehensile Tail of the Possum.

Fig. $10 a$, page 17. A transverse section of the Horn of the Rhinoceros, (showing the ends of two hairs.)

Fig. $10 b$, page 17.-A horizontal section of the same, (also showing the hairs.).

Fig. 11, page 19-A transverse section of the Spine of the Porcupine, (showing its complicated internal conformation.) 
Fig. 12, page 19.-The Spine of the Pecary. 1, the button, neck, and a small part of the shaft; 2, a transverse section of the button; 3 and 4, transverse sections of the shaft; 5 , a longitudinal section of the cortex; 6 , the termination of the shaft; 7 , a longitudinal section of the stellated figure, No. 4.

Fig. 13, page 21.-The Whisker of the Possum; $a$ and $b$, the stalk, (with its posterior extremity perforated, and no button;) $c$ and $d$, transverse sections of the same, (showing the large canal in the centre.)

Fig. 14, page 22.-A longitudinal section of a Bristle, (showing the disrupted fibres of the interior.)

Fig. 16, page 25.-A transverse section of the 'T'ail of the Hippopotamus, (showing the ends of the fibres.)

Fig. 16, 2, page 25.-A transverse section of the Tail of the Elephant.

Note.-These two last figures onght to have been numbered "15." In consequence of this mistake, No. 16 has to be repeated in Chapter II.

\section{CHAPTER II.}

Fig. $16 a$, page 2\%.-Button of one of the Oval-Haired Species-as it appeared immeiately after it was drawn-(showing the cells.)

Fig. 16 , page 27.-The same as it appeared after it had been drawn a few days.

Fig. 17, page 27.-Another Button on a Hair from the same Head.

Fig. 18, page 27.-A Hair drawn out of the Button, (showing the posterior portion of the shaft.)

Fig. 19, page 28.-A Button upon a Hair that fell out.

Fig. 21 1, page 28.-Button of a Female pure American Indian's Hair.

F'ig. 212 , page 28.-Button of a Male pure American Indian's Hair.

Fig. 21 3, page 28. - Another of the same.

Fig. 22, page 28.-Button of a pure African Pile.

Fig. 241, page 29.-Button of a Hair of the Meatus Auditorins Externus.

Fig. 24 2, page 29.-Another from the same; $a$, a vessel; $b$, a portion of the disrupted tissue.

Fig. 25 1, page 29.-Button of the Supercilium of a very fat person; $a$, a part of the shaft; $b$, the button; $c$, a part of the follicle; $d$, a portion of the disrupted tissue.

Fig. 252, page 29.-Another of the same, (with two vessels at the posterior extremity.)

Fig. 26 , page 30.-Button of the Cilium. (This specimen has been artificially deprived of the greater part of the coloring matter, so as to exhibit the interior arrangement.)

Fig. 26b, page 30.-A Hair of the Cilium, drawn out of the Button, (showing the cortex, and a small portion of the disrupted tissue.)

Fig. 27, page 30.-Button of a Hair of the Nasal Fosse. It is sub-oval; the neck is distorted; $a$, the shaft; $b$, marked with transverse stria; $c$, a portion of coloring matter in the centre 
Fig. 28 a, page 30 - - Button of the Hair of the Beard, which grew under the chin, with a portion of the follicle and disrupted tissue.

Fig. $28 b$, page 30.-Three Shafts growing out of one Button of the Beard.

Fig. $29 a$, page 32,-Button of a Hair of the Axille, (exhibiting a portion of the shaft, the follicle, and vessels.)

Fig. $29 b$, page 32.-Another of the same, (with its vessels as seen in the transverse section of the skin of a male of 25 .)

Fig. 30, page 32.-A Button of a Hair of the Pubes; $a$, the button; 6 , a portion of the follicle; $c$, the shaft; $d$, the tissue, disrupted and torn out of the soft, sebaceous skin.

Fig. $31 a$, page 33.-Button of a Hair of the Forearm; $a$, the button; $b$, portion of the follicle; $c$, the shaft; $d$, a part of a disrupted vessel; $e$, a portion of the tissue.

Fig 31 b, page 33.-A Button of a Hair of the back of the Hand.

Fig. 32 a, page 33.-The Hair of a Mexican Mummy, with no Button. (The posterior termination of the shaft is inclined, and some minute vessels make their appearance.)

Fig. 326, page 33.- The Hair of a Peruvian Mummy, with its diminutive Button.

Fig. 33, page 33.-Button of an Uvarian Hair; $a$, the button; $b$, the shaft, showing the scales of the cortex; $c$, a white substance with which the hair is enveloped.

Fig. $34 a$, page 34.-Outlines of the Buttons of Hairs of some of the Lower Animals, viz: $A$, the Troglodyte Gorilla; $B$, Horse; $C$, Zebra; $D$, Cow; $E$, the Arabian Bull Calf; $F$, the Gnou; $G$, Rocky Mountain, American or Long-Horned Antelope; $H$, Elk; $J$, the Lama; $K$, Dasyprocta Nigra; L, Kangaroo Rat; $M$, Dicranoceros Americanus.

Fig. $34 b$, page 34.-Button of the Animals that have a Paved Cortex.

Fig. 36, page 35.-The Shaft of a Hair fractured in the centre, and the fibres obtruding.

Fig. $37 a$, page 35.-Pile of the Oval-Haired species, furcated.

Fig. 37 b, page 35.-Pile of the Eccentrically Elliptical Species, furcated.

Fig. 38 a, page 35.-Pile of the Cylindrical-Haired Species, tri-furcated.

Fig. 38 b, page 35.-Pile of the same, quadra-furcated.

Fig. 39, page 35.-Pile of one of the Oval-Haired Species, so much furcated as to resemble a brush.

Fig. 40, page 36._-"Branched" Pile; $a$, posterior extremity; $b$ and $c$, appear to be two separate shafts; $d$, a branch of $b$, and $e$, a branch of $c$.

Fig. 43, page 37.-A Ribbon of Cortex, from the Spine of the Pecary

Fig. 44, page 37.-The Paved Cortex of the Hair of the Elk.

Fig. $451,2,3,4$ and 5, pages 40 and 41 . -The Pile of the Three-Toed Sloth. 1, the cortex and the interior, when the cortex is removed; 2, the fissures in the cortex; 3 , the grains into which the cortex divides; 4 , a disk; 5 , tufts of the wool.

Fig. $46 a$, page 41 .-The Intermediate Fibres of Pile, deprived of the cortex, except in one place left for comparison.

Fig. 466 , page 41.-Fibres of the Hair of one of the Oral-Piled Species.

Fig. $46 c$, page 41 . - Fibres of a Hair of the same, laboring under the disease of serofula, having separated in the act of drawing the hair out of the hearl. 
Fig. $46 d$, page 41.-Fibres of the Hair of the Head of one of the Cylindrical-Piled Species.

Fig. 47, page 41.-A Crushed Hair; $a$, the crushed part, where the diameter is $\frac{1}{75}$ of an inch; $b$, the part not crushed, where the diameter is $\frac{1}{2} \frac{1}{2}$.

Fig. 48, page 42.-a, $b, c$ and $d$, Transverse Sections or Disks of Pile; $a$, hair disk in Plica Polonica; $b$, of an Indian hair; $c$, of a hybrid, Indian and white; $d$, of an oval-haired person.

Fig. 49, page 42.- $a, b$ and $c$, the Central Portion of Pile; $a$, the hair of one of the oval-piled species, artificially made transparent, to show the coloring matter; $b$, pile of the cccentrically elliptical, which has undergone the same operation; $c$, the coloring matter in grains.

Fig. $50 a$ and $b$, page 43.-Pile of the Dog-Faced Monkey, where the coloring matter is in dots and lines.

Fig. $50 \mathrm{c}$, page 43.-Pile of the Bat, where the coloring matter is in crucible-shaped bands.

Fig. $50 d$, page 43.-Pile of the African Bat, where the coloring matter is in the cortex and fibres.

Fig. 50 e, pages 43 and 44.-Exumples where the coloring matter is of two or more colors, but appears to the eye to be one only.

Fig. 51, page 46.-The Sheath of Pile in a diseased case.

Fig. 52, page 48.- Hairs without a Button; 52a, hair of a five months' foetus; $52 b$, a nine months' fotus; $a$, the posterior termination of the main shaft; $b$, the shaft; $c c$, two other hairs, one on each side, adhering to the main shaft; 52 $c$, hair of the Horse Diligence.

Fig. 53, pages 48 and $49 .-a, b, c, d, e, f, g$, the formation of Follicles; $a$, the granules; $b$, the lines and fibres; $c$, the button just forming; $d$, the button formed; $e$ and $f$, the follicle just forming; $g$, the follicle formed.

Fig. $54 a, b, c$, page 49.-Follicles of the three Species; $a$, the oval-haired; $b$, the cylindrical-haired; $c$, the eccentrically elliptical-piled

Fig 55, page 49.-Follicle of a Hybrid.

Fig. 56, page 50.-Vessels of Pile.

NotE.-See also figs. 24, 29, 31, for Vessels of Pile

\section{CHAP'TER III.}

Fig. 57, p. 51.-Examples of the three General Forms of Pile; $A$, the cylindrical; $B$, the oval, and $C$, the eccentrically elliptical species.

Fig. 58, page 52.-The Particular Forms of Pile; from $A$ to $a$, cylindroidal; from $a$ to $B$, the lesser ovoidal; from $B$ to $b$, greater ovoidal; from $b$ to $C$, cylindroidal.

Fig. 59, page 53, (but there enroneously called "Fig. 58.")-The Spiral Curl of one of the pure Eccentrically Elliptical Species.

Fig. 60, page 57.-The Trichometer.

Fig. 61, page 67.- See 'Title Page for the heads of the three species 


\section{CHAPTER IV.}

Fig. 62, page 91.-Pile viewed by Polarized Light.

CHAP'TER VI

Fig. 79, page 111.-Hair in Plica Polonica.

Fig. 80, page 112.- Hair in Tinea Capitis.

Fig. 81, page 113.-Hair in Softening of the Brain.

Fig. 92, page 119.-Hair of Lunatics.

a, Hair of a Lunatic from the Pennsylvania Hospital.

b, " " " " " $"$ "

$c$, " " " " " " 6 Staunton, Va., Asylum.

d, " " " " " The Ohio Asylum.

C HA P T ER VII.

Fig. 95, page 133.-The Revolver and Stretcher.

\section{CHAPTER VIII。}

Fig. 96, page 143.-Pile of the Mazama.

Fig. 97, page 147.-Pile of the Lama.

\section{CHA PTER IX。}

Fig. $98 a$ and $b$, page 156.-Explanation of the Scales on the Spiral Curls of Wool. Fig. 99, page 172.-The Woolly Sheep.

Fig. 100, page 172.-Example of the Hairy Sheep. 



\section{CORRECTIONS.}

Page 8, line 3, of note *, for "filamentus" read "filamentous."

Page 12, line 1, for "mystecetus" read "mysticetus."

Page 19, last line but one, for "andar e" read "and are."

Page 25, line 13, for "cerous" read "cervus."

Page 31, last line, for "axilla" read axille."

Page 33, line 29, for " no" read " $a$ diminutive."

Page 36, line 17, for "I" read "we."

Page 37, line 9, for " 42 " read "44."

Page 41, line 4, for "fissure" read "fissures."

Page 48, line 16, for "53" read "52."

Page 53, line 9, for "58" read "59."

Page 90, line 8, for "di" read "de."

Page 93, line 10, for "of" read "and."

Page 93, line 24, for "in" read "on."

Page 105, line 24, for "manipulation" read "manipulations."

Page 106, line 17, for "platyp/ $/$ us" read "platypus."

Page 133, between lines 4 and 5 , on the figure, for " $a$ " substitute " $D$."

Page 136, line 11, for "Tatpa" read "Talpa."

Page 137, line 5, for "forming" read "form." 
, 






$$
\begin{aligned}
& \text { Solato } \\
& \text { 6. } 42613 \\
& \frac{2,0}{2,0} \\
& 8501-150
\end{aligned}
$$




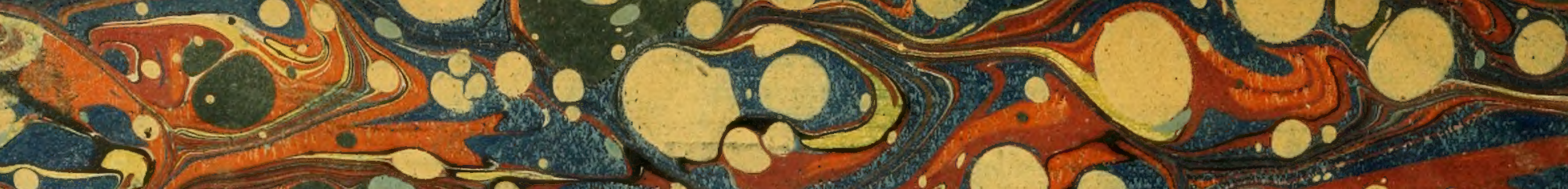
(
$\lambda$

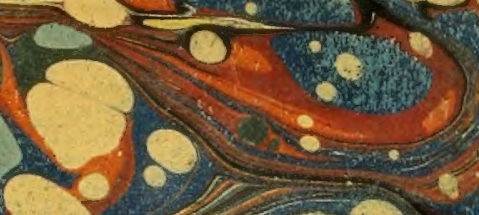

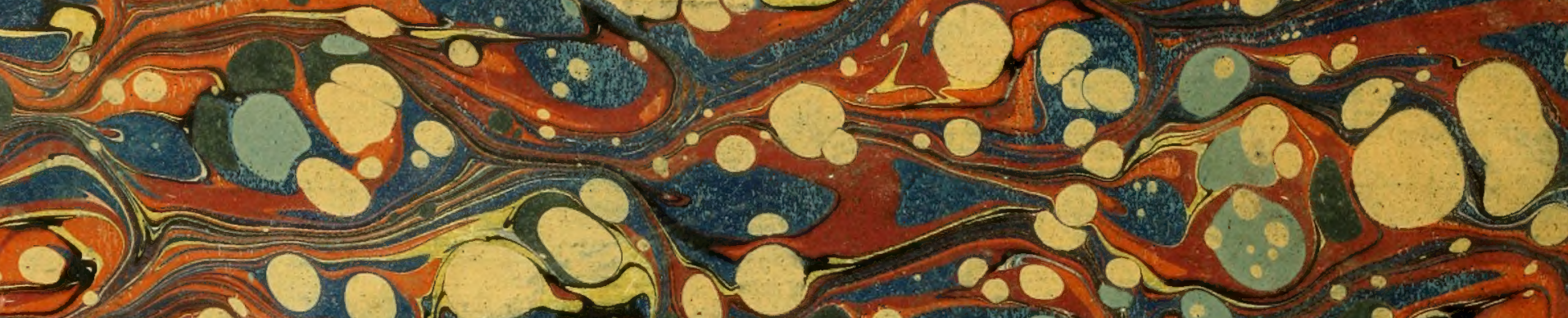
.9 00 .

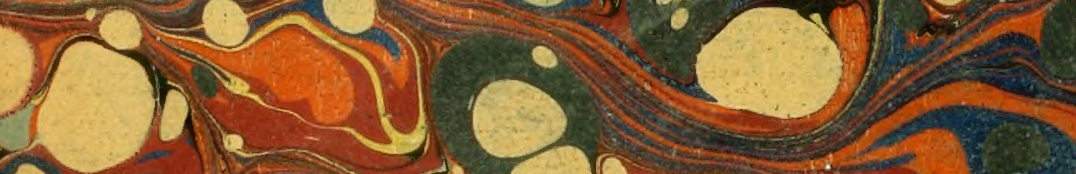

300.0

.20

020

10.9 .9

$\Rightarrow$

8

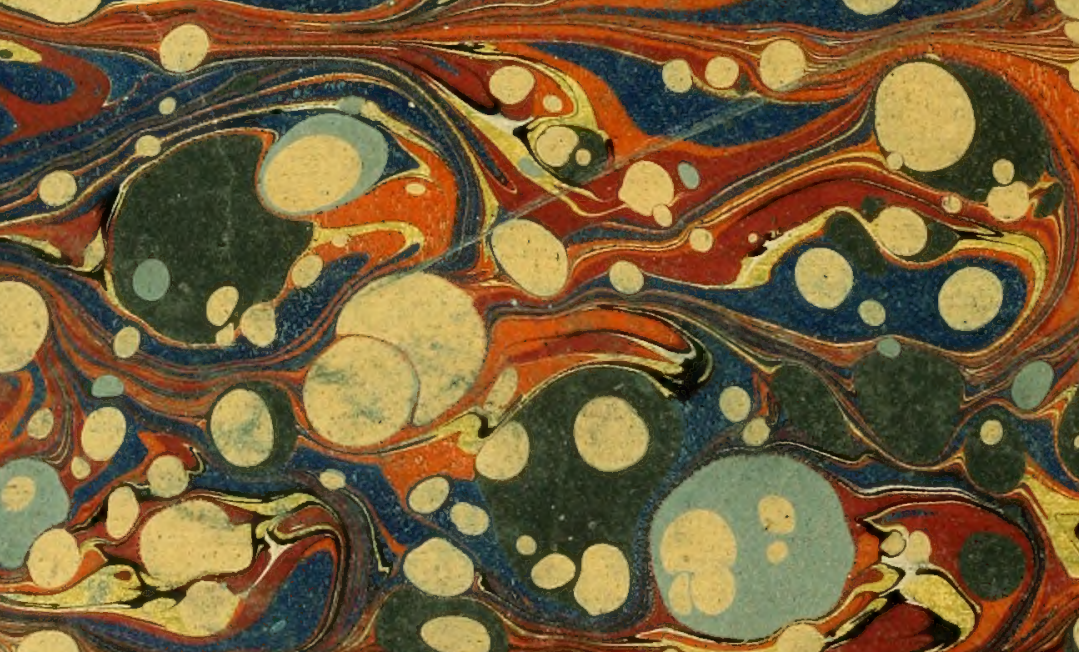

090.9020 .0

30 ००:5

i

$$
\text { ( }
$$

. 0.03

.

(1) 500

9 $5=10$

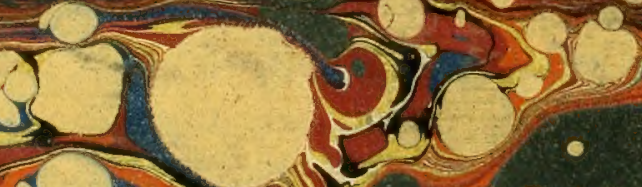

a 52

$2.120 .2 \%$

$2.120 .2 \%$

0.00 .96

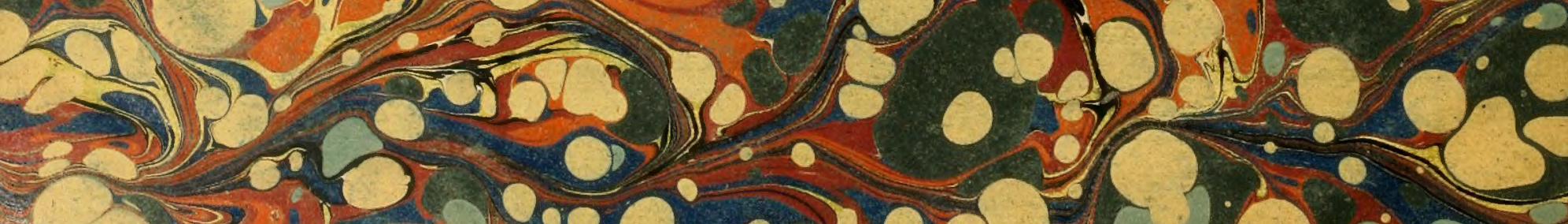

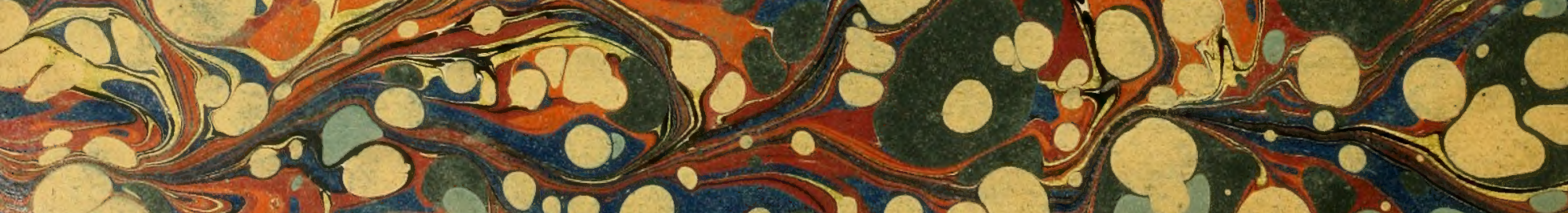

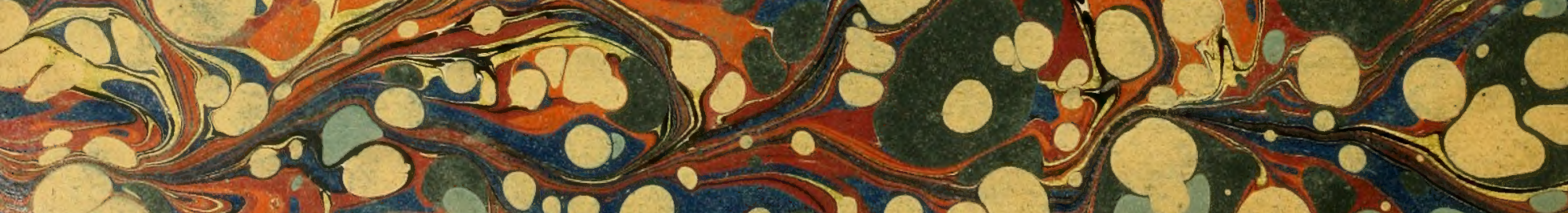

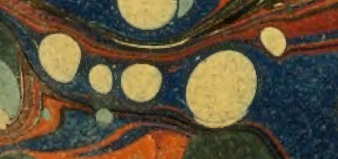

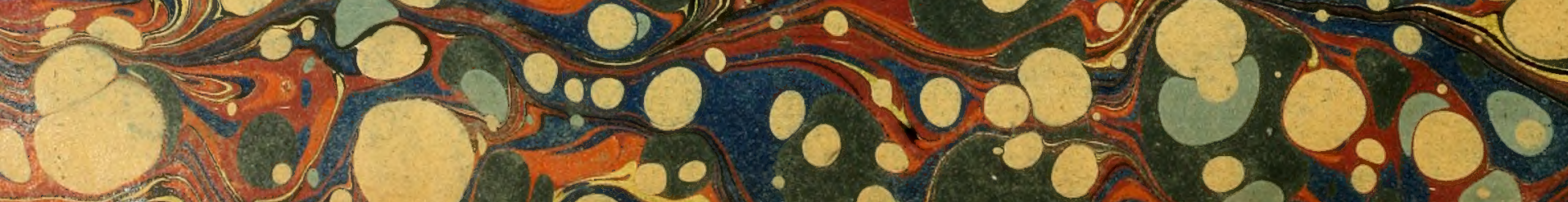

3:0

0

$2 \approx 20: 5$ 
